\title{
LEARNER AUTONOMY AND EFL LEARNING AT THE TERTIARY LEVEL IN VIETNAM
}

By

Nguyen Thi Cam Le

\begin{abstract}
A thesis
submitted to the Victoria University of Wellington

in fulfilment of the requirements for the degree of

Doctor of Philosophy

in Applied Linguistics
\end{abstract}

Victoria University of Wellington

2009 


\section{ACKNOWLEDGEMENT}

First of all, I wish to thank my supervisor Peter $\mathrm{Gu}$ for his continued guidance, support, and patience. I feel fortunate and honoured to have had him as my primary supervisor. It was his expertise and research experience that provided me with practical knowledge of how to conduct a quantitative study, including how to validate a questionnaire, and how to interpret the results. More specifically, I have learned how to actually test the reliability of a questionnaire, a skill I had not practised before embarking on this study, let alone mastered. I also benefited a great deal from Peter being a "strategy" man who taught me very good strategies for conducting research effectively and writing academically.

I am grateful to the staff at the School of Linguistics and Applied Language Studies for providing a stimulating, friendly, and professional research and study environment. I wish to express my sincere gratitude to David Crabbe, Paul Nation, Paul Warren, Janet Holmes, Angela Joe, and Bernie Hambleton for their encouragement and support.

My special thanks go to Mary Roberts at the Student Learning Support Service for her inputs which helped make this piece of writing more coherent and cohesive.

I thank my linguistics friends Misty, Leilarna, Sharon, Julia, Jeanette, Laura, Kazuyo, Barli, Myq, Brian, and for their inputs in $\mathrm{PhD}$ group meetings.

I am also grateful to my friend Minh and her family for their friendship which has made my time in Wellington full of beautiful and unforgettable memories.

Finally, I thank my husband Dong and my son Duy for their love and support. They have not only tolerated my temper at times but also have learned how to share the housework with me throughout the three and a half years we stayed in New Zealand. Without them, I would not have been able to complete this study. 


\begin{abstract}
There has been a growing interest in the role of learner autonomy (LA) in language teaching and learning. Over the last twenty years, researchers have extensively explored LA in a range of settings and have developed various approaches to fostering it both as a means to language learning and as an end in itself. This study attempts to investigate LA in the Vietnamese EFL context, and to explore the relationship between LA and language learning results.

In this study, LA was conceptualised and operationally defined as learner selfinitiation and learner self-regulation. The research was composed of three phases. The pilot study looked at the range of activities, and the amount of time devoted to learning English by 388 Vietnamese English majors of different levels of academic achievement. It identified differences in LA among students of different year levels as well as LA at two types of tertiary institutions in Vietnam. In the first phase, an exploratory correlational study was conducted among 177 students to comprehend features of LA as demonstrated by these students, their preferred self-initiated activities both inside and outside the classroom, and the relationship between each aspect of LA and language proficiency. In the second phase, an intervention study was conducted with the participation of 37 students in an experimental group, and 54 students in two control groups. Phase two explored the efficacy of a learner-based approach to promoting LA with a focus on strategy-based instruction.

The three phases revealed several important findings. The pilot study discovered that the level of autonomy was related to students' level of academic achievement but not to their year level. In addition, autonomy seemed to be affected by the social setting in which it was exercised. In Phase one, the findings revealed that Vietnamese learners' self-initiation efforts mainly concentrated on covert learning in class. Outside the classroom, these learners preferred to undertake receptive rather than productive activities, and tended to avoid social interaction. Moreover, most aspects of LA positively and significantly correlated with EFL proficiency measures. Lastly, the task-specific training of self-regulation in Phase two resulted not only in significantly improved writing scores but also in greater LA. However, these metacognitive skills in writing did not seem to transfer to other areas
\end{abstract}


of language learning, although improvements in writing were maintained in a delayed test.

Overall, the study suggests that LA appears to be linked positively to language proficiency. High achievers are more likely to be autonomous learners. Most importantly, training learners in metacognitive regulation improved learners' writing ability and their autonomy in learning. 


\section{TABLE OF CONTENTS}

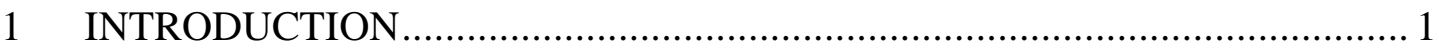

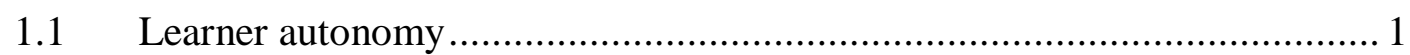

1.2 Learner autonomy in Vietnam............................................................. 1

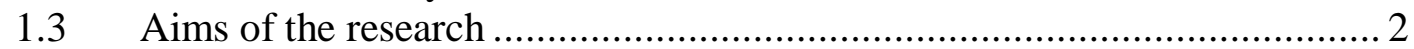

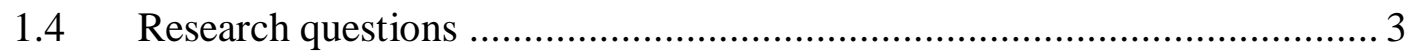

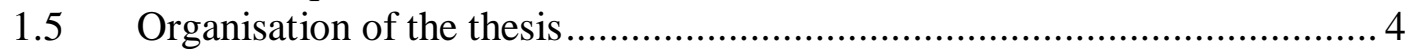

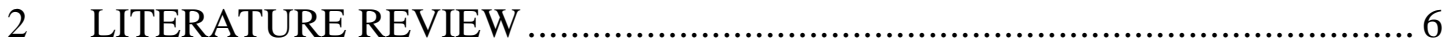

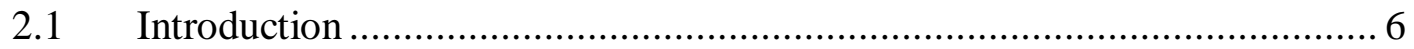

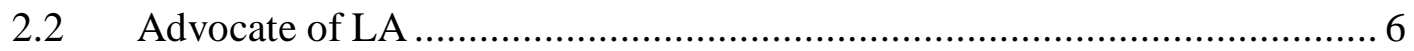

2.2.1 Assumptions about LA............................................................. 7

2.2.2 Activities carried out by an autonomous person................................. 8

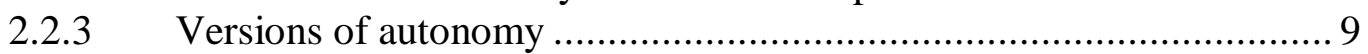

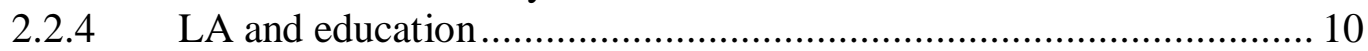

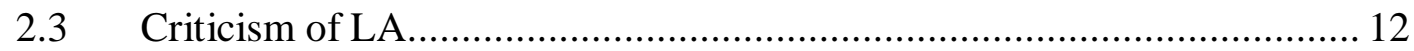

2.3.1 Technical meaning of LA ........................................................... 12

2.3.2 Limited values of LA .............................................................. 13

2.3.3 Disapproval of LA as an educational goal ..................................... 15

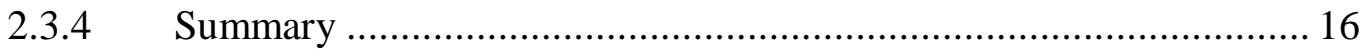

$2.4 \quad$ Foundation of LA ......................................................................... 16

2.4.1 Cognitive psychology and humanistic psychology ……………........ 16

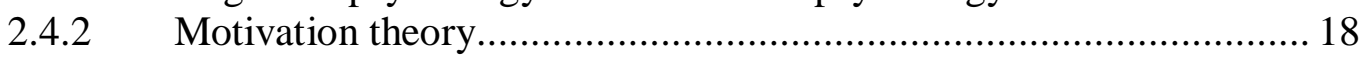

2.4.3 The theory of constructivism .......................................................... 19

2.4.4 Self-regulated learning ………………………………………..... 20

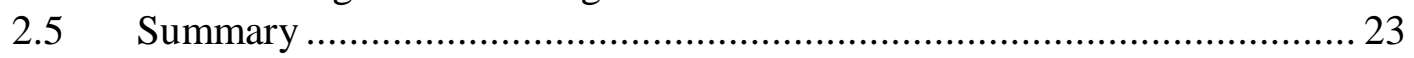

2.6 LA in language education .................................................................. 24

2.6.1 History of LA.......................................................................... 24

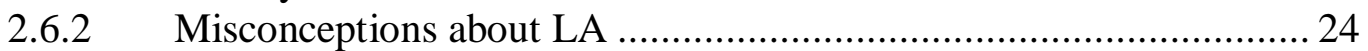

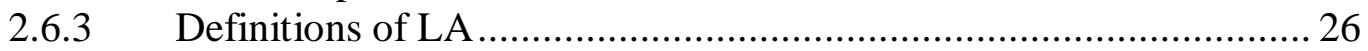

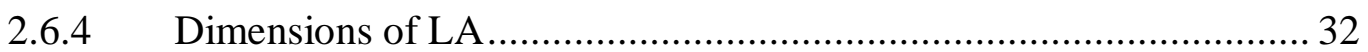

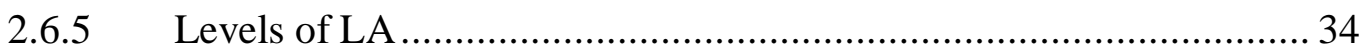

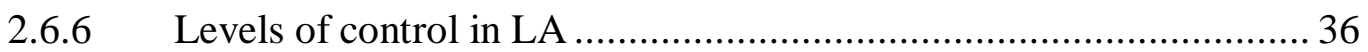

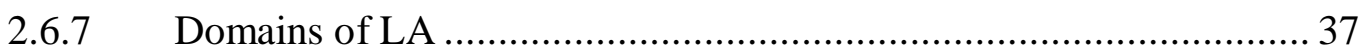

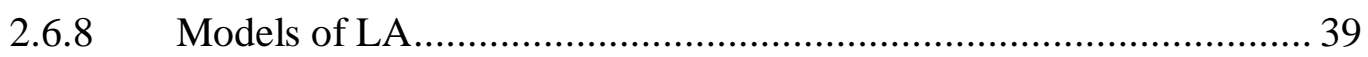

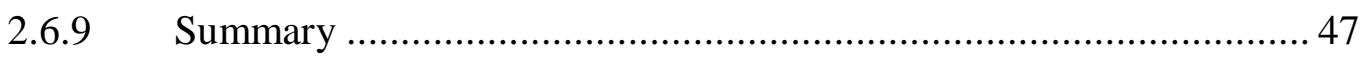

2.7 An operational definition of LA ........................................................ 50

2.7.1 Elements of LA in operational definition ......................................... 50

2.7.2 Measurability of LA and operational definition ............................... 52

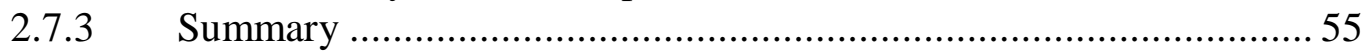

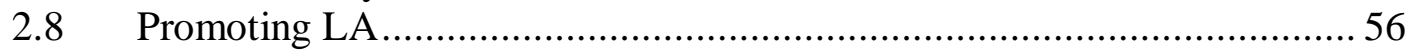

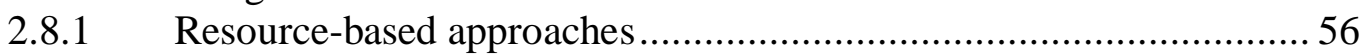

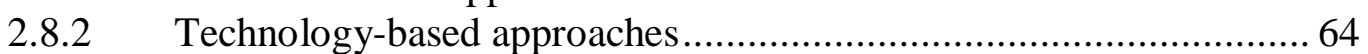

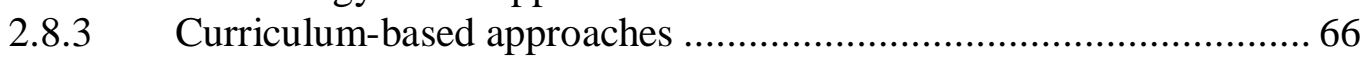

2.8.4 Teacher-based approaches.............................................................. 73

2.8.5 Classroom-based approaches.......................................................... 77

2.8.6 Learner-based approaches …………………............................. 92

2.8.7 Summary of the six approaches to promoting LA ........................... 100

2.9 Learner autonomy and learner strategy ................................................... 103 


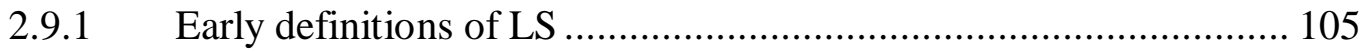

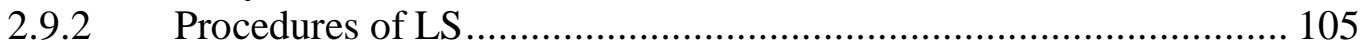

2.9.3 Common types of strategies ................................................... 106

2.9.4 Focus of LS research .......................................................... 108

2.9.5 Converging and diverging points between LA and LS ................. 108

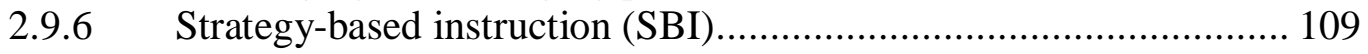

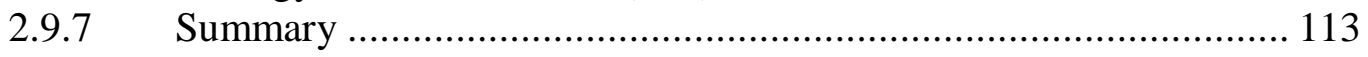

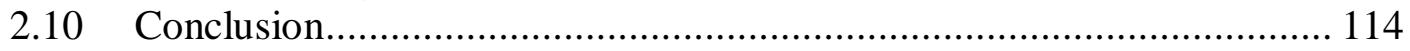

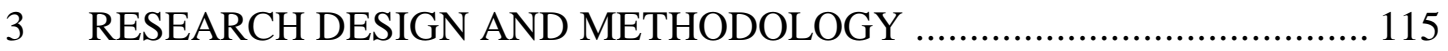

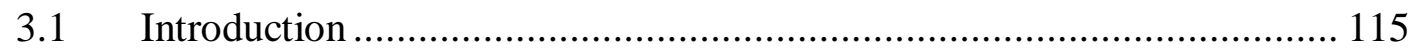

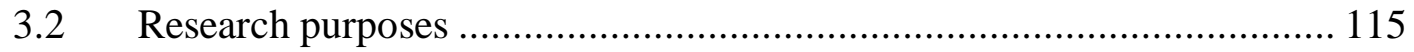

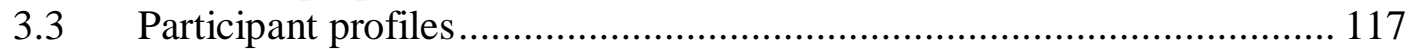

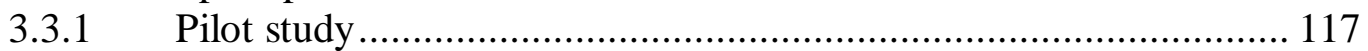

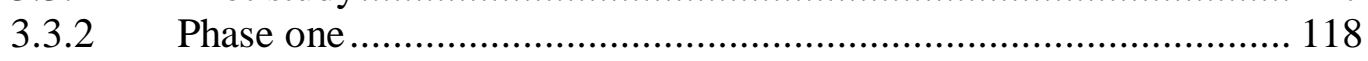

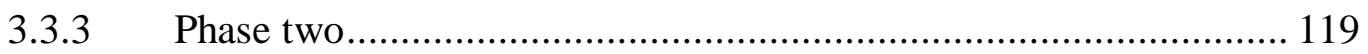

3.4 Research process and procedures ................................................. 120

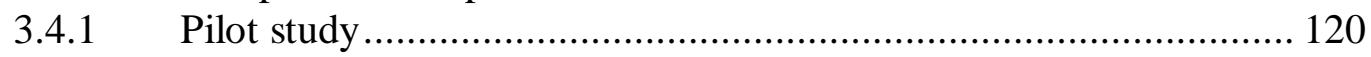

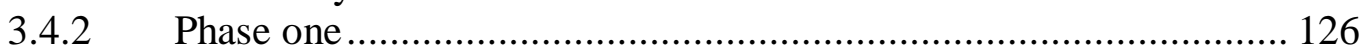

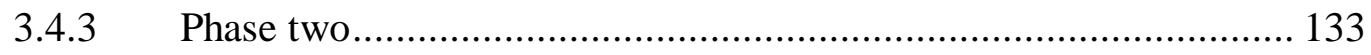

3.5 English as a foreign language (EFL) measures ................................. 145

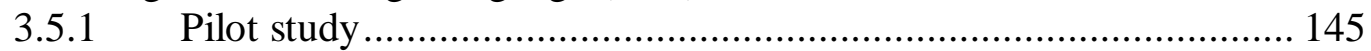

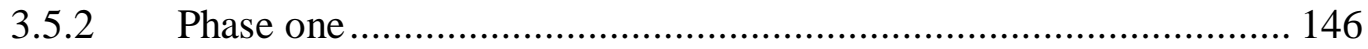

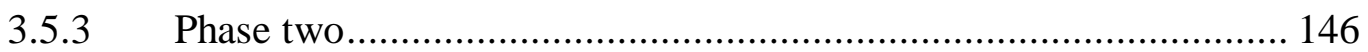

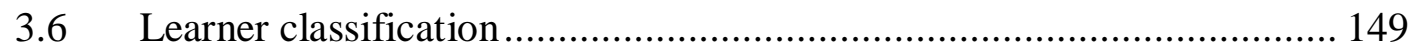

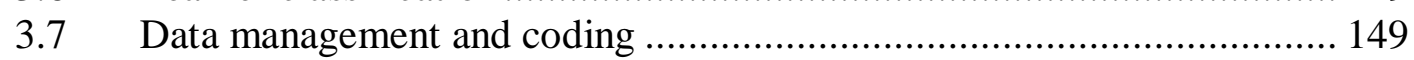

3.7.1 Coding interview data ........................................................ 149

3.7.2 Coding learning logs ....................................................... 150

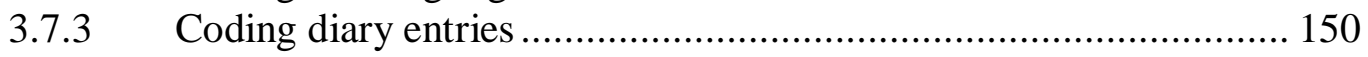

3.7.4 Coding classroom observations .............................................. 151

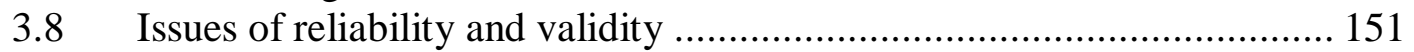

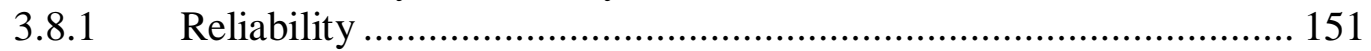

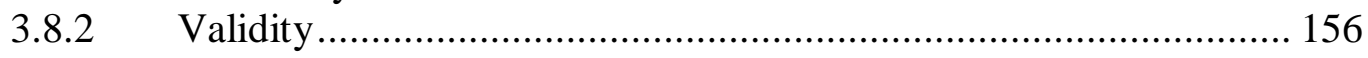

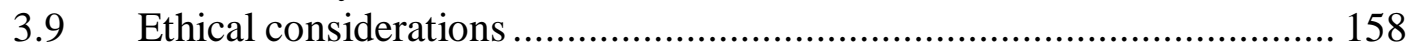

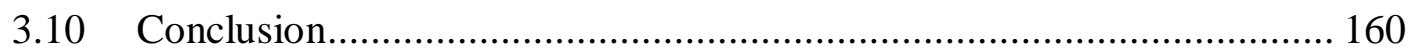

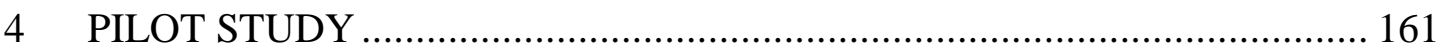

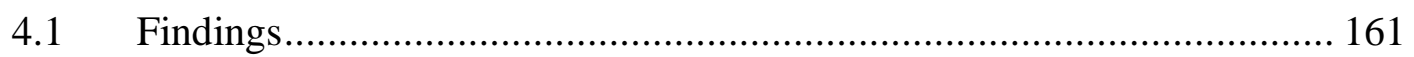

4.1.1 Constructs of LA................................................................ 161

4.1.2 Relationship between LA and general language proficiency ........... 163

4.1.3 LA and students of different year levels ..................................... 165

4.1.4 LA at two different universities ............................................. 170

4.1.5 LA and students of different levels of achievement ..................... 174

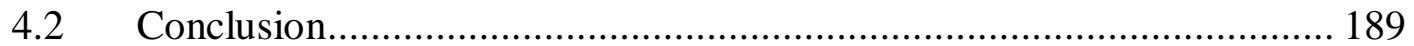

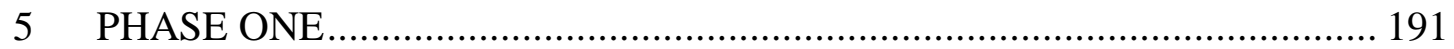

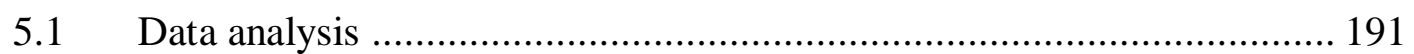

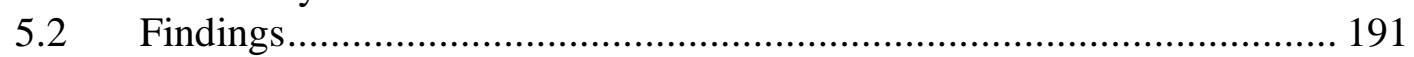

5.2.1 LA among Vietnamese undergraduate EFL students ...................... 192

5.2.2 The most popular activities among Vietnamese students ............... 193

5.2.3 Relationship between LA and EFL proficiency ........................... 198

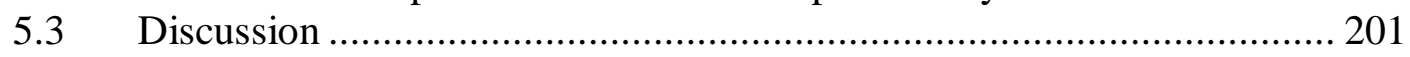

5.3.1 In-class covert learning as a preferred mode of learning ................ 201 
5.3.2 Significance of out-of-class use of English................................. 203

5.3.3 Prominent features of LA in Vietnam .......................................... 205

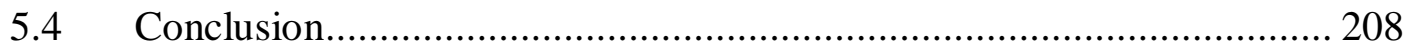

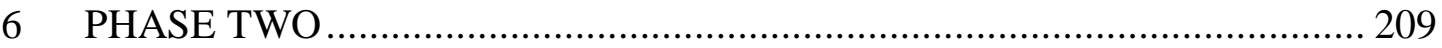

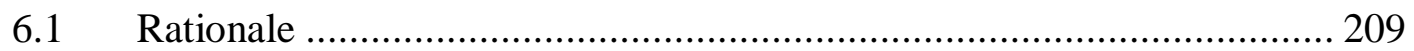

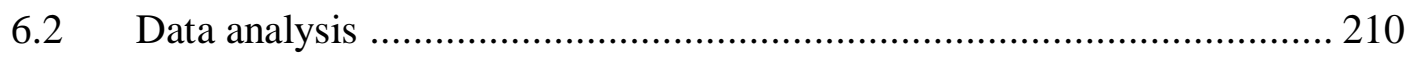

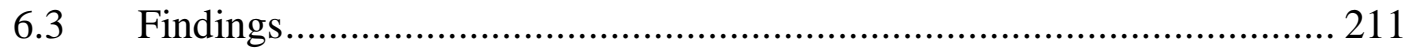

6.3.1 MT and improved English writing ............................................ 211

6.3.2 MT and improvements in different writing components ................ 227

6.3.3 MT and improvements for students of different academic achievement 250

6.3.4 MT and maintaining of English writing improvements ................ 252

6.3.5 MT and improvement in LA....................................................... 257

6.3.6 MT and transfer of metacognitive skills .................................... 280

6.3.7 Feedback about MT ….......................................................... 285

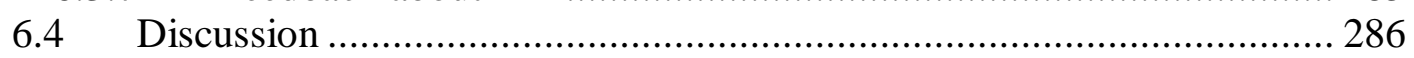

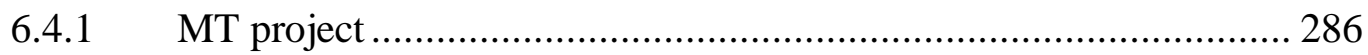

6.4.2 Popular model of LA in Vietnam .............................................. 290

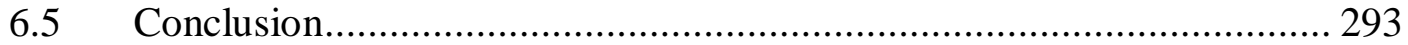

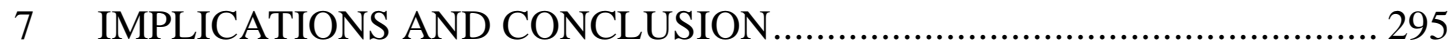

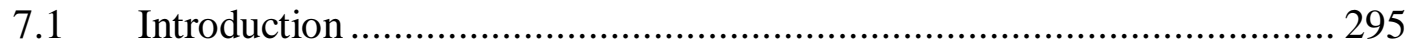

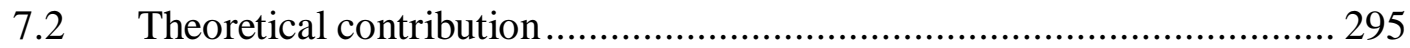

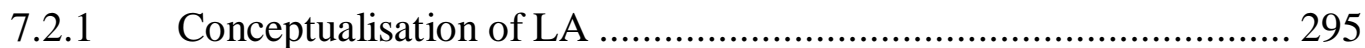

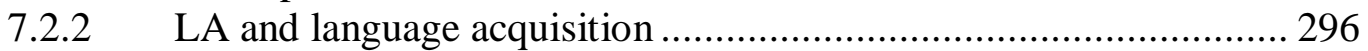

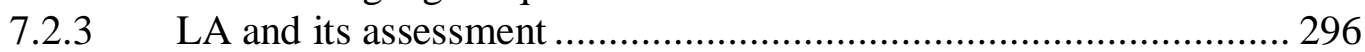

7.2.4 Inter-relation between LA and LS ........................................... 297

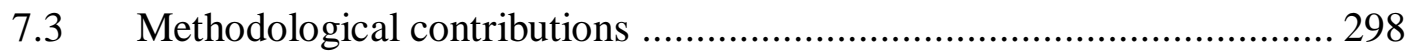

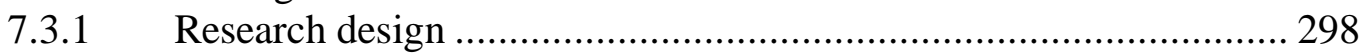

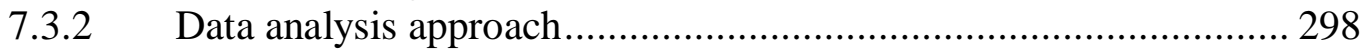

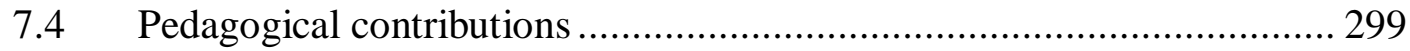

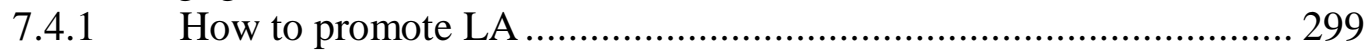

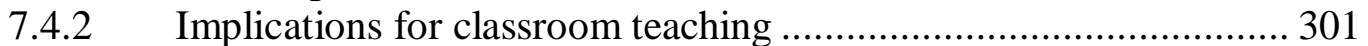

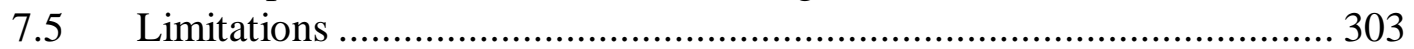

7.6 Conclusion and directions for further research .................................... 304

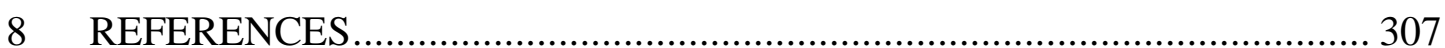

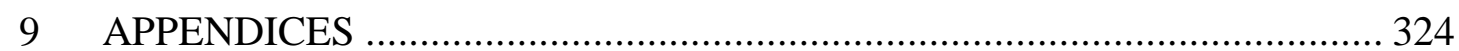




\section{LIST OF TABLES}

Table 2.1: Types of Autonomous Learners according to LA Dimensions.................. 33

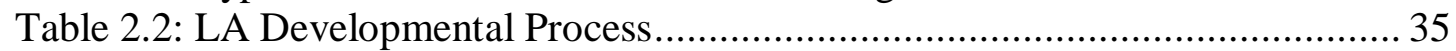

Table 2.3: Summary of Major Definitions of LA …................................................ 49

Table 2.4: Models of Teacher Autonomy ............................................................... 74

Table 2.5: Summary of the Six Approaches to Developing LA ............................. 100

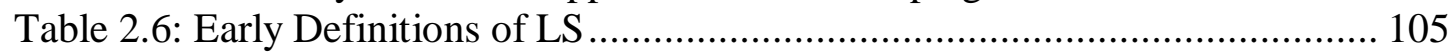

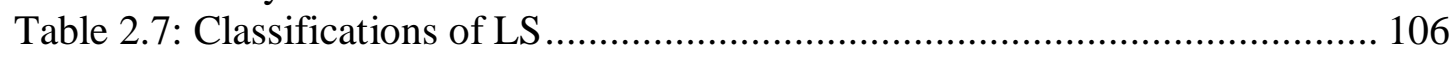

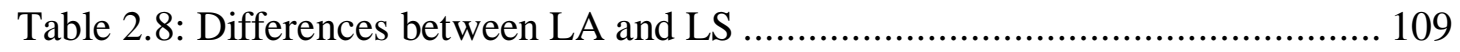

Table 2.9: Differences between SBI Top-down and Bottom-up Models................. 113

Table 3.1: Research Purposes and Research Questions .......................................... 116

Table 3.2: Participant Profile of Pilot Study .......................................................... 118

Table 3.3: Participant Profile of Phase one …....................................................... 118

Table 3.4: Participant Profile of Phase two ........................................................... 119

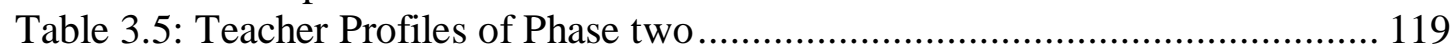

Table 3.6: Summary of the Questionnaire Used in Pilot Study............................. 124

Table 3.7: Questionnaire Development Process .................................................... 130

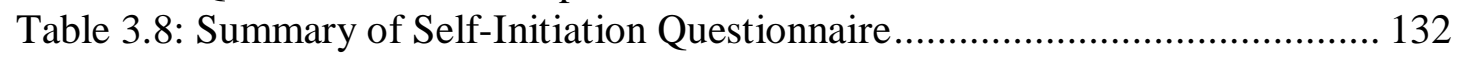

Table 3.9: Summary of Self-Regulation Questionnaire ...................................... 133

Table 3.10: Latest Writing Examination Scores across Three Groups .................... 137

Table 3.11: Weekly Metacognitive 60-minute Sessions ...................................... 138

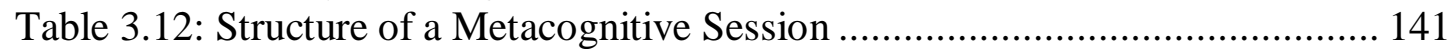

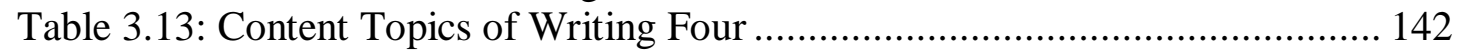

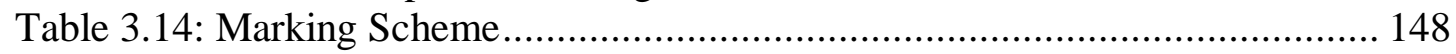

Table 3.15: Student Classification Scheme ....................................................... 149

Table 3.16: Reliability Statistics of 13 Items of Learning English outside Class .... 153

Table 3.17: Item-Total Statistics of 13 Items of Learning English outside Class .... 153

Table 3.18: Gradual Dropping Items Causing Substantial Decrease in Alpha ........ 154

Table 3.19: Reliability Statistics of 6 Items of Learning English outside Class ...... 154

Table 3.20: Item-Total Statistics of 6 Items of Learning English outside Class ...... 154

Table 3.21: Reliability Statistics of the Final Questionnaire ................................. 155

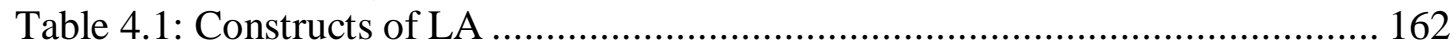

Table 4.2: Correlation between LA and General Language Proficiency ................. 164

Table 4.3: Descriptive Statistics for LA among First, Second, and Third Years ..... 166

Table 4.4: ANOVA for LA among First, Second, and Third Years ....................... 167

Table 4.5: Differences in LA among First, Second, and Third Years ..................... 168

Table 4.6: Group Statistics for LA at Two Types of University ............................ 171

Table 4.7: Independent Samples Test for LA at Two Types of University ............. 172

Table 4.8: Summary of LA Aspects Demonstrated by Top and Bottom Students ... 176

Table 4.9: Time and Range of Out-of-Class Activities by Top Students ............... 178

Table 4.10: Time and Range of Out-of-Class Activities by Bottom Students ......... 179

Table 4.11: Out-of-Class Activities and Self-Regulation by Top Students ............. 180

Table 4.12: Out-of-class Activities and Self-Regulation by Bottom Students......... 180

Table 4.13: Time and Use of Self-Regulation for Out-of-Class Activities .............. 181

Table 4.14: In-Class Activities and Self-Regulation by Top Students ................... 185

Table 4.15: In-Class Activities and Self-Regulation by Bottom Students ............... 185

Table 4.16: Summary of Self-Regulation for In-Class Activities ......................... 186

Table 5.1: Mean Scores of LA Constructs ......................................................... 192 
Table 5.2: Ranking of Out-of-Class Learning English Activities .......................... 194

Table 5.3: Ranking of Out-of-Class Using English Activities .............................. 195

Table 5.4: Ranking of Overt In-Class Language Learning Activities ..................... 196

Table 5.5: Ranking of Covert In-Class Language Learning Activities.................... 197

Table 5.6: Correlation between Self-Initiation and EFL Proficiency ..................... 198

Table 5.7: Correlation between Self-Regulation and EFL Proficiency ................... 200

Table 6.1: Descriptive Statistics for Writing Scores of Three Groups ................... 211

Table 6.2: ANOVA for Pre- and Post-Writing Tests across Three Groups ............ 213

Table 6.3: Differences in Writing Scores across Three Groups ............................ 213

Table 6.4: Structure of a Writing Lesson Conducted by Ms Phuoc ........................ 216

Table 6.5: Scores of Writing Components Obtained by Student K and Student T .. 223

Table 6.6: Descriptive Statistics for Writing Components across Three Groups..... 228

Table 6.7: ANOVA for Writing Components across Three Groups ....................... 229

Table 6.8: Differences in Writing Components across Three Groups .................... 230

Table 6.9: Gains in Writing Components across Three Groups ............................. 232

Table 6.10: ANOVA for Gains in Writing Components across Three Groups........ 232

Table 6.11: Differences in Gains in Writing Components across Three Groups ..... 233

Table 6.12: Number of Cohesive Devices Used by Students in EG ...................... 243

Table 6.13: Scores of English-Related Subjects for Three Average Students ......... 246

Table 6.14: Descriptive Statistics for Writing Improvements for EG .................... 251

Table 6.15: ANOVA for Writing Improvements for EG ….............................. 251

Table 6.16: Differences in Writing Improvements for EG ............................... 251

Table 6.17: Descriptive Statistics for Three Tests across Three Groups ................ 253

Table 6.18: ANOVA for Three Tests across Three Groups ................................. 253

Table 6.19: Within-Subjects Effects for Three Tests across Three Groups ............. 253

Table 6.20: Between-Subjects Effects for Three Tests across Three Groups .......... 254

Table 6.21: Differences in Three Tests across Three Groups ............................... 254

Table 6.22: Descriptive Statistics for Writing Loss for Students in EG ................. 256

Table 6.23: ANOVA for Writing Loss for Students in EG ................................. 256

Table 6.24: Differences in Writing Loss for Students in EG ............................... 256

Table 6.25: Descriptive Statistics for LA before MT across Three Groups............. 259

Table 6.26: ANOVA for LA before MT across Three Groups .............................. 260

Table 6.27: Differences in LA before MT across Three Groups............................ 261

Table 6.28: Descriptive Statistics for LA after MT across Three Groups .............. 263

Table 6.29: ANOVA for LA after MT across Three Groups ............................... 264

Table 6.30: Differences in LA after MT across Three Groups.............................. 265

Table 6.31: Reasons for Learning English in C2 ….......................................... 266

Table 6.32: Making Efforts to Learn English by Students in EG .......................... 268

Table 6.33: Descriptive Statistics for LA before MT among Students in EG......... 273

Table 6.34: ANOVA for LA before MT among Students in EG ….................... 274

Table 6.35: Differences in LA before MT among Students in EG ....................... 275

Table 6.36: Descriptive Statistics for LA after MT among Students in EG ........... 277

Table 6.37: ANOVA for LA after MT among Students in EG ............................ 278

Table 6.38: Differences in LA after MT among Students in EG......................... 279 


\section{LIST OF FIGURES}

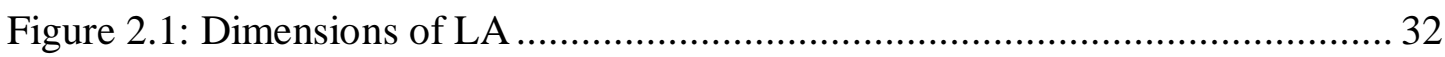

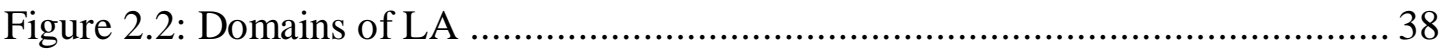

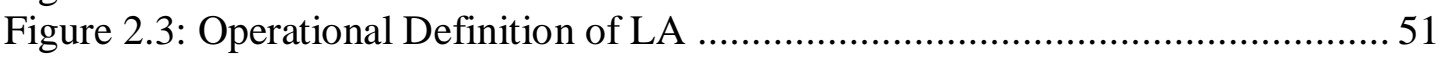

Figure 2.4: Strategy Instruction Framework ...................................................... 111

Figure 4.1: LA Demonstrated by Vietnamese Learners................................... 162

Figure 4.2: LA among First, Second, and Third Years ..................................... 170

Figure 4.3: LA at Two Types of University ...................................................... 173

Figure 4.4: Time Spent on Out-Of-Class Activities by Top Students ................... 183

Figure 4.5: Time Spent on Out-Of-Class Activities by Bottom Students ................ 183

Figure 4.6: Percentage of Self-Regulation Skills Used for Out-Of-Class Activities 184

Figure 4.7: Percentage of Self-Regulation Skills Used for In-Class Activities........ 187

Figure 5.1: Mean Scores of LA aspects .......................................................... 193

Figure 6.1: Writing Scores across Three Groups before and after MT ................... 212

Figure 6.2: Gains Made in Writing Components across Three Groups ................... 234

Figure 6.3: Writing Scores of Three Groups across Three Tests............................ 255

Figure 6.4: Elements of LA prior to and after MT across Three Groups................. 266

Figure 6.5: LA Demonstrated by EG prior to and after MT ............................... 271 


\section{INTRODUCTION}

\subsection{Learner autonomy}

The last three decades have witnessed a growing interest in learner autonomy (LA) in language learning. Many claims have been made about the values of LA for language teaching and learning. Empirical research in support of these theoretical claims has remained largely descriptive. Some of the most often-reported strengths of LA include learners' active participation in classroom activities (Dam, 1995; Natri, 2007; Nunes, 2004; Rao, 2005), increased motivation (Lee, 1996; Tagaki, 2003), and enhanced responsibility for learning (Cunningham \& Carlton, 2003; Mizuki, 2003; Stephenson \& Kohyama, 2003). A few researchers (Champagne et al., 2001; Dam \& Legenhausen, 1996; Vickers \& Ene, 2006) have also explored the relationship between LA and language proficiency.

LA seems to be an area that promises positive results in language teaching and learning. However, more research into LA is needed for three reasons. Firstly, the overwhelming number of LA definitions has led to a vague understanding of the concept and has made it hard for practitioners and researchers in the field to pursue their research. While much effort has recently been put into examining ways of promoting LA, little has been done in developing a clear operational definition. Therefore, the field of LA is in need of a concept that reinforces understanding and facilitates the operationalisation of LA. Secondly, investigation into cross-cultural aspects of LA has been conducted but there is room for more research to be done, especially in the Vietnamese context. Thirdly, the link between LA and language learning results has been little studied to date. Although research has started showing that LA is related to learners' language learning results, little is known about an effective approach to fostering LA.

\subsection{Learner autonomy in Vietnam}

Much research has been carried out to explore LA in Asian countries such as Hong Kong (Chan, 2001; Chan et al., 2002; Chan, 2003) Thailand (Dickinson, 1996), or Japan (Aoki, 2001; Aoki \& Smith, 1999). Research has shown different types of LA 
demonstrated by learners in various educational settings. Nevertheless, very little has been done in the Vietnamese educational context. So far Lap's (2005) work has been the only study focussing on LA in Vietnam. For this reason, it would be necessary and interesting to conduct more research which investigates LA in the Vietnamese learning environment.

Despite the lack of empirical research about Vietnamese learners, some strong claims have been made about LA in Vietnam. For example, Lap (2005) states that "the communicative needs of Vietnamese learners of English and the results from the empirical studies revealed that graduates' communicative competence is far from satisfactory and that they lack learner autonomy” (p. 20). Lap's (2005) claim seems to resonate with Riley's (1988) description of Vietnamese learners who “...said nothing, did nothing... didn't want to know..." (p. 14). It will, therefore, be useful to look into the reliability of such claims, and at the same time, help identify ways of promoting LA among Vietnamese learners.

\subsection{Aims of the research}

This study sets out to achieve four aims. Firstly, it will reconceptualise and operationalise LA. This conceptualisation of LA is intended to break LA into different components in order to measure and assess each of them independently. It is hoped that the assessment of LA will be made more accurate because of the possibility of separately measuring different aspects of LA. An operational definition of LA which reinforces understanding of LA might contribute to strengthening the reliability and validity of research into LA. On the basis of the operational definition of LA conceptualised in this study, learners could identify aspects of LA they need to improve and could invest more effort in them.

Secondly, this research project will examine LA in the Vietnamese context. It will investigate aspects of LA demonstrated by Vietnamese university students majoring in English. Specifically, it will look at differences in LA exhibited by students of diverse year levels as well as students of different levels of academic achievement, and students from different tertiary institutions. This will add to the literature on LA in the cultural environment of Vietnam, the social and educational contexts of which are unlike those in other Asian counties. 
Thirdly, the study will attempt to go beyond a qualitative and descriptive approach that characterises much of LA research to date. The operational definition pins down the LA concept to a measurable construct. This enables further collection of data in order to map out LA patterns among Vietnamese learners, and to test the relationship between LA and other related variables. It will also enable the design of concrete measures for the promotion of LA in the classroom.

Lastly, this study aims to explore whether LA leads to improved language learning. The approach adopted to foster LA will be strategy-based instruction (SBI). In language education, one of the main aims of cultivating LA is to produce independent learners who can manage and control their own learning. Given independence as an ultimate goal, learners need scaffolding provided by the teacher (Vygotsky, 1978). Studies which took advantage of metacognitive strategy training (Butler, 1997; Carrell, 1992; Goh \& Taib, 2006; Gu, 2007; Nakatani, 2005; Rubin \& McCoy, 2008; Thompson \& Rubin, 1996) have demonstrated that learners achieve higher language learning results after being trained in learning strategies. Participants in this study will be taught strategies to enhance their metacognitive management of their own learning in general and EFL writing in particular. The effectiveness of SBI to the promotion of LA and the improvement of language learning results will be examined.

\subsection{Research questions}

This study is divided into three phases, a pilot phase, Phase one, and Phase two. Each phase has a distinctive purpose and answers a different set of research questions.

The pilot phase tries to explore patterns of LA at the tertiary level in the Vietnamese context. Data obtained in this phase will help establish the instrument used in Phase one. Research questions that will be answered in the pilot phase include:

1. Are there differences in the number of activities and in the amount of time devoted to learning English by learners of different levels of academic achievement?

2. Are there differences in LA among students of different year levels?

3. Are there differences in LA at different tertiary institutions? 
Phase one is a survey study. It attempts to extend and establish the patterns found in the pilot phase. Research questions for this phase include:

4. Are Vietnamese undergraduate students of English autonomous learners?

5. What is the relationship between LA and these Vietnamese learners' English language proficiency?

Phase two is an intervention study. It tries to put the previous findings to test by teaching task-specific metacognitive management strategies. Research questions answered in this phase include:

6. Does training in metacognition lead to improved written English?

7. Will improvements in written English be maintained?

8. Does training in metacognition result in higher LA?

9. Does metacognitive training in the context of English learning and teaching result in the transfer of metacognitive skills to other areas of language learning?

\subsection{Organisation of the thesis}

The thesis consists of seven chapters. Chapter one presents the aims and importance of the study. Research questions are also introduced in the first chapter.

Chapter two reviews fundamental ideas and theories related to LA in both general education and language education. Specifically, the chapter deals with dimensions, levels, domains and versions of LA which help shape a fuller understanding of the concept. The main approaches to promoting LA and studies categorised under each approach are outlined. The chapter then examines the link between LA and LS.

Chapter three discusses the research design of the study. It starts with methodological issues in LA, followed by descriptions of the research purposes, research questions, and participants. It then presents a detailed account of the procedures for data collection, the measures of English language proficiency, and the criteria for learner classification. Next, the methods for managing and coding the data are described. The chapter also deals with issues of reliability and validity, and 
consideration of ethical issues. Finally, it provides a complete report of the researcher's involvement in the research.

Chapters four to six provide comprehensive information collected from the pilot study and the two phases of the study. Data analyses and detailed discussions on the findings are presented in these three chapters.

Chapter seven summarises the methodological and pedagogical contributions this study has made to the field of LA. Finally, it lists the limitations of the study and gives directions for future research. 


\section{LITERATURE REVIEW}

\subsection{Introduction}

The last three decades have seen a substantial increase in the amount of attention and interest given to LA in both general education and in language teaching and learning. LA has become the concern of a growing number of researchers, teachers and practitioners. Tracing back to ancient Greece, the word autonomy consists of two parts: 'autos' (self) and 'nomos' (rule or law). The concept of autonomy has a political origin and indicates a state that is self-ruled or self-governed (Boud, 1981). However autonomy is possible in every single field wherever a person can have his/her reasons for doing things (Dearden, 1972).

This chapter reviews fundamental strands in both general education and language education which are crucial to the advancement of LA understanding. The chapter begins with the description of differing views on LA in general education. It then summarises learning theories that are relevant to LA. It goes on to examine LA in language education, focusing on the history of LA, misconceptions about LA, and current definitions of LA. This chapter also categorises current understanding of LA in terms of dimensions, levels, domains, and versions with an aim to establish an operationally working definition of LA for this study. It then summarises the six most popular approaches to fostering LA. Finally, it discusses the close link between LA and LS.

\subsection{Advocates of LA}

Conceived as learners' ability to make reflective, rational, conscious and worthwhile decisions in the learning process that do not violate the moral principles of their society, LA has been defended as a goal of education by an overwhelming number of liberal educational philosophers (Boud, 1981; Dearden, 1972, 1975; Levinson, 1999; Morgan, 1996; Reich, 2002; Winch, 2002). Supporters describe LA as a capacity which can be enhanced through learning. 


\subsubsection{Assumptions about LA}

Based on Gibbs' (1979, p. 119) ideas about an autonomous individual having both independence from external authority and mastery of himself and his powers, Boud (1981), within the educational context, indicates that autonomy is used to refer to "the capacity of an individual to be an independent agent, not governed by others" (p. 22). He suggests several working assumptions related to three perspectives: the nature of autonomous learning in higher education, the characteristics of students, and the characteristics of staff. First of all, the following group of assumptions relates to the nature of autonomous learning:

- autonomous learning is a goal to be followed, rather than an absolute standard to be satisfied. Directions for students' responsibility are more important than the degree of the change

- the goal of developing student autonomy must be explicitly stated and actively pursued

- autonomy in learning does not imply students working in isolation from others. Students should be given an opportunity to choose what they want to learn according to their own needs. Developing autonomy does not mean getting rid of structured teaching

- the exercise of autonomy operates in every single part of the learning process, including students making decisions about course content, assessment, and objectives. Autonomous learning engages the whole person, not just his/her intellect. What is to be learned should be based on the style and desires of students

- in autonomous learning it is important that the goals of learning derive from students' needs and wants

- students should be judged and rewarded on a basis which is consistent with the goals.

The second group of assumptions refers to the characteristics of students, including:

- students' prior learning and experience should be exploited. They know best what they need but rely on the teacher's assistance in identifying those needs 
- regardless of their age, all students are capable of working individually at different levels and in various situations. They can facilitate and support each other's learning if they are given a chance to work together.

The third group of assumptions is concerned with the staff, specifically as follows:

- the presence of teachers who play the role of facilitators rather than transmitters of knowledge is indispensable

- teachers' competence and authority remain essential in the development of LA. Teachers themselves need to be autonomous in order to function well in their role of facilitators

- the development of LA should be encouraged in every educational institution however the costs are the same as those required by didactic teaching.

Boud's (1981) assumptions on different parties involved in autonomous learning contribute to building a clear understanding of LA.

\subsubsection{Activities carried out by an autonomous person}

In the view of Dearden (1972), autonomy is not an absolute concept. Relative freedoms and interdependent-mindness are conditions of autonomy. Autonomy is a matter of the degree to which a person's thoughts and decisions are made by himself. Aspects of autonomy involve activities of mind such as choosing, deciding, deliberating, reflecting, and planning. The activities an autonomous person engages in, according to Dearden (1975, p. 7), entail:

(i) wondering and asking, with a sense of the right to ask, what the justification is for various things which it would be quite natural to take for granted; (ii) refusing agreement or compliance with what others put to him when this seems critically unacceptable; (iii) defining what he really wants, or what is really in his interests, as distinct from what may be conventionally so regarded; (iv) conceiving of goals, policies and plans of his own, and forming purposes and intentions of his own independently of any pressure to do so from others; (v) choosing amongst alternative in ways which could exhibit that choice as the deliberate outcome of his own ideas or purposes; (vi) forming his own opinion on a variety of topics that interest him; (vii) governing his actions and attitudes in the light of the previous sorts of activity. In short, the autonomous man has a mind of his own and acts according to it. 
Independent judgment must play a pivotal role in these deeds. More importantly, the actions and thoughts of an autonomous person are not necessarily original. Rather he can collaboratively work and learn from others or conform to the rules in order to do his things in his own way. The way his views, wants, choices, and opinions are shaped is of concern, not their originality.

\subsubsection{Versions of autonomy}

In Winch's (2002) opinion, autonomy requires permission, knowledge, skills, and power to choose goals in life towards which autonomy can be meaningfully exercised. He distinguishes between strong autonomy and weak autonomy. The difference between the two versions resides in endorsement granted by the society for the choice made by a person who is weakly autonomous. Strong autonomy is associated with the freedom exercised by a person to choose and carry out any aims of life as he is pleased. If schools pursued strong autonomy as a goal, they would give students permission to make choices which might not be considered meaningful in the communities where the schools exist. This, he believes, violates the neutrality principle which does not "involve toleration of activities that lead to the undermining of one or more competing reasonable conceptions of the good" (p. 39). His support is for the promotion of weak autonomy which entails reasonable and worthwhile choices as well as engagement in social cooperation. Of importance is the fact that the worthwhile choices a person makes should be harmless to other people and should be of some intrinsic moral benefit. This weak version of autonomy, to some extent, is similar to the minimalist autonomy advocated by Reich (2002). Following is the claim Reich (2002, p. 100) makes about the minimalist autonomy:

\footnotetext{
Minimalist autonomy will not insist that an autonomous life be one that makes the person both author and subject of universal moral laws, nor will it insist that people create for themselves a life like any other. What is important for a minimalist conception of autonomy is that autonomous persons are self-determining, in charge of their own lives, able to make significant choices from a range of meaningful options about how their lives will unfold".
} 
Norman (1994) discusses two versions of autonomy identified as a broad version and a strong version. According to Norman (1994) a person's autonomy lies not merely in the satisfaction of a certain desire. Rather it resides in pulling different desires together into a way of living his life as a whole. Norman (1994) suggests that "it is the life that is important, and the particular desires have a significance for a person's autonomy in virtue of their place within that person's life" (p. 27). Irrespective of their desires, each person, having his own life to live, constructs his own way to live and remains the author of his own life. In the broader version, capacity for autonomy, which people naturally possess, is the endowment of every human being. Therefore, it could hardly be an educational goal. It is the strong version of autonomy, in Norman's (1994) view, that should become an aim of education. His strong version recognises the impact of external circumstances on a person's ability to control his life. A person lives in a certain social context on which he depends for the standards and values governing the choices and the judgements he makes. He also develops social attachments, ties, and commitments with other people in that context, which restrict his ability to control his own life. Autonomy is constituted in a situation where a person agrees to lead his life within the authoritarian institution. However, the consciousness and internal control of a person is essential in this regard. An autonomous person is well aware of his external circumstances and is able to assess them, to take actions in the light of his assessment in order to control them. His internal control asks him to take into consideration and judge the external objects or conditions. The rational and critical reflection which governs a person's standards and values derives not from himself but from his culture. Most importantly the rational activity he undertakes is intended not to alienate himself from those values and standards but to enable him to make judgements and decide which standards and values are more or less fundamental. In this sense consciousness, reflection, and rationality are conditions for autonomy and make it strong.

\subsubsection{LA and education}

Some salient features of autonomy described by Dearden (1972) include the feeling of satisfaction and the self-concept or feeling of dignity. A person normally wants to choose to perform their actions rather than to undertake them according to the will of others. He achieves the feeling of pride when he sees his own accomplishments. 
Furthermore a person exercising autonomy will feel a sense of personal growth which is respected by others. These values are closely related to education. Dearden (1972) also notes that "to become autonomous is not just a purely maturational process, since plainly many do not become so in any significant degree. It is at least in part a learning task set by a particular ideal of human development" (p. 464). Therefore, the exercising of autonomy must be learnt. Within the educational context a person will have an ample opportunity to practise autonomy by exposing himself to learning tasks. Dearden (1975) believes that autonomy is achieved gradually and exercised correspondingly. Another important point in the development of autonomy discussed by Dearden (1972) is self-knowledge which enables a person to master a variety of social interactions, actions, techniques, learning outcomes, and activities. In Dearden's mind (1975), autonomy should be valued in education because it creates a self-determining person who "can achieve command over his desires and emotions, redirecting them towards a more secure, stable and rewarding object" (p. 15). Dearden (1972) suggests that to pursue autonomy as an ideal educational aim, knowledge of the methods, curricula, and patterns of organisation need to be taken into consideration. However, Dearden (1975) believes that before cultivating autonomy as an educational aim, the criteria for judgement should be selected (p. 18).

Seeing theory of autonomy as part of a theory of education, Morgan (1996) makes a claim that "all truly educated people are autonomous" (p. 251). Morgan (1996) argues that personal autonomy is consistent with all aspects of a person's identity. Choices are not indispensable in autonomy because they occur from a background of values which rule the alternatives and evaluate a person's choices. A person can still be autonomous even when he does not express some aspects of his personality due to social constraints. A person's identity thus cannot be completely a matter of his choice. However, rationality is an essential aspect of a person's identity though it does not govern the nature of the person. Rationality is associated with critical self-reflection which aims to increase and sustain consistency of the self. The coherence in a person's self is a necessary characteristic of autonomy in Dworkin's (1988) account of autonomy which is cited in Morgan (1996, p. 241):

Autonomy is conceived of a second-order capacity of persons to reflect critically upon their first-order preferences, desires, wishes and so forth and the capacity to accept or attempt to change these in the light of higher-order preferences and values. By exercising such a 
capacity, persons define their nature, give meaning and coherence to their lives, and take responsibility for the kind of person they are.

This coherence is achieved through rational reflection on every desire a person has. In other words, rationality carries out an executive function in a person's identity. This explains why Morgan (1996) advocates the recognition of autonomy as consistent with a person's identity. He claims that autonomy should be promoted in education because the values of autonomy are consistent with a wide range of social, religious, and personal ideal (p. 250).

\subsection{Criticism of LA}

While strong support for LA has continued, criticisms have begun to emerge. Several educational philosophers value autonomy but they argue against some aspects of the account of autonomy. These aspects involve the technical meaning of LA and its limited values.

\subsubsection{Technical meaning of LA}

Studying the ideas of Foucault and Marshall on personal autonomy in education, several authors point out that it is the concept of autonomy itself that causes disapproval. Following Marshall (1996), Devine and Irwin (2005, p. 320) state that:

\footnotetext{
In Greek 'auto' means self, but 'nomos' means knowledge, law, rule, or standards and since knowledge and standards are socially constructed, nomos can never be the totally individualistic, solitary creation of one individual. That self can only exist in the context of the knowledge of its own society, and can therefore never be autonomous - or indeed free, since it will always reflect the bounds and conventions of its own history.
}

They claim that the self is always influenced by the rules or principles that structure the society. The separation of the self or autonomy from the society is not meaningful. Olssen (2005) criticises the concept of autonomy for being "too diffuse, too abstract and ...too indeterminate" (p. 371). He blames the theoretical and methodological function of the concept of autonomy for carrying with it an expansiveness of the possible meanings such as well-being, freedom, integrity, dignity, and rights. In the 
same line of thinking, Olssen (2005) points out that technically autonomy refers to people being interdependent and connected in the structures of social support. People may have the capacity of dealing with the world, but there are not sufficient grounds to claim that they are autonomous or independent from it. Discussing the ideological function of the autonomy notion, he argues that children are not really educated for reflective selfhood because they actually exercise free choices within certain constraints, and already manage and control much of their own lives. Therefore there is no need to teach autonomy to children. He believes that a degree of self-reliance assumed by the idea of autonomy is illusory because of the strong interdependence and inter-connectedness among people in the society. More importantly, every person must depend on the social and institutional support at a much greater degree than he himself can imagine or make a claim about it. Olssen (2005) acknowledges some important values the concept highlights; however, he argues that it carries with it a number of problems. Thus, he calls for an emphasis on democracy. In the light of democracy, it is important to help children understand the meaning of freedom and the ways it is expressed in contexts which are socially, nationally, and globally connected. In the educational context, he promotes a 'capabilities approach', which, according to him, "links with needs, where resources and the structures of support are emphasised" and "has the virtue of balancing freedom with equality and the concerns of justice" (p. 379).

\subsubsection{Limited values of $L A$}

Stone (1990) raises questions about the meaning and value of autonomy based on Dearden's (1972) account. She criticises Dearden (1972) for ignoring the role of feelings, emotions and desires in his analysis of autonomy. In this account, an autonomous person thinks and acts on the basis of his own reasoning, judgements, choices, and decisions rather than the outcomes of external or internal pressures (Stone, 1990, p. 273). Also, whatever he thinks and does is not necessarily original. He may choose to follow different ways of doing things or to comply with certain authorities because he sees good reasons for doing that. Stone claims that whatever reasoning or judging occurs is formed by independent judgement based on criteria made subject to continuous reassessment. There is no explicit analysis of emotions, feelings, and wants. Therefore Stone (1990) suggests Telfer's (1975) model as a way 
of understanding how emotions, feelings, and wants can positively contribute to the thoughts and the actions of an autonomous person. In the first stage, an autonomous person discovers and defines his wants and his opinions. He exercises his selfknowledge by asking himself what he actually wants, believes, and feels. This stage is for him to acknowledge his actual wants, opinions and feelings. In the second, stage he evaluates and criticises his own wants and opinions and those wants and opinions suggested by other people. This process might result in a person putting his own wants in order of importance and giving up some of his wants. He can also form new opinions on matters on which he lacks a view. In the third stage, he forms purposes, makes decisions, and takes actions according to his wants, beliefs, feelings and emotions that remain after the critical process. Stone (1990) suggests that an autonomous person should have a certain kind of basis in beliefs, attitudes, wants, feelings, and emotions on which he undertakes reflective and evaluative activities, thinks and acts. She also argues that Dearden's (1972) account of autonomy applies only to the masculine areas of the self. She suggests the need for cooperativeness, and capacity for trusting and working together, which are perhaps more expressive of the feminine self. Dialogue and balance are proposed as an ideal development that can regulate both the masculine and the feminine aspects of an autonomous person. Consideration of emotions, feelings, and wants is therefore of great importance in the practice of individual autonomy and in the maintenance of relationships with other people.

The interdependence of LA is supported by Cuypers (1992) who disapproves of personal autonomy (Frankfurt, 1982) as the first principle of education. In Frankfurt's (1982) version of personal autonomy, self-identification and selfevaluation are the main conditions. Being independent from other people's influence, a person assesses, rules himself, and proceeds on self-chosen values and norms. Cuypers (1992) criticises personal autonomy for its valuational system which is merely grounded in a person's free choice. She argues that a person must depend on the community to which he belongs for his standards of evaluative judgement. The principles, rules, norms, and values set by other people in the community are essential. Social dependence is what personal autonomy fails to promote. Cuypers (1992) states that seeking recognition and appreciation of oneself by other people is an important condition of a person's true self-evaluation and personal worth because it facilitates him in the production of certain self-feelings and reactive attitudes towards himself. 
She argues for the replacement of Frankfurt's principle of 'caring about something' by a 'caring about oneself' rule. Following the former, the object a person cares about "provides a liberation from his self-centred preoccupations and makes him free for what he really values" (Cuypers, 1992, p. 11). This principle of self-identification is criticised because a person sometimes has to deny freedom of action in order to find his true self if the focus of his concern is damaged by that action. The 'caring about oneself' principle, which acknowledges both a person's self-identification and social self-evaluation and which aims to educate "devoted and sociable people instead of detached observers or cool manipulators" (p. 15), should be taken as an ideal educational practice.

\subsubsection{Disapproval of LA as an educational goal}

Cuypers (1992), Norman (1994), and Stone (1990) believe autonomy is of limited value and argue for the consideration of other elements in the account of autonomy such as wants, feelings, emotions, and interdependence. Hand (2006) strongly argues against the cultivation of autonomy as an aim of education. Using Dearden's (1972) analysis of autonomy that a person is autonomous to the degree that he reasons about what he thinks and does, Hand (2006) argues that autonomy is already a required feature of personhood. Autonomy, hence, is not an educational goal. Defining an autonomous person as the one who is "free to determine her own actions" (p. 573), he explains that the declaration of an autonomous person is not psychological but political. This is because autonomy is defined in relation to others rather than in relation to a person's dispositions and preferences. For this reason, he proposes two senses of autonomy, neither of which, for him, should be cultivated as a goal of education. These two senses involve circumstantial autonomy and dispositional autonomy. Circumstantial autonomy refers to a freedom from any conditions on the way in which a person lives. In other words this person is not imposed upon by external rules and is not forced to follow other people's instructions. Although this kind of autonomy is desirable, as he argues, it cannot be taught or learned because it is the external conditions and the social arrangements that restrict a person, not his character. Circumstantial autonomy, serving as a political aim rather than an educational one, should not be defended as a goal in education. Dispositional autonomy indicates the "inclination to determine one's own actions" (p. 537). It is a 
quality of character of a person who wishes to rely on his own judgment, to have a free mind, and to do things at his own disposition. This is a worthwhile, teachable and learnable sort of autonomy. However, Hand (2006) argues that dispositional autonomy should not be established as an educational aim. He states that whatever situation a person is in, there often are other people who are in a better position to take more effective, appropriate and worthwhile actions than that person himself. He supplies two reasons for his argument. Firstly, since other people often own the expertise which a person is short of, it is advantageous for him to submit to other people's directions. Secondly, in different organisations and contexts, especially in schools, other people possess more authority to make effective decisions. It is prudent and reasonable to abide by their instructions. Hand (2006) does not vote for the imparting of dispositional autonomy because "the effect of cultivating dispositional autonomy in pupils would simply be to make their lives more difficult in situations requiring heteronomous action" (p. 539). He suggests giving autonomy another name.

\subsubsection{Summary}

It has been demonstrated that in general education, educational philosophers explore the notion of autonomy more or less from the political perspective, rather than from the psychological point of view. Despite the existing variety of views on autonomy, the worthwhile values of LA are widely recognised. The following section examines fundamental theories in education that are related to LA.

\subsection{Foundation of LA}

The roots of LA can be traced back to cognitive and humanistic psychology, constructivism, motivation, and self-regulated learning. The theories of these fields have created foundational ideas that shape the research and practice in the field of LA.

\subsubsection{Cognitive psychology and humanistic psychology}

Autonomy is founded on cognitive and humanistic psychologies (Broady, 1996). From the cognitive psychology perspective, knowledge is learned, and changes in knowledge cause changes in behaviours. Learning is viewed as a process in which 
learners actively acquire, remember, and use knowledge (Woolfolk, 2004, p. 268). Learning becomes effective when learners incorporate their knowledge within a personal framework. More specifically, according to Gagne (1974), the outcomes of learning increase if learners have the five main capabilities of verbal information, intellectual skills, cognitive strategies, attitudes, and motor skills. The first four abilities are more prominent in education than the last one. According to Gagne (1974) learners have the capability of verbal information when they are able to articulate in propositional form what they have learned. This ability was later termed by cognitive theorists as declarative knowledge. Learners' intellectual skills teach them how to process, to transfer, to relate, and to respond to the verbal information they have gathered from their outside environment. The term procedural knowledge is used to refer to this kind of knowledge. While the intellectual skills are oriented towards elements of the learner's outside environment, cognitive strategies deal with the internal capabilities such as attending, learning, remembering, and thinking. Gagne (1974) believes that if "strategies of attending, coding, retrieving, transfer, and problem solving can be learned and improved by formal educational means, the learner will increasingly become a self-learner and independent thinker" (p. 64). Hence, cognitive strategies are essential for self- and independent learning.

Humanistic psychology (Rogers, 1983; Underhill, 1989) focuses on a high level of health and well-being, the whole person, the human motivation towards selfrealisation, change, and development. Criticising task learning for the involvement of the mind only, Rogers (1983) supports experiential leaning which involves feelings and personal meanings and is related to the whole person. Rogers (1983, p. 20) defines experiential learning as follows:

It has a quality of personal involvement- the whole person in both feeling and cognitive aspects being in the learning event. It is self-initiated. Even when the impetus or stimulus comes from the outside, the sense of discovery, of reaching out, of grasping and comprehending, comes from within. It is pervasive. It makes a difference in the behaviour, the attitudes, perhaps even the personality of the learner. It is evaluated by the learner. She knows whether it is meeting her need, whether it leads toward what she wants to know, whether it illuminates the dark area of ignorance she is experiencing. The locus of evaluation, we might say, resides definitely in the learner. Its essence is meaning. When such learning takes place, the element of meaning to the learner is built into the whole experience. 
For Rogers (1983) whole learning is significant because it makes use of both masculine and feminine aspects. It "combines the logical and the intuitive, the intellect and the feeling, the concept and the experience, the idea and the meaning" (p. 20). Based on Rogers' (1983) ideas, Kohonen (2000a) advocates and promotes the integration of learners' own experience and existing knowledge into their learning. He argues that experiential learning involves both observing the phenomenon and taking meaningful actions through an active participation.

The theories of cognitive psychology and humanistic psychology establish very strong connections with LA. Firstly, the most prominent features of cognitive psychology include learners' ability to use their knowledge, to obtain information, and to employ learning strategies for processing the information gathered. Secondly, as suggested by humanistic psychology, learners' self-initiation and their ability to evaluate their learning are important in their engagement in the learning process.

\subsubsection{Motivation theory}

In language education Gardner and Lambert's (1972) fundamental concept of learning motivation is extensively used. They distinguish between integrative and instrumental forms of motivation. This distinction is similar to a later distinction of intrinsic and extrinsic motivation (Deci \& Ryan, 1985). The former describes learners' willingness to learn. They eagerly pursue language learning because they are personally interested in it without caring about any kind of incentives. The latter, on the other hand, is similar to instrumental motivation, "a desire to gain social recognition or economic advantages through knowledge of a foreign language" (Gardner \& Lambert, 1972, p.14). Extrinsic and instrumental motivation is associated with the expectation of exterior rewards or punishments determined by other people. Gardner and Lambert (1972) believe that the integrative motivation is the better of the two because learners are more likely to maintain long-term effort required for the mastery of language learning. Integrative motivation is based on self-determination and personal choice (Santrock, 2004).

To relate motivation to LA, Ushioda (1996) claims that the definition of LA by itself implies motivated learners. Intrinsic motivation is advocated by Ushioda (1996). Some positive features of intrinsic motivation include:

- it is self-sustaining because it generates its own rewards; 
- it leads to voluntary persistence at learning;

- it focuses on skill development and mastery;

- it is an expression of personal control and autonomy in the learning process.

(Ushioda, 1996, p. 19-20)

She believes that intrinsically motivated learning bears personal meanings and relevance. This form of learning entails learning by doing, by trying, by observing, and by practising. Most importantly, it is tied to language learning and language use. In addition to intrinsic motivation, self-motivation, according Ushioda (1996), is relevant to LA. Learners' self-motivation implies taking charge of the affective dimension of the learning experience to maintain learner involvement in learning. This capacity of taking charge enables learners to think and interpret relevant experience in order to get fully involved in learning. They also sustain their positive beliefs and self-perceptions, and reconcile with negative experiences to produce positive outcomes. From the perspective of motivation, intrinsic motivation serves as a foundation for LA.

\subsubsection{The theory of constructivism}

Constructivism is grounded in Piaget's and Vygotsky's theories of development to indicate that individuals learn best when they actively construct knowledge and understanding (Santrock, 2004). It is generally known that Piaget's theory focuses on learners constructing knowledge by transforming and organising prior knowledge and information on an individual basis. Vygotsky's theory, on the other hand, stresses social interactions through which learners' knowledge and understanding are constructed. In education, constructivism is concerned about how learners interpret events and ideas, and how they build structures of meaning (Candy, 1991). Candy maintains that learning is an active search for meaning from events, not memorising knowledge. The term constructivism is used by educators and psychologists to mean various things. The followings points are agreed among constructivists. Good teachers:

- embed learning in complex, realistic, and relevant learning environment

- provide for social negotiation and shared responsibility

- support multiple perspectives and use multiple representations of content 
- nurture self-awareness and an understanding that knowledge is constructed

- encourage ownership in learning.

(Woolfolk, 2004, p. 327)

In Candy's (1991) view the central idea embedded in constructivism is people "selfconstructing" who can "reconstrue their circumstances through the application of their personal worldview" (p. 277). Learners have their own purposes and intentions for their actions and behaviours. Candy (1991) claims that the notion of a selfconstructing person implies a tendency towards being autonomous. On the basis of constructivism, he draws some assumptions about personal autonomy. The points entail:

- personal autonomy is naturally strived for

- personal autonomy is a process that can be renewed on a frequent basis

- both learners' personal characteristics and the external environment determine their autonomy.

Other researchers link constructivism with different aspects of LA. For example, Benson (2001) acknowledges the relevance of constructivism through learners' full involvement in making decisions about the content and processes of learning. Little (1991), based on Vygotsky's view on social interactions, maintains that interdependence, rather than dependence, is of importance to LA.

Following constructivism, in relation to LA, several salient points should be recognised. These tenets involve learners' ability to self-construct their own knowledge rather than just responding to instructions, their active participation in learning, their contribution to the decision making processes on what and how to learn, and their interdependence in the learning process.

\subsubsection{Self-regulated learning}

There are two statements made by the most well-known researchers in self-regulated learning (SRL) and LA, which put forward the relation between the two fields. Zimmerman (1998) argues that self-regulated learners "are distinguished by their view of academic learning as something they do for themselves rather than as something that is done to or for them" (p. 1). Little (2007) believes that "learner 
autonomy now seemed to be a matter of learners doing things not necessarily on their own but for themselves" (p. 14). It follows that, learners' ability to do things for themselves is what links the two fields.

\subsubsection{What is SRL?}

Zimmerman (1998) defines self-regulation as a self-directed process through which learners transform their mental abilities into academic skills. Self-regulation is closely associated with self-generated thoughts, feelings, and behaviours which are aimed at achieving goals (Zimmerman, 2000, 2002). Similarly, self-regulation is a type of metacognitive skill which is part of the inner world of a person and helps him plan, monitor, evaluate his goals, and adjust his cognitive activities (Brown, 1987).

For Winnie and Perry (2000), SRL bears three features. It is metacognitively guided, partly intrinsically motivated, and strategic. It is worth considering the detailed explanation of the idea of SRL denoted by Winnie and Perry (2000, p. 533):

\footnotetext{
Metacognition is the awareness learners have about their general academic strengths and weaknesses, cognitive resources they can apply to meet the demands of particular tasks, and their knowledge about how to regulate engagement in tasks to optimize learning processes and outcomes. Intrinsic motivation refers to self-regulated learners' beliefs in incremental learning, a high value placed on personal progress and deep understanding as opposed to besting peers or impressing others, high efficacy for learning, and attributions that link outcomes to factors under their control (e.g., effective use of strategies). "Strategic" describes the way in which these learners approach challenging tasks and problems by choosing from a repertoire of tactics those they believe are best suited to the situation, and applying those tactics appropriately.
}

Pintrich (1999) specifies three categories of strategies that students need in order to regulate their learning, including: cognitive learning strategies (rehearsal, elaboration, and organisational), metacognitive and self-regulatory strategies (planning, monitoring and regulating), and resource management strategies (managing and controlling time, effort, and study environment). This has shown that SRL is to a great degree in line with 'control over cognitive process' and 'control over learning management', two of the three levels of control in the definition of LA suggested by Benson (2001). 
Self-regulated learners, accordingly, have both the skill and the will to learn (Woolfolk, 2004). Their academic learning skills and self-control make their learning easier. Santrock (2004) describes self-regulated learners as those who:

- set goals for widening their knowledge and maintaining their motivation

- $\quad$ are aware of their emotions and learn how to manage their emotions

- regularly monitor their progress toward a goal

- modify their strategies on the basis of their progress

- assess hindrances that may arise and make adjustments.

Boekaerts (1999) makes a distinction between internal and external regulation while Kehr, Bles and von Rosenstiel (1999) differentiate between self-regulation and self-control modes. Learners who internally regulate their learning are learners who identify their own learning goals and use their own strategies to achieve their goals without relying on instructions from others. External regulation, on the other hand, requires guidelines or instructions from others in order to get started. Learners following self-regulation mode set and pursue their self-set goals while selfcontrolled students adopt goals set by others. Internal regulation or self-regulation mode and external regulation or self-control mode, basically, resemble proactive and reactive kinds of autonomy (Littlewood, 1996b) which will be discussed later.

\subsubsection{SRL process}

A cycle of SRL developed by Zimmerman (1998) and revised by Zimmerman (2002) involves three phases: forethought, performance, and self-reflection. The forethought stage includes task analysis and self-motivation beliefs. When learners are engaged in task analysis they focus on goal setting and strategic planning. Self-motivation beliefs consist of learning goal orientation which refers to the valuing of the task, and the learning for learners' own merits as well as their beliefs of self-efficacy, outcome expectations, and intrinsic interest. The performance period is broken into self-control and self-observation. Self-control implies the application of strategies learners choose during the forethought stage. Specifically, they use imagery, self-instruction, attention focusing, and task strategies. Self-observation is classified into self-recording and self-experimentation. Learners keep an eye on the time they spend studying and trying out learning by themselves or with peers to find out which form of learning 
works best for them. The self-reflection stage comprises self-judgement and selfreaction. There are two forms of self-judgement: self-evaluation and causal attribution. Learners evaluate their performance based on some kind of standard. They also judge the reasons for their success or failure. Self reaction refers to learners' feelings about their performance such as self-satisfaction and positive affect. Self-reactions involve both defensive and adaptive reactions. The former implies learners' efforts to preserve their self-image by escaping from opportunities to learn and perform. The latter refers to modifications or changes aimed at improving their performance. Basically, central to the three-phase cycle are the metacognitive selfregulatory skills of planning, monitoring and evaluating. To be more specific, Zimmerman (2002, p. 66) lists the following component skills of SRL:

- $\quad$ setting specific proximal goals for oneself

- $\quad$ adopting powerful strategies for attaining the goals

- monitoring one's performance selectively for signs of progress

- restructuring one's physical and social context to make it compatible with one's goals

- managing one's time use efficiently

- $\quad$ self-evaluating one's method

- $\quad$ attributing causation to results

- $\quad$ adapting future methods.

According to Holec (1981, p. 4) SRL is an umbrella concept which might result in a person who autonomously learns at different levels. In this sense it would be reasonable to claim that SRL is strongly associated with LA. It could be argued that developing learners' ability to self-regulate their learning is of great importance to the development of LA.

\subsection{Summary}

The purpose of this section has been to introduce the major tenets of cognitive and humanistic psychology, constructivism, motivation, and SRL, and to consider some of their implications for understanding LA. The concept of LA integrates a range of ideas from these fields. The next section investigates LA within the field of language education. 


\subsection{LA in language education}

The primary purpose of this study is to advance a fuller understanding of LA in language education. For this reason essential aspects of LA will be reviewed. These include the historical background, misconceptions, and existing definitions of LA. Additionally, dimensions, levels, domains and versions of LA will be examined.

\subsubsection{History of LA}

As documented by Benson (2001, 2007), Gremmo and Riley (1995), Holec (1981), and Little (1991), the concept of autonomy originated from the European political unrest of the 1960s which supported the development of individual freedom. LA started from the changes in adult education in the 1960s, as a result of which the Council of Europe's Modern Language Project was born. The aim of this project was to provide adults with opportunities to pursue life-long learning by engaging them in self-directed language learning. In its early days, LA was associated with self-access learning centres which were established to facilitate self-directed learning. Later the concepts of individualisation (Allwright, 1988), learning strategies (Wenden, 1991a), learner training (Dickinson, 1992), independence and interdependence (Little, 1991) entered the field of LA. This explains the variety of terms used by different researchers to define the concept. Sinclair (2000) agrees that "autonomy can be viewed as a concept which accommodates different interpretations and is universally appropriate, rather than based solely on Western, liberal values" (p. 13). Likewise, Little (1999) believes that autonomy is a universal human capacity which is available to everyone not only people in the Western society. Irrespective of its Western origin, LA has been accepted, demonstrated, and exercised by people from various social and cultural backgrounds. However, mistaken ideas about LA exist.

\subsubsection{Misconceptions about LA}

There are five potential misconceptions about LA described by Little (1991). First of all, LA does not mean learning without a teacher. Autonomy is often associated with individualisation which implies learners working on their own. LA should involve collaboration and interdependence. The learners need to work collaboratively with 
their peers and with the help of teachers. What is important is the fact that in the process of developing autonomy, learners necessarily are freed from the direction and control of others. However, any decisions made by them should be made with respect to social and moral norms, traditions, and expectations of others. The second false assumption is the belief that teacher intervention might destroy LA. The third misguided notion is related to the idea that autonomy is a new teaching methodology. Teachers do play a crucial role in the development of LA. However, this development cannot entirely be structured in lesson plans. The fourth misconception is that LA is easily described through a single behaviour. In essence, it is a multifaceted concept which cannot be merely described by learners' behaviours. LA can manifest itself in various forms depending on a range of learner-related factors such as age, needs, background, and so forth. The fifth mistaken belief is linked to the fact that the autonomy learners have achieved will remain stable in every area. Learners might become autonomous in one domain but not demonstrate their autonomy in other domains.

Along this line, Aoki and Smith (1999) investigate three misconceptions about LA and culture. The first misguided concept is related to the view that a culture and a nation share the same boundaries. In fact, there are national and family cultures. Regarding the status of culturally specific activities, some activities such as religious or gender-related activities are permanent while others are temporary. The culture of an educational environment might share some features of the national culture but is not necessarily equated with it. Since cultures are interconnected and overlapping, complex and huge, people should be careful whenever they make claims about the cultural inappropriateness of a phenomenon. The second false idea is about the view that sees culture as static and unchanging. A culture is nurtured in a social, economic, and political setting which is subject to change. The stance that looks at culture as ever-changing and relative will avoid the issue of cultural stereotyping. Aoki and Smith (1999) argue that "by claiming that such a people have such and such a culture, we may run the risk of disempowering them, as this kind of positioning denies their potential to be active agents of change, i.e. participants in the creation of cultures" (p. 20). In another misapprehension, the influence of one culture on another is seen as without doubt unfavourable when a person from one culture tries to impose his cultural values on another person from a different culture. In order to judge the hostile impact one culture might have on another culture, people should attend to the social, 
ideological or idiosyncratic differences between the two cultures. In an educational setting, it is inevitable that teachers and learners influence each other's cultures. They can, however, work out a version of "negotiated culture" (Aoki \& Smith, 1999, p. 21) which takes into consideration the views of learners from different cultures.

\subsubsection{Definitions of LA}

A number of definitions of LA exist in the field. Within about two decades from the start of LA in the 1960s until the early 2000s, researchers attempted to give LA diverse definitions. The current understanding of the concept developed from the 1980s onwards. It has been recognised that the educational philosophers place much focus on personal autonomy which is connected with the political aspect which was the concern of thinkers between the decades of 1970-1990. When autonomy became involved in language education, it has shifted its main focus to the psychological aspect. This section exhibits the different terms employed to form various notions of LA.

\subsubsection{Capacity or ability}

In language education, Holec's (1981) definition is the most often cited. There are six characteristics in his definition. Firstly, autonomy is an ability to take charge of one's own learning. Secondly, this ability is not innate but necessarily is acquired through systematic and purposeful means of learning. Thirdly, it describes a potential capacity to act in a learning situation, and not the actual behaviour of an individual in that situation. The fourth feature is related to learners' ability to take charge of their learning by becoming responsible for the decisions made in the learning process, including:

- determining the objectives;

- defining the contents and progressions;

- $\quad$ selecting methods and techniques to be used;

- monitoring the procedure of acquisition properly speaking (rhythm, time, place, etc);

- evaluating what has been acquired.

(Holec, 1981, p. 3) 
Another trait is concerned with learners accepting responsibility for learning with or without the support from a teacher. The other description involves learning which can be completely or partly self-directed.

Little (1991) conceptualises autonomy as "a capacity for detachment, critical reflection, decision-making, and independent action" (p. 4). He believes that the capacity for autonomy will be demonstrated in the way learners learn and in the way they transfer what they have learned to wider contexts. The idea of autonomy implies a high degree of freedom that learners enjoy. However, he emphasises that the freedom is necessarily conditional and constrained. He argues that as social beings, people's dependence is always balanced by dependence. Thus, interdependence is an essential feature of autonomy.

Taking the position that autonomy is a legitimate and desirable goal of language education, Benson (2001) broadly defines autonomy as "the capacity to take control over one's own learning" (p. 2). It is not a method of learning; rather it is an attribute of the learner's approach to the learning process. According to him, control over learning may take different forms at different levels of the learning process. He states that autonomy is accepted as a multidimensional capacity that is displayed in different forms for different individuals, and for the same individual this capacity may differ depending on the context.

\subsubsection{Qualities}

Several authors associate LA with certain qualities. Based on the works of other educational philosophers, Candy (1991) systematises and draws a thick profile (pp. 459-466) of an autonomous learner. Assessing the qualitative similarities of attributes, characteristics, and competencies of learners, he classifies them into various groups. Similarly, Breen and Mann (1997) consider what it means to be autonomous in a language learning classroom by suggesting that autonomous learners possess the following eight qualities:

- the learner's stance towards the world

- the desire to learn

- the sense of self

- the learner's metacognitive capacity

- the management of change 
- the independence from educational processes

- the strategic engagement with learning

- the capacity to negotiate.

Breen and Mann (1997) argue that autonomy is a way of being in the world where learners are firstly in charge of and develop their relationship as to what and how they learn. Secondly, they have the desire to learn. This desire might be either intrinsic or extrinsic. Next, a sense of self suggests that learners' relationship to themselves as learners is not damaged by assessment made by others in the teaching and learning process. Instead they learn how to use evaluation as a rich source of feedback. They also learn how to reject judgments that are irrelevant and unhelpful. Another quality, which enables learners to reflect and make decisions about what, when, and how to learn, is their metacognitive ability. This allows learners to make use of any feedback they receive in a constructive way. The ability to manage change, on the other hand, allows learners to evaluate the usefulness and relevance of the changing resources around them in order to adapt themselves to the changes. It is their ability to be alert to change and to change themselves to fit in the changed and changing environment. Independence, the sixth quality, is regarded as an ability to take on the responsibility for instruction which is shifted from teachers to learners. Learners are able to make use of available resources for their own learning as well as to look for other sources outside the classroom or institution. Another quality is learners" ability to "choose the right thing at the right time for the right reasons against their own evolving criteria" (p. 136), which is called strategic engagement with learning. Achieving this ability, learners will be able to consider their needs and wants, thus fully and strategically exploiting the environment they engage in. The other quality is concerned with learners' capacity to negotiate their needs and wants with those of other group members in a strategic way. The ability to interact, to negotiate, and to collaborate with other members is crucial for learners to best use what is available to them as well as the potential resources given to them.

However, Benson (2001) does not agree with Breen and Mann (1997) who equate LA with a checklist of the desirable qualities of an autonomous learner. For Benson (2001), the qualities listed in such a checklist are presented in a way that 
autonomous learners appear to be a particular kind of person, rather than people who possess particular cognitive skills or abilities that can be acquired.

\subsubsection{Responsibility}

Learners' acceptance of responsibility for their learning and their constant reflection on what, why, and how they are learning with a certain degree of success is fundamental for LA (Little, 1999). LA is conceptualised by Scharle and Szabo (2000) as "freedom and ability to manage one's own affairs, which entails the right to make decisions" (p. 4). Autonomous learners share some attributes with responsible learners who:

- value their own efforts in the learning progress, and take appropriate actions accordingly

- are ready to work on a collaborative basis with teachers and others for mutual benefit

- monitor their own development and make use of all opportunities and resources to their benefit.

For them, central to both autonomy and responsibility is learners' active involvement. The ability to act independently of the teacher rather than waiting to be told what to do is considered to distinguish autonomy from responsibility. Scharle and Szabo (2000) perceive autonomy and responsibility as attitudes that learners may possess to different degrees.

\subsubsection{Strategies, knowledge, and attitudes}

Wenden (1991a) believes that autonomous learners are the ones who "have acquired the learning strategies, the knowledge about learning, and the attitudes that enable them to use these skills and knowledge confidently, flexibly, appropriately and independently of a teacher" (p. 15). She argues that to develop LA, knowledge about learning strategies (cognitive, self-management), knowledge about language learning (metacognitive), and knowledge about learner attitude are essential.

Firstly, cognitive strategies are described by Wenden (1991a) as mental operations such as selecting, comprehending, storing, and retrieving information 
employed by learners to process the linguistic content. In the self-management strategies, learners need to develop an ability to plan, monitor and evaluate their learning. Secondly, the metacognitive knowledge of the language includes beliefs, insights and concepts that learners acquire about language and the language learning process. The three kinds of metacognitive knowledge involve person knowledge (what learners know about themselves as learners, cognitive and affective factors that enhance learning), strategic knowledge (what learners know about strategies, what specific tasks are effective and the principles to make a decision on a chosen strategy), and task knowledge (what learners know about the purpose, the nature of the task, the deliberate learning, the resources, the how to go about doing the task). Thirdly, attitude in general covers three components: cognitive, evaluative, and behavioural.

Learner attitude towards autonomy is concerned with learners' role in the learning process and their capacity as learners. The two important attitudes autonomous learners are supposed to develop comprise their willingness to take on responsibility for their own learning and the confidence they have in order to selfdirect or manage their learning. However, learner attitudes towards autonomy might be influenced by the following factors:

socialisation processes might inhibit rather than enhance learner independence in learning

- conflicting role demands and complexity of roles might happen when learners reject their new role as more active and independent language learners, and refuse to take more responsibility

- lack of metacognitive knowledge prevents learners from observing, evaluating, and changing their own cognitive behaviours

- learner helplessness resulting from learners' failure to learn could lead to poor cognitive performance and further confirm the view that they do not have the ability to learn

- lack of self-esteem could cause learners to develop negative attitudes towards their ability to learn autonomously.

From Wenden's (1991a) suggestions, LA is closely related to learning strategies, knowledge about the learning process, and attitudes toward learning. 


\subsubsection{Readiness, willingness}

Dam (1995) endorses the Bergen definition of autonomy (1990) which was agreed upon by a group of scholars at a conference in Bergen, Germany:

Learner autonomy is characterized by a readiness to take charge of one's own learning in the service of one's needs and purposes. This entails a capacity and willingness to act independently and in co-operation with others, as a socially responsible person. An autonomous learner is an active participant in the social processes of learning, but also an active interpreter of new information in terms of what she/he already and uniquely knows. It is essential that an autonomous learner is stimulated to evolve an awareness of the aims and processes of learning and is capable of the critical reflection which syllabuses and curricula frequently require but traditional pedagogical measures rarely achieve. An autonomous learner knows how to learn and can use this knowledge in any learning situation she/he may encounter at any stage in her/his life.

(cited in Dam, 1995, p. 1)

Central to this definition are learners' readiness and willingness to take charge of their own learning. The underlying assumptions in the Bergen definition contain the following notions:

- learners' right to learn for themselves

- learners' willingness to control their own learning

- teachers supporting LA by co-creating with learners optimal conditions for the exercise of LA

- further development of LA based on the engagement of existing LA.

At the core of the notion of autonomy developed by Littlewood (1996a) reside learners' ability and willingness to make choices independently. These two abilities are interdependent and are divided into subcomponents. Littlewood (1996a) points out that ability depends on knowledge about the alternative choices and skills available for carrying out appropriate choices. Willingness depends on the motivation and confidence a person has in order to take responsibility for necessary choices. In order to obtain success in acting autonomously, a person needs to have four subcomponents: knowledge, skills, motivation, and confidence. He suggests that these components be honoured in the development of LA. 
It is important to note that in Dam's (1995) view, LA “cannot be taught, and there is no simple recipe for its implementation" (p. 6). Rather it is an experiencebased learning process for both teachers and learners. Her view is different from that of Holec (1981) who maintains that LA necessarily is acquired through systematic and purposeful means of learning.

\subsubsection{Dimensions of LA}

Three key dimensions of LA including learner independence, learner agency and selfcontrol are demonstrated by $\mathrm{Gu}$ (2009).

Figure 2.1: Dimensions of LA

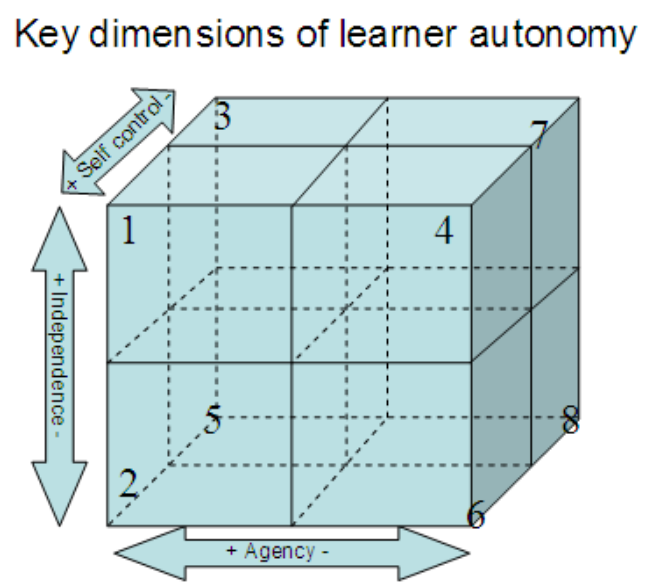

$(\mathrm{Gu}, 2009)$

Learner independence implies the degree to which learners are dependent on their teachers or other experts for any decisions made in learning. Learner agency refers to the degree to which learners display their volition and self-initiate their learning. Selfcontrol describes learners' ability to self-regulate their learning through planning, monitoring, and evaluating. While out-of-class LA is characterised by external factors or learner independence, in-class LA represents internal factors such as learner agency and self-control. When LA shifts its focus from outside learning to classroom learning, learner agency and self-control rather than learner independence become more relevant in the classroom context. The three interconnected dimensions are presented in Figure 2.1. On the left-hand side of each dimension is the positively active role and self-initiation on the learners' part. The right-hand side of the continuum, on the other hand, indicates passiveness, lack of independence, volition and self-control. 
Table 2.1: Types of Autonomous Learners according to LA Dimensions

\begin{tabular}{|c|c|c|}
\hline $\begin{array}{l}\text { Types of } \\
\text { learner }\end{array}$ & Descriptions & Examples \\
\hline 1 & $\begin{array}{l}\text { - } \text { completely independent from teachers } \\
\text { - } \quad \text { total volition and proactive } \\
\text { engagement in learning } \\
\text { - } \quad \text { complete self-control and management }\end{array}$ & $\begin{array}{l}\text { A self-taught gardener who wants to } \\
\text { create her garden by herself. }\end{array}$ \\
\hline 2 & $\begin{array}{l}\text { - } \text { dependent on teacher } \\
\text { - } \quad \text { volition and proactive engagement in } \\
\text { learning } \\
\text { - } \quad \text { self-control and management }\end{array}$ & $\begin{array}{l}\text { A student learning in a formal } \\
\text { classroom where teachers are in control } \\
\text { of the learning. }\end{array}$ \\
\hline 3 & $\begin{array}{l}\text { - } \text { independent from teachers } \\
\text { - } \quad \text { volition and proactive engagement in } \\
\text { learning } \\
\text { - no self-control or management }\end{array}$ & $\begin{array}{l}\text { A very diligent student who can study } \\
\text { on her own but constantly asks her } \\
\text { teachers for confirmation. }\end{array}$ \\
\hline 4 & $\begin{array}{l}\text { - } \text { independent from teachers } \\
\text { - } \quad \text { no volition, passive engagement in } \\
\text { learning } \\
\text { - } \quad \text { self-control and management }\end{array}$ & $\begin{array}{l}\text { A bright student but only does what is } \\
\text { needed. }\end{array}$ \\
\hline 5 & $\begin{array}{l}\text { - } \text { dependent on teacher } \\
\text { - } \quad \text { volition and proactive engagement in } \\
\text { learning } \\
\text { - no self-control or management }\end{array}$ & $\begin{array}{l}\text { A student who is very keen to study } \\
\text { but has no idea of how to study. }\end{array}$ \\
\hline 6 & $\begin{array}{l}\text { - dependent on teacher } \\
\text { - } \quad \text { no volition, passive engagement in } \\
\text { learning } \\
\text { - } \quad \text { self-control and management }\end{array}$ & $\begin{array}{l}\text { A bright but bored and lazy student } \\
\text { who might become frustrated because } \\
\text { she finds it too easy for her to learn in } \\
\text { class. }\end{array}$ \\
\hline 7 & $\begin{array}{l}\text { - } \text { independent from teachers } \\
\text { - } \quad \text { no volition, passive engagement in } \\
\text { learning } \\
\text { - no self-control or management }\end{array}$ & $\begin{array}{l}\text { A distance student who is distracted by } \\
\text { distance modes of learning. }\end{array}$ \\
\hline 8 & $\begin{array}{ll}\text { - } & \text { totally dependent on teachers } \\
\text { - } & \text { no volition, passive engagement in } \\
& \text { learning } \\
\text { - } & \text { no self-control or management }\end{array}$ & $\begin{array}{l}\text { A student, who is not interested in the } \\
\text { subject, never studied it before but now } \\
\text { she is compelled to study it by her } \\
\text { parents. }\end{array}$ \\
\hline
\end{tabular}

Figure 2.1 also exhibits eight types (numbered from 1 to 8 and located on Figure 2.1) of learners with various levels of independence, agency, and self-control. Examples 
of the types of autonomous learners are presented in Table 2.1. The instances of the eight types of autonomous learners explained in Table 2.1 are tentatively simplified to illustrate each type. In reality, there might not be a clear cut division among the learner types. The degree to which they are autonomous depends on the various dimensions of LA.

\subsubsection{Levels of LA}

Littlewood (1999) highlights the interpersonal environment which facilitates LA through the provision of help and resources, personal concern, involvement of others, opportunities for making choice, and freedom from being controlled by external agents. He distinguishes two levels of autonomy: proactive and reactive autonomy. The former refers to situations where learners are able to take charge of their own learning by setting up their personal agendas and directions, and evaluating progress in the learning process. The latter is considered a preliminary step towards the former. Reactive autonomy encourages learners to learn without being forced. Although learners do not create their own directions, when a direction has been set up by teachers or the curriculum, reactive autonomy enables them to autonomously organise their resources to achieve their objectives and goals. Collaborative and cooperative learning strategies by Flannery (1994) are used by Littlewood (1999) to manifest distinctions between proactive and reactive levels of LA. Central to collaborative learning strategies is learners having a greater degree of choice and judgment about what and how they should learn, and they themselves set the agenda for their learning. Employing cooperative learning strategies, learners work independently on tasks but rely on the teacher for setting up the agenda for learning.

Littlewood (2002) believes that in order to move from reactive autonomy to proactive autonomy, there should be a shift from cooperative learning which is controlled by teachers or the syllabus to collaborative learning which is based on learner-directed activities where they select the content and methods of their learning. He followed Ribe and Vidal (cited in Littlewood, 2002, p. 35) to construct his framework for LA developmental process. Table 2.2 adapted from Littlewood (2002, p. 37) reflects essential phases of the LA development process.

At the starting point, collaborative tasks are intended to build up learners' communicative ability through the application of CLT. The next step is to increase 
both communication skills and cognitive strategies to process information. These cognitive strategies include activities aimed to enhance learners' problem solving and analysing skills necessary for the task completion. The purpose of the third stage is to develop students' personal and interpersonal skills by learning and using the target language. Collaborative learning, therefore, is at the heart of proactive autonomy.

Table 2.2: LA Developmental Process

\begin{tabular}{lll}
\hline $\begin{array}{l}\text { Activities for communicative } \\
\text { development }\end{array}$ & $\begin{array}{l}\text { Activities for communicative } \\
\text { and cognitive development }\end{array}$ & $\begin{array}{l}\text { Activities for communicative, } \\
\text { cognitive and personality } \\
\text { development }\end{array}$ \\
\hline $\begin{array}{l}\text { Students work independently } \\
\text { towards objectives defined by } \\
\text { teacher or curriculum }\end{array}$ & $\longrightarrow$ & $\begin{array}{l}\text { Students work independently } \\
\text { towards objectives they } \\
\text { themselves have defined }\end{array}$ \\
\hline 'Cooperative' learning & 'Collaborative' learning \\
techniques, e.g., jigsaw learning & techniques, e.g. project work \\
\hline 'Reactive autonomy' & 'Proactive autonomy'
\end{tabular}

Table 2.2 suggests that there are different levels of autonomy. Engaging learners in communication-oriented activities is only the first step in the LA development process. It is where the principles of CLT and LA overlap. The aims of the next two stages could be considered the salient features of LA which have recently made LA more popular than CLT. The three stages of the process move learners to higher levels of autonomy. Hence, LA could be regarded as an umbrella covering CLT.

As far as autonomy in Asia is concerned, Littlewood (1996b) makes the following comments:

- Asian learners have a high level of reactive autonomy because they follow authority to a high degree

- Asian learners manifest a high level of proactive autonomy when they work with peers due to their group-oriented nature. Their proactive autonomy becomes weak when they perform in public or status-dominated domains such as school or family 
- the control and authority of schools hinder Asian learners from shifting from reactive to proactive autonomy. As a result, they demonstrate proactive autonomy in the private rather than in the public domain.

It is argued that the process described in Table 2.2 would be a useful tool for autonomy practitioners in the Asian context for many reasons. To begin with, as Benson (2002) and Little (1991) argue, the development of LA is a long-term and incremental process. For Asian learners, the initial goal is to develop reactive autonomy and then step by step they will move to the proactive level. This long-term process would be more effective in the Asian context because learners need to see the practical values of LA in order to pursue it as a legitimate goal of education, and to develop a positive attitude towards it. Also, for those learners who are made aware of LA and exercise it for the first time, they would need to see the positive changes brought about by autonomy-driven activities before they would make further steps towards LA. Another reason for this process to be accepted and used in the Asian context is that a steady, rather than a hasty shift away from dependence on the teacher would work better. No matter what kind of learners they are, whether they are those who would like to explore knowledge for themselves, or those who prefer to be guided by their teachers, they need more time to build their confidence and to learn how to make decisions by themselves in the learning process.

To summarise, learners going through various stages in the LA development process will achieve different levels of autonomy.

\subsubsection{Levels of control in LA}

Benson (2001) argues that autonomy should be described in terms of observable behaviours. He explains three interdependent levels of control including learning management, cognitive management, and learning content.

Control over learning management is associated with behaviours that learners employ to plan, to organise, and to evaluate their learning. First of all, control over learning manifests itself in the learners' ability to plan their learning. Secondly, learners should be able to use different learning strategies in the learning process. There are cognitive, metacognitive, social, and affective strategies. Benson (2001) believes that metacognitive, social, and affective strategies are more closely related to 
autonomy. They reflect the thinking about, the planning, the monitoring, and the evaluating of the learning process in the form of observable behaviours.

Control over cognitive process is concerned with the psychology of learning including directing attention, reflection on the learning process, and building metacognitive knowledge. Benson (2001) argues that reflection is a distinctive characteristic of autonomy. Reflection has both individual and social dimensions. It is also a mental process in which learners demonstrate their understanding and interpretation of their rational thoughts, emotions, judgment, and beliefs at a deeper level. It is regarded as a tool to help learners gain better understanding of language structure, thus contributing to their autonomy as language users. Conscious reflection on the learning process, the existing beliefs, and the practices also yields autonomy as language learners.

Control over learning content is identified as a third level of control. It is broadly accepted by researchers in the LA field that learners should, and have the right to, choose and make decisions on what they would like to learn. This involves both determining the contexts of experience where learning takes place and deciding the linguistic content to be learned. Also, control over the learning content should enable learners to engage in social interactions in order to make decisions on what to learn and on the contexts in which to implement those decisions. The interactions may be made through negotiation of learning goals and tasks with teachers and other authorities who have a voice in the negotiation of the curriculum. It is also vital that both teachers and authorities create situational contexts where learners are rewarded and encouraged to exercise freedom of learning. In this respect, autonomy involves the social and political aspects of learning.

\subsubsection{Domains of LA}

Littlewood (1996a) discusses three domains of LA. These involve communication, learning, and personal life (Figure 2.2). These domains are broken down into the following specific areas:

- autonomy as a communicator is task-specific and concerned with communication through language. It relies on learners' ability to creatively use the language and to employ suitable strategies in order to express meanings in specific situations 
- autonomy as a learner is the process of learning how to use language for communication. It relies on learners' ability to participate in independent work and to employ appropriate learning strategies for both in-class and out-of-class learning

- autonomy as a person is achieved when learners' capacity of communicating and learning independently enables them to make choices in their personal lives. It relies on learners' ability to communicate personal meanings and to create personal learning situations.

Figure 2.2: Domains of LA

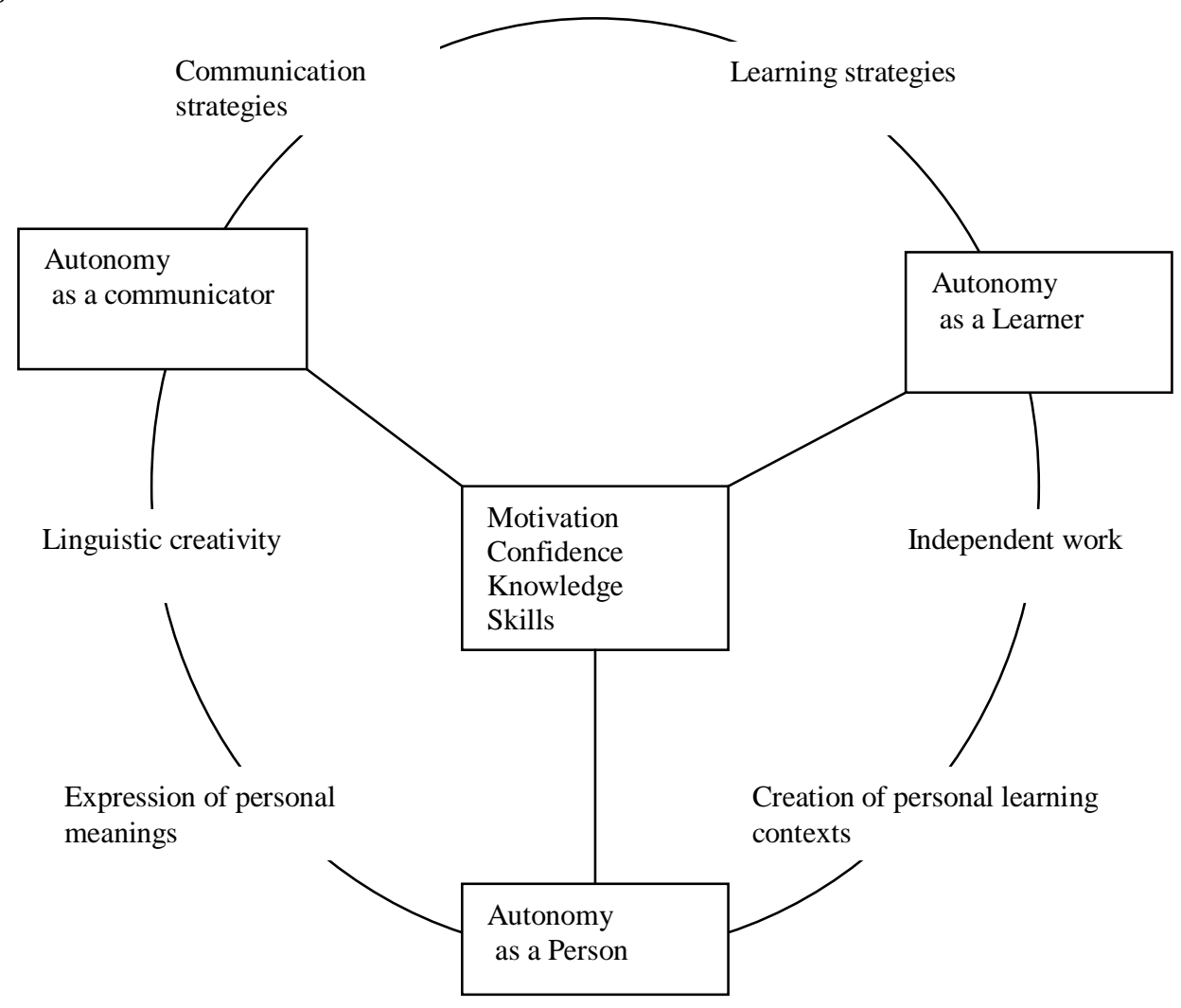

(Adapted from Littlewood, 1996a, p. 432)

He argues that these three domains are highly interrelated and overlapping. For example, while linguistic creativity is most clearly connected to autonomy as a communicator, it contributes directly to autonomy as a person because it facilitates the expression of personal meanings. Similarly, learning strategies are often associated with autonomy as a learner. However, they contribute to developing a person's autonomy as a communicator since they enable the learner to enlarge his/her 
communicative repertoire. From Littlewood's (1996a) explanations, it is reasonable to believe that the autonomy attained in one domain will enable learners to reinforce and achieve autonomy in other domains.

From another angle, Dickinson (1996) describes four domains of autonomy from perspectives of researchers, teachers, and learners:

- from the perspective of researchers and teachers: the focus is on learning techniques rather than on teaching techniques

- from the perspective of teachers: efforts should be made to guide or prepare learners for autonomy by giving them opportunities and engaging in autonomous learning

- from the perspective of students: awareness of LA as a learning mode which will lead to effective learning and is encouraged by teachers is raised

- from the perspective of students, teachers, and researchers: performing learning outside a formal educational environment is promoted as a crucial aim of all educational activities.

These four domains could be interpreted as awareness and allocation of responsibilities for people involved in the learning and teaching process which is intended to foster LA. To put it simply, learning strategies, provision of opportunities for learners' engagement in autonomy-oriented activities, teacher involvement, and out-of-class learning become crucial domains of LA in language teaching and learning.

While Dickinson's (1996) classification focuses on the assignment of responsibilities, Littlewood's (1996a) framework indicates specific areas for the development of LA that are important for the improvement of both LA and language learning. The common features of the two approaches lie in the guidance from teachers and in learners' ability to employ learning strategies for the selfimprovement of their learning both inside and outside the classroom.

\subsubsection{Models of LA}

Technical, psychological, and political aspects (Benson, 1997), and a critical aspect (Pennycook, 1997) are fundamental versions of LA. Recently the socio-cultural 
feature of autonomy (Holliday, 2003; Oxford, 2003; Schmenk, 2005) has been examined and added to the field of LA.

\subsubsection{Technical autonomy}

What Benson (1997) calls "technical autonomy" is concerned with providing learners with skills they need to manage their own learning outside the framework of an educational institution, and without the intervention of teachers. This model of autonomy comes out of the positivist view that knowledge is a reflection of the objective reality of the world. Learning is viewed as the transmission of knowledge from one individual to another, and the knowledge is best discovered with the help of a teacher. The positivist view encourages the preservation of traditional teacherlearner relationships in which the knowledge learners acquire is transmitted directly from teachers to learners; language learning consists of the acquisition of predetermined structures and forms; and the classroom is considered a natural place for that acquisition to occur. Accordingly, autonomy is seen as a particular set of situational conditions (other than the classroom) under which the language acquisition can take place. Technical autonomy, thus, refers to a set of skills which support learner independence, thus helping them acquire knowledge through discovering learning, and making decisions for their own learning by themselves, not waiting for knowledge to be passed down from the teacher.

\subsubsection{Psychological autonomy}

Psychological autonomy is denoted as a capacity or a construct of attitudes and abilities that encourages learners to take on more responsibilities for their own learning. Autonomy is associated with an internal transformation within each learner and might be supported by technical autonomy but not necessarily dependent on it. Constructivist theory is at the heart of this version of autonomy. In contrast to the positivist view, constructivism maintains that knowledge is represented as the construction of meaning. On the basis of the same objective reality, individuals construct their personal meaning systems. Learning is a matter of reorganisation and restructuring of existing experience, not the gradual memorisation of knowledge. Language learning is not simply the internalisation of a set of structures and forms. Instead individuals generate their own version of the target language with their own 
creativity. Learners are in charge of their own learning and are expected to think and act according to their thinking. Interaction, creativity, and meaning negotiation lay the foundation for psychological autonomy.

\subsubsection{Political autonomy}

Political autonomy indicates control over the process and content of learning in individual and institutional contexts where the learning takes place. Political autonomy is based on critical theory. Sharing the view with constructivism that knowledge is constructed rather than acquired, critical theory focuses on the social context and the constraints within which the learning is conducted. Critical theory argues that knowledge is not a neutral reflection of objective reality; rather it consists of contradicting ideological versions of the reality which express interests of various social groups. In learning, the critical approach places great emphasis on the issues of power and control. Learning is a process where basic social relationships that lie behind the ideological surface are discovered and criticised. Autonomy grows when learners are more aware of the social context and the constraints in the learning process.

Benson (1997) claims that within applied linguistics, the political perception of autonomy is often reduced to the party political version due to the dominance of the positivist approach to language teaching. He points out three reasons why language teaching withdraws itself from politics. Firstly, language teachers are only concerned with how to pedagogically achieve the objectives of the language course and they treat the aims of the course as a matter for more powerful people to decide. Secondly, the teaching materials and textbooks systematically avoid social and political issues and introduce a totally imaginary world where conflicts in personal relationships do not exist. Thirdly, language learning often does not occur in a real social engagement or community in the target language. Therefore, it depends almost completely on the materials and teachers. In addition, language teaching methodology tends to support the view that learners want to learn how to use the language but do not want to learn about the language and the social contexts in which it is used. To promote the political version of autonomy, Benson (1997) proposes a broader definition of politics in language education. It should not necessarily be narrowed to its pure meaning of elections, parties or revolutions, or language planning, and an 
educational policy. Rather attention should be paid to the political content of everyday language and language learning practice. Political autonomy should entail a number of points in the scale of political engagement:

- genuine interaction with the target language and its users

- learning task decided on the basis of collaboration and collective decision making

- involvement in open-ended learning tasks

- engaging in learning about the target language and its social contexts of use

- investigation into communal and personal learning goals.

Since some learning situations are more politically charged than others, it is wise and important that teachers and learners determine which of the points is more appropriate in their own learning setting.

\subsubsection{Critical autonomy}

The concept of critical autonomy has been identified by Pennycook (1997). Autonomy, according to Pennycook (1997), "is not something achieved by the handing over of power or by rational reflection; rather, it is the struggle to become the author of one's own world, to be able to create one's own meanings, to pursue cultural alternatives amid the cultural politics of everyday life" (p. 39). He emphasises the significance of looking at language learning in terms of 'voice' and the struggle for 'cultural alternatives'.

From the perspective of LA, the 'voice' suggested by Pennycook has strong implications. First of all, it is not merely a matter of providing learners with opportunities to control and negotiate the curriculum, the materials, the ways, and the time they want to learn. Rather it is a matter of developing tools to engage them in the struggle for liberation. Learners are encouraged to question, to become aware of the cultural and ideological world around them, to search for other possibilities, and to pursue cultural alternatives. Pennycook (1997) believes that the notion of pedagogy of cultural alternatives is useful in understanding the concept of autonomy. Autonomy in language learning thus should not be reduced to teachers handing over power to their students without pedagogical interventions. In his argument, language and language learning need to be interpreted in terms of specific social, cultural, economic, and political contexts of use. Autonomous learners, consequently, must 
learn how to question the issue of being autonomous users of language. This is of more value than dealing with LA merely in terms of how learners should take charge of their own learning. Critical autonomy encourages learners to speak against the local and global discourses that might constrain or create the possibilities that shape their lives.

\subsubsection{Socio-cultural autonomy}

Oxford (2003) criticises the current theoretical framework of LA for ignoring the sociocultural perspective. Taking into account essential constructs of LA such as contexts, agency, motivation, and learning strategies, she proposes a more comprehensive and systematic framework for LA. She argues for the examination of these four strands in any discussion about complete LA. In essence, the three models of LA (technical, psychological, and political) in her framework originate from Benson (1997). What is innovative in her framework is the sociocultural perspective which focuses on social interaction as a major part of cognitive and language development. In her model of sociocultural autonomy, there are sociocultural I and sociocultural II. The first type is grounded in Vygotsky's theory of the ZPD which highlights the importance of social relations and interaction in the learning process. The role of parents or teachers as 'more capable' is vital in developing learners' ability to act intentionally and independently. Sociocultural II derives from the theory of communities of practice developed by Lave and Wenger (1991). This perspective focuses on community participation and the context of autonomy. Learners, at first are not members of their community. However, by building relationships with other members of the community, they gradually become peripheral and later full participants of the community to which they belong. Oxford (2003) maintains that from the angle of sociocultural II, the practitioners or old members play a significant role in helping "the newcomers to gain the strategies, meanings, and artifacts needed to enter the community of practice" (p. 88).

Holliday (2003) argues for a model of social autonomy which takes into account what learners bring from their own worlds outside the classroom. He hopes that this description of autonomy can avoid the culturism which implies "reducing the foreign Other to simplistic, essentialist cultural prescriptions" (p. 114) and which takes the position that educational cultures or contexts negatively influence students 
who are assumed not to have autonomy. Holliday (2003) makes a claim that autonomy cannot be produced in the educational setting. Since autonomy resides everywhere and within the world learners carry with them, it should be encouraged and nurtured. He disapproves of the view that associates the notion of autonomy with the concept of participation and liveliness. In this view, passive learners are thought to lack the autonomy to learn effectively. Active learners, in contrast, are defined as those who speak in the class. He also criticises the ways in which native-speakerism perceives teachers and learners from other non-Western cultures as discouraging autonomy. He discusses three approaches to autonomy, including native-speakerist, cultural relativist, and social autonomy. The first two approaches are criticised for their culturism.

In the native-speakerist approach, learners are considered autonomous when their behaviours comply with the culture of native-speakers. This model is criticised because learners have to operate in a setting which is constructed and defined by native speakers. In this model, the culture of native speakers is perceived as better than the culture of the learners. Learner training or acculturation is proposed as a solution. However, this solution places many teachers in a very difficult situation where they are unable to teach in their preferred way because of the rejection from learners.

Different from the native-speakerist approach, the cultural relativist model assumes that Western native speakers cannot expect learners from other cultures to be autonomous like them due to differences in cultures. To deal with this issue, the cultural relativist approach suggests developing special methodologies that suit learners coming from dissimilar cultures. This model, according to Holliday (2003), still bears traits of culturism in the sense that autonomy is seen as a culturally western value. Therefore, western native-speakers do not expect learners from other cultures to adopt this western phenomenon.

He advocates the social autonomy approach that avoids culturism. The three elements of the social autonomy approach consist of:

- avoiding essential cultural descriptions of learners and refraining from the assumption that autonomy is suitable only in Western cultures 
- preventing the impact of native-speakerism by widening current views on TESOL professionalism and seeking to understand the worlds which learners carry with them

- assuming that autonomy is universal until opposite evidence is found in learners' behaviours, and employing fair and equal treatment with all people.

This approach is congruent with Little's (1999) argument that autonomy is a universal concept and can work in any culture. Teachers are supposed to accept learners as they are rather than blaming them for their failure to conform to certain norms due to the cultural differences. Teachers also are advised to consider the environment in which the learning occurs.

Little (2000) highlights the notions of individuality and independence as being the nucleus of the concept of LA. He argues that "individual cognition is embedded in processes of social interaction" (p. 16). He explicitly points out that interdependence and individuality are part of developing autonomy. Supporting the theory of ZPD by Vygotsky (1978), he argues that as a goal of learning, new levels of autonomy are attained through interaction with others. Learning occurs when learners move to new phases of dependence in the process of learning where social interaction occurs. Several implications for the language classroom are drawn from the close relationship between learning and the development of LA proposed by Little (2000).

The first implication is the pedagogy of autonomy-driven learning. It should provide learners with a capacity to learn and use the target language beyond the physical and temporal limits of their current learning environment. It is fundamental that learners engage in the practice of autonomous learning and use the target language. To realise this end, the target language should become the means in which the learning process is carried out, and there should be explicit planning, monitoring, and evaluation in the learning process. Another implication entails the need to engage learners in collaborative activities in which they collectively take part in a learning community. Group work is suggested as a form of social-interactive process in which the work can be performed better with each individual learner contributing his bits of knowledge. According to the ZPD theory, it is absolutely true that "group work brings together as many different ZPDs as there are in the group" and that "learners can support one another through their respective ZPDs" (Little, 2000, p. 20). He also 
cautions about the switching of roles that learners must perform when the learning activity they undertake needs a bit of knowledge that can be better contributed by their peers. One more suggestion is connected to the target language input. Initially input provided by teachers is the primary source of the target language. It is recommended that teachers encourage learners to collaboratively produce the language input for themselves by means of journals, posters, and texts of various kinds. The other proposition is concerned with the recognition that not all learning can be carried out collaboratively. Little (2000) maintains that "learners need regularly to step back from the process of learning in order to reflect on what they have achieved, so they need as individuals regularly to step back from the group and do some learning on their own" (p. 21). There is no doubt that this individual way of learning and using the language will result in learners heading to further collaborative activities. In summary, the socio-interactive pedagogy of LA reinforces both learners' dependence and interdependence in the learning community whose aim is to foster LA.

\subsubsection{Glocalised autonomy}

While social, economic, and technological worldwide changes have directly contributed to the triumphal development of LA, Schmenk (2005) cautions against the globalisation of LA. She claims that the globalisation leads to homogeneity in some domains and heterogeneity in others. She argues that so far the global promotion of LA has resulted in homogenisation. The glocalised version of LA which acknowledges the interaction between local and global settings has not been addressed. She criticises technological and psychological versions of LA for homogenising LA.

In the technological model, LA is often attached to self-study at self-access centres. LA is viewed as individual and independent learning which is performed by learners in isolation. Therefore, it can be promoted universally at self-access language centres. Thus LA is globalised for two reasons. Firstly, LA is diminished to the situational dimension of learning. LA can be achieved without learner engagement in social interactions and consideration of political implications. Hence, the social and

political aspects are ignored. Secondly, the computer and computer technology are seen as tools that are particularly effective for developing LA. In this sense, according 
to Schmenk (2005), if the technological model is used, LA may be conceptualised as mainly "a matter of connecting language learners to the global digital network" (p. 113).

With respect to the psychological version, Schmenk (2005) believes that LA is reduced to individual use of strategies through learner training. LA is homogenised in the sense that learners will attain autonomy as long as they are able to select and use strategies to study efficiently and effectively. The psychological version places its emphasis on the internal and individualised changes learners make in the learning process to meet their needs. LA, thus, can be recognised irrespective of cultural, political, social and economic constraints of the local setting where learning takes place. Additionally, the neutralisation of LA, which construes LA as an innate capacity with which people are endowed irrespective of their biological, cultural and political backgrounds, makes it a globalised label. Schmenk (2005) points out that the homogenisation of LA often occurs unintentionally and without being noticed. She argues that LA should not be conceptualised as a universalisable notion. Rather the cultural and political aspects should be addressed. Most importantly, LA should be relocated according to the learners' social and cultural settings. The glocalised model of LA takes into consideration cultural conditions and specific local language environments. It facilitates negotiation about LA education in a particular local setting.

\subsubsection{Summary}

Researchers have invested a great deal of effort in constructing a comprehensive understanding of LA. While the process is still going on, the following characteristics of LA which are selected from the features proposed by Sinclair (2000) would be generally agreed:

- autonomy is a construct of capacity which is not inborn

- autonomy consists of learners' willingness to be responsible for their own learning

- there are degrees of autonomy which are unstable and changeable

- autonomy can occur both inside and outside the classroom

- autonomy has a social as well as an individual dimension

- promotion of autonomy requires conscious awareness of the learning process. 
Table 2.3 summarises major definitions of LA which are classified into the models of LA presented in section 2.6.8. Some conclusions can be drawn from the LA typology described in this section. Firstly, in language education, while the concept of LA originated from Europe (Dam, 1995; Gremmo \& Riley, 1995; Holec, 1981; Little, 1991), it has been further researched and developed mainly by researchers and scholars in the Asian countries such as Hong Kong (Benson 2001; Littlewood, 1996a, 1996b), Thailand (Dickinson, 1996), and Japan (Aoki, 2001; Aoki \& Smith, 1999). In North American educational institutions, LA is addressed from the perspective of learning strategies (Wenden, 1991a). Secondly, within the LA field, an overwhelming number of terms are used by different researchers to refer to an almost identical concept. This causes confusion, especially to novice researchers and practitioners. Additionally, in the existing notions of LA, the coverage is too broad and general. This makes it harder for researchers to evaluate and measure LA. Thirdly, language education tends to pay attention to the psychological aspects of LA which focus on learners' abilities and the internal changes that they make in the learning process. Being the most popularly-accepted, the traditional notion of autonomy conceptualised by Holec (1981), without doubt, has served as a fundamental description of LA. While it is agreed that LA occurs universally, Holec's (1981) definition of LA needs adjusting in order to work in a particular educational setting. 
Table 2.3: Summary of Major Definitions of LA

\begin{tabular}{|c|c|c|c|}
\hline Models of LA & What LA is & What LA involves/ Main focus of LA & Authors \\
\hline Technical & & learning taking place outside classroom & \\
\hline \multirow[t]{10}{*}{ Psychological } & ability & $\begin{array}{l}\text { taking charge of learning by determining objectives, } \\
\text { defining contents and progressions, selecting learning } \\
\text { methods and techniques, monitoring, and evaluating } \\
\text { learning }\end{array}$ & Holec (1981) \\
\hline & capacity & $\begin{array}{l}\text { detachment, critical reflection, decision-making, and } \\
\text { independent action }\end{array}$ & Little (1991) \\
\hline & & $\begin{array}{l}\text { taking control over learning at different levels: learning } \\
\text { management, cognitive management, and learning content }\end{array}$ & $\begin{array}{l}\text { Benson } \\
(2001)\end{array}$ \\
\hline & qualities & $\begin{array}{l}\text { stance towards the world, desire to learn, sense of self, } \\
\text { metacognitive capacity, management of change, } \\
\text { independence from educational processes, strategic } \\
\text { engagement with learning, and capacity to negotiate }\end{array}$ & $\begin{array}{l}\text { Breen and } \\
\text { Mann (1997) }\end{array}$ \\
\hline & responsibility & $\begin{array}{l}\text { cooperating with the teacher and others, monitoring, } \\
\text { making effort to use available opportunities }\end{array}$ & $\begin{array}{l}\text { Scharle and } \\
\text { Szabo (2000) }\end{array}$ \\
\hline & $\begin{array}{l}\text { knowledge } \\
\text { skills } \\
\text { motivation } \\
\text { confidence }\end{array}$ & $\begin{array}{l}\text { taking responsibility for necessary choices as a } \\
\text { communicator, a learner, and an individual }\end{array}$ & $\begin{array}{l}\text { Littlewood } \\
\text { (1996a) }\end{array}$ \\
\hline & $\begin{array}{l}\text { strategies } \\
\text { knowledge } \\
\text { attitudes }\end{array}$ & $\begin{array}{l}\text { knowledge about learning strategies (cognitive, self- } \\
\text { management), knowledge about language learning } \\
\text { (metacognitive), and knowledge about learner attitude }\end{array}$ & $\begin{array}{l}\text { Wenden } \\
\text { (1991a) }\end{array}$ \\
\hline & $\begin{array}{l}\text { readiness } \\
\text { willingness }\end{array}$ & $\begin{array}{l}\text { taking charge of learning, acting independently and in co- } \\
\text { operation with others, actively participating in learning } \\
\text { process, critically reflecting on learning }\end{array}$ & Dam (1995) \\
\hline & $\begin{array}{l}\text { personal } \\
\text { dimension }\end{array}$ & $\begin{array}{l}\text { explaining and justifying intellectual, moral and emotional } \\
\text { actions }\end{array}$ & Candy (1991) \\
\hline & state of being & $\begin{array}{l}\text { being freed from internal and external obstacles that may } \\
\text { hinder the learning process }\end{array}$ & $\begin{array}{l}\text { Tort-Moloney } \\
\text { (1997) }\end{array}$ \\
\hline Social & $\begin{array}{l}\text { membershipping } \\
\text { social relations } \\
\text { interaction } \\
\text { universalisation }\end{array}$ & $\begin{array}{l}\text { coping with problems arising in the learning process and } \\
\text { developing one's own agenda for learning, seeing and } \\
\text { noticing for oneself how the target language is constituted } \\
\text { and how it functions, autonomy is embedded in every } \\
\text { learner }\end{array}$ & $\begin{array}{l}\text { Riley (1999) } \\
\text { Oxford } \\
(2003) \\
\text { Holliday } \\
(2003)\end{array}$ \\
\hline Critical & $\begin{array}{l}\text { struggle } \\
\text { voice }\end{array}$ & $\begin{array}{l}\text { becoming the author of one's own world, creating one's } \\
\text { own meanings, pursuing cultural alternatives among the } \\
\text { cultural politics of everyday life }\end{array}$ & $\begin{array}{l}\text { Pennycook } \\
\text { (1997) }\end{array}$ \\
\hline Glocalised & glocalisation & balancing global and local environments & $\begin{array}{l}\text { Schmenk } \\
(2005)\end{array}$ \\
\hline Political & & $\begin{array}{l}\text { becoming aware of social context and constraints in } \\
\text { learning process }\end{array}$ & $\begin{array}{l}\text { Benson } \\
\text { (1997) }\end{array}$ \\
\hline
\end{tabular}




\subsection{An operational definition of LA}

The researcher believes that a different conception of LA which has both local and universal values is needed. Firstly, the operationalised notion of LA will enable her to investigate LA in the Vietnamese educational context. Adherence to this working concept throughout all three phases of the study ensures the reliability of her research. Secondly, this operationalisation, which pins down LA, allows her to quantify and measure LA, a very difficult and often ignored part of the research into LA. It is hoped that the operational definition will move researchers and practitioners beyond a nebulous state of understanding. They might choose to adopt the operationalised description of LA for their research in order to quantitatively and systematically evaluate LA.

The researcher has been working as a teacher of English in the Vietnamese context where the content of learning including tasks and activities students undertake in class is predetermined by their teachers and the school's curriculum. In this context neither the researcher nor the students have the power and freedom to make decisions in the learning process. She, therefore, wished to seek a definition of LA which is independent of the power relations of learning in the Vietnamese classroom. In this study LA is conceptualised as:

learners' self-initiation plus their ability to self-regulate their own learning. Self-initiation is not only having an initial motivation to learn; it also includes effortful behaviours both inside and outside the classroom... On top of that, autonomous learners should be able to manage or regulate their own learning by planning, monitoring, and evaluating...".

(Nguyen, 2008, pp. 68-69)

\subsubsection{Elements of LA in operational definition}

The operational concept of LA is illustrated in the following diagram (Figure 2.3). In this conception of LA, the two basic threads of self-initiation and self-regulation are closely knit together. Self-initiation is learners' volition and willingness to learn without being forced by other people. It is broken into reasons for learning and making efforts to learn. While the former indicates the cause or motive for learning performed by learners, the latter implies their act of initiating any learning activities and behaviours to support their learning. These two subconstructs are learner- 
focussed. The self-regulation element, on the contrary, is task-focussed. Selfregulation involves the metacognitive skills of planning, monitoring, and evaluating, which can be taught to learners.

\section{Figure 2.3: Operational Definition of LA}

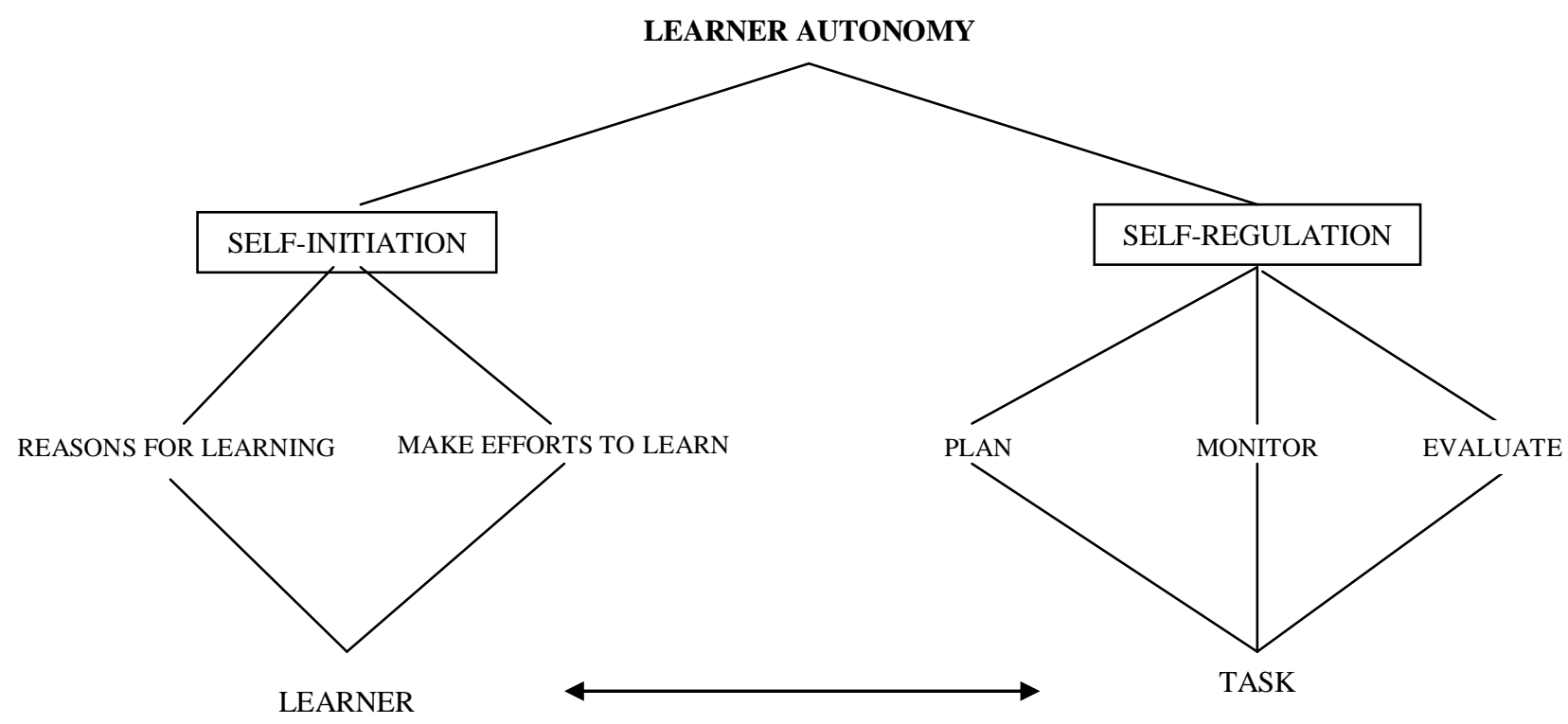

Planning takes place before the task is undertaken. It is a process of setting a plan for carrying out the task. This includes setting goal(s) for a task, conducting analyses of task knowledge (skills and knowledge required by the task), world knowledge (background knowledge and views of the topic of the task), rhetorical knowledge (how to go about doing the task), linguistic knowledge (sentence structure, grammar, vocabulary used in the task), audience knowledge (who the task is written for or presented to), and self-knowledge (personal strengths, weaknesses, and confidence). Planning also covers the proposal of strategies for "handling an upcoming task" (O’Malley \& Chamot, 1990, p. 137).

Monitoring occurs while the task is being performed. This stage is what Zimmerman (2002) calls "a covert form of self-observation" (p. 68). It constitutes learners tracking and noticing any behavioural or affective clues that might cause problems for them or make it difficult for them to complete the task. Learners selfobserve their strategies, language problems, feelings, task concentration, and task performance. Monitoring also includes learners' self-correction of what is observed to ensure they are on the right track. In this process learners also "generate judgments 
about progress and make decisions that shape further learning activities" (Butler, 2002, p. 82).

Evaluating is conducted after the task is completed. It consists of the comparison of progress against task criteria to make judgments about how well learners are doing (Butler, 2002). The process of evaluation involves finding the causes of errors and successes (Zimmerman, 2002), and interpreting externally provided feedback to diagnose challenges, to adjust learning activities, and to find solutions to their problems (Butler, 2002). In this step, learners evaluate their strategies, resources use, internal and external criteria of assessment, and their errors. They also generate self-modifying actions by making decisions on errors to correct, strategies to change, knowledge to seek, affective behaviours to change, and the level of seriousness of the problem as to whether an action is required (Rubin, 1997).

In this notion of autonomy, the self-regulation component in essence represents a set of learning strategies that are teachable. The self-regulation is more skill-focused and can be improved through training. The self-initiation, in contrast, is learner-driven. Hence, it is harder to teach. In other words, self-initiation is less teachable than self-regulation.

This definition should work in Vietnam or in any other contexts where learners are not in the position to take control over the content of the learning, one of the three levels of controls discussed by Benson (2001). Within the classroom, learners are encouraged to use the self-regulatory skills of planning, monitoring, and evaluating to better perform any task given. SRL which emphasises academic success serves as a basis in this definition.

To sum up, both elements in the operationalised concept of LA focus on the interaction between the learner and the task. This makes the concept suitable for teachers and learners whose primary aim is to improve learning and learning outcomes.

\subsubsection{Measurability of LA and operational definition}

Measuring LA is a matter of difficulty (Benson, 2001, 2007; Mynard, 2006) due to the interference of diverse conditions and factors. The most important factors affecting the measurement of LA are discussed by Benson (2001). Firstly, LA is a multidimensional construct. It is possible to identify autonomous behaviours but there 
are not sufficient grounds to conclude that autonomy consists of any combination of those behaviours. Also, the extent and the degree to which learners are autonomous depend on a range of variables such as the cultural context, the particular situation, the stage of learning, the individuals and their experiences. Secondly, learners may possess autonomy as a capacity but not necessarily exercise these skills. They know how to control and manage their learning but do not execute this knowledge. Thirdly, learners may acquire autonomy as a result of developmental process. The more mature they become, the more autonomy they gain.

To quantitatively measure LA, Benson (2001, p. 188) suggests asking the following questions:

- do learners make and use a learning plan?

- do they participate in classroom decisions?

- do they reflect upon their learning?

- do they initiate changes in the target language?

Benson (2001, p. 190) also proposes answering the following questions to find out about learners' ability to learn a language:

- are they able to create situations of learning for themselves?

- are they able to monitor and self-access their own performance?

On a more practical ground, Lai (2001) develops two measurement scales for accessing LA at two points: process control at the task level and self-direction at the level of overall process. Lai (2001) operationally defines the former as learners' ability to: (1) set realistic task aims for a chosen activity; (2) identify problems; (3) use appropriate strategies to solve the problems; and (4) carry out self-assessment of the learning experience with an aim to set future challenges. In a study to develop a measurement scale for evaluating process control, Lai (2001) guided learners to keep a listening journal for every programme they listened to or watched under such headings as: Activity/Programme, Task Aims, Brief Content Summary, Problems, Strategies and Self-assessment. Each learner accumulated 15 such entries through the term but only six entries were assessed, three at the beginning and three at the end of the course. The entries were assessed by two different raters who attended special training sessions. For the purpose of her study only two headings (Task Aims and Self-Assessment) in their entries were assessed based on two criteria for judgement 
and the use of a four-item, five-point rating scale ( 0 to 4$)$. The first criterion for evaluating task aims looks at the relevance of the type of programme chosen. The second criterion is concerned about the conduciveness to training of aspects of listening strategies. The two criteria for evaluating self-assessment are the relevance of self-assessment to the set aims and its relevance to learners' listening process and performance. Self-direction is operationally defined by Lai (2001) as learners' ability to: (1) set realistic goals for their learning, (2) identify scope of learning, relevant materials and activities to engage in, and (3) conduct self-assessment. To obtain this construct, learners were asked to design a personal course for self-directed learning covering the three aspects of the operational definition. They were provided with a framework with components of self-directed learning to follow: long-term goals; short-term goals; choice of materials; skills to practice; activities to engage in; types or amount of assignment; approach to take in order to carry out the plan; and form of assessment. Lai (2001) used the seven-point rating scale to mark students' work. Three different raters evaluated students' work in terms of adequacy, usefulness, and coherence.

Champagne et al. (2001) evaluated LA and language improvement of Thai AIT students through a range of measures. They advocated the critical version of LA developed by Pennycook (1997) so their study focused on the assessment of learners' ability to express who they are, what they think, and what they would like to do in their learning. The researchers set LA and language proficiency goals and objectives against which they evaluated LA. There were two sources of data. The qualitative data came from interviews, self-assessment, portfolios, written graphical work, audio and video tapes made outside classroom, teacher observations, reports, individual consultations, field trips, classroom videotapes, journals, and writing feedback sessions. For quantitative data, dictations were used to measure language proficiency, listening comprehension, and accuracy. The researchers assessed students' writing and found that some students made gains in grammatical accuracy. The students made improvements in their learning such as showing their confidence in the way they expressed their ideas, and attaining more fluency in their pieces of writing. Encouraging results were obtained from the study. However, the study did not clarify the kind of measures the researchers used to access LA quantitatively. It is unknown whether the dictations were standardised. 
Sinclair (1999) proposes four main ways to evaluate LA including monitoring learners' gains in proficiency in the target language, collecting feedback from teachers and learners, logging learners' behaviours, and researching the effects of strategy training. The weaknesses of each approach are also pointed out. As for proficiency gains, some students following the intervention programme to promote LA have improved their language proficiency compared with those who did not follow the programme. Still, there is little evidence on which to base a claim that the gains they achieved are the results of the training intervention. Researchers who collect qualitative data from feedback from teachers and learners need to consider the fact that the positive changes in learners might be brought about by other factors, not merely by their engagement in the course aimed at fostering LA. Evaluating LA by assessing learners' logs is neither easy nor reliable because some students prefer actually doing an activity to writing about what and why they have done it while others may write much more about what they have done. Sometimes, learners may 'put on the mask' of autonomy by writing about what their teachers expect them to without actually doing it in reality. Autonomy as well as learners' proficiency cannot be judged on the basis of the number of words students put down in their logs. A solution to the problem could be a combination of the four approaches.

The argument has been that the operational definition of LA enables the researcher to quantify LA in order to measure it. Specifically, LA can be assessed according to learners' self-initiation and self-regulation. Self-initiation is evaluated by considering learners' reasons for learning and their efforts to learn. Self-regulation is measured by taking into account learners' ability to plan, to monitor, and to evaluate their learning.

\subsubsection{Summary}

An operationally working definition of LA has been created. This operationalised description of LA serves as a guiding principle for the researcher in conducting her research, analysing data, presenting, and discussing the findings. 


\subsection{Promoting LA}

The review has exhibited the fundamental theoretical background for LA. LA has become not only relevant but also central for classroom language learning. The fact that LA has entered the mainstream of applied linguistics rapidly and has remained a central concern in every aspect of language education has strengthened the claim that LA is worthwhile. In this section, the six approaches to promoting autonomy classified by Benson (2001) will be summarised. These approaches are resourcebased, technology-based, curriculum-based, teacher-based, classroom-based, and learner-based. They focus on different aspects of control in the learning process. Studies aimed at fostering LA are also reviewed. These studies have been undertaken on the basis of four major assumptions. Firstly, LA is a universal value and an educational goal. Secondly, the more autonomous learners are the better they will learn. Thirdly, LA is learnable, and thus teachable. Fourthly, learners need support in developing their capacity to learn autonomously.

\subsubsection{Resource-based approaches}

Resource-based approaches place emphasis on the provision of opportunities for learners to direct their own learning mainly through individual interaction with the materials provided. Major forms of these approaches involve self-study or self-access, and distance learning. Materials and counselling have become the main instruments for the operation of resource-based approaches.

\subsubsection{Major forms}

Self-access language learning centres are established to enhance individualisation and learner independence (Sheerin, 1997). In terms of individualisation, these centres can cater for learners' different needs, interests, and learning styles. Regarding learner independence, self-access learning centres encourage learners to take responsibility for their own learning. However, self-access centres do not automatically yield independent learning. They remain a practical tool to achieve independent learning provided learner training, learner development activities, and constant teacher support are available (Sheerin, 1997; Sturtridge, 1997). 
Self-access language learning centres are subject to criticism for their organisation and activities in use. Littlejohn (1997) criticises self-access centres for inhibiting learners' creativity. The tasks and activity types that learners perform at self-access language centres engage them in reproductive language use which is limited to the tasks rather than in creative language use. Littlejohn (1997) argues that in order to provide more opportunities for LA, language use, and learning there should be a reorientation in task and activity types. The learners should be encouraged to perform more active and creative roles rather than responsive and reproductive ones by being provided with open-ended tasks and activities. Additionally, roles at self-access centres should be redefined. Learners are expected to participate in joint decision making, and to shift their role from consumers of selfaccess centres to that of the producers. This can be carried out by asking learners to give feedback and evaluation of the tasks and activities and by asking them to produce their own tasks and activities.

To foster independent learning through self-access centres, Sheerin (1997) suggests that learners need preparation and training in how to increase awareness of themselves and to manage their own learning. She makes two recommendations about materials and the role of teachers. The materials should be easily accessible and encourage learners' feedback. Teachers should support learners in setting objectives based on the analysis and re-analysis of their needs, and in evaluating their progress. To create a supportive environment within self-access centres is a recommendation made by Esch (1996). She works out the following five criteria:

- providing learners with genuine choices on the mode of learning, the time, the materials, the activities, and the kind of evaluation for their learning

- developing a flexible structure which allows learners to self-repair or change their options

- adjusting and responding to learning plans and strategies

- encouraging learners to reflect on their learning experience through a learning advisory service

- providing learners with an opportunity to work together and share activities and problems with one another. 


\subsubsection{Main instruments}

\subsection{Materials}

Within the domain of a self-access language learning centre, Lee (1996) stresses the important role of materials in "helping learners move towards selfdirected/autonomous learning" (p. 168). In her view, self-access materials can fulfil the affective and cognitive functions. The former refers to increasing learners' motivation in learning and making learning a more enjoyable experience while the latter is meant to provide learners with linguistic inputs, instructions for tasks and systematic learning routes. From the perspective of the development of autonomous learning, Lee (1996) differentiates between textbook materials and authentic materials. Her quantitative study with 50 Hong Kong Polytechnic University students was aimed at testing two hypotheses: 1) whether textbook materials better fulfil cognitive functions and authentic materials better perform affective functions, and 2) if the positive effect on learning produced by materials depends not only on material type but also on the interaction between material type and task type. The data were collected by asking learners to complete three sets of questionnaires and two language practice activities, the process of which took about two hours. The results of the research were consistent with her two hypotheses. To make authentic materials accessible to learners, Lee (1996) suggests a simple cataloguing system, generic guidelines for the use of authentic materials, and task sheets with students' notes. She also votes for learners' involvement in the selection of materials which can be done by asking learners to keep records of materials they have used and to adapt task sheets in order to select new texts and design their own tasks.

In terms of authentic materials, McGarry (1995) argues that activities developed from authentic texts offer exceptional opportunities for fostering LA by allowing a free choice of texts and topics. These activities facilitate negotiation between learners and teachers by fostering the development of a wide range of skills, and by enabling learners to work independently of teachers. Specifically, authentic texts assist learners in matching language learning opportunities to their needs and interests, and in creating conditions under which learners are able to exploit those opportunities successfully. It is McGarry's (1995) argument that activities developed from authentic texts can be used for learners at a beginner's level because the texts 
will challenge students with their complexity. Since the activities engage students at a higher level of their actual cognitive and emotional development, teachers can ensure that students' confidence is being built to cope with the difficulties.

Viewing materials as one of the best tools to help learners exercise autonomy in their learning, Sinclair (1996) argues for explicitness of learner training in the learning materials. To develop LA she recommends two types of materials for use at the self-access centre: directive and non-directive. Directive materials focus on cognitive and metacognitive development of language and skills practice. The aim of the task is explicitly stated to the learners. An example includes strategies for guessing unknown words from a context. Non-directive materials often consist of written and recorded authentic texts with no specific tasks attached. Depending on the amount of direction learners wish to take, they can choose either of the two types of materials that may suit them best in terms of needs and interests at different stages of their learning. They thus would learn how to develop their capacity to be more responsible for their own learning without being forced to do so.

\subsection{Counselling}

In language learning, learning advisory services or counselling have been widely used at self-access language learning centres as a way for learners to get consultation, to negotiate options to their problems in language learning, and to learn how to learn with the help of a language expert or a language teacher. According to Kelly (1996) "counselling is, above all, an enlightening process for the client; it can illuminate aspects of personal experience that, without dialogue, may not become conscious or meaningful" (p. 105).

\subsection{Counselling approaches}

Dingle and McKenzie (2001) argue that in order to develop autonomy, learners need the support necessary for them to work independently in an effective way. They report on the reassessment of the independent learning and advising environment at Nottingham Trent University in England, and the setting up of a framework for collective and individual support. Their framework covers learner support and one-toone advising which embraces the following six steps: 
- clarifying roles and expectations

- identifying and analysing learners' needs

- encouraging learners to reflect

- identifying and evaluating learning strategies

- $\quad$ setting plans

- monitoring and evaluating the plans.

Firstly, the role of advisors as providers of learning support, not of language support is highlighted. The role of learners is carrying out the act of learning with support and guidance from advisors. In the second step learners are supposed to bring along to the advisory sessions their completed profile and needs analysis questionnaires. The learners are also required to briefly outline any issues they would like to discuss at the advisory sessions. The reflection step is believed to be important in LA development. It helps advisors shape a picture of learners by exploring possible causes of any learning problem, previous learning experiences, attitudes and beliefs about learning a language, current proficiency level and desirable learning goals, degree and nature of motivation, preferred learning styles and methods of working, use and effectiveness of present strategies, lifestyle, access to resources, and time to commit to language learning. In the fourth step, the advisor suggests learning strategies which are based on learners' information collected in the reflection phase. At the fifth stage, the advisor and the learner set up a learning plan together with both long term and short term objectives. The advisor assists learners in identifying specific learning points, any resources, and necessary additional support. The advisor also indicates the date when the plan will next be reviewed. In the last stage, learners receive guidance on how to monitor and evaluate their learning process. This can be done by encouraging them to provide information sheets on self-assessment techniques, and to keep reflective language journals. Different sets of guidelines for effective language counselling can also be found in Fu (1996), Kelly (1996, p. 95-96), and Pemberton, Toogood, Ho and Lam (2001, p. 22).

Using learners' autobiographies is another way to facilitate counselling. Carter (2001) strongly believes that learning about learners' previous educational background is helpful for counsellors to understand learner's willingness to take charge of their own learning which in turn will help counsellors to launch appropriate 
counselling programmes. Carter (2001) proposes a collaborative counselling approach that would satisfy learners' needs identified in their autobiographies. Central to her collaborative approach is the gayap model which encourages learners to look for support not only from their teachers but also from their peers. The process of this approach contains three steps:

- identifying their needs

- calling for help from people within their learning community

- engaging in active participation.

Counselling sessions need to be adjusted accordingly. There are two modes of counselling. In the one-to-one model, interaction between the learner and the counsellor takes place. In the gayap mode, other learners also take part in the counselling process.

Another way to conduct counselling is through learner talking, a problemsolution framework developed by Cotterall and Crabbe (2008) by means of dialogues with learners. The strength of this framework is the data-base which is developed and which contains both the teacher's and students' accounts of their learning. This is very important for teachers to better understand their students because the learning experiences they have had may be far different from those of their students. Cotterall and Crabbe (2008, p. 126) write about strong points of the problem-solution approach as follows:

\footnotetext{
A problem-solution framework is helpful is several ways. It enables teachers and learners to share problem-solving by explicitly exploring and discovering possible solutions to specific learning difficulties. This approach is compatible with learner autonomy and does not overprivilege the teacher's knowledge of how to do things.
}

First of all, their interviews with learners start with learners expressing their difficulties. After that they use the interview data to generate categories of problems and solutions such as remembering, hearing, writing, speaking, and feedback. By doing so, teachers create learning opportunities for learners and encourage them to use those opportunities. At the same time, they can understand the learners better in terms of why they refuse to take up such opportunities. The information provided by learners helps both teachers and learners refine the language learning problems by 
letting them discover a range of options on the basis of learners' real experiences. In short, the data teachers have accumulated by engaging in dialogues with learners not only give them a clearer picture representing learner-perceived difficulties but also display patterns of difficulties and strategies to deal with them, that may be used by other learners.

\subsection{Studies on counselling}

There have been a large number of qualitative studies investigating the effects of counselling on language learning. The roles of counsellors, the steps involved in counselling sessions, and the counselling approaches have become main focus of studies on counselling.

The success of counselling sessions at self-access centres was of interest to Voller, Martyn and Pickard (1999). Their longitudinal action project provides both quantitative and qualitative data about how language counsellors could be more proficient in giving advice and support to learners and how learners could be better at managing their self-directed learning. The results of the first phase of their study indicate the predominant role of the counsellors who gave their advice by lecturing rather than listening to the counselees. Their study also identifies nine different kinds of questions asked by the counsellors about learners' goal setting and self-access learning. In the second phase of Voller et al.'s (1999) study, they made several changes to clarify the functions of the course and to give students more opportunities for negotiation. As for the counselling process, the number of questions the counsellors asked was increased with the hope of enlarging the quantity of learners' talk and improving the quantity and quality of counsellors' questions. The changes made in the second phase resulted in positive feedback about the counselling sessions. The learners found the consultation useful and as a result they came to consultation more often. The learners also acknowledged more confidence in using English, learning how to learn more efficiently, and benefiting from the help provided by counsellors.

Kelly’s (1996) self-improvement project for Hong Kong Engineering students of the lowest English proficiency level focused on needs clarification, goal-setting, contacting, programme planning, monitoring, self-assessment, project evaluation, and reflection. These steps required the most assistance from the counsellor, who tried to 
draw learners' choices and insights into their individual learning processes without imposing her directions and perspectives on learners. Her study has proved that language counselling is a useful process for the development of LA. In particular, as shown by Kelly's (1996) project, language counselling was a powerful tool for developing learning strategy awareness, language awareness, and learner-self management.

At a university in Mexico, Clemente (2003) investigated the degree of learners' satisfaction and the extent to which they felt their expectations of the counselling sessions were met. Interactional processes such as control of turn-taking, development of records, violation of the cooperative principles, and the counsellor's attitude to power were explored. Clemente's (2003) study reveals different levels of satisfaction among learners with only two learners having a positive attitude and the rest being dissatisfied or very negative. Another result displayed by her study is the power the counsellor had over the counselled learner, which led to her control of the openings of the interactions. The study highlights factors that may adversely affect the learning culture of the counselling session. One factor is learners' desire to talk and to take the counselling session as an opportunity to practise English. Another factor is the need for the counsellor to engage in more small talk in order to establish a working relationship with the counselee. The other factor is the counsellor's preference for making suggestions rather than for directing learners because she wants to avoid rudeness. In summary, Clemente's (2003) study provides counsellors with some tips that would help build their awareness of how the flexibilities of a learning culture may give room for both the counsellors and the counselees to negotiate their teaching and learning styles and to creatively adapt to the institutional context of their learning.

\subsubsection{Summary}

The strength of resource-based approaches lies in the provision of opportunities for self-directed learning. However, opportunities alone do not lead to improved LA. Neither do they result in learners' enhanced language proficiency. The two key issues remain the lack of authentic interaction and the learners' withdrawal from the collective and social process of learning (Benson, 2001). Research has mainly focussed on how the approaches can be implemented. Still there has not been 
sufficient evidence on the effectiveness of these approaches in the promotion of LA and language learning except for some studies of counselling. For greater effectiveness, the following points should be taken into consideration:

- learner training and support mechanisms

- appropriate use of technology

- self-access systems to support self-direction

- teacher and learner involvement

- integration of self-access centres with the curriculum.

\subsubsection{Technology-based approaches}

Technological advancements have enabled learners to learn language in a variety of ways with or without the presence of a teacher. In this regard, it is worth considering Littlemore (2001, p. 43) who supports the view that:

- new technologies can be used to encourage different types of independent learning but do not automatically do so; care must be taken not to replace "teacher dependency" with "machine dependency"

- learners need to be trained in the strategies required to make the most of the opportunities offered by the new technologies

- it is important that learners continue to have support from their teachers. They must not simply be left alone with the new technologies.

In technology-based approaches, the roles of teachers and learning strategies are vital. Also, it is the learning activities and opportunities for learning involved in each form of technology that decide the efficacy of technology-based approaches.

Similar to resource-based approaches, technology-based approaches also assume the usefulness of learner opportunities made available by diverse forms of technology. However, apart from the offering of opportunities for self-directed learning, some forms of technology can provide opportunities for collaboration which self-access learning often fails to achieve.

\subsubsection{Major forms}

The most popular form of technology-based approaches is Computer-Assisted Language Learning (CALL) which makes use of the CD-ROM and the Internet for 
language learning. Gardner and Garcia (1996) suggest incorporating an interactive video programme in self-access centres to help language beginners increase authentic language input and use. Researchers such as Milton (1997) propose the use of analytic techniques of linguistic texts in self-access centres to assist learners in planning their writing, generating their ideas and appropriate language, and revising their written work. Similarly, Aston (1997) makes a suggestion about the employment of corpora which are defined as "any computer-readable collection of texts or transcripts which can be assessed and interrogated selectively using text-retrieval or concordancing software" (p. 205).

E-tandem is another way of making use of technology for enhancing LA. According to Brammerts (2003), Brammerts and Calverts (2003), central to language learning in tandem is a learning partnership between a native speaker and a nonnative speaker. Two learners with different mother tongues learn each other's language, culture, knowledge, and experiences by taking responsibility for their own learning. They manage their learning by making decisions on what, how, and when to learn on the basis of commitment, mutual interdependence, and support extended to each other equally. Language learning in tandem started in the 1990s in Europe. It was successfully introduced into the curriculum at Oviedo University in Spain and Sheffield University in the UK. Little (2003) argues that in tandem LA is built into the learning process right from the beginning because learners themselves have to behave autonomously by making important decisions in the learning process. It is in this process that the metacognitive awareness starts developing since each learner has to reflect, to ponder about his/her mother tongue, and to consider the target language in order to find the best way to correct his/her partner's errors. In e-tandem, email, fax, and voiced mail are classified as asynchronous which is a disadvantage to learners because their reactions or feedback to their partner are delayed. However, this disadvantage is also seen as an advantage because learners have more time to prepare detailed feedback and explanations. E-tandem can be organised in a way to suit learners in different countries. However, both the course leaders and learners should be aware of constraints such as different curricula, course sizes, holiday times, and other factors that might have a negative effect on co-operation between partners in the long run (Brammerts \& Calvert, 2003). 


\subsubsection{Summary}

Both teachers and learners have started integrating the use of multimedia and interactive technologies to promote language learning. However, very little research evidence is available in support of the usefulness of technology-based approaches and the development of LA.

\subsubsection{Curriculum-based approaches}

The focus of curriculum-based approaches is positioned in the negotiation between teachers and learners. This is aimed at enhancing learners' participation in making decisions on learning content, activities, and tasks as well as at evaluating learning. These approaches are characterised by learners exercising their autonomy at different levels and degrees of responsibility.

\subsubsection{Responsibility, beliefs and attitudes towards LA}

Within the curriculum, the beliefs and attitudes teachers and learners hold about LA are essential to the development of LA. In the Asian tertiary setting of Hong Kong, Chan (2001) examined the extent to which LA could work from the learner perspective. Her small-scale research explored the learners' attitudes and perceptions of language learning, teacher and learner roles, their learning preferences and perception of LA. A group of 20 second-year English major students participated in the study. To achieve the aims of her research, Chan (2001) asked the participants to fill in four questionnaires which were administered from week one to week three of the English at the Workplace course. It was revealed that the participants had a highly positive attitude towards autonomous learning which could lead to the applicability of LA in the local context. The informants demonstrated that they had a relatively clear understanding of LA and the role of the teacher. Almost all of them preferred to be responsible for their own learning, to evaluate their progress, and to be given an opportunity to discover things by themselves with the teacher's guidance.

Learners' attitudes towards LA were more broadly investigated by Chan, Spratt and Humphreys (2002) at the Hong Kong Polytechnic University. Their largescale quantitative and qualitative research explored the relationship between students' attitudes towards LA, their autonomous behaviour, and the readiness for autonomous 
behaviours in a wider setting of learning. Four hundred and twenty one degree students and 87 higher diploma students answered the questionnaires, and selected students (about $5 \%$ out of the total number of surveyed students) were asked to take part in follow-up interviews. The students expressed their views of their responsibilities as well as teachers', their perceptions of their decision-making abilities, their motivation to learn English, and the frequency with which autonomous activities were conducted both in class and outside it. According to the study, the majority of students regarded aspects of learning such as identifying objectives, choosing materials and activities, and evaluating learning progress as the teachers' responsibilities. However, most students agreed on their responsibility to make decisions for outside class learning. Students also attributed their failure to make decisions to the lack of awareness of their own responsibility in the learning process and the lack of previous autonomous learning experience. The study reports that the students were not ready for autonomous language learning due to constraining factors such as their excessive dependence on the teacher, the heavy workload at the university, and the lack of motivation. The study contributes to raising the awareness of the complexities of students' beliefs and expectations and their influence on learning behaviours. This awareness is associated with the proper transfer of responsibilities from teachers to learners and the consideration of learners' learning realities to inform curriculum design and classroom practice.

Another large-scale study on autonomous language learning was conducted by Chan (2003) in which both students and teachers expressed their views of their roles and responsibilities. The teachers evaluated their students' ability to make decisions in the learning process, students' motivation level, their autonomous learning practices and behaviours, and their awareness of the importance of LA to effective language learning. This questionnaire-based research was undertaken with 508 Hong Kong students and 41 teachers from different countries such as Hong Kong, China, Australia, Britain and USA. The follow-up interview was carried out with chosen groups of students to obtain a richer and more insightful source of information. It was found that teachers preferred to take a predominant role. They had a less positive view towards their students' acceptance of overall responsibilities for the learning. They stated that most decisions made in the learning process remained their responsibility. They worried that students might not have sufficient knowledge and expertise to make decisions. The students thus played a less autonomous role in the 
learning process. Another issue that Chan's (2003) research identified was the mismatch between what teachers recommended as autonomy-orientated activities for their students against what their students actually practised according to their preferences. Constrained by other factors in the Hong Kong study environment, the teachers might be less motivated and less ready to develop LA. The importance of teachers' beliefs in their teaching practices is emphasised. The study also challenges the complicated issue of re-conceptualisation and recreation of the teaching and learning process aimed at developing LA.

\subsubsection{Major forms}

Curriculum-based approaches take two forms: the weak and the strong versions of the process syllabus (Benson, 2001). The weak version involves learners' project work in which determinations on content and methods are made by themselves. In the strong version, the syllabus is not predefined. Rather, it is selected, organised, negotiated, and renegotiated by teachers and learners as the learning goes on.

\subsection{Weak version of the process syllabus}

Group project work is of key concern to Nix (2003), Stephenson and Kohyama (2003), and Cunningham and Carlton (2003) as an optimal way to develop LA and academic literacy. The participants of Nix's (2003) research were 60 third-year students majoring in International Business and Law in his Advanced Speaking and Listening classes. His project went through a continuing process of modification and revision because of a big gap between what he thought would benefit his students and what they actually wanted. Initially, in the first four weeks, students were required to work in groups of between three and six to research and discuss political, legal or economic topics related to their major. In the fifth week they gave a 15-minute presentation followed by a discussion. It was his hope that students would have a chance to arrange things among themselves, to practise reading and speaking in English, and to reflect on what they learned in their major, and thus would improve their English and develop LA. However, students failed to effectively use their language skills, which made Nix think of a more collaborative and critical autonomy. He then developed a framework for students to plan and reflect on their work for each 
step of the new project which was based on students' feedback from the previous steps. Most importantly, he gave students freedom to choose their own ways of organising and designing their projects on a weekly basis. He also engaged himself in dialogues with individual students in order to negotiate the framework with them rather than imposing his own framework on them. To put it another way, he acknowledged students' diversity of approaches to doing their projects.

The language learning project carried out by Stephenson and Kohyama (2003) was designed to help students gain more control of their learning of listening by focusing on out-of-class learning. Participants were 50 freshmen of two listening classes scheduled twice a week. After being introduced to the concept of the language learning project, each student set his own learning goals and chose an activity that would help him achieve the goals set. Students choosing similar activities were put in the same groups. Assistance was given to those who failed to choose an activity for themselves. After making a decision on the activity, students selected materials or resources that matched their objectives. Their study plans were then written and handed to the teacher. Students also were given time in class to present what they had done. At the end of the semester students filled in self-evaluation sheets. The study demonstrates students' diversity in learning goals, interests and activities which could be catered for by the language learning project. It also displays students' reasons for choosing their preferred learning activities, which encouraged their motivation and confidence in learning English. The researchers claimed that the project led to students' increased English ability. However, no empirically-grounded results were provided. The study, to a great extent, proved that language learning projects are an effective way to increase students' responsibility for their own learning.

The class newsletter, a different kind of group work, was the focus of Cunningham and Carlton's (2003) research. First of all, sample newsletters were introduced to students so that they could in pairs select the one they preferred. They then decided on the headlines, the content, and the layout of their newsletter. After the main themes had been announced, students worked in groups to determine the topic for the class newsletter. They also formed an editorial staff that made decisions on the focus of the class newsletter and the articles to be published. The students then held discussions and votes in order to finalise their decisions. When discussions about what to include in their articles had finished, the reporter team conducted a short presentation on the ideas they wanted to write in their articles. The teacher working as 
a consultant for the editorial staff assisted students in proof-reading the articles; however the main decision was left with the editorial team. The teacher also helped students in their decisions and daily progress of the newsletter. After the reporter team handed in their articles, they compiled portfolios of individual and group work during the project for assessment which was important in facilitating learners to take charge of their own success. As a result, the students became more motivated, accepted responsibility, and made their own decisions. The project demonstrates that LA increases when the teacher relinquishes more control and encourages students' responsibility and trusts his students. However, in Cunningham and Carlton's (2003) study only descriptive evidence was gathered.

\subsection{Strong version of the process syllabus}

Following the instructions of the Danish national curriculum that encouraged teachers to shift the responsibility for decisions to learners, Dam's (1995) model for LA promotion was an enormous success. To strengthen learners' ability to make their own decisions about what to do, Dam (1995) created a learner-directed environment which encouraged learners' capacity and willingness to take charge of their own learning with constant effort and collaboration on the part of the teacher and learners alike. This development of LA entailed a shift in focus from teaching to learning. The transfer was characterised by teacher/learner and learner/learner interaction, evaluation as an integral part of the learning process, and a view of the language classroom as a rich learning environment. Dam maintains that teachers should learn the skill of "letting go" which does not mean to deny but to accept. She believes that the most significant aspect in developing LA is a growing awareness of social as well as learning processes for both teachers and learners.

Dam's (1995) 15-year project serves as a resource for language teachers who want to develop LA in their learning and teaching environment. Her project turns the principles of LA in language learning into practice on how goals can be achieved. To facilitate LA in the long and difficult process, both Dam and all her 21 fifth grade Danish students wrote diary entries. Dam's diary contained profiles of all her students. Her diary also recorded evaluation of the ongoing teaching and learning process, provisional plans for her lessons including the what and the why, and her comments on the lesson with things to remember for the following lesson. Learners exercised 
LA by discussing, deciding, and evaluating a variety of materials they have produced themselves such as posters. For example, after two weeks, students were asked to make a list of activities they wished to do individually, in pairs or in groups. They also negotiated and made their own decisions on the kind of homework they wanted to do every week. In addition, they were asked to write evaluations on what they had done. In her class, Dam always left room for learners to reflect and express themselves. The success of the project lies in Dam's ability to get students actively involved in the learning process through the means of learners' free choice of homework, activities, materials, negotiation, and close interaction with peers and with teacher, and constant evaluation of the objectives, outcomes, learners' role, teacher's role, activities and materials. The achievement made by young learners in Dam's project proves that LA can be well fostered not only among adult learners but also among other ages as long as the teacher knows how to put the theory into practice. It is the practice that matters.

Following suggestions made by Dam (1995) about taking learners' ideas and suggestions into consideration while teaching the course, Nicoll (2007) reshaped his American Studies lectures on the basis of students' suggestions from questionnaires and weekly feedback sheets about the lectures. In addition to giving students more space for presentation by holding three poster sessions, he had to reconsider his assumptions about the way he asked students to do presentations and the way he controlled the topic of the presentations. He managed to build a comprehensive corpus of students' responses to the evaluation of his lectures. The areas of responses involved reflection about classroom experiences (such as the benefits students received from lectures and from group presentations, and the relationship between the teacher and student in group presentations), and students' comments and suggestions (about students' wishes, the best part of the course, what they learned most, and suggestions for presentation project). Students' feedback was very important in locating the gaps in his perceptions of what was good for his students in terms of developing LA. For example, students requested more teaching and input from the teacher while he thought leaving students more freedom would help. He thus succeeded in building a flexible environment in which difficulties became opportunities for students to evaluate their teacher who managed to step in to establish directions and foundations for an interactive teaching and learning environment. 
The label of autonomy is denoted as learners' ability to make decisions on what, when, and how to learn as well as an ability to monitor one's progress in the learning process. With this definition in mind, Sert's (2006) case study investigated first-year Turkish EFL students' ability to set learning goals and achieve those goals. Sert (2006) claims that in Turkey, the teacher-led mode of language instruction is still predominant and students are passive language learners who fail to develop the skills needed for real-life communication tasks. She argues that Turkish learners need to develop critical awareness of language learning and learning communication. Her study also examined the extent to which the tasks and activities used in the courses support LA, and the correlation between students' self assessment and the scores they actually got from the Cambridge First Certificate Exam (FCE). The qualitative analysis from classroom observation and interviews with students demonstrates that there is a mismatch between the activities used in class and the promotion of LA. Additionally, the language teaching programmes failed to support learners in directing their efforts towards more autonomous learning. And, the students were unable to identify what they wanted to learn and how they should learn in order to achieve those goals. They also failed to monitor their own learning. The quantitative data coming from students' self-assessment and FCE scores exhibit students' low ability for reflection, one of the important elements of LA. In short, Sert (2006) blames the traditional teaching and learning philosophy in Turkey that hinders the development of LA regardless of the awareness of autonomous learning held by the teachers. The teachers themselves were shaped by this system; it was therefore very hard for them to act differently unless they changed their beliefs and attitudes.

\subsubsection{Summary}

The effectiveness of curriculum-based approaches depends on the scaffolding and support learners receive from their teachers. Research has so far focused on understanding teacher and learner responsibility, beliefs and attitudes to LA. Some studies have described positive feedback and learning behaviours learners have gained as a result of the implementation of either the weak or the strong version of curriculum-based approaches. In order to judge the effectiveness of curriculum-based approaches, much more empirically data-driven research is needed. 


\subsubsection{Teacher-based approaches}

The focus of teacher-based approaches is on teacher professional development and teacher education. These approaches have been developed on the assumption that changing teachers' beliefs about autonomy, building their commitment to autonomy, and encouraging practices to support LA will result in classroom changes, which are in favour of LA. To put it differently, LA is dependent on teacher autonomy. Little (1995) argues that LA depends on teacher autonomy for two reasons. Firstly, teachers themselves must be autonomous if they expect their students to exercise autonomy. Secondly, teachers must be able to make the most of their professional skills autonomously.

\subsubsection{Definition of teacher autonomy}

An autonomous teacher is "aware of why, when, where and how pedagogical skills can be acquired and used in the self-conscious awareness of teaching practice itself" (Tort-Moloney, 1997, p. 52). According to Thavenius (1999) developing LA requires a lot more from teachers than they realise. For her, this process is equivalent to teachers changing their personality (p. 159). The following is how she conceives LA:

Teacher autonomy can be defined as the teacher's ability and willingness to help learners take responsibility for their own learning. An autonomous teacher is thus a teacher who reflects on her teacher role and who can change it, who can help her learners become autonomous, and who is independent enough to let her learners become independent.

(Thavenius, 1999, p. 160)

Thavenius (1999) argues that awareness is the key concept in both teacher autonomy and LA. She holds that the process of teacher awareness development is a long and complex one that needs not only constant training and classroom practice but also a fundamental change of attitudes and a good insight into introspection. Following Little (1991), Thavenius (1999) claims that teachers have to become autonomous by engaging in and experiencing the process with learners in order to support LA. Thus, teacher autonomy and LA happen at the same time and reinforce each other. 


\subsubsection{Framework for the development of teacher autonomy}

McGrath (2000) discusses three levels of teacher awareness developed by Thavenius (1999) as a way to move from an implicit to an explicit support of LA. McGrath (2000) proposes an alternative model of teacher development that encourages teachers to adopt an evaluative view of the elements of the context over which they have control. In the following model, there are three levels at which teachers shift their focus from others to themselves.

Table 2.4: Models of Teacher Autonomy

\begin{tabular}{lll}
\hline Level & Self-focused & Other-focused \\
\hline 1 & achievement of imposed goals (e.g. & inspector/school head/ \\
& covering syllabus, completing text-book, & Head of department \\
& preparing students for exams) & Student performance \\
\hline 2 & own role in managing students' learning & Students' needs/wants \\
& & \\
\hline 3 & own professional development & -
\end{tabular}

He comments that depending on the situation, the teacher may need to shift down a level or two if there is a change in syllabus, textbook or public examination.

Tort-Moloney (1997) generates a framework which suggests that promoting teacher autonomy is essential to the formation of a learner-centred environment in a second language classroom, where individual differences and needs of both learners and teachers are accommodated. Tort-Moloney (1997) believes that the ability to do a good parenting job is an important quality of autonomous teachers. Specifically, teachers play the role of authoritative parents who are different from authoritarian and permissive parents. In her view, authoritarian and permissive parents stand at the two ends of the continuum and are defined respectively as providing too much control and too little nurturance, or too little control and too much nurturance. Authoritative teachers can manage the balance by explaining their requests and commands to promote learners' engagement in learning and by managing time allocation to maintain learners' engagement. The parenting job that teachers are supposed to perform involves: 
- building the usefulness of the skill taught by providing temporary scaffolding for students

- creating opportunities for learners to assume responsibility for their learning through steady practices guided by the teacher

- engaging learners in verbalising the mental steps they are going through.

In addition to the parenting role, the interactive self-regulation pattern is necessary. Tort-Moloney (1997) associates this pattern with teachers' willingness and ability to act not according to their individual character but as part of a process of developmental adaptation. To achieve teacher autonomy, Tort-Moloney (1997) maintains that teachers must "become autonomous from curricular demands, pedagogical material and discourse, as well as from research, by being able to acknowledge the virtues and limitations of these areas" (p. 50).

\subsubsection{Relationship between teacher autonomy and LA}

Vieira (1999) develops pedagogy for autonomy that creates a connection between teacher training and learner training on the ground that reflective teaching and LA are interdependent. Vieira argues that "reflective teaching was not only the means for the development of learner autonomy, but also its outcome" (p. 155). She also claims that linking teaching and researching provides a way to develop as a teacher who wishes to build autonomy in learning.

While Little (1991) argues that LA depends on teacher autonomy, in Aoki's (2002) argument, teacher autonomy does not imply "any relevance to teachers' capacity to support the development of the autonomy of their learners" (p. 111). Instead, the focus is on the relationship between the development of the capacity to foster LA and reflective practice by teachers. She believes that teachers play an important role in developing knowledge and skills that autonomous learners should have. Specifically, teachers need to:

- trust learners

- create a psychologically safe learning environment

- provide choices, leave room for negotiation with learners

- allow voice to learners

- provide information 
- articulate the rationale of their decisions made on behalf of learners so that those decisions are transparent to learners

- stimulate and support reflection on cognitive, affective and social aspects of learning.

However, to support LA, reflective practice alone is not sufficient for many reasons. First of all, there is a degree of participation that may negatively affect the degree of teachers' reflectivity. Secondly, teachers' choices are constrained by the needs and wants of learners. Thirdly, teachers bring to the classroom not only their knowledge but also themselves as persons. Consequently, in order to enhance LA, Aoki (2002) believes that it is essential that teachers interact with learners constantly and make decisions on the grounds of their learners' needs and wishes. In this sense, teacher autonomy is necessary but not enough. She suggests that the curriculum of teacher education programmes be flexible and "leave a lot of room, psychologically as well as time-wise, for student teachers to think, explore and, resist and rebel” (p. 117).

To promote LA, Yang (1998) suggests that teachers embark on new roles as helpers, facilitators, advisors, and guides. In her four-year study 40 students were required to write a proposal for their language learning projects. They were also invited to keep weekly diaries in which they were encouraged to write down as much as possible about the affective factors such as motivation and attitude. Their teachers gave instructions on learning strategies such as techniques for test taking, report writing, giving oral presentations, and reading materials with different purposes. When learners shared their proposals orally in class and in a written form with their teacher, they were requested to self-evaluate their work. Yang's (1998) study suggests that teachers play the role of helpers who provide learners with realistic guidance and encouragement to set realistic goals for language learning by constantly reading learners' diaries. Teachers also provide information and help change learners' misconceptions through lectures, discussions or reading materials, and most importantly through explicit learner training on strategies. For dependent students, teachers need to provide extensive support and arrange peer support for them. For learners who wish to study a language on their own, teachers should encourage them to self-assess their progress. To sum up the teacher's role remains essential in the promotion of LA. 


\subsubsection{Summary}

The effectiveness of teacher-based approaches to the development of LA depends on teachers' commitment to autonomy and their professional skills. So far research has merely focused on understanding the concept of teacher autonomy and on working out principles to foster it. Little is known about the dependence of the achievement of LA on the promotion of teacher autonomy.

\subsubsection{Classroom-based approaches}

Classroom-based approaches assume that learners will be able to develop LA through the management of their learning within the classroom context where they can collaborate with peers and make use of support from teachers. Classroom-based approaches emphasise changing the relationships and classroom practices. The changes enable teachers to transfer responsibility and control over learning goals, learning process, and assessment of learning outcomes to learners.

\subsubsection{Pedagogy for classroom autonomy}

Crabbe (1993) claims that within the classroom, teachers focus mainly on the public domain through shared activities without paying sufficient attention to the private domain of learning through "learners' personal learning activities" (p. 445). He states that public domain tasks and teacher discourse in the public domain do not provide adequate scaffolding as to how learning within the private domain can be performed. He argues that inside the classroom learners can exercise autonomy by undertaking personal learning activities. In order for teachers to bridge the gap between public domain tasks and private domain tasks for the purpose of fostering LA, Crabbe (1993) makes two suggestions.

He suggests changing classroom discourse about tasks and negotiating with students about aspects such as:

- purposes of tasks being done

- potential difficulties in completing the tasks

- appropriate strategies for dealing with these difficulties. 
He suggests designing tasks that model how learning is done. Features of these tasks include:

- the goals for the task should be clear

- the task should be easily carried out by an individual learner

- the progress of the task performance should be recognised by the learner

Smith (2003), through his experience of teaching English to Japanese students, develops a 'strong version' of pedagogy for autonomy. He connected students' outof-class learning with his teaching practice by asking them to write about and to share with their peers their own goals for English learning outside the classroom. After reading students' reflections, he invited them to write their suggestions about classroom activities. He then grouped them according the chosen activities. From his work, Smith (2003, p. 136) has developed a 'student-directed learning cycle'. This cycle involves:

\section{Planning sessions:}

Students clarify individual goals.

Students share ideas and experiences, and draw up individual plans for out-of class learning activities.

Brainstorming of ideas for within-class learning activities; formation of groups.

Students draw up plans for (individual of group-based) within-class learning activities.

\section{Student-directed learning sessions:}

Student-directed within-class learning (generally group-based).

Ongoing out-of-class learning.

\section{Evaluation sessions:}

Groups/ individuals give presentations on within-class learning

Written reflection on out-of-class and within-class learning for homework.

On the basis of his self-directed learning pedagogy, Smith (2001) examined a framework which assisted learners in integrating out-of-class learning into in-class learning. The participants of his study comprised 39 first-year non-English major Japanese students who took a 28 -week listening course. These learners were asked to write about the activities they performed to improve their English outside the classroom context. From students' reflective writing, Smith (2001) was surprised to find out that his students were far from being dependent or "other-directed" (p. 74). Instead they made use of a variety of resources and created diverse tasks for their 
learning outside the classroom. For instance, in addition to doing practice listening tests for TOELF and TOEIC exams, they watched TV programmes, listened to songs, went to the theatres, made overseas phone calls, talked in English with peers, and undertook activities with international students in order to speak English. Group activities such as watching movies on video, TV news or documentaries, TV dramas, songs, conversation were reported. However, some students reported their preference for individual classroom learning, which suggested that group-based arrangements were not appropriate for all learners in the same setting. His research concluded that the requirement for independence rather than interdependence was essential in the development of self-directed learning and LA. This finding was not consistent with Little (1991) and other researchers who have argued that interdependence is central in the development of LA.

During the five years Smith (2003) was applying the 'student-directed learning cycle' he constantly modified and made significant changes based on students' feedback. He increased his explanations of the benefits of the approach and his trust toward his students' ability to learn for themselves but decreased his interventions. Efforts were made to encourage students' involvement in the negotiation of classroom arrangements that were appropriate to certain groups of students to facilitate students' decision-making. Overall, this approach has two major advantages. Firstly, it stimulates teachers to conduct more action research in order to develop a more suitable approach to fostering LA. This approach is based on immediate interaction with students. Teachers, as a result, can learn with and from their students. Secondly, since this approach is developed from the joint involvement of teacher and students, it avoids culturalism. This is of value to Asian countries which are employing an increasing number of native speakers to teach the target language. The negotiation between teachers and students would lead them to new but proper directions for classroom culture, which, according to Smith (2003), "are jointly created within the limits of what proves to be feasible and acceptable in a particular context" (p. 144). The strength of Smith's (2003) approach is the provision of ample opportunities for students to reject and renegotiate. At the same time it creates opportunities for teachers to rebuild a more familiar but necessary authority, an important issue to keep in mind in the Asian context.

With an aim to bring about authentic language autonomy by helping learners express their inner worlds and making personalised meanings, Shao and Wu (2007) 
applied the 'caring pedagogy' in a class of 25 freshmen English majors in China. Perceiving 'caring pedagogy' as encouraging learners' personal interests and concerns, they engaged learners in authentically deep life concerns through topicbased learning. They used such activities as topic-deciding, group-forming, informative learning, in-depth exploration, communal presentation, related discussion and reflective writing. They believe that concerns about authentic life which are incorporated in the pedagogic process would engage both teachers and learners in a dialogue which was aimed to enhance learners' capacity for learning. In their study, the teacher managed to stir up the inner life of learners by sharing with her students an authentic life experience of the smell of grass during her years at Cambridge. Learners' stories and the teacher's journals provide sound evidence that the hearts of students were truly engaged by listening to the teacher's authentic experiences. As a result, the learners became more open, confident, and willing to write and speak in English about their inner worlds in a very touching way. The life-story dialogue between the learner and the teachers was believed to result in authentic and autonomous learning.

\subsubsection{Major forms of classroom-based approaches}

The most popular forms of these approaches include cooperative learning, portfolios, self-assessment and peer-assessment, out-of-class learning, and self-directed learning.

\subsection{Cooperative learning}

Cooperative learning is perceived as a group of learning activities which encourage learners to exchange information, to be more responsible for their learning, and to be motivated to increase the learning of other members in the group. The positive interdependence of cooperative learning is compatible with LA. Tagaki (2003) supports the view that engaging learners in interaction with peers to solve problems and to negotiate differences in opinions can result in complementary skills in autonomy and cooperation. A class was designed with the intention to improve academic reading skills and English vocabulary, to develop critical thinking skills, and to foster cooperation among 48 Japanese freshman students. Jigsaw activities were employed for 13 weeks. Students were assigned different reading passages in 
groups of four. They were asked to join members of other groups that had the same reading passages. Students then took turns to teach their group members about the reading passage they had practised. Although the class was planned to improve the students' reading proficiency, the study did not provide any empirical evidence. However, it received very positive feedback from the researcher's observations, her interviews and students' learning journals. Such feedback included a high attendance rate, students' ability to work in different roles and to freely express their opinions, growth in group cohesiveness, students' awareness about the need to be responsible for their own learning, increase in students' intrinsic motivation, and a change in students' perception about the role of the teacher and that of their classmates. Cooperative learning thus fosters learners' motivation and responsibility for their learning.

Reflective awareness is promoted by Mizuki (2003) as the key to developing LA. His research focuses on group and individual presentation activities for third-year English major-students in Japan. Students were allowed to freely choose their own topics, to take responsibility for their own learning, and to evaluate themselves and their peers by completing self- and peer-evaluation sheets. Before conducting their presentations, students were provided with metacognitive learning strategies through presentation guidelines which also helped them take control of their learning outside of the classroom. Specifically, groups of three or four students decided the topic for their presentation themselves and presented the topic in their groups. In order to achieve this, group members had to complete their part to make sure the work was done. They would then lead the class discussion on the same topic. The audience joined in by asking questions and evaluating their peers' presentation. After the presentation, the presenters completed the self-evaluation forms. Mizuki (2003) evaluated both the presenters and the audience by writing critical comments. This kind of presentation combined both group and individual presentations. The evaluation sheets revealed that learners were aware of their learning, and felt responsibility for their learning because they pointed out their weaknesses during the presentations and ways to overcome those drawbacks. Additionally, they were critical and made comments about their presentations. Mizuki's (2003) study exhibits the link between students' reflections and the development of LA. He argues that these reflections enabled them to review their performance and become more self-critical. 


\subsection{Portfolios}

Portfolios include samples from a range of students' work such as writings, notes, drawings, learning logs or audio or video tapes which reflect different aspects of students' development, achievement, interest or motivation.

\subsection{Strengths of portfolios}

Portfolios offer a range of advantages. One attraction is that they "help teachers help learners assume more responsibility for their own learning" (Hamp-Lyons \& Condon, 2000 , p. xv). Another reason for using portfolios includes the provision of opportunities for learners to monitor their progress and take responsibility for meeting their goals with their teachers (O'Malley \& Pierce, 1996, p. 36). Other strengths of portfolios described by Tierney, Carter, and Desai (1991, cited in Hedge, 2000, p. 390) entail:

- making a collection of meaningful work

- reflecting on strengths and needs

- $\quad$ setting personal goals

- seeing progress over time

- thinking about ideas presented in work

- looking at a variety of work

- seeing effort put forth

- having a clear understanding of roles as a reader and a writer

- feeling ownership for work

- feeling that work has personal reference.

The advantages of portfolios for language assessment are in line with the aims of LA. O'Malley and Pierce (1996) maintain that portfolios encourage students to reflect on their work, to analyse their progress, and to set improvement goals (p. 35). Sharing the same view, Nunes (2004) holds that portfolios can also help learners "selfmonitor their own learning, thus helping them to become more autonomous learners" (p. 334). 


\subsection{Studies on portfolios}

In practice, portfolios have been of interest to a number of researchers. Nunes (2004) employed portfolios as a means to encourage learners' participation in the learning process and to recognise their weaknesses and strengths. She introduced the aims of portfolios to the 10th grade students at a Portuguese high school. The students were asked to keep in their portfolios anything they believed to be of importance to them both as learners and individuals. They were inspired to write about their difficulties and the reasons for those problems. The students were provided with explicit strategy training. They also were asked to describe the strategies they used for particular tasks. Nunes' (2004) new inputs effectively facilitated the students to think about learning, get more involved in their portfolios, and make their voice heard through their portfolios. The benefits of students' portfolios included more interaction and reflection among the students. Interactional benefits involved opportunities for more personal and comprehensive relationships between students and teachers, the chance for students to know themselves better by recognising their strengths and weaknesses, and the opportunity for them to relate their opinions to those of others. As for the reflection, the portfolios described four areas on which students reflected their thoughts: syllabus (its relevance for students, students' emotional reactions to the themes), instruction (teaching methods, materials, activities, tasks), learning (content dealt with in the class, students' weaknesses, strengths, needs), and assessment (students' competence and skills, their performance in classroom tasks and their portfolios). With these reflections, as Nunes (2004) argues, students could become autonomous learners. Firstly, they learned how to make decisions on strategies that best worked for them in different tasks. Secondly, they learned how to self-monitor and self-evaluate their learning by identifying their strengths and weaknesses and find solutions to their problems.

Rao (2005) integrated portfolios into classroom activities and assignments of his English class for six months. In the first month, he specified the purposes of portfolios, matched them with instructional goals and incorporated them into classroom activities, assignments, and course materials. In month two, he introduced what had been done in month one to students in order to prepare them for working with their portfolios. From the third month to the fifth month he incorporated portfolios into classroom instruction and recorded students' progress and performance. 
In month four he arranged a time for students to look at each other's portfolios so that they could have a better understanding of what made a good language portfolio. In the last month of the term, he allocated time for students to present their portfolios and to peer- and self-evaluate their work. Rao's (2005) project revealed that portfolios were useful in fostering LA. Students were given opportunities to take an active control of their learning process through planning, monitoring, evaluating and reflecting on their English learning. Similar to Nunes (2004), Rao (2005) also found that portfolios enhanced interaction among students, as well as between students and their teachers.

Similar to Rao (2005), Shimo (2003) integrated portfolio assessment into her English class of 42 first-year Japanese students majoring in Applied Biology. The primary emphasis was placed on speaking and listening with some writing and reading activities. During the semester, students attended 13 classes of 90 minutes each. They answered a questionnaire about their opinion of portfolio assessment. They completed three tasks including submitting in written form two favourite conversations they engaged in in class, writing two movie reports and one report on an English song of their choice. They were asked to make a list of useful expressions they encountered in class and would like to learn by heart with sample sentences or explanations of usage. During the study students were encouraged to revise their portfolios according to the teacher's feedback so that they could identify their strengths and weaknesses by comparing their earlier work with later work. The study presents students' positive feedback on portfolio assessment through their more active engagement in learning activities. Students received more satisfaction from the ongoing process of portfolio assessment, received freedom to learn what was of interest to them, and increased the sense of responsibility for their learning. Shimo (2003) suggests a framework which gives room for students to exercise their freedom in what they do, promotes student-centeredness, and facilitates initiatives. Three kinds of tasks are recommended for portfolios:

- optional tasks which allow learners to make choices

- decision-making tasks which permit learners to plan and organise their learning

- language tasks which encourage both in-class and out-of-class activities. 
In short, her study shows that portfolios can foster LA by helping learners reflect on their learning and feel a higher sense of responsibility for their learning.

The European Language Portfolio (ELP) by Kohonen (2000b, 2001) contains three sections: passport, language biography, and dossier. The passport consists of an overview of student's language proficiency as well as important language and intercultural experiences. This section is used for self-assessment, teacher assessment and assessment by educational institutions and examination boards. The language biography records students' active participation in the learning process such as planning, reflecting, and evaluating their progress. The dossier provides students with a chance to keep track of achievements or experiences recorded in the other two sections. The dossier exhibits students' language learning outcomes. It also shows the boundary between language learning, teaching and assessment. It functions "both as a pedagogical device for teachers to guide learning and as a practical tool for students to take increasing charge of their learning processes under the teachers' guidance and tutoring" (p. 6). Kohonen's projects indicate that using portfolios teachers can teach reflection, a crucial element of LA, to their students in specific ways through concrete tasks, meaningful questions, and comments from peers.

\subsection{Self-assessment and peer assessment}

Another instrument used to enhance LA is self-assessment. Nachi (2003) invited both teachers and students to participate in her study. The students were in their secondyear and had registered for an elective class on Animal Issues as a requirement of their English course. The course assessment was grounded in the completion of homework, reading comprehension quizzes, project work, presentations, and self- and peer- assessment scores. The students filled in the self-assessment forms during the course. They were required to choose a numerical score which reflected their effort and performance, to write an explanation of their chosen score, and to write a plan on how to improve their performance in class discussions. The self-assessment sheets were collected and returned to the students with the teacher's feedback. The evaluation criteria were reviewed constantly by both the teacher and the students during the course. It was discovered that the students understood the aims and benefits of self-assessment as ways to reflect their efforts and to improve themselves although they saw it as a method which informed them more about weak points than 
strong points. Teachers displayed positive attitudes toward self-assessment. However, issues concerning fairness and accuracy remained. The reason, as Nachi (2003) pointed out, involved teachers and students looking at learning from different aspects and thus producing different scores. The following principles for self-assessment were drawn from her study:

- teacher playing a facilitating role in regular self-assessment discussions with students

- combining holistic ratings with performance-related ratings

- students' involvement in the design and redesign of self-assessment instruments

- application of explicit evaluation standards and criteria

- attending to different perspectives among students, their peers and the teacher

- inclusion of free comment sections, students' personal notebooks or journal

- allocation of time for discussions on materials among peers and with the teacher

- provision of opportunity for students to discuss their completed self-assessment forms with peers.

Thomson (1996) explored the impact of learners' diversity on the self-assessment process of their Japanese language learning among 98 level three students at the University of New South Wales, Australia. The participants were mainly females (75 out of 98) and their mother tongues were English, Chinese, Korean. They took part in three different stages: planning, monitoring, and reviewing. In the first phase they set their learning objectives and made plans for their learning activities which were submitted to their teacher for feedback. In the monitoring stage they evaluated their progress and made adjustments to their plans. In the last stage they reviewed their objectives, learning activities and progress, and rated their performance using the 010 benchmark. Each student was found to represent a unique combination of five variables. The variables included gender, culture, background knowledge of the language, entry level, and maturity. Generally, students displayed a positive attitude towards self-assessment which, they believed, provided them an opportunity to learn what they felt they needed to learn and to be themselves. However, students' lack of confidence in assessment and inappropriate selection of objectives and activities were uncovered. Despite negative feedback, the project proved self-assessment to be an effective way of developing LA. 
Peer assessment was used by Miller and Ng (1996) for a speaking class of 41 first-year Hong Kong students. In order to carry out oral peer-assessment, the students attended a two-hour lecture which taught them how to prepare, administer, and set an oral test. Students were given a week to design their tests and 30-40 minutes to test other groups. After they tested their peers, students gave test scores to the tutors who was present in all tests and provided his own assessment of students' performance. The researchers then compared the scores given by students and by the tutor. It was found that there was almost no difference between the two sets of scores. Though students had no difficulty in preparing and designing the test, the project generally showed students' negative attitudes towards peer-assessment because they were worried about the fairness and the reliability of peer assessment and they did not like being assessed by their peers. In spite of students' dislike of peer assessment, many of them admitted that peer assessment was an effective way to enhance learning.

Natri (2007) designed a shared evaluation system for a course to foster learners' self-awareness and understanding about their strengths and weaknesses in a French language course at a Finnish university. During the six-hour course students were given opportunities to evaluate themselves and to evaluate their peers. At the beginning of the course they rated their levels of different language skills. They also wrote about their histories of learning the language in order to self-identify their strengths and weaknesses. In the next step the mean scores of a particular group were presented for students to compare their own level with that of the average of the group. After the starting level of the course had been discussed, the goals were defined. The use of two types of evaluation was explained. One was completed by the teacher at the end of the course and the other was done by students. During the course students conducted face-to-face peer evaluation in spoken presentations. Students' final grade for the course came from three sources of evaluation including selfassessment (40\%), teacher evaluation (44\%), and peer evaluation (16\%). The implementation of the shared evaluation resulted in the growth in active learnership (term used by Natri, 2007). First of all students knew how to develop their language skills and which skills needed more practice. Secondly, they became more realistic about the possibility of achieving their goals set at the beginning of the course. This led to their revision of their goals. 


\subsection{Out-of-class learning}

Bialystok (1981) distinguishes between formal and functional language use. While the former refers to the language code such as syntax, morphology, and phonology, the latter implies the use of language in communicative situations. She maintains that within the classroom learners are exposed to both language purposes. For instance, a grammar lesson provides them with the form of the language, and discussions about stories or other information will focus on the meaning and use of the language. Nevertheless, she argues that functional practice, which increases learners' opportunities to use the language for communication, is more likely to take place outside the classroom context.

Out-of-class learning refers to learning, practising and using the language in contexts outside the classroom. Out-of-class learning is related to both in-class learning and LA. Firstly, it provides learners with opportunities to practise and to use what they have learned in more natural and authentic situations. Secondly, success in language learning lies in the way learners take advantage of opportunities to learn both inside and outside the classroom context (Crabbe, 1993). Thirdly, with regard to using the language outside the class, problems that occur in real-life situations will enable learners to make their own decisions. Hence, learners are given a chance to exercise LA. Several research projects into this area have been conducted.

Subjects in Pickard's (1995) descriptive study were reported to actively look for opportunities to use English in real-life activities in Germany. The interviews and questionnaires revealed that the three German learners made use of their natural exposure to English. For example, they joined the Royal Scottish Dance Society, wrote letters to their pen-pals, read newspapers and novels, and listened to the radio programmes broadcast by the British Forces Broadcasting Service based in Germany. Unlike the Chinese learners who followed the advice of their teachers to make their choices of language learning materials outside the class in Pearson's (2004) research, the participants of Pickard's (1995) case study initiated out-of-class activities by themselves. In another research project, Pickard (1996) examined the out-of-class strategies employed by 20 German-speaking learners at a secondary school in Germany. From the questionnaire and the interviews, he discovered that the subjects merely focused on the receptive skills of reading and listening. They almost ignored 
speaking and writing. His study reported the following trends in out-of-class learning strategies:

- learners capitalised on activities according to their own needs. They gave less consideration to activities suggested by their teachers

- the exploitation of materials chosen for use came from the learners' intrinsic interest

- opportunities for speaking were inadequate

- learners were aware of their own incompetence and had solutions to deal with their problems.

Yap (1998) described Hong Kong learners' participation in out-of-class activities in terms of the type of activities chosen, their attitude towards these activities, their motivation, and the role English played in their lives. She found that all the subjects took up opportunities to use English outside the classroom. They preferred participating in receptive rather than in productive skills. The rankings were listening to songs, reading magazines or books (excluding textbooks), reading newspapers, and watching TV or movies. Additionally, the participants appeared to enjoy activities that were entertaining. This finding was aligned to that of a study by Chan, Spratt and Humphreys (2002) who discovered that Hong Kong learners preferred engaging in communication- and entertainment-oriented activities such as watching movies, and TV in English or surfing the Internet. The participants in Yap's (1998) study preferred to use English in situations where English use was limited rather than in situations which required considerable communication in English. As for the people they used English with outside the classroom, it was revealed that it was the school environment that provided them with the opportunity for the most frequent use of English. Importantly, they used English with the people they knew from their school. Irrespective of the subjects' level of proficiency, they all identified the importance of out-of-class learning in the improvement of their English. They all were motivated in carrying out out-of-class learning, though more proficient learners saw additional benefits of out-of-class activities as a way to understand the culture of the language they were learning. In terms of LA, Yap (1998) claimed that "although they had the initiative to try language learning activities on their own, their degree of autonomy was limited as they still preferred to have external guidance..." (p. 46). 
However, she believed the participants could be considered independent learners because they were responsible for their decision to take a course in English.

Pearson's (2004) study was carried out in a different setting where learners had an opportunity to be exposed to the English language both in daily life and academic situations. Pearson's (2004) research exhibits how learning in New Zealand created various out-of-class learning opportunities for Chinese students. Data came from eight learners enrolled in a 12-week English for Academic Purposes (EAP) course and a survey delivered to 106 learners at the end of the same course. Eight learners kept written records and evaluations of their learning at the self-access centre and library. The study sought to find out about the ways learners used out-of-class learning opportunities to improve their language proficiency, reasons for their choices of language materials and activities, and any changes in making use of out-of-class learning during the EAP course. It was discovered that learners participated more in receptive activities such as listening/watching news on radio or television, reading books, magazines or newspapers, watching television programmes, videos, or movies, and listening to music or radio than in productive language use. A range of factors impacting on learners' out-of-class learning behaviours were identified. The factors involved learners' language proficiency, their accommodation and the language spoken where they were staying during the course. Pearson (2004) described the changes in the frequency and range of learning opportunities that were exploited by the learners. Although language gains were not identified, Pearson (2004) believes in the underlying contribution that out-of-class learning makes to increased language proficiency in the learners. The study emphasises learners' perception, use, and value of their out-of-class opportunities as having a continuing influence on proficiency gains.

Unlike Yap (1998) and Chan, Spratt and Humphreys (2002), Hyland (2004) looked at the impact of learners' attitudes towards the English language and their communities on the creation and use of the opportunities for out-of-class learning. Questionnaires, interviews, and learners' diaries were used to obtain data for her research. Again, the subjects reported devoting more time to receptive activities. The most often undertaken activities comprised writing emails, reading academic books and articles, and surfing the internet. The link between personal identity and language was uncovered from the two case studies. The respondents focused mainly on private domain-oriented activities. Learners refused to speak English outside the classroom 
for two reasons. Firstly, they believed Hong Kong was not a natural setting for them to use English. Secondly, they did not want to be considered arrogant or superior to other people in their communities. Still the two subjects were successful learners of English. Hyland (2004) suggests that the private domain, which is "less threatening to identity and is also easier for the student to control" (p. 180), may serve as an important setting for out-of-class learning.

\subsubsection{Empirical studies on language gains}

Some research projects have started to find empirical evidence of the efficacy of classroom-based approaches in fostering LA and learning results. This claim is substantiated by Dam and Legenhausen's (1996) study with 21 Danish students who improved vocabulary acquisition in an autonomous approach to learning compared with those who followed a textbook-based approach. Following the autonomy-based approach, students produced the language by themselves. Other classes which followed the textbook-based approach could not be treated as control groups due to the lack of independent measures of comparability. However, the results of the two tests demonstrated that in the same amount of time the 21 students acquired more words in a wider range of semantic fields than those in other classes. This study displayed gains in language proficiency. Quantitative measures were used to establish the effectiveness of autonomy-based approaches to language teaching and learning; nevertheless, the researchers faced problems of comparability between experiment and control groups.

Another source of evidence of language gains came from Vickers and Ene's (2006) project. Their research explored ability to improve grammatical accuracy by 13 advanced ESL learners whose TOEFL score was at least 500. Students were required to recognise and correct their own errors of the past hypothetical conditional. In the pre-test students produced past hypothetical conditional sentences based on the ten given pictures and they achieved only $68 \%$ correct sentences. One week after they completed all the tasks, they sat the first post-test with an average score of $93.05 \%$. The second post-test took place five weeks after the first post-test with an average score of $92.46 \%$. The study showed that explicit autonomous self-correction is effective in achieving grammatical gains. However, it did not provide sufficient grounds to claim that the gains were the result of the autonomous approach to 
teaching and learning. Firstly, all the participants were advanced learners and they may have been exposed to that grammar form before. Less advanced learners might not achieve that level of gains. Secondly, the texts used in their study were designed for the research purposes only. If the text had been authentic, the students might not have made that much progress.

\subsubsection{Summary}

Studies designed to encourage learners to actively engage in planning and assessing classroom learning have shown positive results. In essence, having applied classroom-based approaches, several empirical studies have displayed a close connection between the development of LA and language learning results. Attempts have been made to demonstrate the attraction of classroom-based approaches. However, much more research needs to be undertaken to arrive at more convincing conclusions about the efficacy of these approaches.

\subsubsection{Learner-based approaches}

The five approaches to fostering LA discussed above focus on the provision of opportunities for learners to participate in and control their own learning with a hope that LA and language learning will both improve. The learner-based approaches, in contrast, place emphasis on changing learners' learning behaviours by providing them with necessary skills and thereby enhancing their autonomy and improving their language learning. Learner strategy training or learner training is the main form of these approaches.

\subsubsection{Learner training and metacognitive knowledge}

According to MacLeod, Butler and Syer (1996) the two goals of learner strategy training comprise the support for learners' active management of task engagement, their regulation of cognitive activities, and the construction of a range of knowledge that further fosters self-regulation. According to Kumaravadivelu (2003), learner training includes psychological and strategic preparation. He associates the "narrow view' of LA with training learners in skills and strategies on how to learn, plan, and regulate their learning, and realise their learning potential (p. 133). Hence, the crucial 
task of teachers is to help learners take responsibility for their learning, and to bring about necessary attitudinal changes in them. "Learner development" is used by Wenden (2002) to refer to "a learner-centred innovation in FL/SL instruction that responds to learner diversity by aiming to improve the language learner's ability to learn a language" (p. 32). Learner development is founded both on self-directed language learning and learner strategies in language learning. To integrate learner development into language instruction, Wenden (2002, p. 46) suggests training learners in metacognitive knowledge which involves the nature of the task, the best ways to approach it, and personal factors which may hinder or facilitate the process of language learning.

\subsubsection{Metacognitive studies on writing skill}

Wenden (2001) acknowledges the function of metacognitive knowledge in the selfregulation of learning which contributes to a clearer understanding of LA in terms of how it can be promoted and improved. She argues that the realisation of LA in language learning is partly dependent upon learners' ability to self-regulate their learning. This ability involves conducting task analysis that contributes to the overall planning of a task, monitoring task implementation, and evaluating progress and means of learning.

Evidence has shown that metacognitive skills have been beneficial for learners' writing. Englert, Raphael, Fear, and Anderson (1988) sought to evaluate the relationship between metacognitive knowledge about writing, and the writing performance, working with students with learning disabilities. Students from the fourth and fifth grades were divided into three groups based on their academic achievement. To measure students' metacognition, three vignettes focusing on writing problems of three hypothetical children were used. The students had to give advice to hypothetical children. All the questions which asked them to give advice were embedded in the writing tasks. The first vignette assessed students' knowledge and strategies of planning and organising information relevant to specific expository topics. The steps involved finding answers on how to get ideas for the report, considering what types of information to include, how to brainstorm and organise ideas, how to group, to order, and to present ideas. The emphasis of the second vignette was placed on the processes of report writing that involved planning, drafting, 
and editing. Students needed to fix the problem for hypothetical students. For example, they looked at the paper of the hypothetical students and judged if the hypothetical student was doing the assignment correctly. The third vignette was aimed at evaluating students' editing and revising abilities and the focus of their revision attempts. Students' metacognition was measured by a writing interview. In each interview, the students received a score from one to three for their responses, defined as high-knowledge or low-knowledge depending on an accurate description or explanation of the component of the writing process and organisation. Students' writing performance was assessed by two coders with two scores. The first score reflected the degree to which the composition used the required organisational pattern for a specific text structure. The second score was a holistic score from 0-3 points displaying the degree to which the writing was interesting and effectively communicated the structure of a particular text structure. Their study reveals positive correlation between metacognitive knowledge and students' writing performance. Specifically, the process of writing (steps in the writing process, sources of information, obtaining and integrating information from multiple sources, recognition of value of modelled strategies, presenting sets of related expository ideas, monitoring the paper's completeness, and revising expository compositions and different audiences) and organisation of writing (organising planned ideas, using categories to organise ideas, subordinating and ordering ideas, translating ideas into text, and using text structure in revising text) are important to the success of cognitive performance.

Wenden (1991b) establishes that metacognitive knowledge is directly responsible for the carrying out of a writing task. She explored the use of metacognitive strategies in the regulation of a writing task. Her study sought to find out about the procedures involved in the implementation of each of the metacognitive strategies, the kind of task knowledge required for the execution of each of the metacognitive strategies, and the relationship between metacognitive and cognitive strategies. Eight ESL students were invited to write a composition at the computer and at the same time they introspected what went on before, during and after they had written something. Her study reveals that the planning process consisted of knowledge retrieval and decision making. Task knowledge such as world knowledge, rhetorical knowledge, and linguistic knowledge are important for the learners in the planning of the task. Also, in the planning process learners were reported to use 
cognitive strategies such as clarification, retrieval, resourcing, deferral, and avoidance. In the evaluation process, they used message knowledge and rhetorical knowledge. In monitoring a task, they engaged in problem recognition and problem assessment. For monitoring, Wenden (1991b) claims that task knowledge is a requisite. It was discovered that there was no hierarchical relationship between metacognitive strategies and cognitive strategies. The study demonstrates that the former were used for the execution of a writing task and the latter were used to deal with obstacles while the task was being carried out. Wenden's (1991b) study emphasises the importance of metacognitive knowledge in doing a writing task. However, the data came exclusively from the most successful three writers (out of the eight students). In addition, the eight students who participated in her study hardly received any training on metacognitive skills. The only training they engaged in was a two to four-hour orientation and practice session which prepared them for the word processing programme they were supposed to use for writing the composition on a computer.

Regarding the use of metacognitive knowledge in writing, Zhu (2001) studied difficulties writers faced in argumentative writing. Though metacognitive strategies are essential for a writing task (Wenden, 1991b), they were not much mentioned by the participants in Zhu's study. Zhu (2001) argues that "metacognitive strategies perhaps should have a special place in second language writing strategy training because these strategies may not be used automatically by L2 writers" (p. 47). He also maintains that metacognitive strategy training will be particularly valuable for writers who have limited writing experience even in their first language.

Ojima (2006) employed concept mapping as a pre-planning activity for composition writing. The effects of pre-writing planning in ESL learners' writing performance were investigated. To achieve the aims of her research, she collected two pre-planned and two non pre-planned compositions from three Japanese intermediate students. The first composition was written in class before the concept mapping was introduced. The second composition about any topic of interest to them was completed at home. The third composition was done in class in the third week after the concept mapping had been introduced into the writing class. The students wrote the fourth composition in the last week. After the comparison of the four compositions was conducted, the researcher reported students' better performance in compositions written both at home and in class when they planned their writing by drawing concept maps. Students' development in their English writing involved 
complexity and fluency, but not accuracy. Ojima's (2006) study highlights the link between pre-planning in writing and students' improvement in writing.

\subsubsection{Strategy-based instruction studies}

Training learners to use metacognitive skills has become mainstream in learnercentred approaches. Research in the field of LS has established the relationship between strategy training and learners' improved learning results. Rubin and McCoy's (2008) experiment identified the role of task analysis and its effects on language performance. According to Rubin and McCoy (2008) task analysis is part of planning. Based on their understanding of the task, learners established a goal which constituted whatever aspect of language they wanted to learn. They were also required to consider criteria or behaviours that would help them accomplish their goal. An action plan was set after the task analysis was completed. The two experiment groups of 19 and 39 learners were taught how to use task analysis knowledge in the learning process. The study reveals gains in the knowledge of task analysis and exam performance of the experiment groups and there is evidence of further use of task analysis by learners in the learning process.

The roles of goal setting and self-monitoring in students' self-regulated engagement in tasks were the concern of Butler (1997). Drawing on the Strategic Content Learning (SCL) approach, Butler (1997) designed four studies which applied a model of tutoring for 36 postsecondary disabled students of different backgrounds. The distinguishing features of the studies were the allowance of a variety of tasks and assignments that individual students of diverse backgrounds and levels selected from their programmes of study. Students received both SCL tutoring and remedial instruction on basic skill deficits or vocational counselling. Following the principles of SCL, at each meeting (two or three meetings per week) the tutor provided support for students while they were undertaking self-regulated activities. For each assignment, aid was given to students in analysing the task, setting up performance criteria and setting specific goals. The teacher also assisted students in selecting, adapting, and initiating learning strategies based on the task requirements. The teacher contributed some ideas but it was students' responsibility to make a final decision on strategy selection. The teacher then helped students apply the chosen strategy and monitor the success of their efforts. The last step was to assist students in 
evaluating the strategies they used, and in revising them in accordance with the analysis of goal achievement. During the intervention period students' task performance and strategies were recorded. Additionally, field notes were used. The research reports the improvement in students' task performance, use of strategies, self-monitoring, perceptions of self-efficacy, and patterns of attribution. At the posttest students demonstrated better understanding of metacognition such as conceptions of task requirements, the clarity of descriptions of task-specific strategies, the degree to which the described strategies were linked to the task demands, and students' descriptions of how they self-evaluated progress and managed learning activities consequently.

The focal point of Goh and Taib's (2006) study was metacognitive instruction in listening for young ESL learners in Singapore. Two types of metacognitive knowledge comprising task knowledge and strategy knowledge were examined. The objectives of their study involved identifying participants' metacognitive knowledge about listening, and exploring the usefulness of process-based activities for teaching listening. The participants' self-reports and performance on listening tests were collected and analysed. Eight one-hour listening lessons were conducted. Each lesson aimed to provide students with practice for their public examination and with a better understanding of the process of listening. Every lesson consisted of three stages. In the first stage called 'listen and answer' students had a variety of listening exercises which were modelled after the public examination. In the last two lessons, they not only chose the best option but also wrote down answers for each question. The purpose of doing this was for the researchers to find out if asking students to write down their short answers would leave an impact on their perception of task demands and strategy use. The second stage was called individual reflection where students were required to describe how they had done the listening exercises in stage one. They answered such questions as: "What were you listening to? What helped you to understand the text? What prevented you from getting the correct answers? What did you do to understand as much of the text as possible?". The immediate retrospection was intended for students to report their mental processes during listening to avoid them being forgotten. The last stage called self-report and group discussion was facilitated by the teacher. Students took turns to read aloud their reflections. Their peers asked questions and gave comments afterwards. The study provided evidence of the benefits of metacognitive training in listening. First of all, feedback from students 
indicated an improvement in their listening ability after the strategy intervention. The improvement included students' greater awareness of thinking processes while listening. They not only focused on comprehension of questions and the choices they made when answering the questions but also paid attention to their mental processes during and after listening. Students also demonstrated a wider range of strategies for enhancing listening. The students' listening test scores (pre-test and post-test, midyear and end-of-year examinations) displayed their improved performance after the metacognitive intervention was introduced into the listening lessons. The positive relation between the metacognitive instruction and the achievement of greater language learning results was confirmed by Goh and Taib's (2006) study.

The link between language learning strategies and learning results was strongly established by $\mathrm{Gu}$ (2007). He integrated the strategies-based instruction (SBI) into the writing curriculum of 20 primary five schools in Singapore. The SBI training package lasted nine weeks with one 60-minute session per week. Following the model by Chamot, Barnhardt, El-Dinary, and Robbins (1999), the SBI writing lessons started with the presentation stage where the background knowledge was activated, followed by the teacher's explanation of the strategy in a think-aloud form. After that students were engaged in practicing the strategy. At the end of each SBI session students were asked to summarise and to evaluate what they had learned. The last stage was for expansion where students were given homework with similar tasks so that they could extend the use of that strategy. As students moved from one stage to another, their responsibilities were also increasing. During the training, Gu (2007) closely worked with the teachers by providing them with pre-designed materials and tasks. He also held weekly meetings and discussions with the teachers in order to receive feedback and to provide immediate help if needed. Positive results of the post- and delayed-tests by experimental groups were reported. The study shows that the SBI training contributed significantly to the improved writing scores of students in the experimental groups. In addition, $\mathrm{Gu}$ received a lot of encouraging comments from the teachers and heads of department of the schools where the SBI training took place. Gu's (2007) study displays the causal relationship between metacognitive training and the improvement of students' language proficiency.

While almost all strategy-based instruction studies report positive results, Jing (2006) describes an instance of resistance to a metacognitive project. To boost reflection and LA in EFL learning, he incorporated metacognitive training in a 
reading course for Chinese second-year English majors. The objective of the training was to familiarise students with planning, monitoring, and evaluating EFL reading and general EFL learning with emphasis on monitoring comprehension in EFL reading. The students received mini-lectures on EFL reading processes, and explicit and supplementary instruction in monitoring comprehension. During the reading course, students completed two writing assignments each of which made up $20 \%$ of the final grade. In the first writing assignment they critically wrote a report about what they had read. In the second writing assignment they put down in their reading journals the reading comprehension processes and the language skills they had acquired. The results of the study indicate students' opposition to the metacognitive training. Firstly, they found keeping a journal not directly related to language gains. Secondly, although they said keeping a journal was useful, they did not undertake the task. They expressed preference for the reading report because they thought it was useful for them. Thirdly, the aim of the journal was to enhance metacognitive awareness for students, but not many of them wrote about the reading processes. Fourthly, the researcher's classroom observations showed students' reluctance to take part in class activities aimed at promoting metacognition due to their scepticism about its usefulness. The mismatch between the objectives of the training and expectations of the teacher and the students was revealed. The reasons for learners' opposition to the metacognitive training included the lack of negotiation between teacherresearcher and students, students' psychological unreadiness for training in metacognition, students' preference for tangible language gains, and the socioeducational pressure of the examination-oriented way of learning in China.

\subsubsection{Summary}

Compared with other approaches, learner-based approaches with a focus on training learners in metacognitive skills are the most efficient in terms of improving learners' learning results. This leads to a belief that LA would be best promoted through incorporating learning strategies into the lessons. 


\subsubsection{Summary of the six approaches to promoting LA}

Table 2.5: Summary of the Six Approaches to Developing LA

\begin{tabular}{|c|c|c|c|}
\hline Approaches & Main focus & Main forms & Research evidence \\
\hline $\begin{array}{l}\text { Resource- } \\
\text { based }\end{array}$ & $\begin{array}{l}\text { - provision of } \\
\text { opportunities for self- } \\
\text { directed learning } \\
\text { - individual interaction }\end{array}$ & $\begin{array}{l}\text { - self-access, distance } \\
\text { learning } \\
\text { - materials } \\
\text { - counselling }\end{array}$ & $\begin{array}{l}\text { - little, mainly descriptive } \\
\text { studies on counselling } \\
\text { - no empirical evidence }\end{array}$ \\
\hline $\begin{array}{l}\text { Technology- } \\
\text { based }\end{array}$ & $\begin{array}{l}\text { - provision of } \\
\text { opportunities for self- } \\
\text { directed learning by } \\
\text { diverse forms of } \\
\text { technology } \\
\text { - some collaboration }\end{array}$ & $\begin{array}{l}\text { - Computer-Assisted } \\
\text { Language Learning } \\
\text { (CALL) } \\
\text { - CD-Rom, Internet } \\
\text { - email tandem learning }\end{array}$ & $\begin{array}{l}\text { - very little } \\
\text { - no empirical evidence }\end{array}$ \\
\hline $\begin{array}{l}\text { Curriculum- } \\
\text { based }\end{array}$ & $\begin{array}{l}\text { - negotiation between } \\
\text { teachers and learners on } \\
\text { content, tasks, activities } \\
\text { - learner participation in } \\
\text { decision making } \\
\text { - shift of decision making } \\
\text { from teachers to learners }\end{array}$ & $\begin{array}{l}\text { - weak version of process } \\
\text { syllabus: project work } \\
\text { - strong version of process } \\
\text { syllabus: syllabus is not } \\
\text { predetermined but } \\
\text { negotiated, renegotiated } \\
\text { by teachers and learners }\end{array}$ & $\begin{array}{l}\text { - many descriptive studies; } \\
\text { Dam's study is the most } \\
\text { convincing } \\
\text { - no empirical evidence }\end{array}$ \\
\hline $\begin{array}{l}\text { Teacher- } \\
\text { based }\end{array}$ & $\begin{array}{l}\text { - teacher professional } \\
\text { development } \\
\text { - teacher education } \\
\text { - teacher roles }\end{array}$ & $\begin{array}{l}\text { - changing teachers' } \\
\text { beliefs, commitments, } \\
\text { personality, and practices } \\
\text { to support LA } \\
\text { - teachers embarking on } \\
\text { the roles of helpers, } \\
\text { facilitators, advisors and } \\
\text { guides }\end{array}$ & $\begin{array}{l}\text { - descriptive studies } \\
\text { focusing on defining } \\
\text { teacher autonomy } \\
\text { - no empirical evidence }\end{array}$ \\
\hline $\begin{array}{l}\text { Classroom- } \\
\text { based }\end{array}$ & $\begin{array}{l}\text { - relationships and } \\
\text { classroom practices } \\
\text { - transfer of responsibility } \\
\text { from teachers to learners }\end{array}$ & $\begin{array}{l}\text { - planning learning goals } \\
\text { - selection of tasks } \\
\text { - self-assessment and peer } \\
\text { assessment } \\
\text { - collaborative learning } \\
\text { - portfolios } \\
\text {-out-of-class learning }\end{array}$ & $\begin{array}{l}\text { - numerous descriptive } \\
\text { studies, especially on } \\
\text { portfolios } \\
\text { - some initial empirical } \\
\text { evidence on LA and } \\
\text { language learning results }\end{array}$ \\
\hline Learner-based & $\begin{array}{l}\text { behavioural and } \\
\text { psychological changes in } \\
\text { learners }\end{array}$ & $\begin{array}{l}\text { - learner strategy training: } \\
\text { top down and bottom-up } \\
\text { models of SBI }\end{array}$ & $\begin{array}{l}\text { - plentiful empirical } \\
\text { evidence on the use of } \\
\text { learning strategies and } \\
\text { language learning results }\end{array}$ \\
\hline
\end{tabular}


The review of the six approaches (as summarised in Table 2.5) and studies aimed to foster LA has provided insights into research practice in the field of LA. Some remarks about research into LA have been made on the basis of this review. Generally, most of the studies have been flawed. Their weaknesses included poor validation of research instruments, poor operationalisation of the concept of LA, failure to quantify LA, lack of adequate assessment of LA, lack of well-designed empirical research, and poor exploitation of learner-based approaches to fostering LA.

Firstly, there has been a great body of LA research; however, most studies are descriptive. Research methods used for investigating LA included observations, evaluation sheets, oral interviews, learner diaries and journals. Having employed these research tools, many researchers have claimed that learners became more autonomous. Their statements have been based on learners attending class more regularly (Tagaki, 2003), actively engaging in classroom activities (Dam, 1995; Natri, 2007; Nunes 2004; Rao, 2005), demonstrating a high level of reflection (Kohonen, 2000b, 2001; Mizuki, 2003; Shimo, 2003), and accepting responsibility for their own learning (Cunningham \& Carlton, 2003; Stephenson \& Kohyama, 2003). While these studies have an important function of giving insights into learners' autonomous behaviours, they may not provide complete and sufficiently empirical evidence of the link between LA and learners' language learning results. It is believed that conclusions about significant values of LA should be based on empirical investigation rather than on the basis of conceptual and speculative findings. Questionnaires, a powerful tool for data-driven research, have been rarely used in LA studies. In some projects (Chan, 2001; Chan et al., 2002; Chan, 2003) questionnaires were employed, however, little or no information has been provided as to how the questionnaires were validated.

Secondly, while an ongoing concern of LA research designed to develop LA in a particular setting has been to ascertain LA and measure it, operationalised descriptions of LA have not often been offered. This, to some extent, influenced the validity and reliability of research which was intended to evaluate LA. Researchers tended to describe the positive results of their studies rather than to evaluate the reliability of their research instrument. In fact, some researchers have dedicated much effort to assessing LA, yet there have been limitations in the way they measured it. Failure to quantify LA led to interpretations and conclusions being made on the basis of researchers' subjective observations of learners' behaviours and attitudes rather 
than on objective statistics. While it must be acknowledged that evaluating changes in learner behaviours is a matter of difficulty, this does not mean it is impossible to do so. In fact, MacLeod, Butler \& Syer (1996) developed a consistent and direct measurement of (1) students' motivational beliefs, (2) construction of metacognitive knowledge, and (3) self-regulation of learning activities. They used a combination of self-report questionnaires and behavioural measures to assess metacognition including evaluating the interplay between knowledge about learning and students' strategic approaches to tasks. Additionally, they developed very detailed and clear scoring and definitions as well as scoring criteria for metacognitive measures for scoring learners' responses. In the area of LA too little attention has been directed towards developing and refining tools for measuring LA (except for Lai, 2001).

Thirdly, the tendency towards LA advocacy has led to an "overriding concern to produce evidence for the effectiveness of initiatives designed to help learners become more autonomous" (Benson 2007, p. 34-35). Research studies therefore have mainly been concerned with how to promote LA rather than with whether the employment of LA makes a difference. A large number of studies have explored diverse ways to foster LA as described in the six approaches, however, the superior effectiveness of any particular approach has yet to be identified. Researchers have so far focused on changes in learning behaviours that learners have made as a result of engaging in classes where particular approaches to developing LA were applied. Researchers appear to assume that before learners participated in autonomy-based classes they all had a low level of LA even though no initial assessment was made to judge the level of autonomy learners possessed before and after the application of a certain approach to fostering LA. The way in which research into LA has been conducted seems to be problematic. Several researchers intended to demonstrate positive learning results obtained from an autonomous approach to learning (Champagne et al., 2001; Dam \& Legenhausen, 1996; Vickers \& Ene, 2006). However, their claim about the efficacy of their approaches to developing LA was not sufficiently strong and convincing due to either their failure to employ rigorous research methods or the lack of compatibility among groups of participants (Dam \& Legenhausen, 1996). Therefore, the empirical evidence showing the relationship between the improvement of LA and language learning outcomes has been weak. Research into LA needs to substantially address the relationship between LA and language proficiency. 
Fourthly, while resource-based, technology-based, curriculum-based, and classroom-based approaches to LA development are concerned with the provision of opportunities for learners to actively engage in their learning and to exercise control over their learning, it is the learner-based approaches that equip them with specific skills and strategies which enable them to take up the learning opportunities. The most salient empirical evidence has so far come from the area of SBI for language learning, especially a study by $\mathrm{Gu}$ (2007). For this reason, learning skills and strategies should be acknowledged as necessary tools for the development and enhancement of LA.

In an EFL context such as Vietnam where the decision on what students learn in class still rests with the school and the teachers, it is believed that providing students with strategy training would be useful. It is argued that the learner-based approaches would be the most effective method to enhance LA and to improve language learning results. In addition, following the learner-based approaches will well accord with the operationalised definition of LA proposed by this study. In this regard, the development of LA depends on both learners' self-initiation and selfregulation. While the volition and the will of learners are less teachable, it is definitely possible to teach learners the self-regulation skills of planning, monitoring, and evaluating. These metacognitive strategies are essential to the achievement of LA. Hence, the close and necessary connection between LA and LS should be recognised.

\subsection{Learner autonomy and learner strategy}

The primary concern of this study has been to determine the relationship between LA and students' language proficiency and investigate how LA can best be integrated into the classroom learning. As discussed above, the main aim of the six approaches to LA development has been to help learners become better language learners. On the basis of the operational definition of LA in this study and the data-driven research on strategy training studies, especially research on SBI in language learning, it is argued that LS could be employed to promote LA. LA and LS appear to be interconnected.

Cohen (1998) makes a link between LA and LS. He argues that explicitly teaching learning strategies to students would "enhance students' efforts to reach language program goals because it encourages students to find their own pathways to success, and thus it promotes learner autonomy and self-direction" (p. 67). In a recent 
study conducted on LS researchers and experts, Cohen (2007) reports the general consent among them. The terms such as autonomy, self-regulation, self-management, independent and individual learning, which are interchangeably used to refer to LA, are systematically related to learners' use of strategies.

Wenden (1998) argues that to help learners develop "linguistic autonomy" through a self-directed approach, teachers play an important role. She suggests that "learners also need guidance in improving and expanding their knowledge about learning so that they may also become more autonomous in their approach to the learning of their new language" (p. 531). The "knowledge about learning" is in essence the metacognitive knowledge that helps learners self-manage and selfregulate their learning.

White (1995) argues that "the ability to exercise autonomy requires the learner to have developed an understanding of the nature of language learning and of his/her role in that process, and as part of this to have an appropriate repertoire of language learning strategies" (p. 209). She believes that metacognitive strategies are closely related to LA. Her study is among the very few studies which explored the relationship between LA, the instructional contexts of distance learning and classroom learning, and strategy choice. The questionnaire, which aimed to establish the relationship between strategy use and language learning context, was administered to 143 classroom learners and 274 distance learners. She discovered that while learners in two different instructional settings demonstrated comparable cognitive strategy use, distance learners deployed more metacognitive strategies; thus they were more autonomous than classroom learners. She suggests that "autonomy in language learning results from the way in which, and the extent to which, the learner manages his/her interactions with the TL (target language), rather than from the use of any specific set of cognitive strategies" (p. 217). In terms of the management skills, although distance learners manifested greater use of metacognition, monitoring was the least mentioned by learners in both instructional settings.

Generally, there was a consensus that "the use of learner strategies can lead to enhanced autonomy" (Cohen, 2007, p. 44). 


\subsubsection{Early definitions of LS}

To investigate the relationship between LA and LS, it is worth looking into the definitions of LS in language teaching and learning. Similar to LA, LS has a number of definitions. Table 2.6 displays early definitions of LS summarised by Gu (2009).

Table 2.6: Early Definitions of LS

\begin{tabular}{|c|c|c|}
\hline Authors & What are language LS? & What are language $\mathrm{LS}$ for? \\
\hline Rubin (1975, p. 43) & techniques or devices & acquire knowledge \\
\hline Bialystok (1978, p. 76) & methods/conscious enterprises & $\begin{array}{l}\text { for exploiting available information to } \\
\text { increase the proficiency of L2 }\end{array}$ \\
\hline $\begin{array}{l}\text { Naiman et al. (1978, p. } \\
\text { 2) }\end{array}$ & $\begin{array}{l}\text { general, more or less deliberate } \\
\text { approaches }\end{array}$ & to learn \\
\hline Cohen (1984, p. 110) & mental operations & to accomplish learning tasks \\
\hline Rubin $(1987$, p. 19) & $\begin{array}{l}\text { set of operations, steps, plans, } \\
\text { routines, what learners do }\end{array}$ & $\begin{array}{l}\text { to facilitate the obtaining, storage, } \\
\text { retrieval, and use of information to } \\
\text { regulate learning }\end{array}$ \\
\hline Wenden (1987, pp. 6-7) & $\begin{array}{l}\text { learning behaviours, strategic } \\
\text { knowledge, knowledge about } \\
\text { learning }\end{array}$ & $\begin{array}{l}\text { to learn and regulate the learning of an } \\
\text { L2 }\end{array}$ \\
\hline $\begin{array}{l}\text { O’Malley and Chamot } \\
(1990, \text { p. 1) }\end{array}$ & special thoughts or behaviours & $\begin{array}{l}\text { to help comprehend, learn, or retain } \\
\text { new information }\end{array}$ \\
\hline Oxford (1990, p. 8) & specific actions & $\begin{array}{l}\text { to make learning easier, faster, more } \\
\text { enjoyable, more self-directed, more } \\
\text { effective, and more transferable to new } \\
\text { situations }\end{array}$ \\
\hline
\end{tabular}

Regardless of the variety of terms used by different researchers to define LS, they all are associated with various tools used to improve the learning process and outcomes.

\subsubsection{Procedures of LS}

Gu (2007) describes a learning strategy as a dynamic process. An ideal strategy involves: 
- problem identification and selective attention

- analysis of task, situation, and self

- choice of decisions and planning

- execution of plan

- monitoring progress and modifying plan

- evaluating results.

These procedures are similar to learners' abilities to determine the objectives, to define the content and progression, to select methods and techniques to be used, to monitor the procedures of acquisition, and to evaluate what has been acquired, tenets stated in the traditional and most often cited definition of LA developed by Holec (1981, p. 3). The most recognised similarity between LA and LS is the employment of the metacognitive skills of planning, monitoring and evaluating the learning process.

\subsubsection{Common types of strategies}

The most important classifications of LS (Table 2.7) are mentioned by Gu (1996, p. 18):

Table 2.7: Classifications of LS

\begin{tabular}{ll}
\hline Authors & Major classifications of LS \\
\hline Rubin (1981) & direct strategies, indirect strategies \\
\hline Oxford (1990) & direct strategies, indirect strategies \\
& \\
\hline O’Malley and Chamot (1990) & cognitive strategies, metacognitive strategies, social/affective \\
& strategies \\
\hline Stern (1983) & academic leaning, active planning, social learning, affective \\
& strategies \\
\hline
\end{tabular}

From the functional perspective, direct strategies and academic learning are almost equivalent to cognitive strategies used to handle the cognitive task of learning. In language learning, cognitive strategies deal with "the manipulation of target language 
structures" (Weaver \& Cohen, 1997, p. vi). These strategies, as categorised by Oxford (1990), comprise practising, receiving and sending messages, analysing and reasoning, and creating structure for input and output (p. 19).

Indirect strategies and active planning are comparable with metacognitive strategies which refer to the control and analysis of behaviours and which are employed to control and execute learning. Fundamentally, "metacognitive strategies involve thinking about the learning process, planning for learning, monitoring the learning task, and evaluating how well one has learned" (O’Malley \& Chamot, 1990, p. 137). They classify metacognitive strategies into the following seven groups:

1. Planning: Previewing the organizing concept or principle of an anticipated learning task (advance organisation); proposing strategies for handling an upcoming task; generating a plan for the parts, sequence, main ideas, or language functions to be used in handling a task (organisational planning).

2. Directed attention: Deciding in advance to attend in general to a learning task and to ignore irrelevant distractors; maintaining attention during task execution.

3. Selective attention: Deciding in advance to attend to specific aspects of language input or situational details that assist in performance of a task; attending to specific aspects of language during task execution.

4. Self-management: Understanding the conditions that help one successfully accomplish language tasks and arranging for the presence of those conditions; controlling one's language performance to maximize use of that is already known.

5. Self-monitoring: Checking, verifying, or correcting one's comprehension or performance in the course of a language task.

6. Problem identification: Explicitly identifying the central point needing resolution in a task or identifying an aspect of the task that hinders its successful completion.

7. Self-evaluation: Checking the outcomes of one's own language performance against an internal measure of completeness and accuracy; checking one's language repertoire, strategy use, or ability to perform the task at hand.

Social strategies describe actions taken by learners to interact with and make use of other people in the learning process. These actions involve asking questions, cooperating with others and empathising with others (Oxford, 1990, p. 21). Affective strategies refer to learners' internal efforts to deal with personal motivation, attitudes and emotions. These strategies include lowering their anxiety, encouraging themselves, and taking their emotional temperature (Oxford, 1990, p. 21). This classification of strategies displays the relevance of metacognitive strategies to LA. 


\subsubsection{Focus of LS research}

The two major goals of language LS research include the identification and comparison of the LS used by more and less successful learners and the provision of instruction to less successful learners in order to help them become more successful (Chamot, 2001). Investigating the correlation between the use of strategy and learning results has become the other main direction in LS research. In essence, there is ample evidence in the LS body of research that training students to use strategies yields improved learning results (Carrell, 1992; Gu, 2007; Nakatani, 2005; Thompson \& Rubin, 1996). The main focuses of LS studies, as pointed out by Cohen and Macaro (2007) in the most recent book on language LS have been on context-dependent, taskdependent, and person-dependent strategies.

\subsubsection{Converging and diverging points between LA and LS}

$\mathrm{Gu}$ (2009) summarises aspects which manifest the similarities and differences between LA and LS (Table 2.8). In terms of converging points, learners remain the concern of both fields which share the primary aim of shifting learning responsibility from teachers to learners. Both LA and LS focus on learner self-management and both are regarded as a means to help learners become more successful in their learning. The differences between the two fields involve the goal, the overall focus, the specific focus, levels of control and critical perspective.

On the basis of the operationalised concept of LA (Figure 2.3), it could be argued that it is the self-management aspect, in which the learner and the task are interwoven, that integrates the two fields into each other. To promote language learning, both the learner and the task should be taken into consideration. LA focuses more on who learners are. LS, on the other hand, is concerned with what learners do and how they do it in the learning process. It is crucial to attend to a more sophisticated aspect of learning such as learner agency and learner self. However it would be practical to consider the learnable element of learning. In the light of this, training learners in metacognitive management strategies, which are more person dependent, appears to be the right formula. SBI, therefore, has become a key approach adopted by this study to enhance LA. 
Table 2.8: Differences between LA and LS

\begin{tabular}{|c|c|c|}
\hline & Learner autonomy & Learner strategy \\
\hline Goal & $\begin{array}{l}\text { - Autonomy as a goal in itself } \\
\text { - Autonomy as a means to achieve better } \\
\text { learning }\end{array}$ & $\begin{array}{l}\text { Strategies as tools to: achieve better } \\
\text { learning results, perform specific tasks, } \\
\text { solve specific problems, make learning } \\
\text { easier, more enjoyable, and compensate } \\
\text { for a deficit in learning (Cohen, 2007) }\end{array}$ \\
\hline $\begin{array}{l}\text { Overall } \\
\text { focus }\end{array}$ & $\begin{array}{l}\text { Who the learner is: } \\
\text { - Learner agency (willing and self- } \\
\text { propelled) } \\
\text { - Learner's self in relation to others, i.e., } \\
\text { independence } \\
\text { - Learner self-management }\end{array}$ & $\begin{array}{l}\text { What the learner does: } \\
\text { Focus on the dynamics of what can best } \\
\text { be done when learner meets task in } \\
\text { context }\end{array}$ \\
\hline $\begin{array}{l}\text { Specific } \\
\text { focus }\end{array}$ & $\begin{array}{l}\text { - Resource-based } \\
\text { - Technology-based } \\
\text { - Curriculum-based } \\
\text { - Teacher-based } \\
\text { - Classroom-based } \\
\text { - Learner-based }\end{array}$ & $\begin{array}{l}\text { - Person-dependent strategies such as } \\
\text { learner management } \\
\text { - Task-dependent strategies } \\
\text { - Context-specific/sensitive strategies }\end{array}$ \\
\hline $\begin{array}{l}\text { Levels of } \\
\text { control }\end{array}$ & $\begin{array}{l}\text { - Over management of learning } \\
\text { - Over cognitive processes } \\
\text { - Over learning content }\end{array}$ & $\begin{array}{l}\text { - Over management of learning } \\
\text { (metacognitive strategies) } \\
\text { - Over cognitive processes (cognitive } \\
\text { strategies) }\end{array}$ \\
\hline $\begin{array}{l}\text { Critical } \\
\text { perspective }\end{array}$ & A perennial, hotly debated & Not applicable so far \\
\hline
\end{tabular}

\subsubsection{Strategy-based instruction (SBI)}

Researchers and practitioners in LS believe in the usefulness of training students to use particular strategies. Fundamentally, SBI has been built on a number of assumptions. Firstly, a difference in learning results will be made if appropriate strategies are employed effectively. Secondly, learners often are not aware of the importance of strategy use and the learners do not use LS in their learning. Thirdly, learners do not use strategies efficiently or effectively. Fourthly, training learners to use strategies will help learners improve their use of strategies. Fifthly, strategy training will help improve their learning results. One of the major concerns of SBI is the decision on the strategies to be taught to learners. Chamot and Rubin (1994, p. 
772) suggest that this decision be made on the basis of the discovery of and discussions on strategies learners have already used for specific learning tasks.

Five essential steps for SBI models were initially developed by Chamot and Rubin (1994, p. 772). The sequence of these steps has been revised by Rubin, Chamot, Harris, and Anderson (2007, p. 142):

1. raising awareness of the strategies learners are already using;

2. teacher presentation and modelling of strategies so that students become increasingly aware of their own thinking and learning processes;

3. multiple practice opportunities to help students move towards autonomous use of the strategies through gradual withdrawal of the scaffolding; and

4. self-evaluation of the effectiveness of the strategies used and transfer of strategies to fresh tasks.

\subsubsection{SBI approaches}

SBI has taken two approaches: top-down and bottom-up. While the former model commences with a predefined set of strategies, the latter starts from the task learners are working on.

\subsection{Top-down model of SBI}

The top-down model is more popular among SBI researchers and practitioners who have adopted a technique of whole class instruction. The most comprehensive framework for SBI (Figure 2.4) has been developed by Chamot, Barnhardt, El-Dinary, and Robbins (1999, p. 46).

The most prominent feature of this framework as $\mathrm{Gu}$ (2007) notes is the increased responsibility on the part of learners when they move from one stage to another. Teachers step by step remove the scaffolding to let learners take on their responsibilities as learners. It is worth commenting that flexibility is another strength of this framework. Depending on learners' knowledge and their experience on the use of a certain strategy, time allocation and teacher support for each step might be adjusted accordingly. For example, Vietnamese learners rather than needing ideas on how to organise an essay might need more background knowledge, explanation, and modelling from their teacher on monitoring their written text, of which they have very little experience. Since the SBI can be integrated into the curriculum, the time allocated for each step can also be extended or shortened to fit in the content of the 
curriculum into which SBI is incorporated. In this sense, the consideration as to which strategies would be taught in which content lesson would be of importance.

Figure 2.4: Strategy Instruction Framework

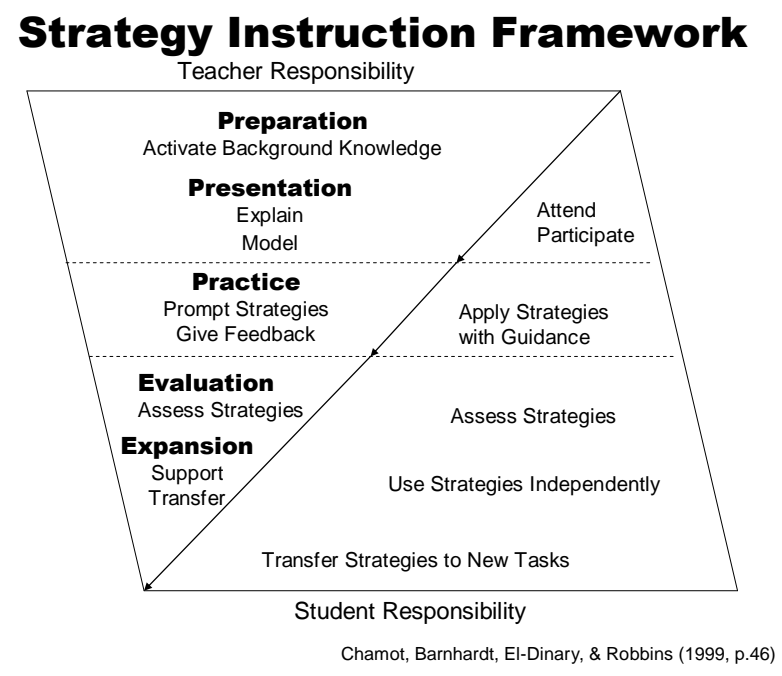

\subsection{Bottom-up model}

The bottom-up model of SBI is promoted by Butler (2002). Her model is developed from Strategic Content Learning (SCL) which is intended to foster self-regulated learning. The strong point of SCL is the individualised instruction in self-regulation which is facilitated by teachers within one-on-one, small-group, as well as wholeclass instruction. SCL is influenced by three theoretical principles. First of all, it is based on the analysis of strategic performance. This analysis is made on the basis of the guidelines provided by teachers on how to conduct task analysis. This constitutes consideration of the requirements of a particular task, selection, adaptation or invention of strategies which help learners achieve the task objectives. Teachers also provide learners with aid in strategy implementation and self-monitoring. The scaffolding enables learners to build metacognitive knowledge, motivational beliefs and self-regulation. Second, SCL promotes close collaboration between teachers and learners who co-construct strategies based on the task analysis. Butler (2002) argues that the strategy instruction which originates from a task that learners are working on rather than from predefined strategies will allow them to work out their own solutions to problems better. Third, SCL takes into account the constructivist and sociocultural 
theories of learning. The focus of the former is on the construction of knowledge which is based on interaction of learners' own prior knowledge and their existing experience and skills. In the latter theory the emphasis is placed on the influence of the cultural context in which they learn. Taken together, according to Butler (2002), the central points of strategy instruction include:

- collaboration with learners to complete meaningful work

- identification of learners' strengths and weaknesses through listening to them

- engaging learners in joint problem solving while working towards the achievement of task goals

- provision of calibrated support in areas of need to learners

- using language in discussions with learners to enable them to make sense of their experience

- encouraging learners to articulate strategies in their own words.

Butler's (2002) bottom-up model of SBI is flexible for it can be conducted in one-onone, small group, or whole-classroom modes. In one-on-one instruction, the teacher starts by finding out a task of importance to the student. Alternatively, the learner might bring any tasks related to her immediate needs. After task selection, the teacher provides support to guide the learner's self-regulation by asking her to produce her own list of criteria, and by giving directions on strategy selection and monitoring. The teacher also needs to help the learner think through tasks by asking guiding questions on what she thinks she should do rather than telling her what to do. Teacher support is needed for the learner to self-monitor and self-evaluate her strategy use and her performance against task criteria. Unlike one-on-one instruction, in small group instruction the task selection can be made straightforwardly through a negotiation between the teacher and a group of learners. Another difference of small group instruction is peer interaction which enables learners to discuss, to share ideas, to coconstruct strategies, and most importantly, to observe how to create personalised strategies that meet individuals' needs. The peer interaction could yield more complicated knowledge which learners might fail to acquire in one-on-one instruction. In whole-classroom instruction, the teacher set tasks and performance criteria. This helps her to integrate self-regulation activities into the classroom exercises or assignments. In this type of instruction discussions aimed to define performance 
criteria and to develop strategies are either led by the teacher or undertaken in small groups. Learners might try out certain strategies to complete their tasks or assignments. They should be made aware of articulating strategies they currently use and will use in the future, which in turn will further develop their metacognitive knowledge. Self- monitoring and self-evaluation are performed in the whole class through the teacher asking learners to outline and to describe evaluation criteria and strategies which have been used.

\subsubsection{Summary}

Table 2.9: Differences between SBI Top-down and Bottom-up Models

\begin{tabular}{|c|c|c|}
\hline Differences & Top-down model & Bottom-up model \\
\hline Basic principles of instruction & $\begin{array}{l}\text { starts with a pre-defined set of } \\
\text { strategies }\end{array}$ & $\begin{array}{l}\text { starts with a task learners work } \\
\text { on }\end{array}$ \\
\hline Mode of delivery & whole-class & $\begin{array}{l}\text { one-on-one, small group, or } \\
\text { whole-classroom }\end{array}$ \\
\hline Specific aim & $\begin{array}{l}\text { ability to use a particular } \\
\text { strategy in learning }\end{array}$ & $\begin{array}{l}\text { promotion of self-regulated } \\
\text { learning }\end{array}$ \\
\hline Sequence of instruction & $\begin{array}{l}\text { preparation } \rightarrow \text { presentation } \rightarrow \\
\text { practice } \rightarrow \text { evaluation } \rightarrow \\
\text { expansion }\end{array}$ & $\begin{array}{l}\text { task } \rightarrow \text { task analysis } \rightarrow \\
\text { performance criteria } \rightarrow \text { strategy } \\
\text { formation } \rightarrow \text { strategy } \\
\text { implementation } \rightarrow \text { self- } \\
\text { monitoring } \rightarrow \text { self-evaluating }\end{array}$ \\
\hline Teacher responsibility & $\begin{array}{l}\text { - being reduced and shifted to } \\
\text { learners when moving from one } \\
\text { step to another. } \\
\text { - presenting and modelling new } \\
\text { strategies. }\end{array}$ & $\begin{array}{l}\text { - remaining providers of } \\
\text { constant scaffolding in all steps } \\
\text { - playing the role of facilitators, } \\
\text { asking guiding questions or } \\
\text { modelling when needed. }\end{array}$ \\
\hline Learner responsibility & $\begin{array}{l}\text { increases in the order of the } \\
\text { sequence }\end{array}$ & $\begin{array}{l}\text { learners being decision makers } \\
\text { in every step }\end{array}$ \\
\hline Learner needs & mostly ignored & $\begin{array}{l}\text { taken into consideration, } \\
\text { especially in one-on-one } \\
\text { instruction }\end{array}$ \\
\hline Strategy articulation & not required & required \\
\hline
\end{tabular}

In summary, both top-down and bottom-up models of SBI intend to help learners become better language learners and independent strategic learners. In both 
approaches, the role of teachers is essential in terms of explaining and modelling a new strategy to learners. However, they do diverge on some points. The differences involve basic principles of instruction, mode of delivery, specific aims, sequence of instruction, teacher responsibility, learner responsibility, learner needs, and strategy articulation. The distinguishing features are outlined in Table 2.9.

It has been established that LS is theoretically relevant to LA. It follows that to foster LA, it would be productive to explore LS training and specifically training in metacognitive strategies which are more learner-dependent and more related to task completion. SBI is a possible guiding principle for LA intervention projects. Depending on the purpose and the context in which SBI takes place, top-down, bottom-up, or modified versions of SBI should be employed.

\subsection{Conclusion}

This chapter has shown that LA is useful for language learners. However the verification of the relationship between LA and language acquisition is still weak due to the overriding reliance on qualitative evidence. The LA field alarmingly lacks the quantitative research which could provide empirical and rigorous evidence of that relationship. The chapter has also shown that learner-based approaches to LA development, while demonstrated to be effective, have not been fully exploited. More importantly, practitioners and researchers in LA have not taken advantage of LS, which, as shown by studies on SBI, directly contributes to improved learning outcomes for learners. Additionally, this chapter has provided a sound basis for the research questions in section 1.4 of this study. One of the researcher's hypotheses about the relationship between LA and learners' language proficiency derived from the ample evidence that LA is generally valuable for learners. However, there have been very few empirical studies showing that LA is related to language acquisition. The other hypothesis originated from convincing experimental evidence of SBI studies, especially the study by $\mathrm{Gu}$ (2007). Hence, this study chose to follow SBI with a focus on metacognitive skills to promote both LA and language learning results. The subsequent chapter explains the research methods and procedures this study followed in order to find answers for the research questions. 


\section{RESEARCH DESIGN AND METHODOLOGY}

\subsection{Introduction}

The previous chapter showed that LA has gained much popularity among researchers, teachers, and practitioners who employed mainly qualitative research methods to foster LA. It also demonstrated that LS could be valuable in the promotion of LA. This chapter focuses on the methodology used in this study. It starts with a summary of the research purposes and questions, and a description of the participants. It then provides a detailed account of the procedures for data collection, the measures of English language proficiency, and the criteria for learner classification. Next it explains the methods for managing and coding the data. Finally, the chapter also deals with issues of reliability and validity, and consideration of ethical issues.

\subsection{Research purposes}

The research was carried out in three phases including a pilot study and two main phases. Research purposes and research questions for each phase are presented in Table 3.1.

Although the pilot study was undertaken mainly to test the research instrument and to look for initial indications of the nature of the relationship between LA and language proficiency, it explored the differences in the number of activities and the amount of time dedicated to learning by Vietnamese English-majors of different levels of academic achievement. The pilot study also examined the differences in LA among students of different year levels as well as LA at two types of tertiary institutions. In the first phase, this study investigated the relationship between LA and Vietnamese learners' English language proficiency. Another aim of Phase one was to judge if they were autonomous learners. The purpose of the second phase was to conduct an experiment to train learners in metacognitive skills. It also investigated the causal relationship between the MT and LA.

The strengths of quantitative research, as highlighted by Dornyei (2007), involve "systematic, rigorous, focussed, and tightly controlled" inquiry, "precise measurement", and "reliable and replicable data" (p. 34). According to Mackey and Gass (2005), quantitative research is theoretically classified into associational and 
experimental types. Both designs are intended to determine a relationship between or within variables. The purpose of the former is establishing the existence of a relationship as well as the strength of that relationship. The goal of the latter is to investigate whether there is a causal relationship between variables. This study required the employment of both associational and experimental approaches. To answer research questions about the relationship between LA and language proficiency in the first phase, associational research, which is often statistically tested through correlations, was used. Responses to research questions about the effectiveness of MT in the promotion of LA in Phase two were obtained by conducting the MT experiment.

Table 3.1: Research Purposes and Research Questions

\begin{tabular}{|c|c|c|}
\hline Phase & Research purpose & Research questions \\
\hline Pilot study & $\begin{array}{l}\text { - testing research } \\
\text { instruments } \\
\text { - looking for initial } \\
\text { indications of nature of } \\
\text { relationship between LA } \\
\text { and language proficiency }\end{array}$ & $\begin{array}{l}\text { 1. Is there a relationship between LA and language } \\
\text { proficiency? } \\
\text { 2. Are there differences in LA among students of different } \\
\text { year levels? } \\
\text { 3. Are there differences in LA at the two types of tertiary } \\
\text { institutions? } \\
\text { 4. Are there differences in the number of activities and the } \\
\text { amount of time devoted to learning English by learners of } \\
\text { different levels of academic achievement? }\end{array}$ \\
\hline Phase one & $\begin{array}{l}\text { - investigating relationship } \\
\text { between LA and language } \\
\text { proficiency } \\
\text { - exploring LA in } \\
\text { Vietnamese educational } \\
\text { context }\end{array}$ & $\begin{array}{l}\text { 1. Are Vietnamese undergraduate students of English } \\
\text { autonomous learners? } \\
\text { 2. What are the most popular learner self-initiated out-of- } \\
\text { class and in-class activities performed by these } \\
\text { Vietnamese students? } \\
\text { 3. What is the relationship between LA and these } \\
\text { Vietnamese students' English language proficiency? }\end{array}$ \\
\hline Phase two & $\begin{array}{l}\text { - conducting experiment to } \\
\text { train students in } \\
\text { metacognitive skills } \\
\text { - examining relationship } \\
\text { between MT and LA }\end{array}$ & $\begin{array}{l}\text { 1. Does training in metacognition lead to improved written } \\
\text { English? } \\
\text { 2. Will improvements in written English be maintained? } \\
\text { 3. Does training in metacognition techniques result in } \\
\text { higher LA? } \\
\text { 4. Does metacognitive training in the context of English } \\
\text { learning and teaching result in the transfer of } \\
\text { metacognitive skills to other areas of language learning? }\end{array}$ \\
\hline
\end{tabular}


The flexible and emergent nature of the qualitative paradigm makes it possible for researchers to make sense of complicated situations and to get a fuller understanding of the phenomenon (Dornyei, 2007). The researcher of this study was interested in examining other external factors that might have both positive and negative effects on the outcomes of the MT. She was also keen to fully comprehend the differences in activities and behaviours of learners among experimental and control groups. Hence, she followed the qualitative research design model. Information from qualitative data would aid her in formulating reasonable interpretations and searching for acceptable answers for the hypotheses about the relation between LA and learners' language proficiency as well as the causal association between the MT and learners' language proficiency. The qualitative design of this study used interviews, learners' diary entries, learning logs, and classroom observations to collect additional data.

\subsection{Participant profiles}

This study involved both learners and teachers from two universities in Vietnam. The number of learner participants varied across the three stages of the study.

\subsubsection{Pilot study}

English majors totalling 388 from one private and one state-run university in Vietnam took part in the pilot study. One hundred and twenty eight first-year, 33 second-year, and 27 third-year students came from a private university. The number of first-year English majors from a state university was 200. By the time the subjects participated in the research, all first-year students had had about 450 periods of English lessons including listening, speaking, reading, writing and grammar. Each period was 45 minutes long. Second-year students had attended 975 periods, and third-year students had received 1,590 periods of English lessons. Apart from the English languagerelated subjects, English majors needed to learn other compulsory subjects required by the Ministry of Education and Training of Vietnam, such as Theory of Marxism philosophy, Vietnamese language, Tertiary learning methods, the History of the Vietnamese Communist Party, Ho Chi Minh idealism, Basics of the Vietnamese culture, Basics of Information technology. These subjects were taught in Vietnamese 
language and took up about $31 \%$ of the course (870 periods out of total of 2,745 periods of the Bachelor English-degree course). The subjects' ages ranged from 18 to 22. The numbers of female and male participants were 337 and 49 respectively.

Table 3.2: Participant Profile of Pilot Study

\begin{tabular}{llll}
\hline Year & $\begin{array}{l}\text { Number of periods of English } \\
\text { lessons }\end{array}$ & $\begin{array}{l}\text { Number of students at } \\
\text { private university }\end{array}$ & $\begin{array}{l}\text { Number of students } \\
\text { at state university }\end{array}$ \\
\hline First year & 450 & 128 & 200 \\
\hline Second year & 975 & 33 & 0 \\
\hline Third year & 1,590 & 27 & 0 \\
\hline
\end{tabular}

\subsubsection{Phase one}

One hundred and seventy seven English majors from a university in Vietnam took part in the first phase of the study. In fact, 202 students answered the self-initiation questionnaire and 198 students took part in the self-regulation questionnaire but only 177 returned both questionnaires. Among them, there were 36 first-year, 82 secondyear, 32 third-year, and 27 fourth-year students. The first and second-year students were training to become interpreters and tourist guides, while the third and fourthyear students were being taught to become interpreters. The numbers of males and females were 20 and 157 respectively. Participants' ages ranged from 19 to 24 . The average age was 21.23. By the time the subjects participated in Phase one of the research, all first-year students had received about 150 periods (45 minutes each) of English lessons of listening, speaking, reading, writing and grammar. The secondyear students had received 450, the third-year students 975 periods and the fourthyear students 1,590 periods of English lessons.

Table 3.3: Participant Profile of Phase one

\begin{tabular}{llll}
\hline Year & Number of students & $\begin{array}{l}\text { Number of English } \\
\text { lessons }\end{array}$ & Minor \\
\hline First year & 36 & 150 periods & Interpreters and tourist guides \\
\hline Second year & 82 & 450 periods & Interpreters and tourist guides \\
\hline Third year & 32 & 975 periods & Interpreters \\
\hline Fourth year & 27 & 1,590 periods & Interpreters \\
\hline
\end{tabular}




\subsubsection{Phase two}

Both learners and teachers took part in the second phase of the study.

\subsubsection{Learner profiles}

The second phase originally involved 94 students who were training to become interpreters. However three students did not submit sufficient tests and therefore the results shown only relate to 91 students. There were eight male students and 83 females; all aged between 20 and 22. By the time they took part in Phase two, they had received approximately 1,000 periods (45 minutes each) of English lessons. These included listening comprehension, speaking, reading, writing and grammar. Out of the 1,000 periods of English lessons taken, there were 150 periods of writing lessons.

Table 3.4: Participant Profile of Phase two

\begin{tabular}{llll}
\hline Year & Number of students & $\begin{array}{l}\text { Number of English } \\
\text { lessons }\end{array}$ & Minor \\
\hline Third year & 94 & 1,000 periods & Interpreters \\
\hline
\end{tabular}

\subsubsection{Teacher profiles}

The two teachers who voluntarily took part in the second phase of this study have been given the pseudonyms Ms Phuoc and Ms Loc for the purpose of this report.

Table 3.5: Teacher Profiles of Phase two

\begin{tabular}{llllll}
\hline Name & Age & Class & $\begin{array}{l}\text { Highest } \\
\text { degree }\end{array}$ & $\begin{array}{l}\text { General teaching } \\
\text { experience }\end{array}$ & $\begin{array}{l}\text { Teaching writing } \\
\text { experience }\end{array}$ \\
\hline Ms Phuoc & 42 & Experiment & Master & 13 years & 3 years \\
& & Control 1 & $(2007)$ & & \\
\hline Ms Loc & 43 & Control 2 & Master & 13 years & \\
& & & $(2007)$ & & \\
& & & & & \\
& & &
\end{tabular}

\section{Ms Phuoc}

Ms Phuoc had been teaching English at a Vietnamese University for 13 years. She earned her Masters degree in Applied Linguistics in 2007. She used to teach English 
to tourism students but this was her first time teaching academic writing. Ms Phuoc had been one of the strongest students in her class at university. Her lecturer had often praised her for the coherence and cohesiveness of her English writing.

\section{Ms Loc}

Ms Loc had also been teaching English at a Vietnamese University for 13 years. She was granted her Masters degree in Applied Linguistics in 2007 and had been teaching academic writing to English-major students for more that nine years. She had considerable specific experience of teaching English writing and worked as the Head of the writing subject for four years. She was in charge of designing writing courses and selecting textbooks and writing materials for English-major students at the department of English.

\subsection{Research process and procedures}

This section provides a detailed account of the process and the procedures for data collection for the three phases of the research.

\subsubsection{Pilot study}

The main purpose of the pilot study was for the researcher to test the questionnaires which would later be used for the two rounds of data collection. It also aimed to gather information on the number of activities, and the amount of time devoted to learning English by learners of different levels of academic achievement. Additionally, it explored the differences in LA among students of different year levels as well as LA at two universities.

To address the research questions of this phase, both qualitative and quantitative research methods were employed. First, interviews with four second-year and four first-year students from a private university were conducted. After that learning $\operatorname{logs}$ were sent to 20 first-year students (from the same university) who voluntarily took part in writing down their English learning activities for two weeks. The last step was to distribute the questionnaire to students at the two universities. 


\subsubsection{Interview}

The interview comprised three parts. The first part asked students to provide information on their English learning including their strengths and weaknesses, and their perceptions on student and teacher responsibilities in the learning process. The second part intended to investigate students' writing behaviours. Specifically, students were asked about how they: 1) planned for the overall process of learning writing in English and for a specific writing task, 2) monitored task concentration, problems, strategies, and their feelings, and 3) evaluated assessment criteria and goal achievement. The third part questioned students about activities they initiated both inside and outside class in order to improve their English.

The interviews were conducted in Vietnamese and were audio-recorded. Each student spent about 30 to 40 minutes answering the interview questions. The interviews were arranged at the participants' convenience. They were carried out at a room on the university campus. The researcher guaranteed that the information given by the participants would be kept confidential and it would not in any way affect the students' test results and the way their teachers would treat them in class.

Eight students (four second-year and four third-year students) from a private university, among whom there were three top, two average and three bottom students, voluntarily took part in the interviews. Students' academic records were used to classify students into top, average or bottom groups. Due to some technical problems with the digital recorder, the researcher failed to record the interviews with $3^{\text {rd }}$ year students at the first set of the interview. Therefore, third-year students were invited to come for interviews a second time. Some students said they felt a little funny telling the same story a second time. In terms of seeking more choices of activities from students to add to the questionnaire, not much came out from the interviews with the students. After the interviews finished, two more questions on out-of-class learning activities were added to the questionnaire. The two new questions included:

- I keep the portfolios of what I have learned to monitor my progress

- I do some reading in English for my pleasure such as English literature or some topics of my interest. 


\subsubsection{Learner learning logs}

A "log is a recording of facts pertaining to specific occurrences" (Holly, 1987, p. 5). In the pilot study learning logs are defined as an organised and detailed description of the activities performed both in class and during self study outside the classroom context. The purpose of the learning logs was to explore autonomous behaviours demonstrated by top and bottom students. The logs written in Vietnamese recorded the number of activities and the amount of time devoted to learning English by top and bottom students. Twenty first-year students, i.e. five tops and five bottoms in each class from a private university were recruited and willing to write the logs. Initially, the researcher wanted to include some average students. However, only two average students (from both classes) voluntarily took part in the study. The researcher, therefore, decided not to include average students in the learning logs.

\subsection{Types of learning logs}

Two different forms of the learning logs were used: out-of-class and in-class which learners were asked to keep for two weeks. In the out-of-class form, learners were requested to write about any English-learning related activities that they performed outside the classroom context. They were provided with fourteen sets of sheets. Each set of paper consisted of two A4 two-sided sheets which gave them enough space to write in any activities they carried out every day. Learners were also required to put in the date, the time, and amount of time they spent on each activity. They answered the following six questions:

- what did you do in this activity?

- why did you do it?

- how well did you do it? How did you know?

- did you have any difficulty in completing it? If yes, what solution(s) did you find? How well did the solution(s) work for you?

- what improvements would you like to make next time?

- what materials, resources or human support did you use?

In the in-class form learners were required to write about writing-related activities that they undertook in the two writing lessons within two weeks. Each week 
they had two writing lessons of 45 minutes each. Learners were supposed to put the activities in the order they actually happened in class. They were provided with two sets of sheets. Each set consisted of two A4 two-sided sheets. There were five guiding questions in this form:

- what were your teacher's aims for this activity?

- did you make a plan for how you would complete this activity?

- what problem(s) did you face while doing this activity?

- what did you do to solve the problem(s)? What strategies did you use to complete the given activity?

- how well did you do the activity? How did you know?

The learning logs played an important role in revising the questions in the questionnaires. In fact, after students' learning logs were analysed, five more questions were added to Using English out of class.

\subsection{Learning log procedures}

There were four first-year classes. The researcher by herself came to two classes and asked for voluntary participation from learners but she failed because only three (top students) wanted to take part. Talking to learners the researcher realised that it was close to the end of the semester (week 50 of the 54 weeks of the entire school year) and students had to do a lot of preparation for end-of-term exams. Therefore they did not have time to write the learning logs which would take two weeks to complete. So the researcher decided to ask for help from the two writing teachers from the other two classes instead of coming to the classes by herself in order to ask for voluntary participation. Following the discussion with the two teachers, five top and five bottom learners from each class were recruited. The recruitment was made based on their academic records and willingness to participate in the study.

The following day all 20 learners from the two classes were invited to a meeting with the researcher who informed them about her research aims and their responsibilities in the process of writing the learning logs. After the researcher explained and gave instructions on what and how to write learning logs, she allowed them time to ask questions and ensured that they correctly understood what they were supposed to put in their learning logs. Only three students asked questions concerning 
the amount of information included in their logs. Each student was provided with fourteen out-of-class forms to record any English-learning activities they would do in the two-week period, and two in-class forms to write in activities performed during the two writing lessons they would have in class during the two weeks.

After week one, the 20 learners were again invited to a feedback session, however only eight learners (six tops and two bottoms) showed up. Basically they did not ask any questions. One learner suggested that the researcher put one more question in the in-class-form: Did you like the activity the teacher asked you to do? This suggestion was worth including in the log, and the researcher immediately asked other learners to add this question to their forms. However, when they submitted their logs, it was revealed that that only one learner (the one who initiated this idea) added this question to the form. (The researcher should have added this question to the form herself and made new forms to send out to learners instead of only asking them to add this question to the forms themselves). In the feedback session learners were also required to bring the logs they had written in the first week and show them to the researcher. The researcher then quickly read their logs to ensure that they were on the right track. Another feedback session was held in week two for the same purpose but only two learners arrived. On the submission date, only 16 learners handed in their logs. Four learners gave up. Among the 16 learners who voluntarily submitted their learning logs, there were nine top learners and seven bottom learners.

\subsubsection{Questionnaire}

In the pilot study a 5-point Likert scale (1-5) questionnaire of 66 questions (Table 3.6) was used to investigate the relationship between LA and language proficiency.

Table 3.6: Summary of the Questionnaire Used in Pilot Study

\begin{tabular}{llll}
\hline \multirow{2}{*}{ Sections } & Subsections & Questions & $\begin{array}{c}\text { Number of } \\
\text { questions }\end{array}$ \\
\hline \multirow{2}{*}{ Activities to improve English } & Out-of-class activities & Q1-Q29 & 29 \\
\cline { 2 - 4 } & In-class activities & Q30-Q35 & 6 \\
\hline \multirow{2}{*}{ Task-specific learning behaviours } & Planning & Q36-Q39 & \multicolumn{2}{|c}{} \\
\cline { 2 - 4 } & Monitoring & Q40-Q47 & 8 \\
\cline { 2 - 4 } & Evaluating & Q48-Q52 & 5 \\
\hline General learning & & Q53-Q65 & 13 \\
\hline Motivation & & Q66 & 1 \\
\hline
\end{tabular}


There were four sections in the questionnaire covering the five constructs of LA operationally defined in the research. To answer each question, students were asked to tick 1, 2, 3, 4 or 5 for Never, Rarely, Sometimes, Often or Always respectively. The first section comprising 35 questions asked students about activities they initiated to improve their English both outside and inside class. The number of out-of-class activities for each language skill (listening, speaking, reading and writing) was nine. There were two open ended questions (Q29 and Q35) in which learners were asked to put in other activities which they performed but which were not listed in the first section of the questionnaire. Section two covered 17 questions about learners' task-specific learning behaviours of planning (Q36-Q39), monitoring (Q40-Q47), and evaluating (Q48-Q52). The third section questioned learners about their general learning behaviours and included 13 questions (Q53-Q65). Only one question on learner motivation was included in the last section of the questionnaire. The questionnaire was carefully translated into Vietnamese before being distributed to the participants.

First of all, the questionnaire was tried out by two $4^{\text {th }}$ year volunteer students. They spent about an hour answering it. They were asked to think aloud while they were circling their responses. The think-aloud protocol was audio-recorded. After finishing each question in the questionnaire, the two students were asked if the question made sense to them. They were also asked to suggest ways to reword the questions. Although the questionnaire was proof-read by a Vietnamese colleague who was an experienced teacher of English in Vietnam, the two students trying out the questionnaire found some questions incomprehensible. The questions were then reworded according to the students' suggestions. The two students recognised two overlapping questions. As a result, one question was deleted. After the try-out, the questionnaire was revised based on the comments made by the two students. The last version of the questionnaire was sent out to 388 students of 13 classes at two universities. During the time students were answering the questionnaire only three of them asked for clarification of some questions. It took them from 35-40 minutes to complete the questionnaire. 


\subsubsection{Phase one}

The major purpose of Phase one was to investigate the relationship between LA and language proficiency. It also examined LA issues which have barely been examined in the educational context of Vietnam. This will not only provide the missing link in understanding the Vietnamese situation, but also add to current understanding about LA in Asia.

There are two types of correlational research: exploratory and prediction designs. The first phase of this study followed the exploratory design. Exploratory is interchangeably termed by Creswell (2005) "explanatory" to indicate a correlational design in which researchers are interested in the extent to which two or more variables share common variance. In other words, exploratory correlational research is intended to investigate whether changes in one variable are reflected in changes in the other. This kind of design was chosen for this study because it helped the researcher comprehend the relationship between each aspect of LA and language proficiency, which gave her further directions on how LA could be fostered.

Two 5-point Likert scale (0-4) questionnaires including a questionnaire on self-initiation and a questionnaire on self-regulation were employed. The questionnaires were carefully developed, piloted, and revised. They went through three steps and in each step they were repeatedly refined. All the items in the questionnaires were vigilantly worded and reworded, categorised and re-categorised, and randomised. Because questionnaires played a crucial role in the data collection process of this study, the researcher followed careful procedures to develop and administer them.

\subsubsection{Questionnaire development process}

The questionnaires were developed in four steps: (1) piloting, (2) revising, (3) trying out and getting feedback, and (4) incorporating that feedback into a final version of the questionnaire.

The pilot study (from April to June 2007) conducted with 388 Vietnamese English majors at two different universities provided some insights into LA in the Vietnamese context. The qualitative data demonstrated the differences between top and bottom students. The quantitative data, however displayed unexpected results (there was negative relationship between planning and language proficiency) which 
made the researcher go back to her questionnaire and revise it. In fact, in the pilot questionnaire the researcher only asked students very general questions about planning. In this regard general planning might not be much connected to students' language proficiency. Although in the pilot questionnaire students were asked questions about specific learning behaviours, they were not given any task to write. Therefore, it was hard for them to produce valid answers concerning specific planning behaviours. The pilot study provided the researcher with invaluable handson experience of how to design a questionnaire that would work in the context of her participants. The researcher made many changes in the revised version of the questionnaire.

In the second step, the revised questionnaire went through four revisions. This was done through face-to-face discussions between the researcher and her supervisor. Straightforward feedback from her supervisor contributed a great deal to the considerable improvements in the new questionnaire. Initially the questionnaire items were formulated based on the theories in the field to ensure the conceptual coverage. But later many more items were added according to other sources of information that the researcher managed to collect such as the interviews and the students' learning $\log$ from the pilot study. The following items were added to using English outside the class:

- I write my blog in English

- I do English tutoring

- I do part-time jobs that require me to use English

- I do voluntary work such as working as a free tour guide or meeting and showing around students who visit my city

- I join English forum discussions on topics of interest.

All the items in the questionnaire were re-categorised. Section one (Activities you do on your own to improve your English) in the pilot questionnaire was classified into Out-of-class activities and In-class activities. This section was further broken to include Learning and Using as well as Covert and Overt activities. In addition to the categorisation of questionnaire items, measures were taken to ensure that each item covered only one aspect. The following question was broken into two separate items: 
Original item: I consider assessment criteria set by teachers or comments made by other people to judge how well I have written the paper.

New item 1: I consider assessment criteria set by teachers to judge how well I have written the paper.

New item 2: I consider comments made by other people to judge how well I have written the paper.

The items were carefully reworded to ensure they conveyed the intended meaning. Many items required rewording that expressed accurate and specific ideas.

Original item: I consider the audience to produce a more appropriate paper.

Reworded item: I consider who will read my paper and what they will expect to read in my paper.

Original item: I have considered the plan I have set in order to judge if I have achieved my objectives.

Reworded item: When I finish the writing task, I go back to my plan and see if I have achieved my objectives.

Original item: I consider my confidence in my ability to perform the writing task.

Reworded item: Before I write, I think about how confident I am about completing the writing task.

Several items were deleted because they were either too general or irrelevant to the Vietnamese educational practice. Some of these items are:

- I know when I finish my paper.

- I can identify my language problems.

- I know my strengths and weaknesses as a language learner.

- I decide what I should learn in my English lessons.

- I choose what activities to use in English lessons.

- I choose what materials to use in English lessons.

The section about general learning behaviours in the pilot questionnaire was excluded from the revised version of questionnaire. 
The third step was to try out the revised version of the questionnaire. After the questionnaire was translated into Vietnamese and randomised by the researcher, she asked both her Vietnamese colleague and two Vietnamese students to proof-read the translation to make sure that it made sense to both kinds of reader. The researcher also tried out the questionnaire with a first year Vietnamese student studying at Victoria University of Wellington. The think-aloud protocol was used for receiving feedback from the student trying out the questionnaire. Both the student and the researcher went through each question and the student was asked to tell the researcher which questions did not make sense and why. The think-aloud session was very useful because it helped shape the questions in a way that made sense to students, not only to people in the field of LA. While the researcher's Vietnamese language version was longer because of the great amount of detail the researcher added in to make the questions clear, the student's suggestions made it more succinct and more comprehensible. The think-aloud protocol took one and a half hours. Then the researcher revised the questions according to the suggestions made by that student. In fact, almost two thirds of the questions needed refining. Three overlapping questions were deleted. After this process there were still two questions which were hard to understand. The researcher also had difficulty translating the subheadings on overt and covert in-class learning into Vietnamese. She therefore sought suggestions from her Vietnamese colleague. When both the researcher and her colleague agreed on the translation for those questions and subheadings, the researcher sent an email to the student who then tried out the questionnaire to ensure the clarity of each question. The second try out was conducted with another Vietnamese student who was in his second year of study at Victoria University of Wellington. In this try out, the student was asked to do both questionnaires and note down any questions that he did not understand. The actual time he spent answering both questionnaires without doing the writing tasks was 35 minutes. Basically, there was not a single question that was difficult for him to interpret. In fact there was only one question that needed clarifying. Both try-out sessions were audio-taped. Both students said that the time of 35-45 minutes allowed for a writing task they were required to do before they answered the self-regulation questionnaire was too long. However after consulting with two English teachers at the university where the data collection would take place, the researcher decided to leave it as it was because the students of that university would need that much time to finish the task. 
The fourth stage involved incorporating all of the comments and suggestions into a final, polished version of the questionnaire. The two questionnaires (selfinitiation and self-regulation) were sent to Vietnam on 9th November 2007 for actual data collection which took place from November 2007 to the end of January 2008. First of all, the self-initiation questionnaire was delivered to all English majors. About a week after the self-initiation questionnaire was collected, students were asked to write at home about a topic of their interest. They were given a week or so to complete this writing task. Students were supposed to return their work within a week, however due to the terrible floods in mid November 2007, only one third of the students managed to submit their work. However in the end almost all students (90\%) returned their writing texts. The self-regulation in writing questionnaire was then sent out to students a week after the first writing task was collected. Students were then asked to do a second writing task in class right before they answered the selfregulation questionnaire so that the self-regulation behaviours could be recalled under both timed and untimed writing conditions.

In order to elicit LA, two 5-point Likert scale (0-4) questionnaires were employed. The first questionnaire focused on self-initiation, and the second tried to elicit the subjects' self-regulation before, during, and after a writing task.

Table 3.7: Questionnaire Development Process

\begin{tabular}{llll}
\hline Steps & Activity & Time spent & $\begin{array}{l}\text { Method of question } \\
\text { formulation }\end{array}$ \\
\hline Step one & Piloting & 3 months & $\begin{array}{l}\text { Top-down: based on theories in } \\
\text { the field }\end{array}$ \\
\hline \multirow{2}{*}{ Step two } & Revising & Top-down and Bottom-up: & based on theories in the field \\
& & & $\begin{array}{l}\text { and data from students' learning } \\
\text { logs and interviews; face-to- }\end{array}$ \\
& & & $\begin{array}{l}\text { face meetings with the } \\
\text { researcher's primary supervisor }\end{array}$ \\
\hline Step three & Trying out and getting feedback & 1 month & $\begin{array}{l}\text { Think-aloud protocol with two } \\
\text { students and one teacher }\end{array}$ \\
\hline Step four & $\begin{array}{l}\text { Incorporating feedback into a } \\
\text { final version of the questionnaire }\end{array}$ & 2 months & $\begin{array}{l}\text { Bottom-up: students' } \\
\text { suggestions were included }\end{array}$ \\
\hline
\end{tabular}




\subsubsection{The two LA questionnaires}

Both top down and bottom up approaches were used to formulate the questions in the questionnaires. The top-down analysis of the LA construct resulted in the conceptual breakdown of the construct into self-initiation and self-regulation. Self-initiation was further divided into reasons for learning English and efforts to learn English. Selfregulation, on the other hand, was broken down into the traditional planning, monitoring, and evaluating sub-constructs. Questionnaire items came from three main sources: (1) adapted from existing literature; (2) self-designed; and (3) taken from results from a previous pilot study among another group of learners at the same university that elicited autonomous learner behaviours through an open-ended interview and a learning activities log.

To answer the questionnaires, students chose 0 for never (no time per week), 1 for rarely (1 time per week), 2 for sometimes (2-3 times per week), 3 for often (4-5 times per week) and 4 for always (more than 5 times per week). They also used this scale to rate the degree of truth that applied to themselves ( 0 for Not true of me, 1 for Slightly true of me, 2 for Moderately true of me, 3 for True of me, and 4 for Definitely true of me). The pilot study revealed that the instructions to respondents as to how to rate their behaviours were insufficiently specific. Therefore the questionnaire in Phase one gave more guidelines. To illustrate, to answer each question, students in the pilot study were asked to tick 1, 2, 3, 4 or 5 for never, rarely, sometimes, often or always respectively. Students might have had difficulty defining how many times would be considered rarely, sometimes, often or always. Most importantly, the researcher did not know if every student conceptualised the measures of frequency in the same way.

\subsection{Self-initiation questionnaire}

Version one of the self-initiation questionnaire was composed of 91 questions focusing on 1) activities students initiated both outside and inside class to learn English, and 2) their reasons for learning English. The out-of-class activities were designed based on activities developed by Spratt, Humphreys, and Chan (2002). Outof-class activities were classified into: learning English out of class and using English out of class. In-class activities were categorised into overt learning behaviours and covert learning behaviours. All 28 questions in the reasons for learning English part 
of the self-initiation questionnaire were adapted from Gao, Zhao, Cheng, and Zhou (2004, 2007).

Table 3.8: Summary of Self-Initiation Questionnaire

\begin{tabular}{llll}
\hline Sections & Subsections & Questions & $\begin{array}{l}\text { Number of } \\
\text { questions }\end{array}$ \\
\hline \multirow{3}{*}{$\begin{array}{l}\text { Activities to improve } \\
\text { English }\end{array}$} & Learning English outside classroom & Q1-Q13 & 13 \\
\cline { 2 - 4 } & Using English outside classroom & Q14-Q37 & 24 \\
\cline { 2 - 4 } & Overt learning behaviours & Q38-Q54 & 17 \\
\cline { 2 - 4 } & Covert learning behaviours & Q55-Q63 & 9 \\
\hline \multirow{3}{*}{ Motivation } & Immediate achievement & Q64-Q66 & 3 \\
\cline { 2 - 4 } & Information medium & Q67-Q68 & 2 \\
\cline { 2 - 4 } & Individual development & Q69-Q75 & 7 \\
\cline { 2 - 4 } & Social responsibility & Q76-Q78 & 3 \\
\cline { 2 - 4 } & Going abroad & Q79-Q81 & 3 \\
\cline { 2 - 4 } & Intrinsic interest & Q82-Q87 & 6 \\
\cline { 2 - 4 } & Learning situation & Q88-Q91 & 4 \\
\hline
\end{tabular}

\subsection{Self-regulation questionnaire}

The initial version of the self-regulation in writing questionnaire consisted of 55 questions under three main categories: planning, monitoring, and evaluating. It asked students about steps they undertook before, during, and after writing. Before students actually answered the questionnaire, they were asked to do two writing tasks (one task written at home and the other written in class right before they answered the questionnaire). The purpose of the two writing tasks was for students to provide more truthful responses about their specific self-regulatory behaviours in writing based on their immediate experiences with the two writing tasks. 
Table 3.9: Summary of Self-Regulation Questionnaire

\begin{tabular}{|c|c|c|c|}
\hline Sections & Subsections & Questions & $\begin{array}{l}\text { Number of } \\
\text { questions }\end{array}$ \\
\hline \multirow{8}{*}{ Before writing } & Goal setting & Q1-Q3 & 3 \\
\hline & Pre-writing & Q4-Q6 & 3 \\
\hline & Task knowledge & Q7-Q12 & 6 \\
\hline & World knowledge & Q13-Q17 & 5 \\
\hline & Rhetorical knowledge & Q18-Q21 & 4 \\
\hline & Linguistic knowledge & Q22-Q24 & 3 \\
\hline & Audience knowledge & Q25-Q26 & 2 \\
\hline & Self knowledge & Q27-Q28 & 2 \\
\hline \multirow{7}{*}{ During writing } & Monitoring task progress & Q29-Q31 & 3 \\
\hline & Monitoring strategies & Q32-Q35 & 4 \\
\hline & Monitoring language problems & Q36-Q40 & 5 \\
\hline & Monitoring feeling & Q41 & 1 \\
\hline & Monitoring task concentration & Q42 & 1 \\
\hline & Monitoring knowledge & Q43 & 1 \\
\hline & Monitoring task performance & Q44 & 1 \\
\hline \multirow{6}{*}{ After writing } & Evaluation of goal achievement & Q45-Q46 & 2 \\
\hline & Evaluation of strategies & Q47-Q48 & 2 \\
\hline & Evaluation of resources use & Q49 & 1 \\
\hline & Evaluation of assessment criteria & Q50-Q52 & 3 \\
\hline & Evaluation of mistakes & Q53-Q54 & 2 \\
\hline & Evaluation of self-modifying & Q55 & 1 \\
\hline
\end{tabular}

\subsubsection{Phase two}

The purpose of the second phase was to conduct a MT experiment to train learners in metacognitive skills of planning, monitoring, and evaluating. This phase explored the causal relationship between the MT and LA.

Before and after the MT was conducted, at the beginning of week one and by the end of week eight, all 91 third-year English major students were invited to sit the writing test and to answer the LA questionnaire. In the pre- and post-tests of writing, students were given 60 minutes in class to write a comparison and contrast essay of about 150 to 200 words. Both the pre- and post- questionnaires were distributed to students a day after they had finished the two writing tests. Students absent on the day 
of the writing tests and the questionnaires were asked to do the test and to answer the questionnaire on a different day of the same week.

The 36-hour Writing Four course of the experimental group was co-taught by Ms Phuoc and the researcher. Ms Phuoc, taking up three fourths of the course time (27 hours), taught them the course content as listed in Table 3.13. The researcher, using one fourth of the course time (nine hours), taught them the metacognitive skills of planning, monitoring and evaluating writing. Each week they had one 60-minute metacognitive session and three 60-minute regular writing lessons. In week eight, however, two metacognitive sessions were conducted due to a change in the timetable initiated by the department of English. Throughout the course, students were encouraged to apply the metacognitive strategies they had been taught in learning writing as well as in learning other language skills of listening, reading and speaking. In addition, they were told not to share their experiences or the hand-outs obtained from the metacognitive sessions with students from the two control classes. They were also invited to write diary entries and submit them to the researcher for feedback at their convenience.

Since there was no additional time provided to compensate for the nine hours taken by the researcher, the researcher met with Ms Phuoc on a regular basis to ensure the full content coverage for the experimental class. In fact, lessons three and five on Essay Outlining and Comparison Essay (as outlined in Table 3.13) were excluded from the content coverage by Ms Phuoc because they were part of the content of metacognitive sessions.

Students in the two control classes did not receive MT and materials. Both Ms Phuoc and Ms Loc were told to conduct their writing lessons as they would normally do. They both followed the same topics included in Writing Four curriculum and the same textbook. Three writing lessons were observed by the researcher in each class at the beginning, in the middle, and at the end of the writing course.

After the MT was completed Ms Loc, Ms Phuoc and two teachers who taught speaking and listening in the experimental group were invited to interviews. Five learners from the experimental class willingly took part in the group interview. Finally, 11 learners across the three classes volunteered their participation in the follow-up interview through email. 


\subsubsection{Questionnaire}

In order to capture the participants' changes before and after the intervention, a learner autonomy questionnaire was used in Phase two. The questionnaire was a revised version of the questionnaire that was employed to collect data in the first phase of the study. This time the 5-point Likert scale (1-5) was changed back to 1-5 in order to conform to traditional practices in the field. The questionnaire was translated into Vietnamese to ensure all students understood what was required of them. The first and the second sections remained the same as in the questionnaire of phase one. The former focussed on reasons for learning English and the latter addressed making effort to learn English.

In the version used in Phase two, another 11 questions were added in the third section on Self-regulation in writing. The added questions were directly related to the content covered in the MT package. Specifically, there were three additional questions in planning:

1. I think of what I already know about the topic to see what I can include in this piece of writing.

2. I think of the effect I want to achieve with this piece of writing.

3. I think of the language such as vocabulary, grammar or linking words I will use in this piece of writing.

Four supplementary questions were included in monitoring:

1. When I am nervous, I calm myself down.

2. When I do not know or cannot remember a specific word or phrase, I substitute other words or phrase.

3. Every now and then I check what I am writing to make sure each paragraph contains a topic sentence and supporting sentences.

4. I make sure that I provide examples, facts or figures to support my points.

In evaluating, there were another four questions:

1. I read what I have written to find the mistakes I have made in my piece of writing.

2. I check the organisation and clarity of my piece of writing. 
3. I check the development of ideas for the points I have made in my piece of writing.

4. I evaluate my strengths and weaknesses so that I can improve my writing next time.

In brief, having gone through several rounds of refining, the questionnaire was improved considerably. The summary of the final version of the questionnaire used in Phase two is presented in Table 3.21.

\subsubsection{MT Intervention}

In an experiment researchers deliberately control or manipulate the conditions through a treatment which determines the variables. The aim of an experiment is to test an idea or practice in order to establish the cause and effect between or within the variables (Creswell, 2005). A typical experiment would be an intervention study which involves at least two groups of learners: one is called the experimental group and the other is called the control group (Dornyei, 2007). The exploratory correlational research carried out in the first phase of this study revealed a relationship between LA and language proficiency. For that reason the researcher conducted an experimental study in which the intervention took the form of the MT developed and delivered by herself. MT is a form of SBI focusing particularly on training in planning, monitoring, and evaluating. The researcher's hypothesis was that fostering LA through MT would result in changes in language proficiency for the learners who received the MT treatment. Her goal was to establish the causal relationship between the independent variable of LA and the dependent variable of language proficiency.

\subsection{Principles for selecting experimental and control groups}

It would be ideal in an experimental study that individuals are randomly assigned to the treatment. The randomisation facilitates "control for extraneous characteristics of the participants that might influence the outcomes" (Creswell, 2005, p. 284). The purpose of random assignment is for researchers to distribute the bias in personal characteristics randomly. In the setting of this study the randomisation of individuals 
was not feasible due to the researcher's absolute dependence on the learning schedule of the department where the MT was conducted. The fact that the MT was incorporated in regular class time made it impossible for the researcher to make random assignment of participants who were fixedly assigned by the department in three different classes. Since the researcher was not allowed to make any changes in the assignment of learners, she used whole classes. The intact classes, according to Mackey and Gass (2005), have the advantage of enhancing the face validity which is "the degree to which a survey instrument looks valid to untrained people" (Brown, 2001, p. 176).

The participants were kept in three intact groups as assigned by the Department of English. There were two control groups and one experimental group (EG). The decision for selection of experimental and control groups was made on the basis of learners' latest writing examination results. It was important to ensure that each group was of a similar ability at the start of the research. Control group 1 (C1) was similar in level to the EG. Control group 2 (C2) was the most proficient among the three classes. The assignment was made as follows:

Table 3.10: Latest Writing Examination Scores across Three Groups

\begin{tabular}{lll}
\hline Groups & Number of students & Mean score of the latest writing exam \\
\hline EG & 37 & 6.3 \\
\hline C1 & 26 & 6.3 \\
\hline C2 & 28 & 6.8
\end{tabular}

The class which had thirty seven learners was designated the experimental group because the highest number of learners among the three would make any claim based on the findings more convincing. All learners in the EG participated in the eight-week MT which was conducted between August and October 2008. The MT was integrated into their Writing Four course. Learners in $\mathrm{C} 1$ and $\mathrm{C} 2$, receiving no treatment, attended their regular writing classes of the Writing Four course.

\subsection{MT package}

\subsection{Content of MT}


To train the EG in the metacognitive skills of planning, monitoring and evaluating in English writing, a package of nine sessions was incorporated in the eight-week Writing Four course. English was used as the language of instruction with some Vietnamese translations provided for easier understanding. During the sessions, students were encouraged to interact with their peers and the researcher in English but Vietnamese was also welcomed when they wanted to ask questions or could not express their ideas in English.

The language objective of all training sessions was writing a comparison and contrast essay. The consistency allowed students to learn every step involved in the process of planning, monitoring and evaluating their essays. The package included the sessions shown in the following figure:

Table 3.11: Weekly Metacognitive 60-minute Sessions

\begin{tabular}{lll}
\hline Sessions & Contents & Week \\
\hline Session 1 & General introduction to the MT & Week 1 \\
\hline Session 2 & Introduction to planning and setting SMART goals & Week 2 \\
\hline Session 3 & Planning for content & Week 4 \\
\hline Session 4 & Doing organisational planning & Week 5 \\
\hline Session 5 & Doing language planning & Week 6 \\
\hline Session 6 & Practise using all planning strategies & Week 7 \\
\hline Session 7 & Introduction and practice of monitoring & Week 8 \\
\hline Session 8 & Introduction and practice of evaluation & Week 8 \\
\hline Session 9 & Practice of planning, monitoring and evaluating strategies & \\
\hline
\end{tabular}

\section{Session one}

This introduction session provided students with information about all the training sessions such as the purpose, time frame, contents of the training and student responsibilities during the training sessions. It also equipped students with background knowledge about the metacognitive strategies of planning, monitoring and evaluating for learning English in general and for daily life activities.

\section{Session two}

This session gave students further background and strategies to plan for a writing task. Its other aim was to develop in students an awareness of the importance of writing with a clear purpose. It was designed to train them to use the strategies of setting 
SMART (Specific, Measurable, Achievable, Relevant, and Time-based) goals (Rubin $\&$ McCoy, 2008, p. 299) and doing Task analysis for a specific writing task.

\section{Session three}

This session taught students how to plan the content of their essay before writing. Students learned how to brainstorm ideas to activate their background knowledge about the topic, to stimulate their thinking, to find ideas about the topic, to let ideas interact, and to organise their ideas. They also learned how to use different kinds of resources available to them such as discussing with peers or reading more about the topic in magazines, newspapers, others' compositions, and articles.

\section{Session four}

The fourth session trained students how to do organisational planning for a writing task including making decisions about their rhetorical plan such as what to write about, what their views on the topic were, how to support their views and how to present information, both rhetorically and linguistically.

\section{Session five}

This session gave students directions on how to plan the language content of their essays, by attending to appropriate vocabulary, sentence structure, and cohesive devices. The session put its emphasis on the use of connecting words which helped students string their ideas together to make a coherent piece of writing.

\section{Session six}

The sixth session allowed students to practise the planning skills they had learned, including planning for content, organisation and language for a comparison and contrast essay. During the session students were encouraged to apply the planning skills to their writing. There were three stages in the session:

1. The researcher reviewed the planning strategies with students.

2. Students planned for their essays individually.

3. Students sat in groups of three or four and asked each other questions about how they had planned for their essays. In this stage they also reported any planning strategies group members had actually used. Other students listened and gave their comments. 


\section{Session seven}

The seventh session familiarised students with how to monitor the performance of a writing task. Students learned how to recognise if they were on track and make decisions on how to solve their problems. This included:

- checking production to keep track of progress and identified problems

- paying attention to what they knew best when writing

- reducing anxiety by reminding self of progress, and availability of resources

- working with others to generate ideas, and to receive feedback and comments

- finding another way to express their ideas if they failed to know the exact word in English.

\section{Session eight}

This session equipped students with the skill of evaluating their performance of a writing task by reflecting on how well they wrote according to their plan, and how well they corrected their errors.

\section{Session nine}

The ninth session was a practical one in which students practised using all the metacognitive skills they had learned in their actual writing.

\subsection{Structure of MT sessions}

The SBI models developed by Chamot, Barnhardt, El-Dinary, and Robbins (1999), and $\mathrm{Gu}$ (2007) served as a guiding principle for the implementation of the MT package. Their framework included five basic stages: preparation, presentation, practice, evaluation, and expansion. The MT project followed similar procedures but included seven steps: review or warm-up, preparation, input, demonstration, practice, evaluation and summary (Table 3.12).

Initially, the session started with the researcher summarising the main points of the previous session. However, after the second session, the review stage was slightly modified to meet the needs of students. Instead of reviewing the metacognitive strategies students had just learned, the teacher asked them questions about current events happening in their city, or activities they undertook over the weekend, as well as future events or their short-term plans. Students preferred to 
speak English and were very much engaged in the warm-up phase which did not have much to do with the content of the metacognitive session as planned. In the preparation stage, students were asked to reflect on the experiences they had with the target strategy of the session. After the background knowledge was activated the researcher explained the target strategy to students and demonstrated it by thinking aloud. To save time at the input stage, hand-outs explaining in detail each metacognitive strategy were distributed to students to read at home a week before the actual session took place. Students were then provided with worksheets, tasks or sample essays to practise the target strategy. Before the session ended students were required to evaluate their use of the newly-taught strategy in the tasks and to review the content of the session. Students were given homework which always asked them to use the target strategy on their own. Gu (2007) notes that "from the preparation stage to the expansion stage, responsibility of strategy use is gradually shifted from teachers to learners" (p. 8).

Table 3.12: Structure of a Metacognitive Session

\begin{tabular}{llll}
\hline Procedures & Activities & Responsibility & Time \\
\hline Warm-up & $\begin{array}{l}\text { Asking and talking about daily events and } \\
\text { activities }\end{array}$ & $\begin{array}{l}\text { Teacher and } \\
\text { students }\end{array}$ & 5 minutes \\
\hline Preparation & $\begin{array}{l}\text { Activating background knowledge about the } \\
\text { target strategy }\end{array}$ & $\begin{array}{l}\text { Teacher and } \\
\text { students }\end{array}$ & 5 minutes \\
\hline Input & Explaining the new strategy & Teacher & 10 minutes \\
\hline Demonstration & Modelling the use of the target strategy & Teacher & 20 minutes \\
\hline Practice & $\begin{array}{l}\text { In-class actual use of the target strategy in } \\
\text { writing tasks }\end{array}$ & Students & \\
\hline Evaluation & $\begin{array}{l}\text { Evaluation of the use of the new strategy in } \\
\text { in-class writing tasks }\end{array}$ & Students & 5 minutes \\
\hline Summary & $\begin{array}{l}\text { Review of the content of the session with } \\
\text { emphasis on the new strategy }\end{array}$ & Students & 5 minutes \\
\hline
\end{tabular}

\subsection{Writing Four course}

The experiment took place during a writing course named "Writing Four". It was the final writing course running in the bachelor course in English. All learners taking 
Writing Four had completed three other writing courses, each of which consisted of 45 lessons of 45 minutes each. The Writing Four course was made up of 36 lessons of 60 minutes each. Learners in all three classes (experimental and control) were taking Writing Four at the same time. The main textbook used for Writing Four was Writing Academic English written by Alice Oshima and Ann Hogue (1999). The topics of the Writing Four course are outlined in Table 3.13.

Table 3.13: Content Topics of Writing Four

\begin{tabular}{ll}
\hline Lesson & Topic \\
\hline 1 & The Introductory Paragraph \\
\hline 2 & The Concluding Paragraph \\
\hline 3 & Essay Outline \\
\hline 4 & Narrative Essays \\
\hline 5 & Comparison Essays \\
\hline 7 & Cause and Effect Essays \\
\hline 8 & Discursive Essays \\
\hline
\end{tabular}

The amount of time designated for each topic and any additional materials for reference was decided upon by the teacher. Both the experimental and control classes covered these topics during the course.

\subsubsection{Learners' diaries}

Rubin (2003) believes that diaries can help build learners' awareness of the process of learning and their efforts to learn. Especially "diaries can help the learner begin to monitor his/her own progress..." (p. 10). Writing diaries can enhance learners' awareness of the use of strategies, and enable them to select appropriate strategies to solve learning problems. The strengths of diary writing accord well with the goal of the MT in the second phase of this study, which was aimed at developing learners' metacognition. Therefore, learners in the EG were invited to write diary entries about each of the MT sessions. The purpose of the diary was three-fold:

- to gather information on the improvements learners were making regarding the use of metacognitive skills in writing as well as in learning other skills such as speaking, listening, and reading 
- to raise learners' awareness about metacognitive strategies

- to provide immediate feedback for the researcher to adjust the training sessions that would help learners better comprehend and apply metacognitive skills taught.

Learners submitted their diary entries for feedback each week. Their diary entries were written based on the following questions:

- what did you learn from today's training session?

- how did you find the information given in today's session?

- did you apply the strategies you were taught in the learning of writing as well as in the learning of other subjects such as reading, listening or speaking?

- how useful were those strategies to you?

All learners preferred to write in English so that they could have their diary entries corrected by the researcher. In the first four weeks, almost all learners in the EG submitted their diary entries. However, due to the number of writing tasks assigned by the researcher and Ms Phuoc, the learners became reluctant to write their reflections about the training sessions. From the fifth week until the end point of the course, only three or four entries were submitted per week. The researcher spent a lot of time reading and correcting students' grammatical mistakes to encourage them to write more diary entries.

Sometimes, the researcher would find similar mistakes in many diaries and so would not correct them all. Instead, she wrote on the board the most commonly-made errors and gave learners an opportunity to correct their own mistakes. If they did not self correct, the researcher would then go back and correct their diaries again. This type of correction, contributed to the improvement of grammatical accuracy, one of the four components of the marking scheme used in this study (table 3.14). In addition, the researcher would meet learners after the lesson to answer specific questions which they did not want to raise in class.

\subsubsection{Classroom observations}

Observation methods are powerful tools for gaining insight into situations (Cohen, Manion \& Morrison, 2000, p. 315). Observations make it possible for researchers to gather firsthand information in a natural setting. In the second phase of this study, to 
capture any differences in the way learners in the EG applied metacognitive skills in writing, and the way Ms Phuoc and Ms Loc conducted their writing lessons in $\mathrm{C} 1$ and $\mathrm{C} 2$, nine classroom observations were conducted. These observations took place across all three classes in the first, third, and the last weeks of the course. The researcher took the position of a non-participant observer who was not involved in the activities of the participants. In order for the researcher to obtain insights into metacognition-related activities performed by EG students, she not only took notes of what was happening in the class, but also approached students when they were doing pair-work or group- work and asked questions about how they went about to get the writing task done. She also asked the students to give her permission to look at the scrap papers on which they noted their ideas or drafted their essays. The classroom observations were audio-recorded and the researcher kept detailed field notes. For some observations, when clarity was an issue, the researcher approached either the teacher or the learners to ask for explanation of their activities or behaviours.

\subsubsection{Interview}

To obtain information from both student and teacher perspectives on the application and the transfer of metacognitive strategies in students' English learning, structured interviews were employed. Due to practical constraints in the second phase such as time and the availability of interviewees, group interviews were carried out with learners. The advantage of group interviews is the interviewees' interaction which encourages them to share the best information. It was hoped that these interviews would add additional value to the student diary entries and classroom observations. Some insights into the use and application of metacognitive strategies could be gained. The interviews were conducted in the final week of the course.

Two different sets of interviews were conducted with students. A face-to-face group interview was conducted with five voluntary participants from the EG. Individual follow-up interviews through email were conducted with eleven learners from all the three classes. The group interview was aimed at collecting student feedback on the MT and the transfer of metacognitive skills. When the researcher was analysing the data, she felt that she needed more information from the participants in order to clarify some points in her research. Therefore, a follow-up interview through email was used to gather further information from students about how Ms Phuoc and 
Ms Loc taught their lessons. Students from all three classes were invited to take part in the follow-up interview, however only 11 students volunteered their participation. The 11 voluntary students were spread over the three groups (EG: four; $\mathrm{C} 1$ : four; and C2: three) and the interview questions were sent by email. The 11 students were asked questions about content, steps involved, materials, points of focus of the lesson, types of activities and tasks given by their writing teachers. They were also asked about how the teachers corrected their writing in class and out of class. The follow-up structured interview through email aimed to clarify and get insights into issues raised during the data collection process. Although the researcher did not have a direct chance to ask further questions on new emerging issues, this form of interview appeared to work better for students who may not have given truthful responses and opinions when in direct interaction with the researcher.

To gather information from the teacher perspective, both Ms Phuoc and Ms Loc were interviewed. In addition, two teachers who taught listening and speaking to the experimental class were also interviewed to explore if the metacognitive skills learned by students in the experimental group were transferred to other areas of the English course. All the interviews were conducted in Vietnamese, audio-recorded, and transcribed.

\subsection{English as a foreign language (EFL) measures}

Measures of language proficiency were important in locating the proficiency range of learners. They provided a means of measuring the relationship between LA and language proficiency, and comparing the scores of writing for the pre-, post-, and delayed tests.

\subsubsection{Pilot study}

The scores (0-10 marks) gained by the students in the previous semester for all the four skills (listening, speaking, reading, and writing) were used for the pilot study. 


\subsubsection{Phase one}

For English language proficiency, the latest internal examination results (0-10 marks) were obtained. These included a score for listening, speaking, and reading respectively. A writing score (S2) was also obtained by marking the composition the participants wrote before they answered the self-regulation questionnaire. Each composition was marked by two markers independently. The average of the two marks was used as the writing score for each participant. It was decided not to use the internal writing score (S1) from the previous semester because it was believed that the scores students received for their compositions written prior to the self-regulation questionnaire were more trustworthy. These compositions were marked based on the same marking criteria and by the same two markers. In fact, using the $\mathrm{S} 1$, the correlations among the aspects of LA were not very high and there was no positive correlation between general planning and task-specific planning. However, when the S2 was used the correlations become significantly positive afterwards. This confirmed the trustworthiness of the scores of the compositions marked by two independent markers. The scores of the four skills were then combined into the overall proficiency measure. Because the tests for the four language skills were different, the test scores were turned into $\mathrm{Z}$ scores which are useful in locating individual scores, especially when data come from tests with different categories of measurement (Hatch \& Lazaraton, 1991).

\subsubsection{Phase two}

In experimental studies, it is important that researchers equate attributes or characteristics of the groups of participants. In this particular study, determining the participants' English language proficiency prior to and after the treatment was essential. Pre-tests and post-tests were used for this reason. One of the goals of Phase two was to investigate whether learners' improvements in writing were maintained after the MT. Therefore the delayed test was used.

\subsubsection{Writing tests}

The participants were assessed over a set of three separate tests. In order to measure students' language proficiency in English writing prior to and after the 
implementation of the MT, two parallel comparison and contrast writing tasks were designed. These were taken in addition to the normal course examination. Each test was sixty minutes duration. All students in the experimental and two control groups took all three writing tests. The three examinations taken were as follows:

1 pre-writing test

2 post-writing test

3 delayed test of the Writing Four examination (taken six weeks after the post-writing test). It was a regular end-of-term writing test which was set and administered by teachers at the Department of English of the university where the MT was conducted.

It is important to note that while the three tests were compatible in terms of time allocation, and essay length, only the pre-test and the post-test reached comparability in terms of essay type and administration. In the delayed test the participants across the three classes were required to write an argument essay. The delayed test was supervised and administered by the Department of English, not the researcher.

\subsubsection{Marking scheme}

The marking scheme was developed by the two writing teachers of the Writing Four course and the researcher. It consisted of four components:

- content

- organisation

- language

- grammatical accuracy.

The score for each component ranged from 0.5 to 2.5 marks. The total possible score for each test was 10 marks. 
Table 3.14: Marking Scheme

\begin{tabular}{|c|c|}
\hline Components & Criteria \\
\hline $\begin{array}{l}\text { Content } \\
\text { ( } 2.5 \text { marks) }\end{array}$ & $\begin{array}{l}\text { The information given in their essay is relevant to the topic and the kind of the } \\
\text { essay they are writing } \\
\text { There should be } 2 \text { or } 3 \text { main points that are discussed in the body of the essay } \\
\text { The information given is sufficient, appropriate and interesting } \\
\text { The essay should not be too short (fewer than } 150 \text { words) and should not be too } \\
\text { long (more than } 300 \text { words) }\end{array}$ \\
\hline $\begin{array}{l}\text { Organisation } \\
\text { ( } 2.5 \text { marks) }\end{array}$ & $\begin{array}{l}\text { There must be a thesis statement } \\
\text { There must be a topic sentence and supporting sentences in each paragraph } \\
\text { Each paragraph should discuss one main point mentioned in the thesis statement } \\
\text { There must be examples, facts, figures or personal experiences to illustrate the } \\
\text { point(s) mentioned } \\
\text { There must be a concluding sentence }\end{array}$ \\
\hline $\begin{array}{l}\text { Language } \\
\text { (2.5 marks) }\end{array}$ & $\begin{array}{l}\text { There should be descriptive words (verbs and adjectives) } \\
\text { There should be connective words to make the sentences cohesive } \\
\text { There should be a variety of sentence structures } \\
\text { There should be an appropriate choice of vocabulary } \\
\text { The sentences must make sense }\end{array}$ \\
\hline $\begin{array}{l}\text { Grammatical } \\
\text { Accuracy } \\
\text { (2.5 marks) }\end{array}$ & $\begin{array}{l}\text { The sentences must be grammatically correct (subject-verb agreement, verb tense, } \\
\text { verb form, active/passive, punctuation, number, article, pronoun, preposition, word } \\
\text { order, idiomatic expression, spelling) }\end{array}$ \\
\hline
\end{tabular}

\subsubsection{Marking}

The pre- and post-tests were marked by a separate experienced writing teacher (marker one) who did not teach the course and was not informed whether the papers being marked were pre or post tests. To ensure marking was consistent across the two tests, another marker (marker two) was asked to randomly mark 30 out of the 182 papers. In the pre-test marking, there were three cases in which the scores given by marker one were different from marker two. The difference was 0.5 marks and fell in the content and language components. In the post-test marking, two discrepancies were found, one in the grammatical accuracy component and the other in the content component. The disparity was also 0.5 marks. The average of the two marks was used as the final score of those papers. As the second round of marking only identified four errors in 30 papers $(13 \%)$, it was considered a normal distribution of results and no 
further adjustments were necessary. The delayed test, the Writing Four examination, was marked by Ms Phuoc and Ms Loc, the two teacher participants of Phase two.

\subsection{Learner classification}

The learners were categorised into top, average and bottom students according to the university classification scheme. For the purpose of this study, in the second phase of the study, the 2007-2008 academic results of English subjects were used to rate students. The final score was the average of the five subjects: Translation theory, Listening translation, Writing translation, Reading, and Writing. All non-English subjects were excluded from the rating scores.

Table 3.15: Student Classification Scheme

\begin{tabular}{lll}
\hline Category of students & Score range & Number of students \\
\hline Top & $\geq 7.5$ & 22 \\
\hline Average & $6.1-7.49$ & 57 \\
\hline Bottom & $\leq 6$ & 14 \\
\hline
\end{tabular}

\subsection{Data management and coding}

All the data collected from learners and teachers in the form of interviews, learning logs, diary entries, and classroom observations were analysed. The researcher filed hard copies of the questionnaires, diary entries, and students' written texts in different paper folders. Digital audio files were organised into electronic folders. The results of the writing tests and the questionnaires were saved in SPSS files. Confidentiality was carefully managed. Only the researcher and her primary supervisor had access to all the files. Pseudonyms were assigned to the teacher participants. For student participants, either initials of the real full names or numbers were used.

\subsubsection{Coding interview data}

The interviews were recorded, transcribed, and then translated into Vietnamese. They were coded according to the names of the interviewees, the number of the questions which were listed in each interview, and the name of the phase in which the interview was conducted. Different sets of interview data were coded in the same way. A 
sample code is "Interview DNMH, Q37, PS". The person who answered the interview was a student whose initials for her real full name were DNMH. This interviewee responded to question 37 in the pilot study interview.

In the follow-up interviews, which were in the form of emails, students were not required to put their names on the paper when they wrote in their responses. For this reason, numbers were assigned to them. The 11 students who volunteered their participation in the follow-up interview were named S1 to S11. To avoid the risk of being identified, the researcher applied the same method of coding for the group interview (face-to face) in which only five voluntary students participated. When students provided more than one response to the same question, their answers were also numbered. A sample code is "Student 4-1, Q1, group interview, P2". Student four gave her first response to question one in the group interview which was held in the second phase of the study. Pseudonyms were assigned to all the teacher participants. Their responses were coded in a similar way. An example of this coding is "Interview L, Q3, P2". Ms Loc answered question three in the interview of Phase two.

\subsubsection{Coding learning logs}

The learning $\operatorname{logs}$ were coded on the basis of the names of the students, the classification of the students, the type of the particular log, and the date on which the log was written. An example is “TTDA, Top student, In-class logs, 24/05/07”. The source came from a student named TTDA who was categorised as a top student. The information was taken from her in-class form of the learning log which she wrote on $24^{\text {th }}$ of May 2007.

\subsubsection{Coding diary entries}

Although students were asked to record the dates in their diary entries, only some of them followed this instruction. Therefore, the initials of the writers and the week in which the diary entry was collected, not the actual date the entry was written, were used in the coding. A sample coding is "BH, Diary, Week 2". The source of the data was a diary entry composed by a student named BH who submitted this entry in week two during the eight-week MT. 


\subsubsection{Coding classroom observations}

Nine observations (three for each class) were conducted. The researcher listened carefully to all the recorded sessions. However, only three observations were used for this research. Then they were fully transcribed and translated into English. The observations were coded according to the order the observation was recorded in a particular class, the name of the class where the observation was conducted, the name of the teacher conducting the lesson, and the turn at which the teacher spoke in class. An example of the coding is "Classroom observation 3, EG, P6". The information quoted came from classroom observation number three. It was conducted in the experimental group by Ms Phuoc. She spoke sixth.

\subsection{Issues of reliability and validity}

Irrespective of the research paradigms researchers select for their studies, all of them, through various means, endeavour to establish reliability and validity for their research projects.

\subsubsection{Reliability}

The purpose of internal consistency analysis is to check if each item on a scale correlates with the other items and with the total scale score. The multi-item questionnaire is effective when its items measure the same target area (Dornyei, 2007, p. 113). Cronbach alpha $(\alpha)$ is the most commonly reported internal consistency reliability measure in questionnaire research (Brown, 2001). One strength of Cronbach alpha involves the provision of a precise internal-consistency estimate. Its other attraction is that it can be used with answers which are on a scale. In other words, if the items are scored as continuous variables, the alpha provides a coefficient to estimate consistency of scores on an instrument.

\subsubsection{Questionnaire validation}

The questionnaire validation, which was performed in the first phase of the study, consisted of two parts. First, exploratory and confirmatory factor analyses were conducted on the 146 questions from the two questionnaires in order to check the 
construct validity of the subconstructs of LA. Item analysis was also performed to obtain the internal consistency reliability of each subconstruct and to determine which items were problematic. The purpose of this was to produce a better version of the questionnaire that had fewer items, but covered similar constructs with satisfactory levels of internal consistency reliability while retaining as much of the original information as possible. After the questionnaire was finalised, the researcher used that version (and the same data) to analyse the relationship patterns between different aspects of autonomy and students' English language scores.

In the original version of the self-initiation questionnaire there were three constructs including: Out-of-class activities with sub-constructs of learning English outside class (13 questions) and using English outside class (24 questions); In-class activities with sub-constructs of overt language learning behaviours (17 questions) and covert language learning behaviours (9 questions); and motivation with subconstructs of instrumental motivation (12 questions) and integrative motivation (12 questions) and situational motivation (4 questions). In order to obtain the most reliable data, factor analysis was conducted with each construct by looking at those variables that clustered together in a meaningful way. This was done, following Field (2005), by finding variables that correlated highly with a group of other variables but did not correlate with variables outside of that group. The factor loading in factor analysis provided the relative contribution that a variable made to the factor. Right after the variables (items in the questionnaire) under each factor were formed, the reliability analysis of those items was run to ensure no item would cause a substantial decrease in alpha. Items whose values of "alpha if item deleted" were higher than .8 were deleted. As a result of this process, under Out-of-class activities, in each of the sub-constructs of learning English outside classroom and using English outside classroom six questions remained with the alphas of .756 and .815 respectively. For In-class activities each sub-construct of overt language learning behaviours and covert language learning behaviours had five questions left. Their alphas were .813 and .850 respectively. As for the motivation construct, the factor loading formed three sub-constructs of individual development, intrinsic interest and going abroad. Each of these sub-constructs had three questions and their alphas were $.673, .774$, and .783 respectively. 
Tables $3.16,3.17,3.18,3.19$, and 3.20 provide a detailed account of the steps the researcher undertook to ensure the reliability of the 13 items categorised as learning English outside the classroom.

The alpha of the 13 questions is .809 (Table 3.16). However, if Q12 is deleted, the alpha will be .814 (Table 3.17). The fewer items but the higher alpha would imply a greater level of reliability for the questionnaire. Therefore, the researcher gradually dropped Q12, Q4, Q3, Q11, Q7 and Q10 that caused considerable decrease in the alpha of the items being examined (Table 3.18). Finally, six questions (Q1, Q2, Q5, Q6, Q8, and Q13) remained and their alpha is .756.

Table 3.16: Reliability Statistics of 13 Items of Learning English outside Class

\begin{tabular}{lll}
\hline Cronbach's Alpha & $\begin{array}{l}\text { Cronbach's Alpha based on } \\
\text { standardised items }\end{array}$ & Number of items \\
\hline .809 & .816 & 13 \\
\hline
\end{tabular}

Table 3.17: Item-Total Statistics of 13 Items of Learning English outside Class

\begin{tabular}{|c|c|c|c|}
\hline & Scale mean if item deleted & $\begin{array}{l}\text { Scale variance if item } \\
\text { deleted }\end{array}$ & $\begin{array}{l}\text { Cronbach's Alpha if item } \\
\text { deleted }\end{array}$ \\
\hline Q1 & 21.72 & 53.421 & .796 \\
\hline Q2 & 21.72 & 53.433 & .796 \\
\hline Q3 & 20.72 & 54.603 & .803 \\
\hline Q4 & 21.77 & 53.688 & .805 \\
\hline Q5 & 21.66 & 52.026 & .794 \\
\hline Q6 & 21.54 & 50.881 & .788 \\
\hline Q7 & 22.31 & 53.349 & .802 \\
\hline Q8 & 21.77 & 50.308 & .788 \\
\hline Q9 & 22.34 & 50.765 & .785 \\
\hline Q10 & 21.90 & 50.663 & .792 \\
\hline Q11 & 22.26 & 49.808 & .795 \\
\hline Q12 & 21.62 & 52.038 & .814 \\
\hline Q13 & 21.59 & 51.261 & .791 \\
\hline
\end{tabular}


Table 3.18: Gradual Dropping Items Causing Substantial Decrease in Alpha

\begin{tabular}{|c|c|c|c|}
\hline Cronbach's Alpha & $\begin{array}{l}\text { Cronbach's Alpha } \\
\text { based on standardised } \\
\text { items }\end{array}$ & Number of items & Items to be deleted \\
\hline .809 & .816 & 13 & \\
\hline .814 & .817 & 12 & Q12 \\
\hline .815 & .819 & 11 & Q4 \\
\hline .811 & .816 & 10 & Q3 \\
\hline .806 & .809 & 9 & Q11 \\
\hline .795 & .798 & 8 & Q7 \\
\hline .779 & .782 & 7 & Q10 \\
\hline .756 & .761 & 6 & \\
\hline
\end{tabular}

Table 3.19: Reliability Statistics of 6 Items of Learning English outside Class

\begin{tabular}{lll}
\hline Cronbach's Alpha & $\begin{array}{l}\text { Cronbach's Alpha based on } \\
\text { standardised items }\end{array}$ & Number of items \\
\hline .756 & .761 & 6 \\
\hline
\end{tabular}

Table 3.20: Item-Total Statistics of 6 Items of Learning English outside Class

\begin{tabular}{llll}
\hline & $\begin{array}{l}\text { Scale mean if item } \\
\text { deleted }\end{array}$ & $\begin{array}{l}\text { Scale variance if item } \\
\text { deleted }\end{array}$ & $\begin{array}{l}\text { Cronbach's Alpha if } \\
\text { item deleted }\end{array}$ \\
\hline Q1 & 9.60 & 12.483 & .720 \\
\hline Q2 & 9.60 & 12.149 & .707 \\
\hline Q5 & 9.55 & 11.881 & .724 \\
\hline Q6 & 9.42 & 11.958 & .727 \\
\hline Q8 & 9.63 & 11.348 & .723 \\
\hline Q13 & 9.47 & 11.745 & .724 \\
\hline
\end{tabular}

In the initial version of the self-regulation questionnaire there were three constructs of metacognitive self-management including planning, monitoring and evaluating. Under each construct there were originally many other sub-constructs with one or more questions. However, for the planning construct, the factor analysis came up with two factors of general planning and task-specific planning. The number of items of each factor was four and the alphas were .751 and .786 respectively. After the factor analysis for the monitoring construct was performed, it was very difficult to 
decide which items to retain because the factor loading indicated items that did not closely match the sub-constructs in the original questionnaire. The researcher therefore decided to conduct reliability analysis for all items in the monitoring construct in order to exclude those items whose 'alpha if deleted' was the highest each time. The reliability analysis was carried out until there were seven items left (out of 16 items in the original questionnaire). The alpha of the monitoring construct was .838. As for the evaluating construct, the exploratory analysis showed that all 11 questions in the original questionnaire were loaded in one factor. The researcher used the same strategy of reliability analysis as was applied in the monitoring construct to eliminate items in the evaluating section. As a result, seven items were kept and their alpha was .873.

The resulting new version of the questionnaire (after the reliability analysis was conducted) did not aim to include all possible items related to LA, but only those relating to its five distinct elements: reasons for learning English, making an effort to learn English, planning, monitoring and evaluating. It had only 53 items; however it had higher internal validity. This resulting new version of the questionnaire, covering both self-initiation and self-regulation aspects of LA, was next administered to the 177 participants in the first phase of the study. Table 3.21 shows the internal consistency reliability statistics of both questionnaires.

Table 3.21: Reliability Statistics of the Final Questionnaire

\begin{tabular}{|c|c|c|c|c|}
\hline \multicolumn{3}{|c|}{ Learner autonomy constructs } & $\begin{array}{l}\text { Cronbach's } \\
\text { Alpha }\end{array}$ & $\begin{array}{l}\text { Number of } \\
\text { items }\end{array}$ \\
\hline \multirow{7}{*}{$\begin{array}{l}\text { Self- } \\
\text { initiation }\end{array}$} & \multirow{3}{*}{$\begin{array}{l}\text { Reasons for } \\
\text { learning English }\end{array}$} & Individual development & .673 & 3 \\
\hline & & Intrinsic interest & .774 & 3 \\
\hline & & Going abroad & .783 & 3 \\
\hline & \multirow{4}{*}{$\begin{array}{l}\text { Making an effort to } \\
\text { learn English }\end{array}$} & Learning English out of class & .756 & 6 \\
\hline & & Using English out of class & .815 & 6 \\
\hline & & Overt language learning in class & .813 & 5 \\
\hline & & Covert language learning in class & .850 & 5 \\
\hline \multirow{4}{*}{$\begin{array}{l}\text { Self- } \\
\text { regulation }\end{array}$} & & General planning & .751 & 4 \\
\hline & & Task-specific planning & .786 & 4 \\
\hline & & Monitoring & .838 & 7 \\
\hline & & Evaluating & .873 & 7 \\
\hline
\end{tabular}




\subsubsection{Validity}

Two types of validity are often discussed: measurement validity and research validity. From the perspective of measurement, validity implies that the individual's scores from an instrument make sense and are meaningful, which enables researchers to draw good conclusions from what is found (Creswell, 2005, p. 162). Supporting the concept of validity, Dornyei (2007) suggests that "validity was portrayed now as the conclusion of a complex validity argument which uses various statistical and theoretical sources as evidence" (p. 52). In essence, validity is the quality of the interpretations made by researchers, not of the scores. It is context-dependent and can be backed up with a variety of types of research evidence (Bachman, 2004). From the research viewpoint, researchers are concerned with internal validity and external validity. Internal validity means the findings are affected only by variables that are measured and manipulated by researchers in their studies and not by any other factors. External validity is the extent to which the findings can be generalised to other population or other settings.

In the second phase of this study, the MT was conducted to test the researcher's hypothesis about the causal relationship between LA and the writing outcomes of learners in the EG. To avoid unexpected problems that might threaten the validity of her research, the researcher took a range of actions.

- control of the MT: The researcher tightly controlled the hand-outs and learning materials of the MT to ensure that they were delivered to learners in the EG, not $\mathrm{C} 1$ and $\mathrm{C} 2$. In order to assess the impacts of MT and the application of MT to learning other language skills, the researcher needed the learners in the EG to regularly write diary entries. However the learners would only undertake the task if the researcher agreed to check their diary entries for correctness. Theoretically, her correction might invalidate the results of the writing scores of the post test. However, practically, there was no such a threat to the validity of the writing scores because the writing teachers in $\mathrm{C} 1$ and $\mathrm{C} 2$ also asked their students to write diaries and checked any mistakes the learners had made. The only difference in diary entries between the EG and the control groups was the focus. Learners in the EG wrote their reflections mostly about the MT and the transfer of metacognitive skills in learning other subjects while control groups could put whatever they wanted in their diaries. Even if there was a slight risk that the 
researcher's input might influence the learners' scores of the post-test, the grammar score made up only one fourth of the total writing score because of the inclusion of other components such as content, organisation, and language (as shown in the marking scheme, Table 3.14).

- dropout of participants: The researcher's presence at the research site enabled her to gather information from all participants across the three classes before and after the MT. For participants who failed to come to the pre- and post-test dates, she asked them to come at a date convenient to them. In addition, learners in the EG were encouraged to attend the MT on a frequent basis. As a result, there was no change in the number of participants who took the pre- and post-tests as well as the pre-and post-writing tasks. Some learners did not sit the delayed test. However, this was beyond the researcher's control because the delayed test was administered by the Department of English, not the researcher.

- Hawthorne effect: All the participants agreed to put their names and ID numbers on the questionnaires and permitted the researcher to have access to their academic records for the research purposes. They were aware that their tests would be marked. They also knew that they and their test results were the focus of the study. The fact that learners not only in EG but also C1 and C2 insisted on being given more time to complete their pre- and post-writing tests was indicative of the fact that they all treated the process seriously. Regardless of the class they were in, they all wanted to gain high scores for their writing tests.

In addition to the above mentioned measures, the validity of this research was improved through triangulation.

\subsubsection{Triangulation}

This study drew on two types of triangulation among the seven different categories of triangulation summarised by Brown (2001, p. 228). These included data triangulation and methodological triangulation. The former entails the use of multiple sources of data to look into the phenomenon from different perspectives. The latter requires the employment of several data collection procedures. Because the researcher was interested in additional evidence about the effectiveness of the MT, she interviewed both teacher participants and learner participants. She also asked them to write diary 
entries. When making interpretations of a phenomenon or drawing conclusions about a particular finding, the researcher always referred to additional sources of information she had gathered. She avoided relying solely on the results supplied by the scores of learners' writing tests or the questionnaires.

\subsection{Ethical considerations}

This study required the researcher to have access to the participants' academic records in order to run a correlation test on the relationship between LA and their learning results. For this reason, it was necessary that the researcher have permission to use the participants' learning results. It was also important for her to be allowed to incorporate the MT into the Writing Four curriculum. Before gathering data and delivering the MT, she had obtained consent from various parties including the Rectors, the Heads of the Departments of English, the teachers of English, and the English-major students at the two universities in Vietnam.

In the trialling phase, the researcher needed a large number of participants. She applied for authorisation from two universities: a state-run and a private university. Firstly, she sent emails to the two Rectors describing in detail the purpose of her research and her intention to use learners' academic records. She also outlined her schedule for the data collection process and explained the steps involved. When the researcher arrived at the research site in Vietnam, she obtained the Rectors' formal approval with their signatures and the university stamps on the documents. Her next stage was meeting with the Heads of the Departments of English. After reaching agreement with them on data collection procedures and agendas, the researcher was given the contact numbers and the teaching timetable of each teacher who would assist her in distributing the questionnaires to students. She then talked on the telephone with 25 teachers who gave her permission to come into their classes and deliver the questionnaire to their students. The researcher's plan for sending out the questionnaires was adjusted to the convenience of the teachers who signed and returned the consent form before she entered their classrooms. Regarding the approval from learners, consent forms were distributed to them right before they answered the questionnaire. The researcher explained the goals of her research carefully and asked for their voluntary participation. She also gave students time to read the consent form and to consider their participation. Questionnaires then were 
sent to those who signed the consent form. It was very encouraging for the researcher because she received strong support from all parties involved. They all agreed to volunteer their engagement in this study.

In the first phase of this study, the information was collected from the private university where the researcher has been employed. Therefore, the procedure for obtaining consent forms was simpler because of the involvement of fewer people. The researcher needed to have formal consent only from the students. However, this time the consent form asked for their voluntary participation for two sets of questionnaires which were distributed to them at different times. The researcher did not have any difficulty in recruiting voluntary participants for this phase.

The MT in the second phase lasted for eight weeks. It was essential that the MT be integrated into the curriculum of the Writing Four course. The fact that the MT took up one fourth of the time allocated for the Writing Four course made it harder for the researcher to be granted approval from the university. This was because learners in the EG had to give up nine hours out of 36 hours of the Writing Four course for the MT. The researcher sent a formal letter asking for permission to conduct the MT during Writing Four classes. In her letter she summarised the practical value, the content and the main points of the MT. After that she received an email from the Rector expressing a point of concern. The Rector and the Head of the Department of English were worried about learners in the EG lagging behind in their English writing compared with their peers in $\mathrm{C} 1$ and $\mathrm{C} 2$. However, the insider status and numerous persuading emails from the researcher, who previously worked as a teacher of English, gave her credibility with the university. She finally was allowed to conduct the MT as planned. The researcher's insider status was useful for obtaining consent both from the school and from the teachers. This insider status also enabled her to be trusted by the two teachers on the Writing Four programme. As a result, she gained easy access to course documents, which made it possible for her to incorporate activities into the MT that were relevant to the Writing Four course. Then the researcher approached all the three classes (EG, $\mathrm{C} 1$, and $\mathrm{C} 2$ ) and informed them about the aims of her research and their involvement. All 94 consent forms were distributed to the students. Most of the forms were returned on that day. Some were collected a day later.

In summary this study strictly followed the ethical principles of research. At all stages the participants were assured that the information provided would be 
confidential with pseudonyms being used instead of their real names. All of them reserved the right to withdraw from the study at any time.

\subsection{Conclusion}

Both quantitative and qualitative methods contributed to analysis of the issues explored in the study. However, this study employed mainly quantitative research methods to gather data for testing the hypotheses on the relationship between LA and language learning results as well as between MT and LA. The quantitative process involved the use of questionnaires for correlational research. This process also included an experimental study which focused on training learners in metacognitive strategies. The qualitative method was used to investigate the effect MT had on LA. The qualitative process entailed collecting opinions and feedback from learners and teachers about the MT though interviews, learners' diary entries, and classroom observations. Additionally, learners' learning logs and interviews were also employed in the trialling phase to develop the questionnaire which served as the main instrument for this research project.

Over a period of three years when the data were being collected, careful actions were taken to ensure the reliability and validity of the scores generated from the LA questionnaires. The questionnaires went through a careful process of validation. The research was carried out in three different phases, the results and data analyses of which will be presented in the following chapters. The pilot study aimed to test the research instruments. However, the commitment, the time and the efforts devoted to it were similar to those dedicated to Phase one and Phase two of the study. In addition, the scale of the pilot study was as large as that of the other two phases. Hence, the data collected from the pilot study were considered worthwhile and were used to answer some research questions. These data yielded important insights into LA among Vietnamese learners. 


\section{PILOT STUDY}

The pilot study was conducted at two Vietnamese universities from 20 April 2007 to 20 June 2007. The primary goal of the pilot study was to test the questionnaire ${ }^{1}$ which was the main research instrument, and to look for initial indications of the nature of the relationship between LA and language proficiency. Hence, it attempted to answer the questions below:

1. a) Is there a relationship between LA and language proficiency?

b) What is the relationship between LA and the four language skills of listening, speaking, reading, and writing?

The richness of different sources of the data collected in this phase also helped address the following research questions:

2. Are there differences in LA among students of different year levels?

3. Are there differences in LA at the two types of tertiary institutions?

4. Are there differences in the number of activities, and the amount of time devoted to learning English by learners of different levels of academic achievement?

\subsection{Findings}

The findings are organised around the four research questions above.

\subsubsection{Constructs of LA}

Basic descriptive statistics of LA on the part of 388 students are displayed in Table 4.1 below:

\footnotetext{
${ }^{1}$ The range of the Likert scale used in the pilot study was from 1-5.
} 
Table 4.1: Constructs of LA

\begin{tabular}{llll}
\hline Constructs of learner autonomy & $\mathbf{M}$ & $\mathbf{S D}$ & $\mathbf{N}$ \\
\hline Out-of-class activities & 2.6604 & .46863 & 383 \\
\hline In-class activities & 3.2392 & .67706 & 388 \\
\hline Planning & 3.6056 & .69765 & 386 \\
\hline Monitoring & 3.3844 & .51395 & 384 \\
\hline Evaluating & 3.3943 & .62988 & 388 \\
\hline
\end{tabular}

Overall, Table 4.1 demonstrates that students were more likely to perform selfregulatory behaviours than to take the initiative to learn. With respect to self-initiation, students nearly always 'rarely' initiated out-of-class activities. The mean score of 2.6604 indicates students' low level of effort put into learning English outside the classroom. The standard deviation of this measure was the smallest (0.46863) among the five, showing that this score did not differ much among the students. However, they 'sometimes' engaged themselves in in-class activities, the other subconstruct of self-initiation, reaching the mean score of 3.2392 .

Figure 4.1: LA Demonstrated by Vietnamese Learners

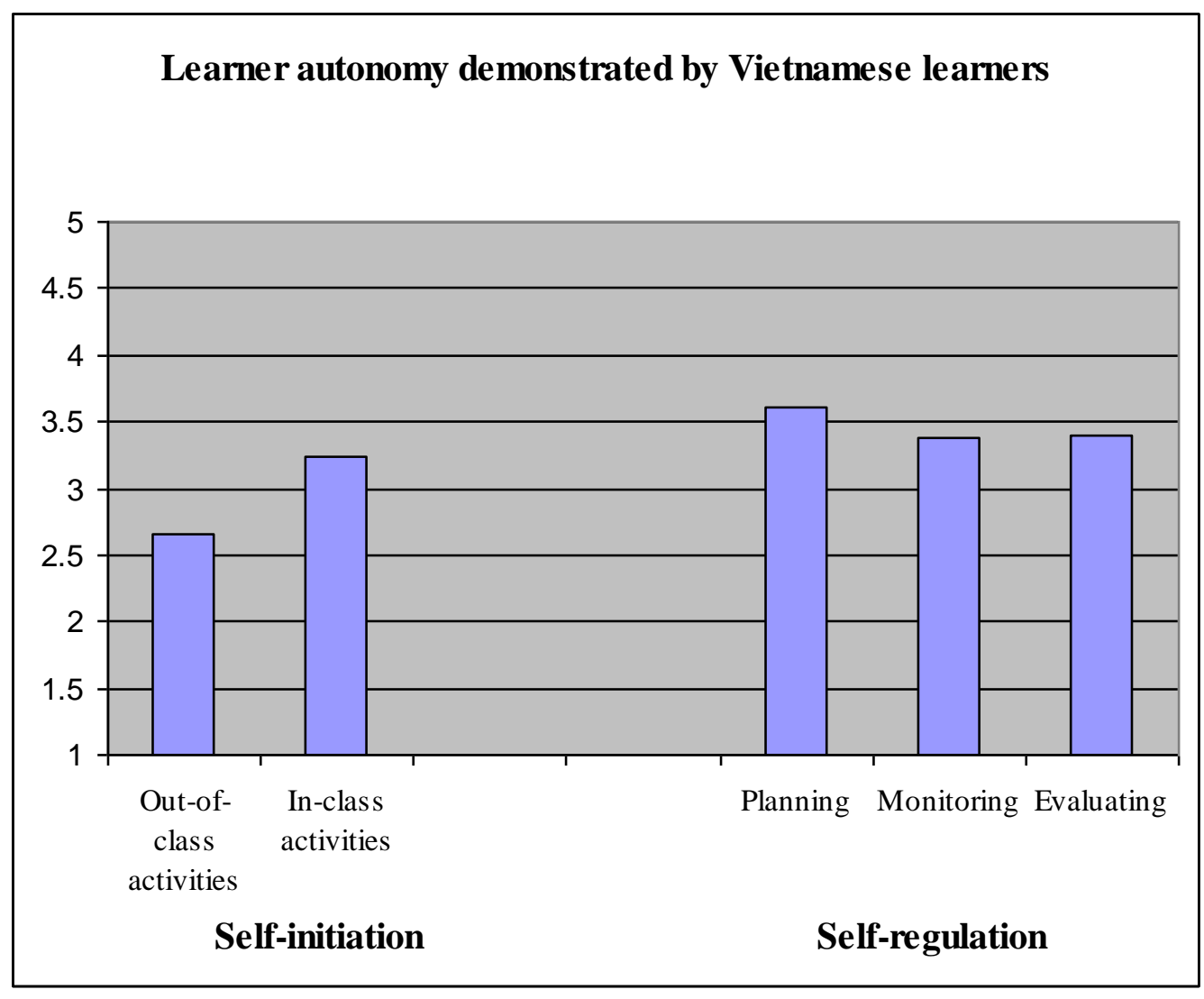


Regarding self-regulation, planning was the most often practised skill, followed by evaluating and monitoring. The mean score of 3.6056 shows that most students 'often' planned for their task, which was an encouraging result. There was not much difference in how often students monitored and evaluated their work. The mean scores were 3.3844 and 3.3943 respectively, displaying almost the same frequency, 'sometimes', for these two skills. However the smaller standard deviation of the measure for monitoring (0.5139) shows little disparity among students compared with the measure for evaluating (0.62988). In short, with most of the mean scores reaching above 3.2 (out of 5), except for the mean score of out-of-class activities, the questionnaire revealed that Vietnamese students did not often demonstrate LA. It was also found that students performed more regulatory behaviours than initiating activities to improve their English (Figure 4.1).

\subsubsection{Relationship between LA and general language proficiency}

Table 4.2 displays the correlations between the five constructs of LA and general language proficiency. The correlation matrix shows that there was a statistically significant positive relationship between general language proficiency and each of the out-of-class activities, monitoring and evaluating aspects of LA ( $p<0.01)$. In-class activities and planning did not have a significant association with general language proficiency. There was, however, an indication of a negative relationship between planning and general language proficiency, which was unexpected. However, this negative relation was not significant $(\mathrm{r}=-.027)$.

Table 4.2 also illustrates the correlations between the five variables of LA and the four language skills. As can be seen, out-of-class activities only significantly correlated (at the $\mathrm{p}<.01$ level) with listening and speaking but not with reading and writing. In-class activities significantly correlated (at the $\mathrm{p}<.05$ level) only with speaking skill but did not correlate with listening, reading and writing. Planning did not correlate with speaking, and it negatively correlated with listening, reading and writing. Monitoring showed significant correlations (at the $\mathrm{p}<.01$ ) with speaking. Monitoring, however, did not correlate with listening, reading and writing. Evaluating displayed significant correlations with listening (at the $\mathrm{p}<.05$ level) and speaking (at the $\mathrm{p}<.01$ level) while it did not correlate with reading and writing. 
The correlation matrix exhibits some unanticipated results. First of all, regardless of the frequency with which students practised planning, it seemed the planning skill was not useful for students when they wrote and read, which was very different from the researcher's expectations. The negative correlation between planning and reading and writing was hard to interpret because it is generally agreed that a piece of writing would become better if students planned what and how they would write. This also applies for reading. However, it is understandable when we look at questions placed under the planning construct. In fact, in the questionnaire the students were asked questions about general planning behaviours, not specific ones. Apart from that they were not required to write any tasks before answering the questionnaire, which could have made it harder for them to provide specific responses regarding planning behaviours.

Table 4.2: Correlation between LA and General Language Proficiency

\begin{tabular}{|c|c|c|c|c|c|c|c|}
\hline $\begin{array}{l}\text { Construct } \\
\text { autonomy }\end{array}$ & of learner & & Listening & Speaking & Reading & Writing & $\begin{array}{l}\text { General } \\
\text { proficiency }\end{array}$ \\
\hline \multirow{4}{*}{ Self-initiation } & \multirow{2}{*}{$\begin{array}{l}\text { Out-of-class } \\
\text { activities }\end{array}$} & $\mathrm{r}$ & $.155(* *)$ & $.197(* *)$ & .068 & .043 & $.166(* *)$ \\
\hline & & $\mathrm{n}$ & 382 & 382 & 382 & 382 & 382 \\
\hline & \multirow{2}{*}{$\begin{array}{l}\text { In-class } \\
\text { activities }\end{array}$} & $\mathrm{r}$ & .069 & $.116(*)$ & .085 & .007 & .093 \\
\hline & & $\mathrm{n}$ & 387 & 387 & 387 & 387 & 387 \\
\hline \multirow{6}{*}{ Self-regulation } & \multirow{2}{*}{ Planning } & $\mathrm{r}$ & -.021 & .025 & -.021 & -.049 & -.027 \\
\hline & & $\mathrm{n}$ & 385 & 385 & 385 & 385 & 385 \\
\hline & \multirow{2}{*}{ Monitoring } & $\mathrm{r}$ & .093 & $.207(* *)$ & .026 & .082 & $.143(* *)$ \\
\hline & & $\mathrm{n}$ & 383 & 383 & 383 & 383 & 383 \\
\hline & \multirow{2}{*}{ Evaluating } & $\mathrm{r}$ & $.118(*)$ & $.174(* *)$ & .011 & .072 & $.133(* *)$ \\
\hline & & $\mathrm{n}$ & 387 & 387 & 387 & 387 & 387 \\
\hline
\end{tabular}


However, these findings corresponded to the results coming from the interviews, and the learning logs where, as well as the top students, the other students also reported doing more general planning for their learning rather than performing specific planning for the task. The consistency among data sources could suggest that general planning correlated negatively with listening, reading and writing, but specific planning might not. Secondly, monitoring was useful only for speaking although it had been anticipated that it would be helpful when one reads and writes as well. Thirdly, evaluating did not correlate with proficiency in writing, which, again, was far from the researcher's expectations.

\subsubsection{LA and students of different year levels}

The study involved students from two types of tertiary institutions, a private university and a state-owned university. At the state-run university, however, the researcher was permitted to collect data only from first-year students. For this reason, this section investigates the relationship between LA and students of different year levels at a private university only. The questionnaires answered by 181 students from year one, year two, and year three were analysed.

According to the descriptive statistics in Table 4.3, there were numerical differences in the five aspects of LA among the three year levels. Second-year students had the highest means on all the measures. Year one outperformed year three in in-class activities, planning and evaluating while they lost ground to year three in monitoring and out-of-class activities. It was interesting to find out that third-year students were the least autonomous learners. However, the three years did not differ significantly from each other (Table 4.4), except for the out-of-class activities measure. Its $F$ ratio was $F(2,178)=3.024, p<.05)$. The $F$ ratios for the other four elements of LA were not significant (n.s), indicating that the students from the three year levels showed a significant difference only in out-of-class activities, but not in the other aspects of LA regardless of the numerical differences found among them.

The differences in the elements of LA among the three years are located in Table 4.5. Although year two had the highest scores for all the five constructs of LA, they differed significantly at the 0.5 level from the other two year levels in the selfinitiation aspect, which involved out-of-class activities and in-class activities. More specifically, second-year students initiated activities to improve their English both 
inside and outside the classroom context significantly more than first-year students but only numerically more than third-year students. In the self-regulation element, including planning, monitoring, and evaluating, year two performed numerically but not significantly better than year one and year three. First-year and third-year students did not differ significantly from each other in LA aspects, though there were numerical differences as shown in Table 4.3.

Table 4.3: Descriptive Statistics for LA among First, Second, and Third Years

\begin{tabular}{|c|c|c|c|c|c|}
\hline & & $\mathbf{N}$ & Mean & Std. Deviation & Std. Error \\
\hline \multirow[t]{4}{*}{ Out-of-class activities } & Year 1 & 121 & 2.6629 & .47391 & .04308 \\
\hline & Year 2 & 33 & 2.8626 & .36630 & .06377 \\
\hline & Year 3 & 27 & 2.8333 & .62561 & .12040 \\
\hline & Total & 181 & 2.7247 & .48779 & .03626 \\
\hline \multirow[t]{4}{*}{ In-class activities } & Year 1 & 121 & 3.2678 & 69979 & .06362 \\
\hline & Year 2 & 33 & 3.5394 & .51109 & .08897 \\
\hline & Year 3 & 27 & 3.2444 & .83635 & .16096 \\
\hline & Total & 181 & 3.3138 & .69672 & .05179 \\
\hline \multirow[t]{4}{*}{ Planning } & Year 1 & 121 & 3.6591 & .67931 & .06176 \\
\hline & Year 2 & 33 & 3.8106 & .57632 & .10033 \\
\hline & Year 3 & 27 & 3.5278 & .65167 & .12541 \\
\hline & Total & 181 & 3.6671 & .65936 & .04901 \\
\hline \multirow[t]{4}{*}{ Monitoring } & Year 1 & 121 & 3.3781 & .52228 & .04748 \\
\hline & Year 2 & 33 & 3.4697 & .44308 & .07713 \\
\hline & Year 3 & 27 & 3.4352 & .57216 & .11011 \\
\hline & Total & 181 & 3.4033 & .51520 & .03829 \\
\hline \multirow[t]{4}{*}{ Evaluating } & Year 1 & 121 & 3.4442 & .61448 & .05586 \\
\hline & Year 2 & 33 & 3.5455 & .64788 & .11278 \\
\hline & Year 3 & 27 & 3.4167 & 68990 & .13277 \\
\hline & Total & 181 & 3.4586 & 62999 & .04683 \\
\hline
\end{tabular}


Table 4.4: ANOVA for LA among First, Second, and Third Years

\begin{tabular}{|c|c|c|c|c|c|c|}
\hline & & $\begin{array}{l}\text { Sum of } \\
\text { Squares }\end{array}$ & df & $\begin{array}{l}\text { Mean } \\
\text { Square }\end{array}$ & $\mathbf{F}$ & Sig. \\
\hline \multirow{3}{*}{$\begin{array}{l}\text { Out-of-class } \\
\text { activities }\end{array}$} & Between Groups & 1.407 & 2 & .704 & 3.024 & .051 \\
\hline & Within Groups & 41.421 & 178 & .233 & & \\
\hline & Total & 42.828 & 180 & & & \\
\hline \multirow[t]{3}{*}{ In-class activities } & Between Groups & 2.066 & 2 & 1.033 & 2.155 & .119 \\
\hline & Within Groups & 85.310 & 178 & .479 & & \\
\hline & Total & 87.375 & 180 & & & \\
\hline \multirow[t]{3}{*}{ Planning } & Between Groups & 1.211 & 2 & .606 & 1.399 & .249 \\
\hline & Within Groups & 77.045 & 178 & .433 & & \\
\hline & Total & 78.257 & 180 & & & \\
\hline \multirow[t]{3}{*}{ Monitoring } & Between Groups & .250 & 2 & .125 & .468 & .627 \\
\hline & Within Groups & 47.527 & 178 & .267 & & \\
\hline & Total & 47.777 & 180 & & & \\
\hline \multirow[t]{3}{*}{ Evaluating } & Between Groups & .321 & 2 & .161 & .402 & .669 \\
\hline & Within Groups & 71.118 & 178 & .400 & & \\
\hline & Total & 71.439 & 180 & & & \\
\hline
\end{tabular}


Table 4.5: Differences in LA among First, Second, and Third Years

\begin{tabular}{|c|c|c|c|c|c|}
\hline Dependent Variable & $\begin{array}{l}\text { (I) Year } \\
\text { Level }\end{array}$ & $\begin{array}{l}(\mathrm{J}) \text { Year } \\
\text { Level }\end{array}$ & $\begin{array}{l}\text { Mean Difference } \\
(\mathrm{I}-\mathrm{J})\end{array}$ & Std. Error & Sig. \\
\hline \multirow[t]{6}{*}{ Out-of-class activities } & \multirow[t]{2}{*}{ Year 1} & Year 2 & $-.19963^{*}$ & .09474 & .037 \\
\hline & & Year 3 & -.17041 & .10267 & .099 \\
\hline & \multirow[t]{2}{*}{ Year 2} & Year 1 & $.19963^{*}$ & .09474 & .037 \\
\hline & & Year 3 & .02922 & .12518 & .816 \\
\hline & \multirow[t]{2}{*}{ Year 3} & Year 1 & .17041 & .10267 & .099 \\
\hline & & Year 2 & -.02922 & .12518 & .816 \\
\hline \multirow[t]{6}{*}{ In-class activities } & \multirow[t]{2}{*}{ Year 1} & Year 2 & $-.27163^{*}$ & .13596 & .047 \\
\hline & & Year 3 & .02332 & .14735 & .874 \\
\hline & \multirow[t]{2}{*}{ Year 2} & Year 1 & $.27163^{*}$ & .13596 & .047 \\
\hline & & Year 3 & .29495 & .17965 & .102 \\
\hline & \multirow[t]{2}{*}{ Year 3} & Year 1 & -.02332 & .14735 & .874 \\
\hline & & Year 2 & -.29495 & .17965 & .102 \\
\hline \multirow[t]{6}{*}{ Planning } & \multirow[t]{2}{*}{ Year 1} & Year 2 & -.15152 & .12920 & .242 \\
\hline & & Year 3 & .13131 & .14003 & .350 \\
\hline & \multirow[t]{2}{*}{ Year 2} & Year 1 & .15152 & .12920 & .242 \\
\hline & & Year 3 & .28283 & .17073 & .099 \\
\hline & \multirow[t]{2}{*}{ Year 3} & Year 1 & -.13131 & .14003 & .350 \\
\hline & & Year 2 & -.28283 & .17073 & .099 \\
\hline \multirow[t]{6}{*}{ Monitoring } & \multirow[t]{2}{*}{ Year 1} & Year 2 & -.09160 & .10148 & .368 \\
\hline & & Year 3 & -.05709 & .10998 & .604 \\
\hline & \multirow[t]{2}{*}{ Year 2} & Year 1 & .09160 & .10148 & .368 \\
\hline & & Year 3 & .03451 & .13409 & .797 \\
\hline & \multirow[t]{2}{*}{ Year 3} & Year 1 & .05709 & .10998 & .604 \\
\hline & & Year 2 & -.03451 & .13409 & .797 \\
\hline \multirow[t]{6}{*}{ Evaluating } & \multirow[t]{2}{*}{ Year 1} & Year 2 & -.10124 & .12413 & .416 \\
\hline & & Year 3 & .02755 & .13454 & .838 \\
\hline & \multirow[t]{2}{*}{ Year 2} & Year 1 & .10124 & .12413 & .416 \\
\hline & & Year 3 & .12879 & .16403 & .433 \\
\hline & \multirow[t]{2}{*}{ Year 3} & Year 1 & -.02755 & .13454 & .838 \\
\hline & & Year 2 & -.12879 & .16403 & .433 \\
\hline
\end{tabular}


The findings regarding LA and the students' year level make sense in light of the researcher's observations and her experience teaching English to university students in Vietnam. Basically, students are experiencing a curve while studying at university. It is generally common in Vietnam that the first year of university is a time when students get to know about what and how to learn. This is similar to the entry stage described by Brundage and MacKeracher (1980) (cited in Boud, 1981, p. 31) when "learners enter a situation which has high a degree of novelty, uncertainty, or lack of familiarity...He may perceive himself as disoriented within the situation, may act as an observer without making a personal commitment to participate... and may communicate largely through monologue". First-year students normally would not perform as well as second- and third-year students. After a year at university, year-one students will be able to develop appropriate approaches to learning which meet the requirements of tertiary education. Additionally, they will have the best energy and enthusiasm for study in their second year. This stage is comparable to the combination of reactive and proactive stages detailed by Brundage and MacKeracher (1980). During these stages, students develop a sense of themselves, and learn how to express their feelings, to engage in conflicts or arguments, and to act independently. By engaging in these activities, they become confident about themselves and get involved in activities aimed at achieving cooperation and negotiation with others. This is the most productive stage of their life at university. In their third year, their energy weakens, and they start worrying about their future job. They might want to focus on what they consider important and necessary. This might explain why thirdyear students were found to have spent more time on out-of-class activities than firstyear students. Fourth year is the busiest time when students get ready for graduation exams and run around to take career-related courses. As the students' goals change over the course of their study, the focus of their autonomous behaviours may also shift. It is, therefore, understandable that the culmination in the exercise of autonomy is reached in the second year of university. 
Figure 4.2: LA among First, Second, and Third Years

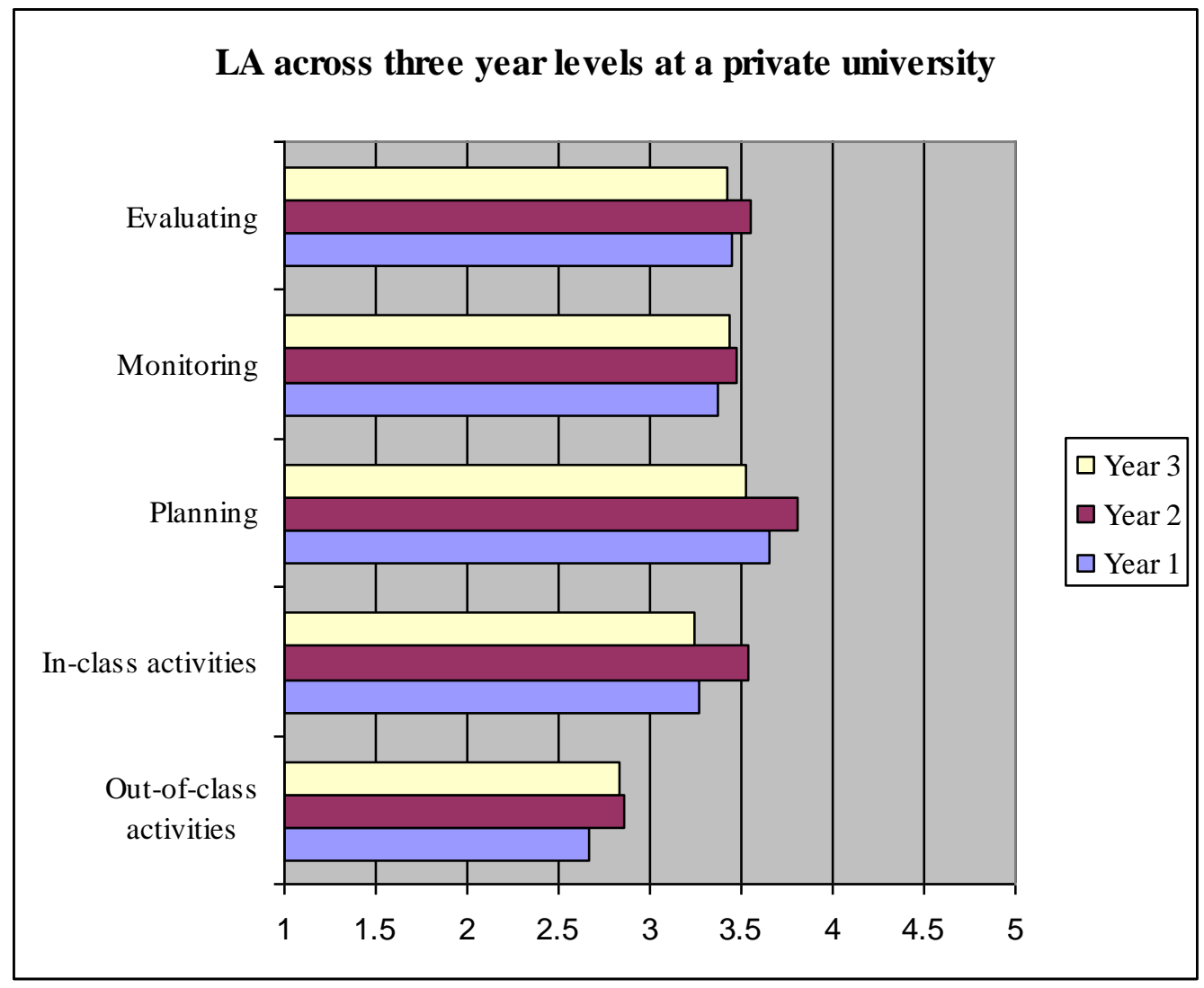

\subsubsection{LA at two different universities}

In is clear from Table 4.6 that students at the private university achieved higher mean scores for all measures of LA than those at the state institution. The numerical difference ranged between 0.0413 and 0.1522 . The smallest distinction of 0.0413 lay in the monitoring measure, indicating that students at both tertiary institutions monitored their work numerically almost at the same level of frequency. The largest disparity of 0.1522 was found in in-class activities. In other words, students at the private university numerically were more autonomous than those at the state university since they numerically displayed a slightly greater level of LA.

However, the differences in LA demonstrated by students at the two types of university were not significant at the .05 level (Table 4.7) even in the in-class activities measure, where the largest numerical difference was found between the two institutions. On average, as shown in Table 4.6, students at the private university initiated more activities to improve their English inside the classroom $(\mathrm{M}=3.313, \mathrm{SE}$ $=.051)$ than the students at a state university $(\mathrm{M}=3.161, \mathrm{SE}=.047)$. This difference 
was not significant, $t(377)=2.181, \mathrm{p}>.05$ (Table 4.7). In the other measures of LA, none of the differences reached a significance value of less than 0.5. Since the means for all aspects of LA did not statistically differ, it could be concluded that the students at both universities were of approximately the same level of LA. Although the students at the private university numerically differed from those at the state university, the differences between them were not significant.

Table 4.6: Group Statistics for LA at Two Types of University

\begin{tabular}{llllll}
\hline & University & $\mathbf{N}$ & Mean & Std. Deviation & Std. Error Mean \\
\hline Out-of-class & Private & 181 & 2.7247 & .48779 & .03626 \\
\cline { 2 - 6 } activities & State & 198 & 2.6010 & .44315 & .03149 \\
\hline In-class activities & Private & 181 & 3.3138 & .69672 & .05179 \\
\cline { 2 - 6 } & State & 198 & 3.1616 & .66175 & .04703 \\
\hline Planning & Private & 181 & 3.6671 & .65936 & .04901 \\
\cline { 2 - 6 } & State & 198 & 3.5354 & .72833 & .05176 \\
\hline Monitoring & Private & 181 & 3.4033 & .51520 & .03829 \\
\cline { 2 - 6 } & State & 198 & 3.3624 & .51792 & .03681 \\
\hline Evaluating & Private & 181 & 3.4586 & .62999 & .04683 \\
\cline { 2 - 6 } & State & 198 & 3.3283 & .63640 & .04523 \\
\hline
\end{tabular}


Table 4.7: Independent Samples Test for LA at Two Types of University

\begin{tabular}{|c|c|c|c|c|c|c|c|c|c|}
\hline & & \multicolumn{2}{|c|}{$\begin{array}{l}\text { Levene's } \\
\text { Test for } \\
\text { Equality of } \\
\text { Variances } \\
\end{array}$} & \multicolumn{5}{|c|}{ t-test for Equality of Means } & \\
\hline & & \multirow[b]{2}{*}{$\mathrm{F}$} & \multirow[b]{2}{*}{ Sig. } & \multirow[b]{2}{*}{$\mathrm{t}$} & \multirow[b]{2}{*}{ df } & \multirow{2}{*}{$\begin{array}{l}\text { Sig. } \\
(2- \\
\text { tailed })\end{array}$} & \multirow{2}{*}{$\begin{array}{l}\text { Mean } \\
\text { Difference }\end{array}$} & \multirow{2}{*}{$\begin{array}{l}\text { Std. Error } \\
\text { Difference }\end{array}$} & $\begin{array}{l}95 \% \text { Confidence } \\
\text { Interval of the } \\
\text { Difference }\end{array}$ \\
\hline & & & & & & & & & Lower Upper \\
\hline \multirow[t]{2}{*}{$\begin{array}{l}\text { Out-of- } \\
\text { class } \\
\text { activities }\end{array}$} & $\begin{array}{l}\text { Equal } \\
\text { variances } \\
\text { assumed }\end{array}$ & 1.916 & .167 & 2.588 & 377 & .010 & .12373 & .04782 & .02971 .21776 \\
\hline & $\begin{array}{l}\text { Equal } \\
\text { variances } \\
\text { not } \\
\text { assumed }\end{array}$ & & & 2.576 & $364.4 C$ & 5.010 & .12373 & .04802 & .02929 .21817 \\
\hline \multirow[t]{2}{*}{$\begin{array}{l}\text { In-class } \\
\text { activities }\end{array}$} & $\begin{array}{l}\text { Equal } \\
\text { variances } \\
\text { assumed }\end{array}$ & .849 & .358 & 2.181 & 377 & .030 & .15220 & .06979 & .01497 .28943 \\
\hline & $\begin{array}{l}\text { Equal } \\
\text { variances } \\
\text { not } \\
\text { assumed } \\
\end{array}$ & & & 2.176 & 369.61 & 8.030 & .15220 & .06995 & .01464 .28975 \\
\hline \multirow[t]{2}{*}{ Planning } & $\begin{array}{l}\text { Equal } \\
\text { variances } \\
\text { assumed }\end{array}$ & .188 & .665 & 1.840 & 377 & .066 & .13177 & .07160 & ${ }^{-} .00901 .27256$ \\
\hline & $\begin{array}{l}\text { Equal } \\
\text { variances } \\
\text { not } \\
\text { assumed }\end{array}$ & & & 1.849 & 376.96 & 6.065 & .13177 & .07128 & ${ }^{-} .00839 .27193$ \\
\hline \multirow[t]{2}{*}{ Monitoring } & $\begin{array}{l}\text { Equal } \\
\text { variances } \\
\text { assumed }\end{array}$ & .005 & .945 & .771 & 377 & .441 & .04094 & .05313 & ${ }^{-} .06352 .14540$ \\
\hline & $\begin{array}{l}\text { Equal } \\
\text { variances } \\
\text { not } \\
\text { assumed }\end{array}$ & & & .771 & 374.31 & 0.441 & .04094 & .05311 & ${ }^{-} .06350 .14538$ \\
\hline \multirow[t]{2}{*}{ Evaluating } & $\begin{array}{l}\text { Equal } \\
\text { variances } \\
\text { assumed }\end{array}$ & .002 & .966 & 2.000 & 377 & .046 & .13028 & .06513 & .00221 .25835 \\
\hline & $\begin{array}{l}\text { Equal } \\
\text { variances } \\
\text { not } \\
\text { assumed }\end{array}$ & & & 2.001 & 374.60 & 8.046 & .13028 & .06510 & .00227 .25829 \\
\hline
\end{tabular}




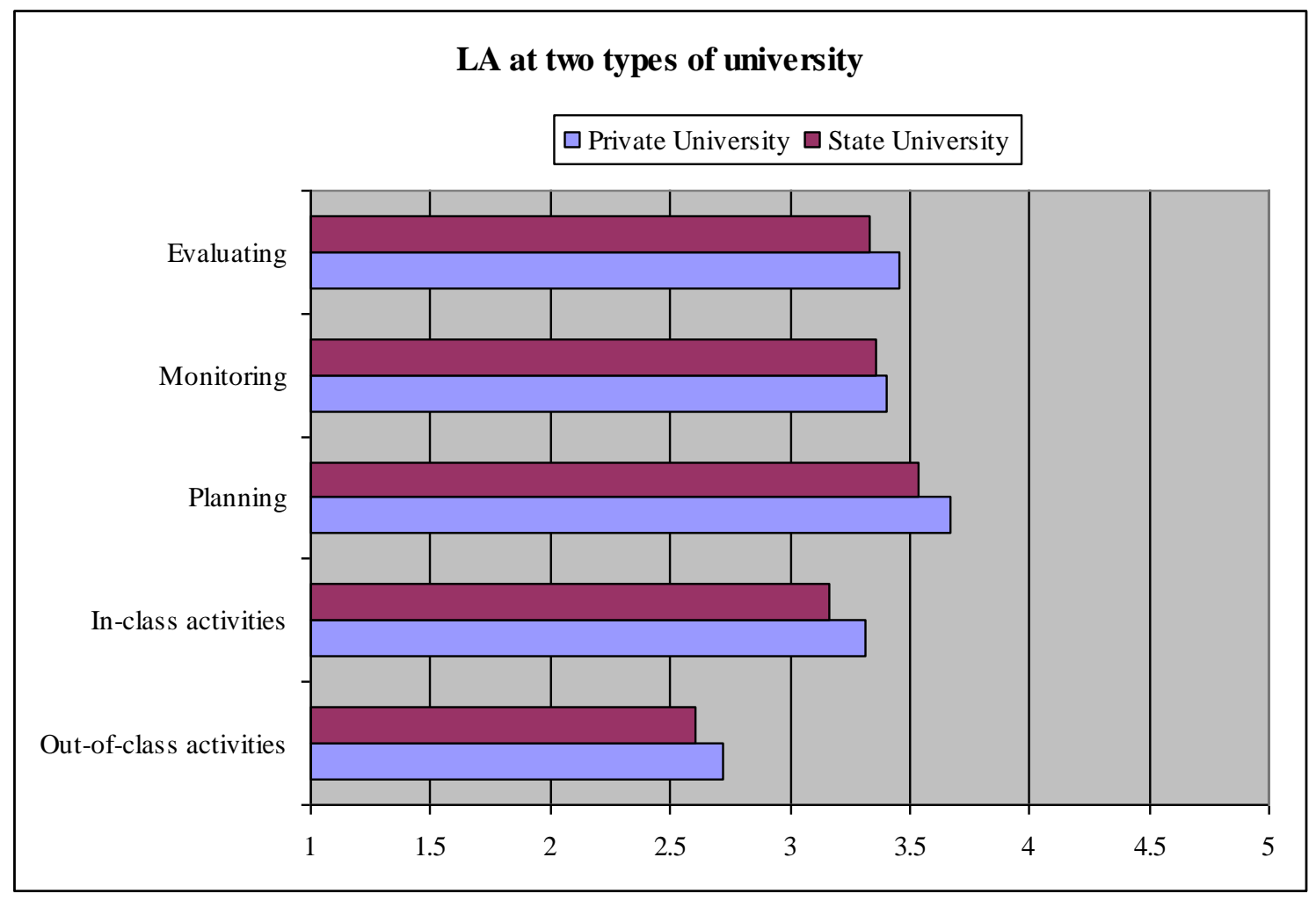

There was expectation that the differences in LA between the two universities would be higher. In Vietnam, state universities outshine private ones. There have been many contributing factors, including state-owned universities being established much earlier, receiving financial support from the government, and recruiting students of better performance. Additionally, the quality of teaching and training at private universities is not recognised by the public. Therefore, according to the researcher's understanding and experience, both teachers and students at private universities have to try their hardest in order to prove their quality, and at the same time build a name for themselves. The researcher's experience and observations during ten years working for a private university have also shown that in the past five years, the Ministry of Education and Training of Vietnam (MOET) has given private universities more autonomy to develop their own curriculum based on the framework it has set. The effort made by private universities and this empowerment from the MOET have brought positive changes. In the past, the MOET used to strictly control the curriculum, and the universities had very limited freedom to change the curriculum. Also, at the university where the researcher was employed, there have been a number of positive changes and innovations made in teaching and learning, 
which called for a replacement of the traditional teaching and learning approaches. The social pressure imposed on private universities, advantageous changes in favour of private universities initiated by the MOET of Vietnam, and the effort made by students and teachers at the private university would have been expected to be catalysts making students more autonomous learners than their peers from the state university. A significant difference in fact was not found.

\subsubsection{LA and students of different levels of achievement}

It was revealed that top students were more autonomous than bottom students. This finding was supported by the data from the interviews, and the learning logs.

\subsubsection{Evidence from interviews}

Table 4.8 presents LA demonstrated by three top and three bottom students. With regard to out-of-class activities, top students performed a lot more activities and their activities were wide-ranging whereas bottom students focussed more on listening. For example, top students wrote a diary in English, spent time with volunteer teachers, and participated in social activities which required them to speak English. Bottom students, on the other hand, spent more time practising listening.

It was interesting to discover that top students also tended to engage in activities that brought them pleasure while bottom students focussed on the activities that were directly related to lessons they learned in class. For instance, top students not only listened to the news on radio but also listened to their favourite songs, or watched a movie. Bottom students, in contrast, spent more time undertaking homework-related activities. The activities bottom students participated in included practising IELTS tests and listening to the radio.

With respect to in-class activities, top students engaged in a lot more activities than their counterparts. To illustrate, they asked their classmates to join games in which only English was used. They also asked their teachers straightaway if they did not understand a point in the lesson. Unlike top students, bottom students acknowledged that these behaviours were useful but said that they did not engage in them. They only "carefully paid attention to what the teachers were saying" in class and "tried their best" (Interview LTM, Q37, PS). 
The interviews demonstrated that top students took more initiative while bottom students stated that they knew what they should do but did not actually do it:

Yeah, I think I will speak English better if I invite volunteer teachers of English out for a cup of coffee and talk to them but...ah...I never did this. Hmm...I guess I should try this (from Interview LTM, Q36, PS).

Regarding the self-regulation skills, both types of students engaged in general planning. However, top students demonstrated specific ways to achieve their goals. For example, one top student said:

For this semester, I wanted to get a score of 8 ( on a 10- mark scale) so I tried to spend at least an hour a day listening to sources of English such as TV, songs, radio, and CDs. I learned to listen to main ideas then I checked the typescripts to find out what I missed out. After that I wrote down those words in my scrapbook, and practised pronouncing difficult words. When I met my friends at school, I often asked them words that I thought they did not know (from Interview DNMH, Q10, PS).

It was also found that only top students participated in task planning while bottom students did not. In terms of monitoring, bottom students were aware of their language problems but they did not have their own ways to check the task completion, and to monitor their feelings. For instance, when being asked about whether they were aware of their own progress while they were completing a task and how they tracked their progress according to their plan, some top students said they considered the number of points they had finished. Bottom students, on the other hand, admitted they just kept doing the task until they ran out of time. As for evaluation, bottom students did not know about assessment criteria of the task they were required to do. Top students, as well as knowing about assessment criteria set by their teachers, had their own assessment criteria. For example, one top student said that her assessment criteria were not the same all the time. They changed according to her plan. More specifically, her own criterion for her writing was producing sentences with the correct tenses. In the following writing task, her assessment criterion was using the right tense plus the right vocabulary (Interview DNMH, Q28, PS). Bottom students, in contrast, did not know about the assessment criteria set by their teachers. Their only strategy was "trying my best" (Interview LTM, Q37, PS). As far as the evaluation of goal achievement was concerned, both top and bottom students practised this skill. Bottom students judged their goal accomplishment on the basis of 
their test scores only while top students took into consideration both scores and comments from their peers and teachers.

Table 4.8: Summary of LA Aspects Demonstrated by Top and Bottom Students

\begin{tabular}{|c|c|c|c|c|}
\hline \multicolumn{2}{|c|}{ Learner autonomy } & \multicolumn{2}{|c|}{ Responses from top students } & $\begin{array}{l}\text { Responses } \\
\text { from bottom } \\
\text { students }\end{array}$ \\
\hline \multirow{2}{*}{$\begin{array}{l}\text { Self- } \\
\text { initiation }\end{array}$} & $\begin{array}{l}\text { Out-of- } \\
\text { class } \\
\text { activities }\end{array}$ & \multicolumn{2}{|c|}{$\begin{array}{l}\text { writing (for one's own blogs), diary, listening to music } \\
\text { (without lyrics the first time and with lyrics the second } \\
\text { time to compare), watching movies in English, doing } \\
\text { tests beyond current level, talking to teacher if do not } \\
\text { understand, asking volunteer teachers of English to go } \\
\text { out and talk to them, taking part in social activities for } \\
\text { youth: meeting international students coming to Vietnam } \\
\text { on exchange programmes, keeping in touch with former } \\
\text { volunteer teachers, chatting with them and asked them to } \\
\text { correct mistakes. }\end{array}$} & $\begin{array}{l}\text { listening to } \\
\text { radio, reading } \\
\text { news on the } \\
\text { Internet, } \\
\text { practising } \\
\text { IELTS tests }\end{array}$ \\
\hline & $\begin{array}{l}\text { In-class } \\
\text { activities }\end{array}$ & $\begin{array}{l}\text { searching games } \\
\text { to play, encouragi } \\
\text { teachers immediat } \\
\text { taking part in clas } \\
\text { expressing opinior }\end{array}$ & $\begin{array}{l}\text { the Internet and books, inviting peers } \\
\text { peers to speak English, asking } \\
\text { y for clarification, and actively } \\
\text { oom activities, not feeling shy when }\end{array}$ & $\begin{array}{l}\text { carefully } \\
\text { paying } \\
\text { attention to } \\
\text { lessons during } \\
\text { class time, } \\
\text { trying their } \\
\text { best }\end{array}$ \\
\hline \multirow{7}{*}{$\begin{array}{l}\text { Self- } \\
\text { regulation }\end{array}$} & Planning & $\begin{array}{l}\text { tasks } \\
\text { overall process }\end{array}$ & $\begin{array}{l}\text { yes } \\
\text { yes }\end{array}$ & $\begin{array}{l}\text { no } \\
\text { yes }\end{array}$ \\
\hline & \multirow{4}{*}{ Monitoring } & $\begin{array}{l}\text { task } \\
\text { concentration }\end{array}$ & $\begin{array}{l}\text { yes, based on task's requirements } \\
\text { and common sense }\end{array}$ & no \\
\hline & & problems & $\begin{array}{l}\text { yes, very well: discussing with peers, } \\
\text { talking to teachers, changing ways of } \\
\text { approaching tasks }\end{array}$ & yes \\
\hline & & strategies & yes & no \\
\hline & & feelings & yes & no \\
\hline & \multirow[b]{2}{*}{ Evaluating } & goal achievement & $\begin{array}{l}\text { yes, and setting their own criteria: } \\
\text { grammar, cohesiveness }\end{array}$ & no \\
\hline & & $\begin{array}{l}\text { assessment } \\
\text { criteria }\end{array}$ & $\begin{array}{l}\text { yes, based on test scores, teachers' } \\
\text { comments and comments made by } \\
\text { other people posted on blogs }\end{array}$ & $\begin{array}{l}\text { yes, based on } \\
\text { score only }\end{array}$ \\
\hline
\end{tabular}




\subsubsection{Evidence from learning logs}

Results from both types of learners' learning logs (out-of-class and in-class) are presented.

\subsection{Out-of-class learning}

Information on the time spent, and the range of activities undertaken by top and bottom students outside the classroom is displayed in Tables 4.9 and 4.10 respectively. Information on the number of out-of-class activities they performed during the two weeks is shown in Tables 4.11 and 4.12. Some students had undertaken the same activities for a number of times. For example, the tutoring activity would appear in their learning logs six times during two weeks because every week they normally conducted three tutoring classes according to the Vietnamese culture of private tutoring. Therefore, tutoring was listed as one activity. However, it was counted six times. In addition, tutoring was categorised as a speaking activity because all students wrote that they wanted to practise speaking English under the "Why did you do it?" heading in their learning logs. 
Table 4.9: Time and Range of Out-of-Class Activities by Top Students

\begin{tabular}{|c|c|c|c|c|c|c|}
\hline $\begin{array}{l}\text { Top } \\
\text { students }\end{array}$ & $\begin{array}{l}\text { Time on } \\
\text { listening } \\
\text { (hours) }\end{array}$ & $\begin{array}{l}\text { Time on } \\
\text { speaking } \\
\text { (hours) }\end{array}$ & $\begin{array}{l}\text { Time on } \\
\text { reading } \\
\text { (hours) }\end{array}$ & $\begin{array}{l}\text { Time on } \\
\text { writing } \\
\text { (hours) }\end{array}$ & $\begin{array}{l}\text { Time of } \\
\text { grammar } \\
\text { and others } \\
\text { (hours) }\end{array}$ & $\begin{array}{l}\text { Total time } \\
\text { in } 14 \text { days } \\
\text { (hours) }\end{array}$ \\
\hline Student 1 & $\begin{array}{l}4.5(\mathrm{CDs} \text { of, } \\
\text { reference } \\
\text { books, } \\
\text { English } \\
\text { songs) }\end{array}$ & none & $\begin{array}{l}4 \text { (online } \\
\text { English } \\
\text { news, sample } \\
\text { paragraphs, } \\
\text { vocabulary) }\end{array}$ & none & none & 8.5 \\
\hline Student 2 & $\begin{array}{l}2.5 \text { (English } \\
\text { songs, VOA } \\
\text { news) }\end{array}$ & none & $\begin{array}{l}3 \text { (stories } \\
\text { with } \\
\text { Vietnamese } \\
\text { translation) }\end{array}$ & $\begin{array}{l}1 \text { (emailing } \\
\text { foreigners or } \\
\text { friends in } \\
\text { English) }\end{array}$ & none & 6.5 \\
\hline Student 3 & $\begin{array}{l}5 \text { (TOEIC } \\
\text { tests, English } \\
\text { songs, } \\
\text { movies In } \\
\text { English) }\end{array}$ & none & $\begin{array}{l}6 \\
\text { (vocabulary) }\end{array}$ & 4 (paragraph) & $\begin{array}{l}\text { 6(grammatical } \\
\text { exercises) }\end{array}$ & 21 \\
\hline Student 4 & $\begin{array}{l}11 \text { (CDs of, } \\
\text { reference } \\
\text { books, } \\
\text { English } \\
\text { songs) }\end{array}$ & $\begin{array}{l}4 \text { (attending } \\
\text { extra } \\
\text { speaking } \\
\text { classes } \\
\text { taught by } \\
\text { foreign } \\
\text { teachers) }\end{array}$ & $\begin{array}{l}4 \\
\text { (vocabulary, } \\
\text { books ) }\end{array}$ & 2 (essays) & none & 21 \\
\hline Student 5 & $\begin{array}{l}11 \text { (VOA } \\
\text { news English } \\
\text { songs) }\end{array}$ & $\begin{array}{l}15 \text { (tutoring, } \\
\text { attend extra } \\
\text { speaking } \\
\text { classes } \\
\text { taught by } \\
\text { foreign } \\
\text { teachers, } \\
\text { practising at } \\
\text { home with } \\
\text { family } \\
\text { members) }\end{array}$ & $\begin{array}{l}7 \text { (Online } \\
\text { English } \\
\text { news, } \\
\text { magazines) }\end{array}$ & $\begin{array}{l}4 \text { (diaries, } \\
\text { reflections) }\end{array}$ & none & 37 \\
\hline Student 6 & $\begin{array}{l}6 \text { (English } \\
\text { songs, } \\
\text { movies in } \\
\text { English) }\end{array}$ & $\begin{array}{l}1 \text { (talking to } \\
\text { foreigners) }\end{array}$ & $\begin{array}{l}7 \\
\text { (vocabulary, } \\
\text { online news } \\
\text { in English) } \\
\end{array}$ & 2 (blogs) & none & 16 \\
\hline Student 7 & $\begin{array}{l}3 \text { (English } \\
\text { songs) }\end{array}$ & none & $\begin{array}{l}10 \\
\text { (Vietnamese } \\
\text { newspaper in } \\
\text { English) }\end{array}$ & $\begin{array}{l}1 \text { (emailing } \\
\text { foreigners or } \\
\text { friends in } \\
\text { English) }\end{array}$ & $\begin{array}{l}8 \text { (grammar } \\
\text { books) }\end{array}$ & 22 \\
\hline Student 8 & $\begin{array}{l}5 \text { (movies in } \\
\text { English) }\end{array}$ & $\begin{array}{l}1 \text { (working } \\
\text { as a tour- } \\
\text { guide) }\end{array}$ & $\begin{array}{l}3 \text { (journals in } \\
\text { English) }\end{array}$ & $\begin{array}{l}1 \text { (practising } \\
\text { paragraph } \\
\text { writing) }\end{array}$ & none & 10 \\
\hline Student 9 & $\begin{array}{l}4 \text { (English } \\
\text { songs, } \\
\text { movies in } \\
\text { English) }\end{array}$ & $\begin{array}{l}7 \text { (talking to } \\
\text { foreigners } \\
\text { coming to } \\
\text { family shop, } \\
\text { tutoring) }\end{array}$ & $\begin{array}{l}8 \\
\text { (Vietnamese } \\
\text { newspaper in } \\
\text { English) }\end{array}$ & none & $\begin{array}{l}14 \text { (part-time } \\
\text { job at an } \\
\text { export } \\
\text { company) }\end{array}$ & 33 \\
\hline $\begin{array}{l}\text { Total hours } \\
\text { in } 14 \text { days }\end{array}$ & 52 & 28 & 52 & 15 & 28 & 175 \\
\hline $\begin{array}{l}\text { Average time } \\
\text { spent per } \\
\text { student in } 14 \\
\text { days }\end{array}$ & 5.7777 & 3.1111 & 5.7777 & 1.6666 & 3.1111 & 19.4444 \\
\hline $\begin{array}{l}\text { Average time } \\
\text { spent per } \\
\text { student per } \\
\text { day }\end{array}$ & 0.4126 & 0.2222 & 0.4126 & 0.1190 & 0.2222 & 1.3886 \\
\hline
\end{tabular}


Table 4.10: Time and Range of Out-of-Class Activities by Bottom Students

\begin{tabular}{|c|c|c|c|c|c|c|}
\hline $\begin{array}{l}\text { Bottom } \\
\text { students }\end{array}$ & $\begin{array}{l}\text { Time on } \\
\text { listening } \\
\text { (hours) }\end{array}$ & $\begin{array}{l}\text { Time on } \\
\text { speaking } \\
\text { (hours) }\end{array}$ & $\begin{array}{l}\text { Time on } \\
\text { reading } \\
\text { (hours) }\end{array}$ & $\begin{array}{l}\text { Time on } \\
\text { writing } \\
\text { (hours) }\end{array}$ & $\begin{array}{l}\text { Time on } \\
\text { grammar } \\
\text { and others } \\
\text { (hours) }\end{array}$ & $\begin{array}{l}\text { Total time in } \\
14 \text { days } \\
\text { (hours) }\end{array}$ \\
\hline Student 1 & $\begin{array}{l}2 \text { (TOEIC } \\
\text { tests, English } \\
\text { songs) }\end{array}$ & none & $\begin{array}{l}1 \text { (newspaper } \\
\text { in English) }\end{array}$ & $\begin{array}{l}1 \text { (search } \\
\text { writing } \\
\text { materials on } \\
\text { Internet, } \\
\text { exercises in } \\
\text { course- } \\
\text { books) }\end{array}$ & $\begin{array}{l}2 \text { (exercises } \\
\text { in course- } \\
\text { books) }\end{array}$ & 6 \\
\hline Student 2 & $\begin{array}{l}5 \text { (TOEIC } \\
\text { tests, English } \\
\text { songs) }\end{array}$ & none & $\begin{array}{l}4 \\
\text { (vocabulary, } \\
\text { newspaper in } \\
\text { English) } \\
\end{array}$ & none & $\begin{array}{l}4 \text { (exercises } \\
\text { in course- } \\
\text { books) }\end{array}$ & 13 \\
\hline Student 3 & $\begin{array}{l}4 \text { (TOEIC } \\
\text { tests, English } \\
\text { songs, BBC } \\
\text { news) }\end{array}$ & $\begin{array}{l}1 \text { (talking to } \\
\text { classmates in } \\
\text { English) }\end{array}$ & $\begin{array}{l}2 \text { (topics of } \\
\text { interest } \\
\text { (tourism), } \\
\text { newspaper in } \\
\text { English) }\end{array}$ & $\begin{array}{l}1 \text { (writing } \\
\text { about topics } \\
\text { of interest) }\end{array}$ & $\begin{array}{l}6 \text { (exercises } \\
\text { in course- } \\
\text { books) }\end{array}$ & 14 \\
\hline Student 4 & $\begin{array}{l}9 \text { (TOEIC } \\
\text { tests, CDs of } \\
\text { reference } \\
\text { books) }\end{array}$ & $\begin{array}{l}1 \text { (voiced } \\
\text { chat with } \\
\text { foreign } \\
\text { friends) }\end{array}$ & $\begin{array}{l}5 \\
\text { (vocabulary, } \\
\text { books about } \\
\text { cultures) }\end{array}$ & none & none & 15 \\
\hline Student 5 & none & $\begin{array}{l}4 \\
\text { (homework) }\end{array}$ & $\begin{array}{l}7 \\
\text { (vocabulary, } \\
\text { short stories) } \\
\end{array}$ & $\begin{array}{l}14.5 \\
\text { (homework) }\end{array}$ & none & 25.5 \\
\hline Student 6 & $\begin{array}{l}1 \text { (English } \\
\text { songs) }\end{array}$ & none & none & $\begin{array}{l}3.5 \\
\text { (homework) }\end{array}$ & none & 4.5 \\
\hline Student 7 & none & $\begin{array}{l}7 \text { (tutoring, } \\
\text { homework) }\end{array}$ & $\begin{array}{l}2 \\
\text { (vocabulary, } \\
\text { newspaper in } \\
\text { English) }\end{array}$ & none & none & 9 \\
\hline $\begin{array}{l}\text { Total hours } \\
\text { in } 14 \text { days }\end{array}$ & 21 & 13 & 21 & 20 & 12 & 87 \\
\hline $\begin{array}{l}\text { Average time } \\
\text { spent per } \\
\text { student in } 14 \\
\text { days }\end{array}$ & 3 & 1.8571 & 3 & 2.8571 & 1.7142 & 12.428 \\
\hline $\begin{array}{l}\text { Average time } \\
\text { spent per } \\
\text { student per } \\
\text { day }\end{array}$ & 0.2142 & 0.1326 & 0.2142 & 0.2040 & 0.1224 & 0.8874 \\
\hline
\end{tabular}


Table 4.11: Out-of-Class Activities and Self-Regulation by Top Students

\begin{tabular}{|c|c|c|c|c|}
\hline Top students & $\begin{array}{l}\text { Number of } \\
\text { activities } \\
\text { undertaken in } \\
14 \text { days }\end{array}$ & $\begin{array}{l}\text { Number of } \\
\text { activities for } \\
\text { which monitoring } \\
\text { of problems and } \\
\text { solutions was } \\
\text { conducted }\end{array}$ & $\begin{array}{l}\text { Number of } \\
\text { activities for } \\
\text { which } \\
\text { monitoring of } \\
\text { strategies was } \\
\text { conducted }\end{array}$ & $\begin{array}{l}\text { Number of } \\
\text { activities for } \\
\text { which } \\
\text { evaluating of } \\
\text { task } \\
\text { completion was } \\
\text { conducted }\end{array}$ \\
\hline Student 1 & 10 & 6 & 7 & 8 \\
\hline Student 2 & 8 & 6 & 5 & 8 \\
\hline Student 3 & 20 & 13 & 15 & 18 \\
\hline Student 4 & 17 & 10 & 13 & 17 \\
\hline Student 5 & 31 & 27 & 26 & 29 \\
\hline Student 6 & 9 & 8 & 6 & 9 \\
\hline Student 7 & 20 & 10 & 15 & 20 \\
\hline Student 8 & 10 & 8 & 7 & 9 \\
\hline Student 9 & 29 & 24 & 25 & 28 \\
\hline $\begin{array}{l}\text { Average number of } \\
\text { activities in } 14 \text { days per } \\
\text { student }\end{array}$ & 17.1 & 12.4 & 13.2 & 16.2 \\
\hline
\end{tabular}

Table 4.12: Out-of-class Activities and Self-Regulation by Bottom Students

\begin{tabular}{|c|c|c|c|c|}
\hline Bottom students & $\begin{array}{l}\text { Number of } \\
\text { activities } \\
\text { undertaken in } \\
14 \text { days }\end{array}$ & $\begin{array}{l}\text { Number of } \\
\text { activities for } \\
\text { which monitoring } \\
\text { of problems and } \\
\text { solutions was } \\
\text { conducted }\end{array}$ & $\begin{array}{l}\text { Number of } \\
\text { activities for } \\
\text { which } \\
\text { monitoring of } \\
\text { strategies was } \\
\text { conducted }\end{array}$ & $\begin{array}{l}\text { Number of } \\
\text { activities for } \\
\text { which } \\
\text { evaluating of } \\
\text { task } \\
\text { completion was } \\
\text { conducted }\end{array}$ \\
\hline Student 1 & 10 & 5 & 4 & 9 \\
\hline Student 2 & 13 & 7 & 4 & 13 \\
\hline Student 3 & 16 & 7 & 6 & 16 \\
\hline Student 4 & 12 & 8 & 6 & 12 \\
\hline Student 5 & 20 & 12 & 9 & 20 \\
\hline Student 6 & 8 & 2 & 5 & 8 \\
\hline Student 7 & 18 & 10 & 7 & 18 \\
\hline $\begin{array}{l}\text { Average number of } \\
\text { activities in } 14 \text { days per } \\
\text { student }\end{array}$ & 13.8 & 7.2 & 5.8 & 13.7 \\
\hline
\end{tabular}


Table 4.13 presents a summary of a record of the amount of time spent on out-ofclass activities, and the number of activities in which self-regulation skills were practised by nine top and seven bottom students. The number of out-of-class activities students engaged in within two weeks (14 days), and the amount of time they devoted to each activity were counted. The average amount of time each student spent learning outside the classroom per day was then calculated. The activities were also classified into listening, speaking, reading and writing. Each skill-related activity was counted to determine the percentage of time each student spent learning a certain skill per day. In addition, based on the total number of activities each student undertook during the two weeks, the proportion of activities which he or she monitored and evaluated was also calculated. It should be noted that planning was excluded from the out-of-class learning logs because the researcher intended to explore this selfregulation skill with in-class activities.

Table 4.13: Time and Use of Self-Regulation for Out-of-Class Activities

\begin{tabular}{llll}
\hline \multirow{2}{*}{$\begin{array}{l}\text { Time spent and number of activities for which self- } \\
\text { regulation skills were used }\end{array}$} & $\begin{array}{l}\text { Top students } \\
(\mathbf{N}=\mathbf{9})\end{array}$ & $\begin{array}{l}\text { Bottom } \\
\text { students (N=7) }\end{array}$ \\
\hline \multirow{2}{*}{$\begin{array}{l}\text { Out-of- } \\
\text { class } \\
\text { activities }\end{array}$} & Total learning time per day & 1.3 hours & 0.8 hours \\
\cline { 2 - 4 } & Time spent on Listening & $0.4(30.7 \%)$ & $0.2(25 \%)$ \\
\cline { 2 - 4 } & Time spent on Speaking & $0.2(15.3 \%)$ & $0.1(12.5 \%)$ \\
\cline { 2 - 4 } & Time spent on Reading & $0.4(30.7 \%)$ & $0.2(25 \%)$ \\
\cline { 2 - 4 } & Time spent on Writing & $0.1(7.6 \%)$ & $0.2(25 \%)$ \\
\cline { 2 - 4 } Self- & Time spent on other E. learning related activities & $0.2(15.3 \%)$ & $0.1(12.5 \%)$ \\
\cline { 2 - 4 } regulation & Total number of activities per student in 14 days & 17.1 & 13.8 \\
\cline { 2 - 4 } & Monitoring problems and solutions & $12.4(72.5 \%)$ & $7.2(52.1 \%)$ \\
\cline { 2 - 4 } & Monitoring strategies & $13.2(77.1 \%)$ & $5.8(42 \%)$ \\
\hline
\end{tabular}

The data drawn from the logs were both interesting and informative. The logs displayed almost the same differences between top and bottom students as revealed by the interviews. First of all, each top student spent more time on out-of-class activities, nearly one and a half hours per day (1.388 hours) while each bottom student devoted only about an hour (0.887 hours) every day to learning English outside classroom. On top of that, top students voluntarily carried out more activities 
than bottom students. On average, top students willingly undertook 17.1 activities over 14 days, while bottom students only engaged in 13.8 activities for the same period of time. The activities they performed also varied. The logs showed that top students had the motivation to engage in a range of activities not only for a study purpose but also for pleasure such as writing diary entries, reflections, and blogs in English. Bottom students, on the contrary, focused much more on doing homework and preparing for the coming lessons. In this regard, this finding was similar to the finding from the interviews.

As far as the language skills were concerned, both groups of students carried out more receptive activities (such as listening to English songs, movies or radio, and reading newspapers, or learning vocabulary) than productive activities (Figures 4.4 and 4.5). The logs showed that TOEIC test was very popular among bottom students (it is very popular in Vietnam in general). While the purpose of the TOEIC test is to test English language proficiency of people who need English for their jobs, bottom students used it as a source of materials to improve listening skill. In this respect, bottom students were practical learners of English because obtaining a TOEIC score was a must for job seekers at banks, airports, or foreign companies where people in Vietnam normally would receive good salaries. Top students listened to more challenging sources of English such as the radio while bottom students did not do this at all.

Additionally, it is clear from the logs that both groups of students associated learning reading with learning vocabulary. This was witnessed by the amount of time they spent on learning new vocabulary. In fact, students devoted more time to learning new words than engaging in other types of reading such as reading journals or books for pleasure. However, both groups of learners enjoyed reading news from the internet. A couple of top students liked reading short stories in English.

Neither top students nor bottom students spent much time on productive skill activities. Bottom students, however, spent more time (25\%) than top students (7.6\%) on writing activities. As for other English learning-related activities, top students tended to undertake more challenging activities such as tutoring English to junior learners of English after class time, working as a volunteer tour-guide, taking a course conducted by foreign teachers of English, and writing their own blogs, diaries, and reflections in English while bottom students almost all focussed on doing their homework as a way of improving those productive skills. 
Figure 4.4: Time Spent on Out-Of-Class Activities by Top Students

Time spent by TOP students on language skill activities

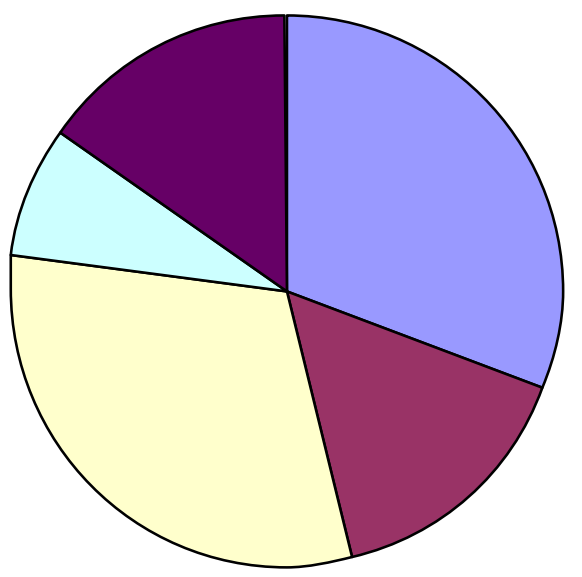

Figure 4.5: Time Spent on Out-Of-Class Activities by Bottom Students

\section{Time spent by BOTTOM students on language skill} activities

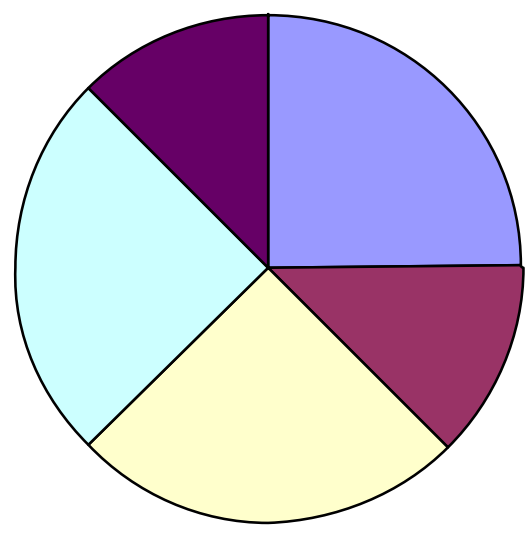

$\square$ Listening

$\square$ Speaking

$\square$ Reading

$\square$ Writing

Other activities

In terms of self-regulation, it was revealed that students monitored and evaluated their work. Again differences between top and bottom students existed (Figure 4.6). Top students surpassed bottom students in monitoring but bottom students did more evaluation than top students. For instance, out of the 17.1 activities they carried out within the two weeks, top students monitored their problems and offered solutions to their problems for 12.4 activities, equivalent to $72.5 \%$. For this 
same category, bottom students only monitored half $(52.1 \%)$ of the 13.8 activities they engaged in. As for monitoring strategies, top students were very well aware of the strategies used for a certain activity. They monitored $77.1 \%$ of the 17.1 activities whereas bottom students did not think much about their strategies. Bottom students, thus monitored their strategies for 5.8 activities (42\%) out of the total of 13.8 activities. It was interesting to discover that both top and bottom students always evaluated their work. More interestingly, bottom students evaluated a little more than top students. In fact, $99 \%$ of their activities were evaluated by bottom students while top students evaluated their activities slightly less, $98.2 \%$.

Figure 4.6: Percentage of Self-Regulation Skills Used for Out-Of-Class Activities

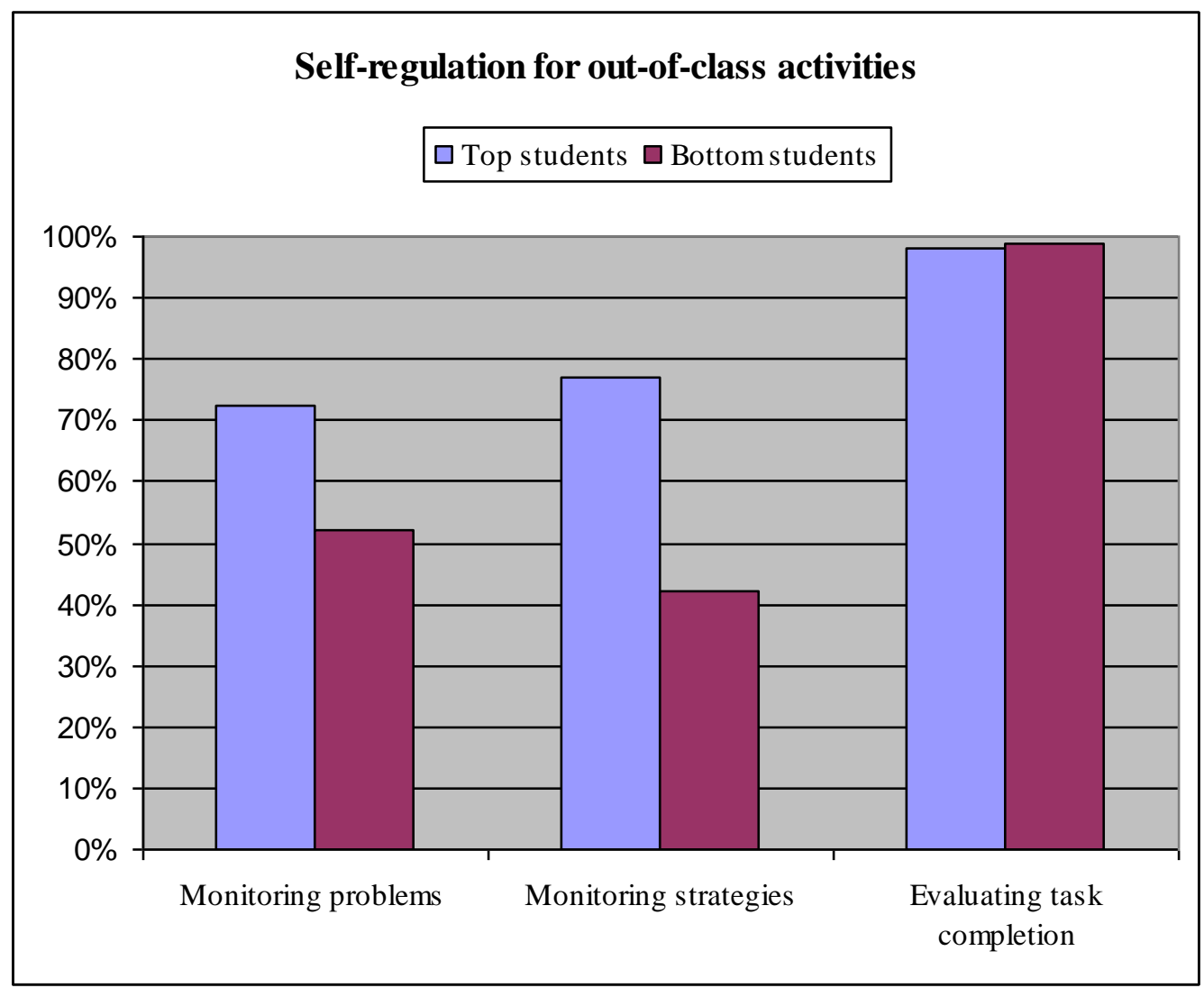

\subsection{In-class learning}

Tables 4.14 and 4.15 present information on the number of activities top and bottom students performed respectively in two writing classes, and the number of activities for which they used the self-regulation skills of planning, monitoring and evaluating. Table 4.16 is a summary of Tables 4.14 and 4.15 . 
Table 4.14: In-Class Activities and Self-Regulation by Top Students

\begin{tabular}{|c|c|c|c|c|c|}
\hline $\begin{array}{l}\text { Top } \\
\text { students }\end{array}$ & $\begin{array}{l}\text { Number of } \\
\text { activities } \\
\text { undertaken in } \\
14 \text { days }\end{array}$ & $\begin{array}{l}\text { Number of } \\
\text { activities for } \\
\text { which } \\
\text { planning was } \\
\text { conducted }\end{array}$ & $\begin{array}{l}\text { Number of } \\
\text { activities for } \\
\text { which } \\
\text { monitoring of } \\
\text { problems and } \\
\text { solutions was } \\
\text { conducted }\end{array}$ & $\begin{array}{l}\text { Number of } \\
\text { activities for } \\
\text { which } \\
\text { monitoring of } \\
\text { strategies was } \\
\text { conducted }\end{array}$ & $\begin{array}{l}\text { Number of } \\
\text { activities for } \\
\text { which } \\
\text { evaluating of } \\
\text { task } \\
\text { completion } \\
\text { was conducted }\end{array}$ \\
\hline Student 1 & 4 & 3 & 3 & 4 & 4 \\
\hline Student 2 & 5 & 3 & 3 & 5 & 5 \\
\hline Student 3 & 6 & 3 & 3 & 6 & 6 \\
\hline Student 4 & 6 & 3 & 4 & 6 & 6 \\
\hline Student 5 & 12 & 5 & 5 & 12 & 12 \\
\hline Student 6 & 5 & 4 & 4 & 5 & 5 \\
\hline Student 7 & 6 & 3 & 4 & 6 & 6 \\
\hline Student 8 & 7 & 3 & 4 & 7 & 7 \\
\hline Student 9 & 9 & 4 & 5 & 9 & 9 \\
\hline $\begin{array}{l}\text { Average } \\
\text { number of } \\
\text { in-class } \\
\text { activities of } \\
2 \text { classes }\end{array}$ & 6.6 & 3.4 & 3.8 & 6.6 & 6.6 \\
\hline
\end{tabular}

Table 4.15: In-Class Activities and Self-Regulation by Bottom Students

\begin{tabular}{llllll}
\hline & $\begin{array}{l}\text { Number of } \\
\text { activities } \\
\text { Top students } \\
\text { 14 days }\end{array}$ & $\begin{array}{l}\text { Number of } \\
\text { activities for } \\
\text { which planning } \\
\text { was conducted }\end{array}$ & $\begin{array}{l}\text { Number of } \\
\text { activities for } \\
\text { which } \\
\text { monitoring of } \\
\text { problems and } \\
\text { solutions was } \\
\text { conducted }\end{array}$ & $\begin{array}{l}\text { Number of } \\
\text { activities } \\
\text { for which } \\
\text { monitoring } \\
\text { of } \\
\text { strategies } \\
\text { was } \\
\text { conducted }\end{array}$ & $\begin{array}{l}\text { Number of } \\
\text { activities } \\
\text { for which } \\
\text { evaluating } \\
\text { of task } \\
\text { completion } \\
\text { was } \\
\text { conducted }\end{array}$ \\
\hline Student 1 & 3 & 2 & 2 & 3 \\
\hline Student 2 & 4 & 2 & 2 & 3 & 4 \\
\hline Student 3 & 3 & 2 & 2 & 3 & 3 \\
\hline Student 4 & 5 & 2 & 2 & 5 & 5 \\
\hline Student 5 & 6 & 2 & 3 & 3 & 3 \\
\hline Student 6 & 3 & 2 & 2 & 3 & 4 \\
\hline Student 7 & 4 & 2 & & 3.2 & 4 \\
\hline $\begin{array}{l}\text { Average } \\
\text { number of in- } \\
\text { class activities } \\
\text { of 2 classes }\end{array}$ & 4 & & 2.1 & & 6 \\
\hline
\end{tabular}


Table 4.16: Summary of Self-Regulation for In-Class Activities

\begin{tabular}{lll}
\hline Self-regulation for in-class activities & Top students (N=9) & Bottom students (N=7) \\
\hline Number of activities per student in 2 classes & 6.6 & 4.0 \\
\hline Planning & $3.4(51.5 \%)$ & $2.0(50 \%)$ \\
\hline Monitoring of problems and solutions & $3.8(57.5 \%)$ & $2.1(52.5 \%)$ \\
\hline Monitoring of strategies & $6.6(100 \%)$ & $3.2(80 \%)$ \\
\hline Evaluating of task completion & $6.6(100 \%)$ & $4.0(100 \%)$ \\
\hline
\end{tabular}

Table 4.16 shows that during class time, top students also performed more activities than bottom students. The figure for the former was 6.6. The figure for the latter was 4. In terms of planning, there was almost no difference between top and bottom students. Top students planned for 3.4 activities out of 6.6 activities they performed in class. That was $51.5 \%$. Bottom students planned for two activities out of the total of four, exactly half (50\%) of all activities they performed. However, careful examination of the students' learning logs indicated that top students planned more carefully for the tasks by putting down more details of what they would write. For example, in one task, students were asked to write a story from the perspective of the opposite sex. To plan for this task, one of the top students listed the following:

- thinking of the content of the story

- reading the sample story a few times and paying attention to the clues

- putting myself in the shoes of the opposite sex

- looking up words in dictionary

- discussing with other students (TTDA, Top student, In-class logs, 24/05/07).

Bottom students, on the other hand, while planning, spent a lot of time looking up words in the dictionary and tried to find appropriate words they would use to write the story. To illustrate, one bottom student recorded the following activities in her logs:

- carefully reading the instructions of the task

- looking up words in the dictionary (NTH, Bottom student, In-class logs, 18/05/07).

Another student wrote in Vietnamese first and translated the sentences into English: 
... my group used Vietnamese to write down our ideas and then translated them into English...(DTKA, Bottom student, In-class logs, 14/05/07).

Top students monitored their problems and solutions slightly more than bottom students. To illustrate, $57.5 \%$ of the tasks were monitored by top students to determine if they had difficulty doing the task and how they could deal with their problems. Bottom students, however, did a little less monitoring for problems (52.5\%). Top students monitored strategy use for every task they were doing. To put it another way, $100 \%$ of the tasks were checked for the appropriateness of strategy. The figure for bottom students was $80 \%$. All students evaluated the task completion for all the activities they were carrying out. The differences in self-regulation for inclass activities performed by top and bottom students can be seen in Figure 4.7.

Figure 4.7: Percentage of Self-Regulation Skills Used for In-Class Activities

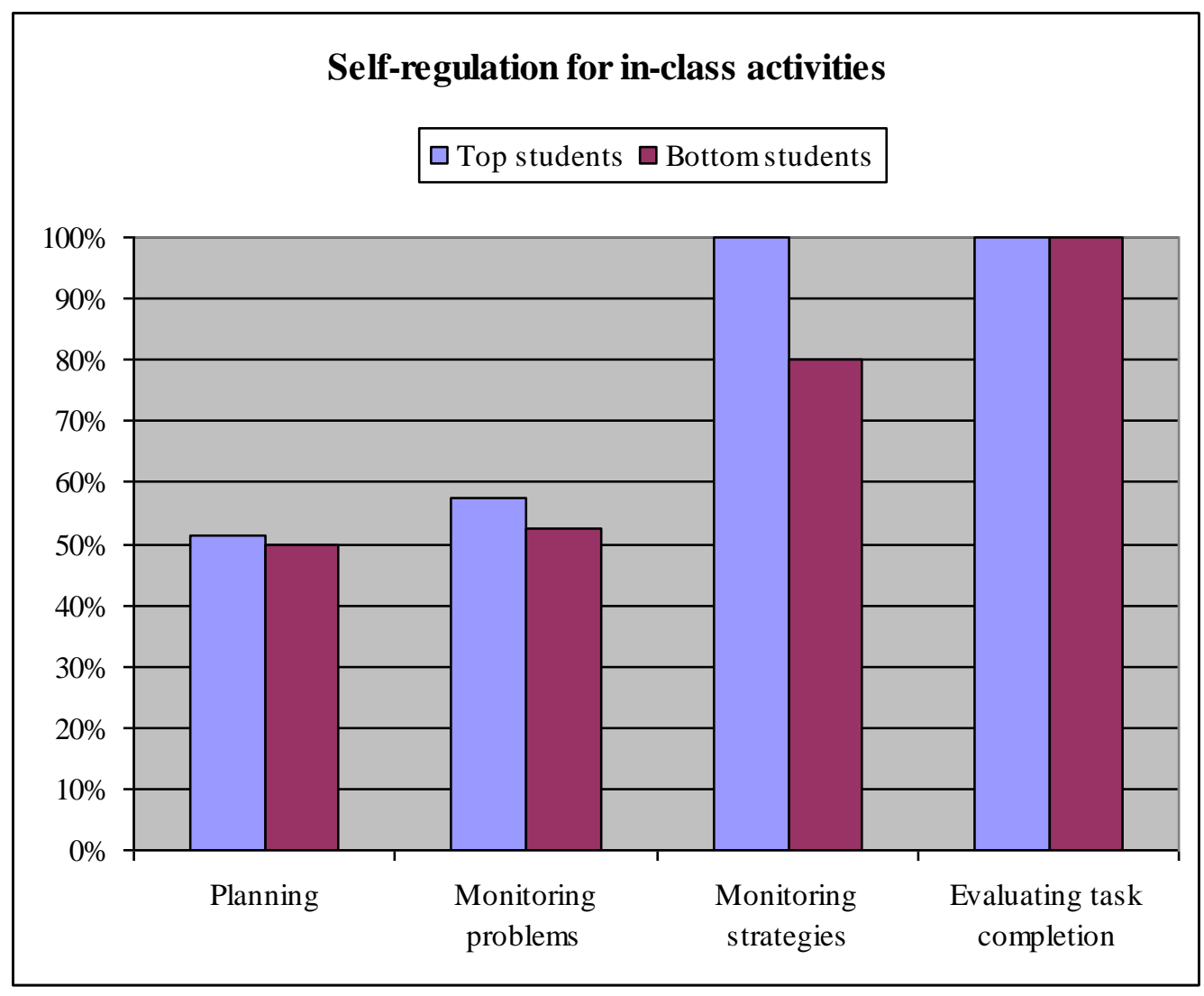

It was shown by the students' learning logs that they monitored strategies for in-class tasks more than for out-of class ones. This is understandable because due to the 
group-work nature of the in-class tasks that the teachers asked students to do, almost all of them turned to their group members as the best resource to get the tasks done. The most popular activity was discussing with peers. A couple of students asked their teacher for help, used the dictionary, or spent more time reading sample writing provided by the teacher. As for the monitoring of problems and solutions, top students did it more for their out-of-class activities than for in-class (72\% and 57\% respectively) while the figure for bottom students remained unchanged (52\%) no matter where the activities or the tasks took place. This was an interesting point, and the interpretation could be connected to the fact that top students might need to be on their own in order to recognise and find solutions to their problems. This finding supports what Aoki and Smith (1999), and Smith (2001) discovered about Japanese students who preferred learning on their own rather than learning with their peers.

In terms of the resources for out-of-class activities, it was discovered that students used course books, reference books, stories, CDs, newspapers, and the internet a lot more than they used human support. Only a couple of students used human support such as asking classmates or talking to a teacher.

\subsection{Limitations of the analysis of the learning logs}

The analysis of the students' learning logs was based on the number of occurrences out-of-class and in-class activities, and the extent to which self-regulation skills were used for those activities. This provided a rich source of information about the differences between top and bottom students. However, some weaknesses existed. Firstly, the differences among group members in each group were unknown. For example, while one bottom student planned for all the activities she or he initiated, another bottom student might have planned for one or two among the many activities done. Secondly, some students listened to music for a relaxation purpose, thus, they did not write in the column under "Did you have any difficulty completing it? If yes, what was your solution? How well did it work for you?" for monitoring, and "How well did you do it? How did you know?" or "What improvement would you like to make next time?" for evaluating. However, listening to music was counted as one activity where they were expected to answer questions about metacognitive selfmanagement. Listening to music was considered by students as a relaxing activity, not as a learning activity. Therefore, they did not either monitor or evaluate it. Thirdly, 
for out-of-class activities, some students did not face any problems while doing them; they, accordingly, did not write anything in the column under monitoring problems and solutions. Other students could have problems but did not really want to write them in the $\log$ forms provided. One more issue was linked to students misunderstanding of what they were supposed to write in their logs. In fact, many students, instead of noting down the strategies they had actually used to do the tasks, wrote about strategies they would use, or other self-modifying actions they would take in the future. In this regard, students associated current learning strategies with future self-modifying actions. The other weakness of the learning logs was connected with the 'learning vocabulary' activity. Once students put 'learning vocabulary' in their logs, they did not write about how they learned and how many words they learned, and whether or not they performed it well. Consequently, the monitoring and evaluating of this activity were ignored.

\subsubsection{General patterns from interviews and learning logs}

Both the interviews and the learning logs have provided insights into the differences in LA between top and bottom students. On the basis of the findings, it could be claimed that both groups of students were autonomous learners of English because they all practised self-initiation and self-regulation though at different levels. However, top students demonstrated greater LA than bottom students. The differences between them showed up in the number, the range, the level of challenge of activities, and the way they approached the task. This finding bears out what $\mathrm{Gu}$ (1994) found in his study on strategies employed by good and poor Chinese learners of English.

\subsection{Conclusion}

The pilot study achieved its aims. The research instruments, the designs of the interviews, the learning logs and the questionnaire all worked. The three sources of data provided the researcher with rich data. Most importantly, several new categories were generated from the interviews and the learning logs. The newly-created questions were of value to the questionnaire, the main research instrument for the following stages of the study. Specifically, seven supplementary questions were 
added to the questionnaire thanks to the bottom-up approach to gathering data. However, the questionnaire needed revising on the basis of the information collected from the interviews, and the learning logs before it could be used again.

The answers to the research questions were also found. Firstly, the results of the questionnaire indicated that Vietnamese English majors demonstrated various aspects of LA. According to the preliminary results, they exercised the self-regulatory behaviours a little more than initiating activities to improve their English. It was found that planning was the most often practised self-regulatory skill, yet only general planning was exercised. Monitoring and evaluating were not sufficiently practised.

Secondly, the initial finding showed a positive correlation between LA and general language proficiency. More specifically, out-of-class activities, monitoring and evaluating positively influenced language proficiency. The unexpected result of planning, leaving a negative impact (not significant) on students' language proficiency, was found to be linked to the participants being asked only about their general planning behaviours, not task-specific behaviours. Nevertheless, the positive correlation between language proficiency and some aspects of LA found in this phase of the study was very encouraging.

Thirdly, it was revealed that third-year students who would graduate from the university the soonest were the least autonomous compared with second- and firstyear students. This implies that some training on LA should be conducted as soon as possible to help counter-balance the pressures on students during their period of university study.

Fourthly, a significant difference in LA between students at a private university and a state-run university was not discovered, although the students at the former were numerically more autonomous than their counterparts at the latter. This could be indicative of LA possibly being affected by the social context.

Finally, the Vietnamese English majors were autonomous in different ways. Top students were more autonomous than bottom students. The differences were found in the number, the range, and the level of difficulty of activities, and the way students approached the tasks. 


\section{PHASE ONE ${ }^{2}$}

The first phase lasted from November 2007 to January 2008. This phase of the study was intended to answer research questions four and five as outlined in section 1.4. However, while data analysis was being conducted, the point about ranking popular out-of-class and in-class activities emerged. Therefore, Phase one sought to specifically address the following questions:

1. Are Vietnamese undergraduate students of English autonomous learners?

2. What are the most popular learner self-initiated out-of-class and in-class activities performed by these Vietnamese students?

3. What is the relationship between LA and these Vietnamese students' English language proficiency?

\subsection{Data analysis}

The data were submitted to SPSS 14.0 for analysis. Research questions one and two were addressed mainly by observing the mean scores of the major LA constructs and those of out-of-class and in-class activities respectively. To answer research question three, correlation coefficients between LA constructs and EFL proficiency measures were presented and analysed. The data from the resulting new questionnaire $(\mathrm{N}=177$, 0-4 Likert scale ${ }^{3}$ ) were submitted to SPSS for Pearson correlation analysis which examined the relationship between LA and language proficiency.

\subsection{Findings}

The findings are organised around the research questions mentioned above.

\footnotetext{
2 The results of this phase were reported in the following article:

Nguyen, T. C. L. (2008). Learner autonomy and EFL proficiency: A Vietnamese perspective. Asian Journal of English Language Teaching, 18, 67-87.

${ }^{3}$ The range of the Likert scale used in Phase 1 was from 0-4.
} 


\subsubsection{LA among Vietnamese undergraduate EFL students}

Table 5.1 presents basic descriptive statistics of the main elements of LA demonstrated by Vietnamese undergraduates. Firstly, regarding reasons for learning English, these Vietnamese English majors were learning English mostly because they were interested in the English language (intrinsic interest, Mean=3.20), followed by their hope of finding a job in the future (individual development, Mean=3.05) and the possibility of going abroad (going abroad, Mean=2.50). The last reason also had the largest standard deviation $(\mathrm{SD}=1.12)$, indicating that these students differed considerably in choosing going abroad as a motivating factor. Secondly, regarding the effort students made to learn English, the figures indicated that in-class covert language learning behaviours were practised most frequently (Mean=2.98), about four or five times per week by undergraduate English-majors.

Table 5.1: Mean Scores of LA Constructs

\begin{tabular}{|c|c|c|c|c|c|}
\hline Elements of LA & & & $\mathbf{N}$ & $\mathbf{M}$ & SD \\
\hline \multirow{7}{*}{ Self- initiation } & Reasons for & Individual development & 175 & 3.05 & .70 \\
\hline & learning & Intrinsic interest & 174 & 3.20 & .77 \\
\hline & English & Going abroad & 174 & 2.50 & 1.12 \\
\hline & \multirow{4}{*}{$\begin{array}{l}\text { Making efforts } \\
\text { to learn English }\end{array}$} & Learning English outside classroom & 176 & 1.80 & .67 \\
\hline & & Using English outside classroom & 172 & 1.13 & .78 \\
\hline & & Overt language learning in class & 174 & .85 & .65 \\
\hline & & Covert language learning in class & 172 & 2.98 & .71 \\
\hline \multirow{4}{*}{ Self-regulation } & & General planning & 176 & 2.24 & .76 \\
\hline & & Task-specific planning & 174 & 2.67 & .81 \\
\hline & & Monitoring & 170 & 2.15 & .72 \\
\hline & & Evaluating & 172 & 2.32 & .72 \\
\hline
\end{tabular}

The figure (2.98 out of 4.0) clearly shows that these Vietnamese undergraduates made a lot of effort to learn English in class in a covert manner. This feature may be typical of Vietnamese students who prefer keeping their thoughts to themselves to speaking out in public. In-class overt language learning behaviours, consequently, were exercised the least (Mean=0.85) due to Vietnamese students' preference for covert learning. Furthermore, they did try to learn English out of class $($ Mean=1.80) but did not make much effort to use it outside the classroom (Mean=1.13). Thirdly, in terms 
of self-management, students did task-specific planning often (Mean=2.67), about four times per week, followed by evaluating (Mean=2.32), general planning (Mean=2.24) and monitoring (Mean=2.15) which were each used about three times per week. Table 5.1 is converted into Figure 5.1 for easier interpretation.

Figure 5.1: Mean Scores of LA aspects

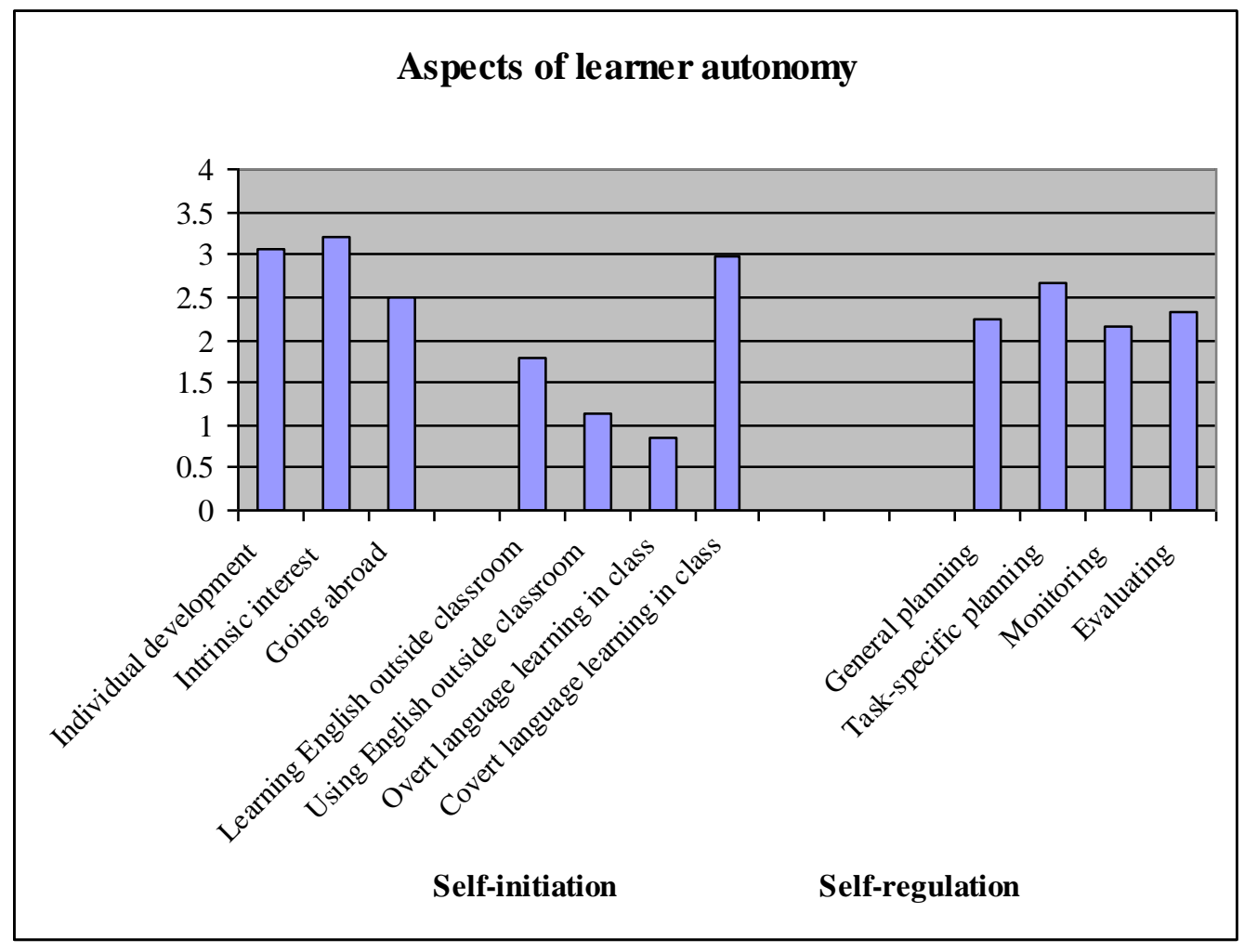

It can be concluded so far that the Vietnamese learners in this study were very motivated to learn English, but their learning efforts mainly concentrated on covert learning in class. They were generally able to manage their own learning. However, there is definitely room for improvement in terms of self-regulation strategies.

\subsubsection{The most popular activities among Vietnamese students}

As can be seen from Tables 5.2 and 5.3, the top five out-of-class Learning activities and out-of-class Using activities that survey respondents indicated they engaged in involved receptive rather than productive language use. As Table 5.2 indicates, the Vietnamese learners did not make use of the Internet or self-learning centres to improve their English outside class. Neither did they participate in activities that 
required social interaction such as joining English speaking clubs or seeing teachers about their work. The five least popular activities in which learners could practise using English as shown by Table 5.3 included joining forum discussions on topics of their interest, doing part-time jobs for which communication in English was a prerequisite, spending time with volunteer teachers of English, participating in youth events such as meeting and showing international students around the city, and writing their blogs in English. When the Vietnamese learners used English in a nonclassroom setting, again, they tended to avoid social interaction.

Table 5.2: Ranking of Out-of-Class Learning English Activities

\begin{tabular}{|c|c|c|c|}
\hline Out-of-class Learning English Activities & $\mathbf{N}$ & $\mathbf{M}$ & SD \\
\hline I note down new words and their meanings when I read or listen. & 177 & 2.86 & .897 \\
\hline I do extra revision not required by the teacher. & 177 & 2.06 & 1.043 \\
\hline $\begin{array}{l}\text { I do some reading in English for my pleasure such as English literature, } \\
\text { topics of my interest. }\end{array}$ & 176 & 1.99 & 1.058 \\
\hline I keep portfolios of what I have learnt to monitor my progress. & 177 & 1.96 & 1.404 \\
\hline $\begin{array}{l}\text { I read books (materials) about how to become a successful language } \\
\text { learner. }\end{array}$ & 177 & 1.92 & 1.041 \\
\hline I read grammar books on my own. & 176 & 1.86 & .875 \\
\hline I do assignments which are not compulsory. & 177 & 1.86 & .884 \\
\hline I collect texts in English (e.g., articles, brochures, labels etc.). & 177 & 1.84 & 1.129 \\
\hline I study English in a group of my classmates or friends. & 174 & 1.80 & 1.070 \\
\hline I use online English-learning programmes to study English. & 177 & 1.68 & 1.169 \\
\hline $\begin{array}{l}\text { I go to English-speaking clubs (held at my university or elsewhere) to } \\
\text { practise my English. }\end{array}$ & 177 & 1.32 & 1.311 \\
\hline I do independent study in a library/self-learning centre. & 177 & 1.27 & 1.051 \\
\hline I go to see my English teachers about my work. & 177 & 1.24 & 1.007 \\
\hline
\end{tabular}


Table 5.3: Ranking of Out-of-Class Using English Activities

\begin{tabular}{|c|c|c|c|}
\hline Out-of-class Using English Activities & $\mathbf{N}$ & $\mathbf{M}$ & SD \\
\hline I listen to English songs. & 177 & 3.00 & 1.011 \\
\hline I read English notices around me. & 177 & 2.85 & 1.058 \\
\hline I try to think and express my ideas in English. & 177 & 2.34 & .999 \\
\hline $\begin{array}{l}\text { I read bilingual magazines (Vietnamese magazines with English } \\
\text { translation). }\end{array}$ & 177 & 2.25 & 1.170 \\
\hline I listen to English radio (BBC, VOA, etc.). & 176 & 2.12 & 1.029 \\
\hline I practise using English with friends. & 177 & 2.11 & .970 \\
\hline I read books or magazines in English. & 177 & 2.06 & 1.010 \\
\hline I use the Internet in English. & 175 & 2.03 & 1.227 \\
\hline I speak English to any foreigner I meet. & 177 & 2.03 & 1.236 \\
\hline I watch English TV programmes. & 177 & 1.98 & 1.100 \\
\hline I watch English movies. & 177 & 1.95 & 1.112 \\
\hline I read newspapers in English. & 177 & 1.90 & .930 \\
\hline I write diary entries in English. & 177 & 1.32 & 1.235 \\
\hline I do English tutoring. & 176 & 1.28 & 1.397 \\
\hline $\begin{array}{l}\text { I make friends with non-Vietnamese people and communicate with them } \\
\text { in English. }\end{array}$ & 176 & 1.23 & 1.184 \\
\hline I send emails in English. & 175 & 1.19 & 1.058 \\
\hline I do online chatting in English. & 176 & 1.16 & 1.059 \\
\hline I write English letters to penpals. & 176 & .93 & 1.101 \\
\hline I join the forum discussions of topics of my interest in English. & 177 & .87 & 1.113 \\
\hline I do part-time jobs that require me to speak English. & 177 & .70 & 1.064 \\
\hline $\begin{array}{l}\text { I go out and spend time with volunteer teachers of English at my } \\
\text { university. }\end{array}$ & 176 & .62 & .960 \\
\hline $\begin{array}{l}\text { I do volunteer work such as working as a free tour guide or meeting and } \\
\text { showing around international students who come to visit my city. }\end{array}$ & 174 & .55 & .909 \\
\hline I write my blogs in English. & 177 & .54 & .866 \\
\hline
\end{tabular}


Table 5.4: Ranking of Overt In-Class Language Learning Activities

\begin{tabular}{|c|c|c|c|}
\hline Overt In-class Language Learning Activities & $\mathbf{N}$ & $\mathbf{M}$ & SD \\
\hline I note down new information. & 177 & 3.04 & .901 \\
\hline I discuss learning problems with my classmates. & 176 & 2.74 & .888 \\
\hline I ask the teacher questions when I do not understand. & 177 & 2.42 & 1.069 \\
\hline I take opportunities to speak English. & 177 & 2.29 & .962 \\
\hline I volunteer first to do tasks required by the teacher in front of the class. & 177 & 1.95 & 1.035 \\
\hline $\begin{array}{l}\text { I encourage my classmates to speak English so that I can practise my } \\
\text { English with them. }\end{array}$ & 177 & 1.93 & 1.098 \\
\hline I try to stick to my "English only" policy in class time. & 177 & 1.74 & .983 \\
\hline $\begin{array}{l}\text { At the end of each lesson, I try to do a short summary of the main points } \\
\text { and work out what information (knowledge) I need to better understand } \\
\text { those points. }\end{array}$ & 176 & 1.58 & 1.118 \\
\hline $\begin{array}{l}\text { I negotiate with the teachers or ask them to teach us any language points } \\
\text { that I think we need. }\end{array}$ & 177 & 1.46 & 1.113 \\
\hline $\begin{array}{l}\text { I suggest or bring to class learning materials that I think will be of } \\
\text { interest to my friends and share with them. }\end{array}$ & 176 & 1.35 & .986 \\
\hline $\begin{array}{l}\text { I initiate or suggest to the teachers interesting activities, games or topics } \\
\text { that my classmates and I are interested in. }\end{array}$ & 177 & 1.31 & 1.128 \\
\hline I ask my classmates to evaluate my English and give me their feedback. & 175 & 1.30 & 1.137 \\
\hline $\begin{array}{l}\text { I propose to the teacher the kind of homework that I would like to do } \\
\text { for a certain lesson. }\end{array}$ & 177 & 1.26 & 1.103 \\
\hline $\begin{array}{l}\text { I try to change my seat in class often so that I will have a chance to } \\
\text { speak English with different classmates. }\end{array}$ & 177 & 1.22 & 1.040 \\
\hline $\begin{array}{l}\text { I record my teachers' English so that I can imitate the way my teachers } \\
\text { pronounce and express their ideas in English. }\end{array}$ & 177 & .38 & .730 \\
\hline $\begin{array}{l}\text { I record a lesson in which I speak English to see if I make myself } \\
\text { understood in English. }\end{array}$ & 177 & .33 & .704 \\
\hline $\begin{array}{l}\text { I record my teachers' English so that I can listen to it again at home to } \\
\text { understand better what they said in class. }\end{array}$ & 176 & .30 & .670 \\
\hline
\end{tabular}

Inside the classroom, in contrast, the learners became more involved in communication with their teachers and peers. According to the illustrations in Table 5.4, except for the activity of "noting down new information" in which learners did not need to carry out any social communication, the rest of the top five activities required a great level of interaction between the learners and their teachers as well as 
between the learners and their classmates. The reason for their more active participation in overt learning activities in class could be the rapport they had developed with their teachers and peers over a long period of time. In the Vietnamese culture, it is often easier for learners to communicate with a person whom they have known for some time. The least undertaken explicit activities in class included recording both their English and the English spoken by their teachers for their reference as well as reflection. In fact, not many learners thought of these activities as one of the ways for them to improve their English.

Table 5.5: Ranking of Covert In-Class Language Learning Activities

\begin{tabular}{|c|c|c|c|}
\hline Covert In-class Language Learning Activities & $\mathbf{N}$ & $\mathbf{M}$ & SD \\
\hline I listen carefully to teachers when they are explaining the lessons. & 175 & 3.28 & .792 \\
\hline $\begin{array}{l}\text { I try to remember phrases used by teachers or friends that I } \\
\text { find new and interesting. }\end{array}$ & 176 & 3.16 & .843 \\
\hline $\begin{array}{l}\text { When my classmates give their answers, I compare their answers with } \\
\text { those I have in my mind. }\end{array}$ & 177 & 3.03 & 2.405 \\
\hline Every time the teacher asks questions, I try to answer them in my mind. & 176 & 2.93 & .960 \\
\hline $\begin{array}{l}\text { When my classmates speak or write in English, I try to think about } \\
\text { how I would speak or write the same thing in my own way. }\end{array}$ & 176 & 2.81 & .871 \\
\hline $\begin{array}{l}\text { I observe the way my classmates speak, write or learn English so that I can } \\
\text { learn from them. }\end{array}$ & 177 & 2.78 & 1.001 \\
\hline $\begin{array}{l}\text { I relate what I am learning during the class to my experiences and to what I } \\
\text { already know to make it clearer. }\end{array}$ & 176 & 2.60 & 3.054 \\
\hline I evaluate in my mind what I have achieved after the lesson. & 175 & 2.17 & .995 \\
\hline
\end{tabular}

Table 5.5 reveals a high level of reflection among the Vietnamese learners who carried out a range of hidden learning activities in the class. It is clear that they listened to their teachers. However, their listening was not passive. Rather they employed very active listening. Active covert learning may well be going on behind what appears to be passive learning behaviours. For example, when listening to their teachers or peers, they tried to remember new phrases. They also compared their answers with those from their friends. In addition, they observed and tried to express ideas in their own way. Among the many covert activities, the evaluation of what they had achieved after the lesson was the least practised activity. 
In summary, outside the classroom context the Vietnamese learners preferred to undertake receptive rather than productive activities. They were reluctant to engage in activities that required social interaction. Within the classroom environment, they appeared more willing to communicate with teachers and peers. Active listening activities were favoured by the Vietnamese learners.

\subsubsection{Relationship between LA and EFL proficiency}

This section answers the research question about the relationship between different LA elements and aspects of the Vietnamese learners' English language proficiency.

\subsubsection{Self-initiation and EFL proficiency}

The self-initiation element of LA is composed of learners' reasons for learning English and the effort they make to learn English. Table 5.6 illustrates how learner self-initiation correlated with students' English language proficiency.

Table 5.6: Correlation between Self-Initiation and EFL Proficiency

\begin{tabular}{|c|c|c|c|c|c|c|c|}
\hline \multicolumn{3}{|c|}{ Self-initiation } & \multirow{2}{*}{$\begin{array}{l}\text { Listening } \\
-.156\end{array}$} & \multirow{2}{*}{$\begin{array}{l}\text { Speaking } \\
-.038\end{array}$} & \multirow{2}{*}{$\begin{array}{l}\text { Reading } \\
.050\end{array}$} & \multirow{2}{*}{$\begin{array}{l}\text { Writing } \\
-.211(* *)\end{array}$} & \multirow{2}{*}{$\begin{array}{l}\text { General } \\
\text { proficiency } \\
-.111\end{array}$} \\
\hline \multirow{4}{*}{$\begin{array}{l}\text { Reasons } \\
\text { for } \\
\text { learning }\end{array}$} & \multirow{2}{*}{$\begin{array}{l}\text { Individual } \\
\text { development }\end{array}$} & $r$ & & & & & \\
\hline & & $n$ & 153 & 153 & 160 & 164 & 131 \\
\hline & \multirow{2}{*}{ Intrinsic interest } & $r$ & $.181\left(^{*}\right)$ & $.165(*)$ & $.301(* *)$ & .093 & $.345(* *)$ \\
\hline & & $n$ & 152 & 152 & 159 & 164 & 131 \\
\hline \multirow[t]{4}{*}{ English } & \multirow[t]{2}{*}{ Going abroad } & $r$ & $.285(* *)$ & $.296(* *)$ & $.168\left(^{*}\right)$ & .086 & $.316(* *)$ \\
\hline & & $n$ & 152 & 152 & 160 & 163 & 131 \\
\hline & \multirow{2}{*}{$\begin{array}{l}\text { Learning English } \\
\text { outside classroom }\end{array}$} & $r$ & -.084 & .061 & .011 & -.045 & -.004 \\
\hline & & $n$ & 154 & 154 & 161 & 165 & 132 \\
\hline \multirow{6}{*}{$\begin{array}{l}\text { Making } \\
\text { efforts to } \\
\text { learn } \\
\text { English }\end{array}$} & \multirow{2}{*}{$\begin{array}{l}\text { Using English } \\
\text { outside classroom }\end{array}$} & $r$ & $.218(* *)$ & $.247(* *)$ & $.210(* *)$ & $.302(* *)$ & $.363(* *)$ \\
\hline & & $n$ & 150 & 150 & 157 & 161 & 128 \\
\hline & \multirow{2}{*}{$\begin{array}{l}\text { Overt learning in } \\
\text { class }\end{array}$} & $r$ & -.017 & -.061 & .117 & .041 & .076 \\
\hline & & $n$ & 152 & 152 & 159 & 164 & 131 \\
\hline & \multirow{2}{*}{$\begin{array}{l}\text { Covert learning in } \\
\text { class }\end{array}$} & $r$ & -.019 & .130 & $.209(* *)$ & .012 & .117 \\
\hline & & $n$ & 150 & 150 & 157 & 162 & 129 \\
\hline
\end{tabular}

** $p<.01 ; * p<.05$ 
Both intrinsic interest and going abroad significantly correlated with general English language proficiency (at the $p<.01$ level). It was surprising to find negative correlations between individual development and proficiency. However, if we look at the questions under the construct of individual development, it becomes more explicable. The participants were English majors who had already chosen to study English to get a job which would require the use of English. That was probably why such reasons as "Learning English will give me a sense of achievement", "English is a symbol of education and cultivation", or "English can help me find a good job" (adapted from Gao et al., 2004), would not serve as an encouragement for them to obtain higher scores in English. Rather, the love students had for English, the enjoyment they had with English learning, and their interest in the language itself were linked very closely to their proficiency. The fact that some students wanted to search for better education and employment opportunities overseas, to have hands-on experiences with English-speaking cultures abroad, and to emigrate to an Englishspeaking country, all arguably integrative orientations, was also related strongly to their proficiency.

It is interesting to note that neither covert nor overt language learning behaviours in class had a strong association with language proficiency measures. The only significant correlation was between covert language learning and reading scores ( $r=.209, p=.009$ ). This was probably because of the fact that the subjects were English majors, and that what mattered for them was not what happened inside the classroom but what they did on their own in addition to the shared activities in class. Having said that, covert language learning behaviours were in general more closely related with English learning results. It was discovered in the last section that the Vietnamese students preferred to perform learning behaviours inside their mind such as observing their peers when they speak or write, trying to answer the teacher's questions in their mind, trying to think how they would speak or write the same thing in their own way, trying to remember new phrases used by the teacher or a friend, and listening carefully to teachers while they were explaining the lessons. For these students, covert learning behaviours might be more important than overt ones. In this sense, the reticence commonly found in Vietnamese classrooms may not be a bad thing after all.

The strongest correlations between learning efforts and learning results were found between using English out of class and various proficiency measures. Learning 
English outside the class, however, had almost no correlation, and even had negative, though insignificant, correlations with language proficiency measures. At first, this finding seems surprising. However, the point is understandable if we look at the relationship between language use and language learning in an EFL context such as Vietnam. If students only learned English outside the classroom without using it, they would waste their time and energy. To put it another way, what they just learned without using would not contribute much to their learning results.

\subsubsection{Self-regulation in writing and EFL proficiency}

Table 5.7 shows that there was a significant positive correlation between each element of self-regulation and general English proficiency (monitoring, $r=.297$; evaluating, $r=.292$; general planning, $r=.204$; and task-specific planning, $r=.197$ ). In other words, the more students planned, monitored and evaluated their own tasks, the higher their EFL proficiency would be.

Table 5.7: Correlation between Self-Regulation and EFL Proficiency

\begin{tabular}{lllllll}
\hline Self-regulation & & Listening & Speaking & Reading & Writing & $\begin{array}{c}\text { General } \\
\text { proficiency }\end{array}$ \\
\hline General planning & $r$ & .082 & .110 & .048 & .121 & $.204\left(^{*}\right)$ \\
\cline { 2 - 7 } & $n$ & 154 & 154 & 162 & 165 & 133 \\
\hline Task-specific & $r$ & .095 & $.170(*)$ & .051 & .130 & $.197\left(^{*}\right)$ \\
\cline { 2 - 7 } planning & $n$ & 152 & 152 & 160 & 163 & 131 \\
\hline Monitoring & $r$ & .114 & $.213(* *)$ & .121 & $.241(* *)$ & $.297\left(^{* *}\right)$ \\
\cline { 2 - 7 } & $n$ & 148 & 148 & 156 & 159 & 127 \\
\hline Evaluating & $r$ & .121 & $.243(* *)$ & .132 & .144 & $.292(* *)$ \\
\cline { 2 - 6 } & $n$ & 150 & 150 & 158 & 161 & 129 \\
\hline
\end{tabular}

$* * p<.01 ; * p<.05$

If we look at each language skill separately, however, a few unexpected results can be found. Among the four language skills, the productive skill of speaking correlated the most with metacognitive self-regulation skills. In fact, speaking was the only skill that showed significant correlations with almost all aspects of selfregulation. Writing scores correlated significantly with monitoring. The correlations between writing and other aspects of self-regulation almost reached significance (general planning, $p=.121$; task-specific planning, $p=.098$; evaluating, $p=.068$ ). The 
receptive skills of listening and reading had very low, positive, but insignificant correlations with self-regulation skills. This could be because the self-regulation questionnaire in this study measured the planning, monitoring, and evaluating skills in language production only. Self-regulatory behaviours in receptive language use (e.g., planning in listening) would probably have been very different from those elicited in this study.

In sum, significant and positive correlations between self-regulation and general EFL proficiency were found. In addition, the self-regulation in writing measures also significantly correlated with speaking and writing scores most of the time. These correlations, though positive, were not very high (the highest being .297). Low correlations were found between self-regulation measures and listening and reading scores. This is understandable because LA is but one of many factors that might contribute to students' language proficiency. These other factors may include students' level of intelligence, learning styles, cognitive strategies, learning materials, teachers and their teaching, and different exposures to the target language.

\subsection{Discussion}

In-depth discussions on the most distinctive features of LA demonstrated by the Vietnamese learners are presented below.

\subsubsection{In-class covert learning as a preferred mode of learning}

Learners put more endeavour into covert than overt learning in class. This confirms Little's (1991) claim that there are degrees of autonomy. Little (1991) holds that "the learner who displays a high degree of autonomy in one area may be non-autonomous in another" (p. 4). Of equal importance is that learners can be autonomous in one aspect but not in another aspect within the same domain; or in Littlewood's (1996a) words "there are different levels of autonomy within each domain" (p. 431). This could be an explanation for learners, within the domain of making effort to learn English, devoting themselves more to in-class learning (mean score of 3.83) than outof-class learning (mean score of 2.93). Furthermore, in the in-class learning aspect, they initiated more covert than overt learning activities. Similarly, in the area of out- 
of-class learning, they undertook more learning-oriented than using-oriented activities.

The presence of a particular task could be a reason for learners' more active involvement in in-class learning than in out-of-class learning. In an in-class setting, there normally were particular tasks for learners to engage in. They thus tended to perform more effortful learning behaviours in class. Classroom learning with a particular task at hand seemed to result in greater autonomy than the out-of-class learning. Benson (2007) believes that the degrees of LA "depend more on the linguistic and communicative demands of a particular task" (p. 24). This suggests that the fostering of LA requires a learning task for students to undertake.

The weak correlation found between overt learning in class and general language proficiency supports Breen's (2001) argument that "overt participation is not necessary for acquisition" (p. 123). Conducting a review of studies on the benefits of learners' overt participation for their language acquisition (e.g. Slilami, 1992), Breen (2001) maintains that overt interaction in class may provide learning opportunities and learners tend to learn different things from getting involved in the in-class overt interaction. Specifically, Breen (2001) points out that some learners who seldom participated in class interaction recalled as many new words as the ones who frequently engaged in the communication. Some learners were able to make progress in their language learning thanks to the teacher-student interaction which they did not overtly take part in. In other words, overt interaction does not necessarily contribute to learners' language proficiency. This might be the reason why the Vietnamese learners were more committed to covert manners of learning. Withdrawing themselves from overt learning behaviours was by no means an indication of passive or dependent learning. In fact, the Vietnamese learners selfinitiated a range of mental activities such as trying to remember new phrases used by teachers or friends, comparing their responses with peers', thinking about how to express the same ideas in their own ways, relating what they were learning during class to their experiences and to what they had already known to make it clearer, and even evaluating in their minds what they had achieved after the lesson. Taking Breen (2001) into consideration, it could be claimed that Vietnamese learners did not need to speak out and overtly participate in classroom interaction in order to be judged as autonomous learners. This statement finds support in Dickinson (1996) who 
recognises that "learning autonomy can be an internal, private activity and does not have to be given public expression" (p. 52).

That Vietnamese learners favoured covert learning and avoided interactionbased activities was similar to Hong Kong learners who preferred private-domainfocused activities as revealed by Hyland (2004). She discovered that her students tended to focus more on private domain activities which did not involve face-to-face interaction. Still the Vietnamese learners were successful language learners. This was evidenced by the positive correlation between covert language learning and learners' language proficiency. The features of Asian culture seemed to have positive, rather than negative effects on the way Asian learners learn the language. It would be reasonable to declare that while some traits of Asian culture might hinder LA (Ho \& Crookall, 1995), the learners in fact could also benefit from those culturally specific features. Therefore, in dissimilar cultural settings, learners are autonomous in different ways. The Vietnamese learners might be judged as non-autonomous according the Western values of speaking out or active participation. They, however, demonstrated a high level of autonomy within the classroom thanks to their vigorous engagement in a range of covert learning activities. The standards and values of Western cultures should not be imposed on Vietnamese learners, who were proved to be autonomous in their own ways. In this sense, following Aoki and Smith (1999), it is absolutely true that any claims made about cultural inappropriateness of LA in the Vietnamese context should take into consideration the social, ideological or idiosyncratic backgrounds of Vietnam. The considerable amount of autonomy found among the Vietnamese learners strongly argues against Riley (1988) who perceived Vietnamese as very passive, dependent learners who “...said nothing, did nothing... didn't want to know..." (p. 14) when they were asked to perform a task.

\subsubsection{Significance of out-of-class use of English}

Out-of-class learning is defined by Benson (2001) as "any kind of learning that takes place outside the classroom and involves self-instruction, naturalistic learning or selfdirected naturalistic learning" (p. 62). In this study, out-of-class learning indicates any English learning related activities that learners initiated to improve their English outside the classroom setting. More specifically, out-of-class learning was further classified into learning English outside class and using English outside class. This 
phase of the study discovered that the learners made more effort to learn English than to use it outside the classroom. However, they volitionally engaged in out-of-class learning, and undertook a range of out-of-class activities. This is aligned with a study by Yap (1998) who found that learners, irrespective of their level of proficiency, were motivated to participate in out-of-class learning and carried out a variety of out-ofclass activities to support their classroom learning. In terms of activities learners undertook outside class, the results bear out the findings of Hyland (2004), Pearson (2004), Pickard (1996), and Yap (1998) who reported their subjects participating more in receptive than in productive activities. Regarding the resources employed by Vietnamese learners for their out-of-class activities, the results correspond with Smith's (2001) study which reported Japanese learners using a range of resources and creating tasks by themselves to aid their English learning outside the classroom.

Learners learning English more than using it was attributed to the EFL context of Vietnam where learners lack the immediate drive to use English, and do not have many chances to use it. Despite the limitations of the EFL environment in Vietnam, activities that learners participated in such as working as a tour-guide, and meeting with international students provided them with authentic opportunities to use English in real-life situations. Therefore, learners' participation in using-Englishoriented activities contributed a great deal to the improvement of their English. This was reflected in the strongly positive correlation between using English outside class and all language skills of listening, speaking, reading, and writing in English (Table 5.6) The finding about negative correlation between the LA construct of Learning English out of class and language proficiency well supports the theories of language learning from the perspective of constructivism which believe that language use plays a key role in language learning (Little, 2007). Learning English out of class should go hand in hand with using it in order to yield good learning outcomes. Little (2000) states that in language education autonomy implies self-management in language learning and self-reliance in language use. Learning a language and using it mutually reinforce each other. In this aspect, Little's (2007) three interacting principles which govern the success in second and foreign language teaching (learner involvement, learner reflection and target language use) are trustworthy. 


\subsubsection{Prominent features of LA in Vietnam}

The finding about Vietnamese learners motivated to learn English confirmed to a large extent what other researchers in Asia have discovered (Aoki \& Smith, 1999; Chan, 2001; Chan, Spratt \& Humphrey, 2002, Smith, 2001) that LA is welldeveloped in Asian classrooms. In their studies Aoki and Smith (1999) reported that Japanese learners demonstrated their ability to take independent decisions in learning and that "many respond eagerly in a more active, self-directed manner" (p. 24). Similarly, Chan (2001) revealed that Chinese learners in Hong Kong had "a highly positive attitude towards learning autonomously" (p. 513). They had clear learning goals, were aware of their learning preferences, and welcomed the opportunity to contribute to learning. Chinese learners also agreed on their responsibility to make decisions for outside class learning (Chan, Spratt \& Humphrey, 2002). In the same way, on the basis of the results of this phase of the study, it could be claimed that the Vietnamese learners were exercising LA.

Apart from the established finding that LA occurs in the educational environment of Vietnam, some specific aspects of LA such as domains, dimensions, and levels of LA were revealed. Within the domain of out-of-class learning, the Vietnamese learners manifested more autonomy in the domain of language learning than in the domain of language use. It was the EFL environment of Vietnam that restricted their autonomy in the language use domain. Based on the three domains of LA (communication, learning, and personal life) classified by Littlewood (1996a), the Vietnamese learners achieved autonomy as learners since they demonstrated their ability to engage in both in-class and out-of-class learning. In addition, they also exhibited their autonomy as communicators because they managed to employ many covert learning strategies to improve their learning within the classroom context. The hidden autonomy-focused activities they performed involved attentive listening and careful observation made when their teachers and classmates wrote and spoke English, answering and comparing their own answers with their classmates'. To put it another way, in their minds, they made efforts to communicate their meanings and express themselves in different in-class learning situations. Compared with communication and learning domains, LA in the domain of personal life was still weak among the Vietnamese learners. They displayed the ability to use covert learning strategies in the classroom. In their personal life, however, they exhibited a limited range of personal 
learning situations to a particularly high level. This was witnessed by the smaller mean score of out-of-class learning compared with that of in-class learning. In short, technically, in the Vietnamese context, the classroom environment was more relevant to the development of autonomy in the domains of communication and learning. LA in personal life seemed to closely connect to ability to create learning opportunities in the out-of-class setting. Therefore, out-of-class learning should be promoted in the Vietnamese context to obtain a balance among the three domains of LA.

The interpretation of LA domains accords well with the LA dimensions classified by $\mathrm{Gu}$ (2009). Internal factors such as learner agency which indicates the degree of learners' self-initiation for their learning, and self-control which implies their ability to self-regulate their learning through planning, monitoring, and evaluating, are more relevant to in-class learning. This is especially true for the Vietnamese classroom where decisions on what to learn rest with teachers. As a result, learners can only make decisions on how to learn and how to self-improve their learning. The Vietnamese learners participated more actively in in-class learning activities, most importantly, they self-initiated a range of hidden learning activities; the learner agency dimension seemed to be dominant. The results show that the Vietnamese learners manifested the self-control dimensions by carrying out general planning (2.24), task-specific planning (2.67), monitoring (2.15), and evaluating (2.32). However, this dimension was weaker than the dimension of learner agency for covert language learning (2.98). Learner independence, the other dimension of LA, describes the extent to which learners are dependent on their teachers or other people for any decisions made in learning. This dimension is an external factor and is more relevant to out-of-class learning. Among the three dimensions, learner independence appeared the least common. The Vietnamese learners did not make sufficient effort to learn English outside the classroom context. This could be due not only to the EFL context of Vietnam which prevented them from actually using English outside class, but also their exceeding reliance on teachers for instructions and guidance. The researcher's long-term experience of teaching English to Vietnamese learners and her informal conversations with her students has provided her with a fuller understanding of the dimension of learner independence. In Vietnam, many learners were able to undertake a variety of out-of-class learning activities by themselves; however they preferred receiving guidance or instructions from their teachers because they believed the teachers' suggestions were more trustworthy and would be more beneficial to 
them. In this sense, it was not that learners lacked the ability to learn independently of their teachers. Rather it was their beliefs about the superior competence of their teachers that caused them to become more dependent. This was similar to Chinese learners in Hong Kong who preferred to be responsible for their own learning, to evaluate their progress and to be given an opportunity to discover things by themselves but always with their teachers' guidance (Chan, 2001).

In terms of the proactive and reactive levels of LA discussed by Littlewood (1999), the Vietnamese learners exhibited a high level of reactive autonomy within the classroom setting. For example, they followed their teachers and when the teachers put a question, they tried to answer it in their own way or compare their answers with their peers'. Littlewood (1996b) claims that Asian learners have a high level of reactive autonomy because they follow authority to a high degree. However, in this case, the Vietnamese learners exhibited reactive autonomy not only because of their encultured tendency to obey authority but also because they had no other choices. In this regard, it is worth considering Cotterall's (2008) view that "learners involved in institutional language learning may find their autonomy constrained by the goals and practices of the course in which they enrol" (p. 118). It was the conventional classroom in Vietnam that confiscated learners' right to make decisions on the content of learning. The predominant role of teachers might also discourage proactive autonomy. In Hong Kong, Chan (2003) found that teachers preferred to take up a predominant role. They had a less positive view towards their students' acceptance of overall responsibility for the learning. They stated that most decisions made in the learning process remained their responsibility. They worried that Chinese students in Hong Kong might not have sufficient knowledge and expertise to make decisions. Since this phase of the study focused merely on Vietnamese learners, it did not look for the evidence about teachers' attitude towards LA. Nonetheless, it is the researcher's long-term observation that Vietnamese teachers would be very likely to share the same attitudes and beliefs about their students who would be perceived by them as lacking ability for independent learning. Hence, it could be the teachers that reduced proactive autonomy among the Vietnamese learners. 


\subsection{Conclusion}

Phase one has resulted in several important findings. Firstly, it was found that the Vietnamese learners in this phase of the study were motivated to learn English but they did not make enough effort to learn it. They generally participated in taskspecific planning when given a writing task, and tended to evaluate their own performances after a task was completed. On the whole, however, despite the fact that all self-regulation measures were above the mean score of 2 (out of 4 ), the learners did not demonstrate very active self-regulation and self-management behaviours.

Secondly, the most popular activities performed by the Vietnamese learners both outside the classroom and inside it were reported. In the out-of-class context, the Vietnamese learners undertook more receptive rather than productive activities. They were not keen on engaging in activities that required social interaction. However, in the classroom setting they appeared more eager to communicate with teachers and peers. In addition, they actively engaged in covert learning in class, e.g., listening attentively and trying to quietly answer every question without verbalising their answers aloud.

Thirdly, this phase of the study provides an empirical connection in this context between LA and most aspects of EFL proficiency. This is a better basis for promoting LA than descriptive accounts alone. 


\section{PHASE TWO}

\subsection{Rationale}

The data from Phase one suggested that having an intrinsic interest in English, trying hard to use English out of class, and being able to plan, monitor, and evaluate their own learning seemed to be associated with success. The Vietnamese students were able to regulate their own learning through planning, monitoring and evaluating. However, there was substantial room for improvement in their self-regulation behaviours. It is strongly believed that in addition to covert learning in class, these learners need to exert much more effort, and will benefit from more self-regulatory behaviours. The finding about learners insufficiently exercising self-regulatory skills indicated the need for training in the metacognitive skills of planning, monitoring, and evaluating of a writing task. Learner training seemed to be an appropriate intervention for the development of LA.

The second phase of the study lasted from August 2008 to October 2008. This part of the research was formulated to answer a number of specific questions relating to the use of the metacognitive techniques. The research programme involved integrating the MT into the Writing Four course that was part of the Bachelor of English degree course. The research involved an experimental class and two control classes, and comparisons of their tests results (pre-, post-, and delayed tests) as well as comparisons of results of the questionnaires (pre-MT and post-MT).

\section{Research questions}

Phase two investigated the causal relationship between the MT and writing results as well as between the MT and LA. Other goals of the second phase included the exploration of the transfer of the metacognitive skills and the maintenance of improvements in writing by the EG. In addition to the four research questions described in section 1.4, this phase found answers to the following specific questions:

1. Does training in metacognition lead to improved written English? Are there differences in improvements: 

a. on different aspects of writing
b. for students with different levels of academic achievement?

2. Will improvements in written English be maintained?

3. Does training in metacognition techniques result in higher LA?
a. on different aspects of LA
b. for students with different levels of academic achievement?

4. Does metacognitive training in the context of English learning and teaching result in the transfer of metacognitive skills to other areas of language learning? In which language skill(s)?

\subsection{Data analysis}

To answer each research question, both sets of data were analysed. The quantitative data coming from 1-5 Likert scale questionnaires ${ }^{4}$ (pre- and post-) and tests (pre-, post- and delayed) were submitted to SPSS 16.0 for analysis. Each research question was answered by observing the mean scores of the writing tests which comprised four components: content, organisation, language, and grammatical accuracy, and the mean scores of LA constructs including reasons to learn English, making an effort to learn English, planning, monitoring, and evaluating. Descriptive analysis, one-way ANOVA, one-way repeated-measures ANOVA, and post hoc tests were performed to compare means and to detect the within- and cross-group differences. It is important to note that the numbers of students who took part in the pre-, post-, and delayed writing tests were different. Ninety one students sat the pre- and post- tests of writing while only 83 of them took the delayed test. For this reason, when ANOVA tests were performed to compare means of the three tests, the eight students who did not sit the delayed test do not appear as ANOVA tests automatically exclude from the data any cases that have a missing value. This explains why there are differences in the total numbers of students in the three tests (83) and in the two LA questionnaires (91). In the findings and analysis of all the three tests, results of 83 students will be presented. In the analysis of pre-, post-test as well as LA questionnaires, data from 91 students will be displayed. The qualitative data originated from student diaries, their

\footnotetext{
${ }^{4}$ The range of the Likert scale used in Phase 2 was from 1-5.
} 
written texts, the researcher's field notes of classroom observations, and the interviews with students and teachers. The interviews were transcribed, coded and analysed. The qualitative information was fully exploited to interpret or to back up the findings.

\subsection{Findings}

The findings are organised around the four research questions presented above.

\subsubsection{MT and improved English writing}

One-way ANOVA was done to see if the three groups (EG, $\mathrm{C} 1$, and $\mathrm{C} 2$ ) performed differently in English writing after the MT. Descriptive statistics comparing the mean scores of the experimental and control classes for pre- and post- writing tests are presented in Table 6.1.

Table 6.1: Descriptive Statistics for Writing Scores of Three Groups

\begin{tabular}{lllll}
\hline Tests & Groups & M & SD & N \\
\hline Pre-test & EG & 5.833 & 1.4878 & 33 \\
\cline { 2 - 4 } & C1 & 5.120 & 1.5294 & 25 \\
\cline { 2 - 4 } & C2 & 5.860 & 1.1413 & 25 \\
\cline { 2 - 4 } & Total & 5.627 & 1.4289 & 83 \\
\hline Post-test & EG & 7.348 & 1.5983 & 33 \\
\cline { 2 - 4 } & C1 & 5.760 & 1.5487 & 25 \\
\cline { 2 - 4 } & C2 & 6.500 & 1.2829 & 25 \\
\cline { 2 - 4 } & Total & 6.614 & 1.6199 & 83 \\
\hline
\end{tabular}

Before the MT took place, the writing mean scores of the three groups varied slightly. C2 had the highest score (5.860), followed by the EG (5.833) and C1 (5.120). After the implementation of the MT, all three classes demonstrated gains in their writing scores. The EG, however, achieved the greatest mean score of 7.348, obtaining an increase of 1.515 marks compared with the mean score of the pre-test. The scores of $\mathrm{C} 1$ and $\mathrm{C} 2$ were 5.7760 and 6.500 respectively. These two groups achieved a similar 
growth of 0.640 marks. The differences in the writing mean scores across the three groups can easily be seen in Figure 6.1.

Figure 6.1: Writing Scores across Three Groups before and after MT

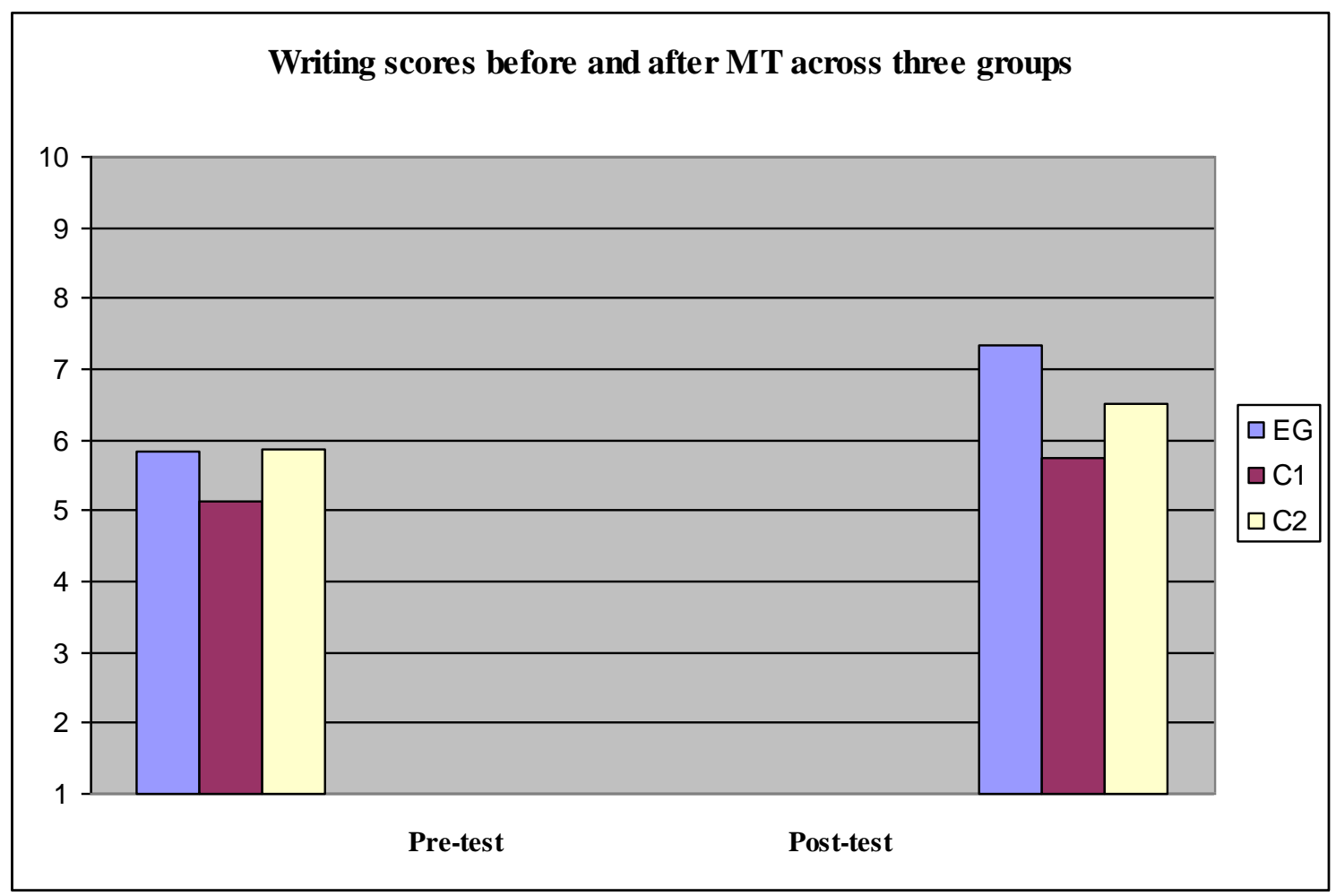

The statistical significance for an ANOVA is determined by the $F$ ratio which is the ratio of variability between groups to variability within groups. Therefore, it is important to look at the $F$ ratio when analysing and reporting results from ANOVA. The $F$ value for the pre-test $(F(2,80)=2.323, n . s)$ (Table 6.2) indicates that the difference in the mean scores of writing for the three groups was not significant at the .05 level. That is, the groups did not perform significantly differently before the MT intervention. However, there was a statistically significant difference in the mean scores for the writing test of the three groups after the MT, $F(2,80)=8.134, p<.05$. The big $F$ value of the post-test shows a significant difference between the means for pre- and post-writing tests. It, however, does not allow us to locate the difference precisely. 
Table 6.2: ANOVA for Pre- and Post-Writing Tests across Three Groups

\begin{tabular}{lllllll}
\hline & \multicolumn{2}{c}{ Sum } & of & & & Sig. \\
\hline Pre-test & Squares & df & Mean Square & F & 2.323 & .105 \\
& $\begin{array}{l}\text { Between } \\
\text { Groups }\end{array}$ & 9.188 & 2 & 4.594 & & \\
\cline { 2 - 7 } & Within Groups & 158.233 & 80 & 1.978 & & .001 \\
\cline { 2 - 7 } & Total & 167.422 & 82 & & & \\
\hline Post-test & Between & 36.360 & 2 & 18.180 & \\
& Groups & & & & & \\
\cline { 2 - 7 } & Within Groups & 178.802 & 80 & 2.235 & & \\
\cline { 2 - 6 } & Total & 215.163 & 82 & & & \\
\hline
\end{tabular}

To identify differences among the three groups, post-hoc tests were performed. As is clearly shown in Table 6.3, differences in the mean score of the pre-test among the three groups were not significant (n.s). The means of 5.860 (C2), $5.833(\mathrm{EG})$, and 5.120 (C1) differ numerically but they do not differ statistically. In other words, prior to the metacognitive project, students' writing levels among the three groups were compatible. However, in the post-writing test, which was taken after the MT had been completed, the EG differed considerably from the two control classes.

Table 6.3: Differences in Writing Scores across Three Groups

\begin{tabular}{|c|c|c|c|c|c|}
\hline Tests & (I) Group & (J) Group & $\begin{array}{l}\text { Mean } \\
\text { difference (I- } \\
\text { J) }\end{array}$ & $\begin{array}{l}\text { Standard } \\
\text { error }\end{array}$ & Significance \\
\hline \multirow[t]{6}{*}{ Pre-test } & EG & $\mathrm{C} 1$ & .5140 & .3748 & .174 \\
\hline & & $\mathrm{C} 2$ & .0594 & .3668 & .872 \\
\hline & $\mathrm{C} 1$ & EG & -.5140 & .3748 & .174 \\
\hline & & $\mathrm{C} 2$ & -.4547 & .3989 & .257 \\
\hline & $\mathrm{C} 2$ & EG & -.0594 & .3668 & .872 \\
\hline & & $\mathrm{C} 1$ & .4547 & .3989 & .257 \\
\hline \multirow[t]{6}{*}{ Post-test } & EG & $\mathrm{C} 1$ & $1.2791^{*}$ & .4158 & .003 \\
\hline & & $\mathrm{C} 2$ & $.8890^{*}$ & .4069 & .032 \\
\hline & $\mathrm{C} 1$ & EG & $-1.2791^{*}$ & .4158 & .003 \\
\hline & & $\mathrm{C} 2$ & -.3901 & .4425 & .380 \\
\hline & $\mathrm{C} 2$ & EG & $-.8890^{*}$ & .4069 & .032 \\
\hline & & C1 & .3901 & .4425 & .380 \\
\hline
\end{tabular}


Specifically, the EG performed significantly better than C1 $(p<.05)$. The difference between the EG and C2 almost reached significance value $(p=.059)$. However, statistically, no significant difference between the two control classes was found after the MT. In short, the EG, after having been trained in the metacognitive skills of planning, monitoring, and evaluating, outperformed both $\mathrm{C} 1$ and $\mathrm{C} 2$ in the post-test of writing. Based on the statistical analyses, it can be concluded that the MT led to improved written English for students in the EG.

\subsubsection{EG vs. C1}

The statistical analysis shows that the three groups were comparable prior to the MT. However, students in the EG improved their writing scores considerably after the MT while students in $\mathrm{C} 1$ and $\mathrm{C} 2$ did not enhance their writing scores much. Since in both the EG and $\mathrm{C} 1$ the Writing Four course was taught by Ms Phuoc, it would be interesting to investigate other factors that might have influenced the performance of these two groups. Apart from the quantitative data which had already been analysed, the triangulation of data from classroom observations, interviews with teachers and students, and students' diary entries would be meaningful in this respect. There were many contributing factors worth exploring. These included the amount of class time, the teachers' teaching approaches, the lesson procedures, the explicitness of strategy teaching, the teacher rapport and error correction, and the content of the MT.

First of all, even though the EG received fewer writing lessons conducted by Ms Phuoc than C1, it still performed better. Ms Phuoc spent 27 hours teaching the content of the Writing Four course in the EG while she had 36 hours with $\mathrm{C} 1$. Therefore, the time devoted to the course content in $\mathrm{C} 1$ surpassed that in the EG. However, the way Ms Phuoc taught her lessons in the two classes was almost the same. The most marked difference, according to her (Interview P, Q16, P2), was that she gave more difficult writing tasks to the class which she found better in writing a certain kind of essay. For instance, because C1 performed well on Cause and Effect essays, it was assigned more difficult tasks on this type of essay than the EG. Another distinction linked to the way Ms Phuoc checked the outlines of students in the EG. Ms Phuoc acknowledged that she did not check their outlines as carefully as she did those of students in C1. Her feedback was not as detailed as that given in C1 (Followup interview P, Q4, P2). 
Regarding the lesson procedures, both classroom observation and interview data indicated that Ms Phuoc started her lesson by reviewing the previous lesson, reminding students about making outlines for every essay they wrote, or checking students' writing texts. Introduction to the new lesson was made as a next step. Sometimes she employed an activity to make a bridge to her lesson but "most of the time I just verbally told them about the new lesson" (Interview P, Q1-2, P2). Ms Phuoc also admitted that because she had no experience in teaching academic writing, she was not very flexible in engaging students in writing activities that might make her lesson more interesting and easier for them to follow even though she was aware of the fact that students always perceived writing as a boring subject. She said that she had difficulty carrying out lesson plans she had prepared. She added that the intensiveness of the writing course (every week she had four one-hour writing lessons in each class) was another constraint for her. The third step was teaching the new lesson which involved presenting, explaining and putting questions about the lesson. It was followed by a practice stage which included explaining tasks to students, and students doing exercises in the book or in the hand-outs. Ms Phuoc noted that during this stage she asked students to do more production-oriented tasks. The last step was for her to correct student work, informing students about the main points of the following lesson, and asking them to get ready for the lesson by reading the materials in advance.

It was found that there was no fixed time designated for each phase. It depended on the number of writing texts that students turned in for feedback which, if more were turned in, could make the first stage longer. The introduction stage would take more time if students engaged in an activity-based introduction. The main step, according to Ms Phuoc, was the teaching of a new lesson. The time allocation for this stage varied according to the type of essay. However, Ms Phuoc said that she normally spent more than half of an hour long class for this step because it was the most important step. To illustrate, Ms Phuoc devoted more time to explaining an argument type essay and less time to in-class writing practice or feedback. Table 6.4 displays the approximate time allocation for each step of the lessons conducted by Ms Phuoc. 
Table 6.4: Structure of a Writing Lesson Conducted by Ms Phuoc

\begin{tabular}{llll}
\hline Procedures & Activities & Responsibilities & Time \\
\hline Review & Revision of previous lesson, feedback for & Teacher and & $5-15$ \\
& student work, homework correction & students & minutes \\
\hline Introduction & Verbal introduction of the new lesson or & Teacher most of the & $5-10$ \\
& employment of an activity & time & minutes \\
\hline Teaching the & Presenting, explaining and putting questions & Teacher & $30-40$ \\
new lesson & about the new lesson & & minutes \\
\hline Practice & Doing exercises in the books or hand-outs & Students & $10-15$ \\
& & & minutes \\
\hline Feedback and & Feedback for student work, getting students & Teacher & $10-15$ \\
homework & ready for the following lesson & & minutes \\
\hline
\end{tabular}

As already mentioned, the lesson procedures were similar in both the EG and $\mathrm{C} 1$. However, because of having more writing classes (36 hours), students in C1 had more time for in-class writing practice and they also received more feedback for their writing texts than students in the EG who had only 27 writing classes. Nevertheless, the EG performed better than $\mathrm{C} 1$. The reason could be the EG always having at least 20 minutes (as demonstrated in Table 3.12) to practise writing using any newly learned strategy during the MT sessions. $\mathrm{C} 1$, in contrast, was allowed only about ten minutes in each lesson for writing practice (Table 6.4). The longer in-class practice time in each lesson could make a difference. The structure of a content lesson in C1 also displayed the overwhelming responsibilities of the teacher. The teacher stayed at the centre of the lesson rather than gradually transferring responsibility to the students. Therefore, the structure of a metacognitive lesson seemed to be more reasonable since it balanced in-class practice time as well as teacher and student responsibilities.

Explicit teaching of learning strategies could be another factor that counted for better performance of the EG. The researcher always openly told her students about the objectives of each training session. Ms Phuoc, on the other hand, stated that she had not told her students the objectives of her lessons. Rather she wanted her students to absorb the points from her teaching (Interview P, Q3, P2). For instance, at the beginning of session three on Planning for content, the researcher overtly informed students about the language objectives, the strategy objectives and the strategy descriptions. She also emphasised the importance of the target metacognitive 
strategies that students were supposed to be able to use after the session. Students would immediately know what, why, and how they would learn the lesson. Ms Phuoc, on the other hand, at the beginning of her lesson normally checked students' homework and started teaching the new lesson straight away without explicitly stressing the lesson objectives. For example, in her lesson on an argument essay, using the PowerPoint software, she firstly showed students the definition of an argument essay in a slide named "What": "Your essay is to state your opinion about an issue and the reasons why your opinion is correct. You will try to convince readers to accept your point of view" (PowerPoint slides provided by Ms Phuoc). Then she went on to tell students about a thesis statement:

The main idea of the thesis statement will be your opinion. Your opinion about an issue is called your proposition. State your proposition using the words should or should not. You will state your opinion in one sentence. The reasons for your proposition will be the sub-points of your thesis statement (from Classroom observation 3, EG, P6).

Next she provided students with useful connective devices and the organisation pattern of an argument essay. Although Ms Phuoc gave a comprehensive coverage of an argument essay, her focus was mainly put on the what rather on the how. The explicitness of lesson objectives, in general, and the explicitness of learning strategies, in particular, would yield a better balanced scheme between the what and the how, which, in turn would be more useful to students.

The positive atmosphere that the researcher created for her students and the way she corrected errors for them could be another contributing factor to the better results of the EG. Compared with the EG, Ms Phuoc had developed a better rapport with $\mathrm{C} 1$. When being asked about other factors that might affect her teaching at the two classes, Ms Phuoc pointed out that:

Both groups have positive attitudes towards their learning. For example, they attend class on a regular basis; they all do homework although sometimes they insist that I give them less homework. Generally, both classes have similar language proficiency. However, BD3 (C1) is more hard-working. The BD2 class (EG) is smarter but less careful. As for the connection between the teacher and students, I have built a closer and better relationship with BD3 (C1) than with BD2 (EG). It is probably because I have more time with BD3 (C1). Although I 'yell' at BD3 (C1) more, I do find myself more relaxed teaching BD3 (C1) (from Interview P, $\mathrm{Q} 14, \mathrm{P} 2)$ 
The point raised was that the rapport the teacher had with her students would be useful to students in some way and thus might link to the effectiveness of the teaching and learning. In this regard, students in $\mathrm{C} 1$ should have performed better than those in the EG thanks to the empathy between them and Ms Phuoc. Nevertheless, the posttest results displayed the opposite.

For the EG, the encouraging learning environment that the researcher created might serve as another contributing factor. Students in the EG claimed that Ms Phuoc was not as generous as the researcher in marking their homework and giving encouraging comments on their work. As shown by classroom observation and the researcher field notes, Ms Phuoc often paid more attention to students' mistakes while the researcher tried to give more positive and encouraging comments on achievements students had made in their writing texts. This point, according to the researcher, was very important because in the Vietnamese culture, people tended not to praise too much, especially in the case of teacher and student relationship. Such admiring comments as: "Well done!", "Very good!", “Excellent!", “I like this point!" used frequently by the researcher to give confidence to her students must have made them feel inspired. Ms Phuoc, on the other hand, only placed such inspiring remarks on a limited number of students' writing texts. This could explain why students felt more relaxed and encouraged in metacognitive lessons. Once students like something, they will normally be more motivated to do it better.

The fact that the MT was integrated into the writing curriculum and there were two teachers sharing the same course in the EG also made the writing lessons less monotonous. This was especially beneficial for a writing subject which was perceived as the most notoriously boring of all the language skill subjects. This point was revealed by students' diary entries. Many students mentioned in their diaries that they either did not like the writing subject or found it boring:

Today, my class was continued to learn the strategies for writing. Actually, I have not liked this subject before, but the new teacher made me be attracted with her teaching... (BH, Diary, Week 2).

Writing subject is a subject I hate best among four subjects: listening, speaking, reading, and writing. The lessons are usually boring and I am very lazy writing (DTML, Diary, Week 2). 
... it's rather boring because there are theory and writing. Some time, I feel asleep in writing class (DPKQ, Diary, Week 2).

With me, writing isn't essay. I want write very much. When I start write, I don't remember ideas and vocabularies so I feel embarrass in writing. Sometimes, I think I can't good at literature so my ideas isn't good. Besides, I feel asleep in writing and don't interesting it (NTHT, Diary, Week 2).

However some students admitted that they liked the writing subject when the metacognitive strategies were incorporated into the curriculum of Writing Four:

In the last unit, I felt funny because I understood the lesson. When I have many ideas, I should ask myself the following sets of questions: what I shall write about? What do I think about this topic? What is my opinion? If I answer themselves, I won't roam in many ideas. I think I want to need write a essay I need follow steps that the teacher provided me. It's not difficult if you make a way clearly. Now I like to learn writing skills (NTMH, Diary, Week 3).

But today I am interested: I have never written in enjoying like this (DTML, Diary, Week 2).

Many others agreed that they learned something new and found the metacognitive intervention very useful because they had not known or used the metacognitive strategies before:

I was not usually plan for the writing as carefully as the teacher taught me. I have just thought about the ideas and write them in my writing assignment (BH, Diary, Week 2).

I think we don't have the habit of setting goals or making plans so we may lost and forget whatever we intend to do. After her first period, I know how to plan for the essay and I always think about the SMART goals she had taught us when I'm about to write anything (HNN, Diary, Week 3).

Setting SMART goals might help us have a good writing. I didn't do this before because I thought it wasn't important. I just read the topic and thought about what I have to put in my essay, then arranged the ideas and put them into a sentence, that's enough. Those are all things I often do in an essay so far. Now I will try to apply what I've learnt today for my essays in the future. I think I will have a better result (LHA, Diary, Week 3).

As for me, SMART goals are the new things (NHH, Diary, Week 3).

Before I just write what I think, no rule, I write anything I like (DTML, Diary, Week 4). 
In training session today, I have learned many profifigure things. When I write an essay, we have to prepare the ideas properly, which ideas is begin, which ideas is final (HTT, Diary, Week 4).

I learned about how to write a good essay. I got 3 steps today: planning, monitoring and evaluating. It's so useful because I've never done these steps before so that I could have a high appreciated essay (LHA, Diary, Week 3).

Some problems such as planning, organisation, brainstorming strategy, outlining... are new to me (NTH, Diary, Week 5).

It is really useful for me when I write an essay or others. It will help me do it easily. I know what I do. It is really practical (HTT, Diary, Week 6).

Moreover, from the lesson, I set goals for my English writing as well as reading, listening, speaking. To writing, I will write a paragraph or an essay about a topic that I am concerned every day. I think it is a way to improve my grammatical structure, vocabulary, ... In listening, every day I will hear as least two news that related to daily events in out country in the world (NTT, Diary, Week 4).

After the lesson, I think I have to pay more attention to vocabulary and learn the connective words my teacher gave carefully to apply in my essays (BH, Diary, Week 6).

Others recognised their weaknesses and knew what they needed to improve when they embarked on the MT:

In this semester I must try learning better about vocabulary, grammar and all skills write an essay better. I hope after this semester I can write an essay easy and the reader understand what I write (NTB, Diary, Week 6).

Many liked the way the researcher conducted metacognitive lessons and enjoyed her lessons:

However, this term, Mrs Le's responsible for teaching so I'm excited because of her precious experiences. She speaks clearly, fluently and teachs theory carefully. She also gives lots examples to help her students receive easily (DPKQ, Diary, Week 2).

In brief, many new thing I learnt from her session. I enjoy my teacher's session (NTMH, Diary, Week 3). 
The theory which was written by English is logical, clear. It make the lesson more excited. I'm very interested in this lesson today and I am sure that everybody are like me (PTMC, Diary, Week 2).

Today was not the teacher I often meet. There was another one. Firstly I didn't feel good when I saw this teacher. But in today's class, I was very happy. She wasn't like that teacher. I found I liked her. The way she did her teaching and the way she spoke, all was fine (LHA, Diary, Week 2).

The lesson is very clear. At the first, I felt difficult knowledge because the teacher taught fast. Time is too short for us to understand it. When the teacher have many examples, the lesson became easier than. I understood it (NTMH, Diary, Week 2).

I can do it well just due to teacher's logical teaching though she speaks fast but it doesn't matter with me. I can catch up the word she says because her voice and pronunciation are clear. So not only I can get well the writing skill but also the listening skill and anothers. I love her session a lot (LHN, Diary, Week 4).

It was discovered that in their diary entries students tended to summarise the content of certain sections. Most of them listed the main points of the lesson taught:

Today in writing class, I learnt about "cohesive devices' and "transitional signal”. My teacher taught me many skills. And I recognised that my writing skills just become better when I understand it completely.... For instance, when you think about the topic, many ideas will come into your mind. At that time, you have to brainstorm strategy, you have to choose which ideas are good for your essay... Another way, after your brainstorming, if you still do not have any ideas, do not worry! You can ask your teacher, classmates about the topic (HN, Diary, Week 6).

Today, I learnt about doing organisational planning. That work require many steps. The first step is choosing some of main ideas. When I brainstorm, I think about many ideas for a topic, but now I have to decide what to write about among that many ideas. Although I listed many ideas, I should choose some of ideas which I know fully. I should ask myself some of question such as what I should write about, what is my opinion. And then I have to develop that ideas by finding example, adding facts, and explaining my ideas. When I begin to write, I have to arrange ideas on my mind, in order. I will choose what ideas to write first, second, and last. And what I will say in my introduction, in conclusion (TTHT, Diary, Week 5). 
Language planning is one of important plans to do before writing an essay. This morning, my class learned how to plan language in an essay. I like this lesson because it is easier than previous lessons. I also knew some advantages of language planning. Language planning includes transitional signals, tense, and vocabulary. If I use the transitional signals appropriately, sentences and paragraphs will be connected. Therefore, my essay will be smooth. I learned more connective words from this session. For example, when I want to introduce a topic, I can use "as for", 'concerning", "with regard to", or "with respect to". These words are useful to write an essay. In addition, I knew collelative conjuctions should be also applied in comparing essay, such as: "both...and", "not only...but also", etc. Rich vocabulary and tense are too important. They made the essay better, attracting and accurate (BH, Diary, Week 6).

After learning the training session I can know how to write an essay corrected. For example, I can give some questions about the topic. I will write or give ideas, words, phrases that I can use in my writing. Besides, in the training session I learnt about the way arrange ideas, order of subtopics and give plan to write an essay. After backgrounding informations on the topic I can write about it and when finishing an essay I monitor whole the essay to find what mistakes about structures, vocabulary, spelling or punctuation (HTML, Diary, Week 7).

From the above extracts of students' diaries, apart from having their awareness raised, there was no clear evidence that they actually applied what they had learned in their writing. However, many acknowledged that they learned things and improved certain aspects of their writing:

And the part I like most is planning for content. Before learning this planning skill I just wrote down everything happened in my mind and then messed up by those. Fortunately, I knowed to categorise ideas and arrange them logically (HNN, Diary, Week 8).

Today, I was happy when my teacher gave me the planning for the organisation of a essay. This is the most important part of a essay. I think it is very difficult to everyone and I often have a lot of mistakes in this part. I have a clear knowledge through some examples are given (NTH, Week 5).

My writing skills aren't good. I always write what I think, so it is very disorderly. And now, in writing 4, I learned some of skills which help me write better (HTT, Diary, Week 8).

I'm really writing very bad. Because my English grammar is very weak. And I don't know to arrange my main idea in a paragraph or an essay. But passing lesson today, I learn method writing a paragraph or an essay (NTB, Diary, Week 4). 
I practised with my classmates when I was writing an essay, developed a plan for the organisational sequence of content, thought about the words and phrases I would need in my essay. By organising and thinking beforehand, I would already have certain words and phrases that I could use in my writing (LTY, Diary, Week 5).

Some acknowledged that the strategies the researcher encouraged them to use for generating ideas were helpful and they would use them in learning other subjects:

Besides, I also find that working in pairs or groups will get a remarkable result. We can share opinions each other. Furthermore, when you work in pairs or groups, it means that you express the spirit of cooperation. I will apply this way in speaking English. You can collect many information about the topic. They can point out things you may not have thought of and helps you make your arguments clearer (NTT, Diary, Week 6).

Briefly, students' diary entries confirmed the usefulness of the MT.

\subsubsection{Attendance at MT and improved English writing}

It was also revealed that in the EG, students who attended the training sessions actually improved their writing, though not significantly. Students absent from most of the metacognitive sessions did poorly in both pre- and post-tests, and did not show any improvement (Table 6.5). For example, student $\mathrm{K}$ rated as a bottom student who attended only the first and the last training sessions (according to the researcher field notes) did not gain any improvement for his post-test. Student T, also classified as a bottom student, nevertheless, did make a small gain in her post-test in the organisation and content aspects. The evidence would suggest that her regular class attendance was a contributing factor.

Table 6.5: Scores of Writing Components Obtained by Student K and Student T

\begin{tabular}{|c|c|c|c|c|c|c|c|c|c|c|c|}
\hline Student & $\begin{array}{l}\text { Number } \\
\text { of } \\
\text { sessions } \\
\text { attended }\end{array}$ & $\begin{array}{l}\text { Pre- } \\
\text { test } \\
\text { Org. }\end{array}$ & $\begin{array}{l}\text { Post- } \\
\text { test } \\
\text { Org. }\end{array}$ & $\begin{array}{l}\text { Pre-test } \\
\text { Content }\end{array}$ & $\begin{array}{l}\text { Post- } \\
\text { test } \\
\text { Content }\end{array}$ & $\begin{array}{l}\text { Pre- } \\
\text { test } \\
\text { Lang. }\end{array}$ & $\begin{array}{l}\text { Post- } \\
\text { test } \\
\text { Lang. }\end{array}$ & $\begin{array}{l}\text { Pre- } \\
\text { test } \\
\text { Acr. }\end{array}$ & $\begin{array}{l}\text { Post- } \\
\text { test } \\
\text { Acr. }\end{array}$ & $\begin{array}{l}\text { Pre- } \\
\text { test } \\
\text { overall } \\
\text { score }\end{array}$ & $\begin{array}{l}\text { Post- } \\
\text { test } \\
\text { overal } \\
\text { score }\end{array}$ \\
\hline $\mathrm{K}$ & 2 & 1 & 1 & 1.5 & 1.5 & 1 & 1 & 0.5 & 0.5 & 4 & 4 \\
\hline $\mathrm{T}$ & 9 & 1 & 1.5 & 1.5 & 2 & 1 & 1 & 0.5 & 0.5 & 4 & 5 \\
\hline
\end{tabular}


Pre-test written by bottom student $\mathrm{K}$ who attended two training sessions out of nine:

Have you ever went on your holiday by car or by train? I think both of them may be interesting and really comfortable too. But I want to share with you that there is little difference from going on by car and by train.

The fact that nowadays car is the fastest way of land and this helps you get where you like pleasantly, in your plan. But it is said that car will be unsafe way and always become accidents. If you don't like this way for your trip you can also choose another way such as train or bicycle. If often want on my holiday by train before. Because I always feel tired and sick when I'm on by another way. Really train maybe slower way than car, it is most safe and you can walk and sleep comfortably on... instead of train is fare price is a little bit expensive. I believe you never mind this for your useful holiday.

All of ways you can get good holiday; However you have to know How to choose.

\section{Post-test written by bottom student K:}

- I am junior at Duy Tan University in Danang city; from time I was far away from my family I seem to get busier every day. I'm really extracted in some hobbies at the weekends, especially, spending all my times on weeken indoors and weeken outdoors. But I maybe easy to realise difference of them.

- When spending weeken indoors, I always enjoy something music, laying, game on my computer, almost of playing guitar. I think that this is the best way for me to relax with my friends. Moreover spending indoors which may not lead you to spend a lot of money. Whereas spending weeken outdoors, you often take your time for shopping, going sightseeing and swimming in the sea. Do you know that in your ways, spend lot of time, money, you never realise, you may become a boit person if you continue to go out.

- I think that everyone has to choose the best way to live and work or study. So I always question on myself to spend less time at the weekens.

\section{Pre-test written by bottom student $\mathrm{T}$ who attended all the nine training sessions:}

For many year ago, going on holiday by car is popular than by train for the weekend and the special ocassions. Nowaday, we have many transports to go on holiday such as plan, car, train... many people want to choice car and train for their holidy. But, many people like to go holiday by car than by train.

Car is a popular transport than diferent transports. When we go from the North to the South, we will see many streets to go. Besides that, going on holiday train, we have to buy ticket and go on time, plan do, too. 
Going on holiday by car is comfortable and interesting than by train. If we lend a car for our holiday, we are active in all situation such as stoping, continousing, coming where we like. Besithat, we can want when the car starts and when the car stops.

In general, going on holiday by car is the best choice with many families and people by many reason: comfortable, fast, easy and interesting. So, many people choice to go holiday by car than by train.

\section{Post-test written by bottom student T:}

In our life, you have many busy works the whole week. So, the weekend is time which you can relax to reduce your tireness. Some people spend a weekend indoors, but other people spend a weekend outdoors, there are similarities and differences such as time, the activyties, the spending money, and the atmostphere.

The obvious similarity of spending a weekend outdoors and indoors is the time. If you are indoor at weekend, you can listen to music, play game on computer, or chat with your friends. If so, you will spend time to do that works. In contrast, if you go outside at weekend, especially you go for a trip, you will spend much time. In short, spending a weekend outdoors will spend much time, spending a weekend indoors is too.

The difference at weekend outdoors and weekend indoors is activyties. A weekend at home, the activyties are very few. The actions are again and again, Evenly, the actions are very boring. In contrast, a weekend outdoors, your activyties is very rich. The outside has many actions to do such as: camping, playing, football, cooking outside with friends, and making a trip. So, spending a weekend outdoors have many activities than spending weekend indoors.

In spit of these differences, they have difference about money. At home, you will use a little money, evenly, you don't pay money at anythings. But, outside, you will pay money for many thing such as: eating, drinking, and pertrolomex. So, spending a weekend outside is very cost.

The final difference is the atmostphere. At home, the atmostphere is very boring when you are alone. But, when you go out, you will have a excited feeling with your friends, or your family. So atmostphere at outside is very exercited than atmostphere at home.

In conclusion, in our modern life, the weekend is very important. Spending a weekend indoors or spending a weekend outdoors, there are more differences and similarities. But, in my option, I will choose spending a weekend outdoors, that thing actually help me relaxed and comfortable with my family or my friends.

Based on the marking criteria (Table 3.14) used in this study, several remarks on content, organisation, language, and grammatical accuracy were made. In terms of content, while no improvement was made in student $\mathrm{K}$ 's post-test, student $\mathrm{T}$ generated more ideas related to the topic she wrote about. This was evidenced by a 
range of ideas she developed in her essay including activities, atmosphere and spending money. Student K, in contrast, only focussed on activities. His essay was not sufficiently developed. As far as the organisation was concerned, the post-test essay by student K lacked a thesis statement. Since he was short of ideas, he did not provide sufficient examples to illustrate his points. Unlike student $\mathrm{K}$, student $\mathrm{T}$ wrote a thesis statement (there are similarities and differences such as time, the activyties, the spending money, and the atmostphere) and a concluding sentence for her post-test essay (In conclusion, in our modern life, the weekend is very important. Spending a weekend indoors or spending a weekend outdoors, there are more differences and similarities. But, in my option, I will choose spending a weekend outdoors, that thing actually help me relaxed and comfortable with my family or my friends). After that she developed each main idea in each paragraph though the way she expressed her ideas was not clear. She also inserted some examples in her essay. Regarding the language, neither student employed a variety of sentence structures. Many of the sentences the two students wrote in their essays did not make sense. Their choice of vocabulary was not appropriate. For example, in his post-test, student $\mathrm{K}$ used extracted in sentence three instead of interested; laying as a substitute of lying in the first sentence of paragraph two, boit instead of spoilt, and question on myself as a replacement for tell myself. Student $\mathrm{T}$ also made this kind of mistake. For instance, she used petrolimex as a substitute of petrol, cost instead of expensive in sentence three of paragraph four, and actions as an alternative for activities in sentences thee, four and five in the third paragraph. She also used the wrong word such as excercited as a replacement for of excited, and evenly instead of even (sentence thee in paragraph three and sentence two in paragraph four). However, student $\mathrm{T}$ employed more cohesive devices than student $\mathrm{K}$. To illustrate, student $\mathrm{K}$ only used three connective words (but, so, whereas) while student $\mathrm{T}$ used at least six and some words were repeated. With respect to grammatical accuracy, both students performed very poorly. They made many grammatical errors.

If the view that it would take time for students to acquire the grammar and the language aspects is accepted, it could be claimed that the MT led to student T's improvement in content and organisation areas, associated with her regular attendance at the training sessions. Student K did not regularly come to the training sessions and did not make progress in the post-test essay. 


\subsubsection{MT and improvements in different writing components}

Table 6.6 displays descriptive statistics of the four elements (organisation, content, language, and accuracy) of the pre- and post-tests of writing across the three groups. Generally, in all three classes, the mean scores for each component improved after the MT had been conducted. The ANOVA values in Table 6.7 show a significant difference in mean scores for each component in the pre- and post-tests. In the pretest, the $F$ ratios for content, language, and accuracy were $F(2,88)=.846, n . s ; F(2$, $88)=.979$, n.s; and $F(2,88)=.311$, n.s, respectively. The $F$ values of less than 1 in these three components indicated that there was no meaningful difference among the three groups. Although the $F$ ratio for organisation was $F(2.88)=1.827$, the significance value was greater than .05 , indicating no significant difference in this element of writing. To put it differently, the three groups did not differ statistically significantly in terms of content, organisation, language, and accuracy before they participated in the MT project. However, these students demonstrated statistically great improvements in almost all aspects of a writing task after the MT, except for the accuracy element. The $F$ values of the post-test for content, organisation, and language were $F(2,88)=4.140, p<.05 ; F(2,88)=5.721, p<.05 ;$ and $F(2,88)=$ $9.418, p<.05$, respectively. It was the accuracy, the $F$ ratio of which was $F(2,88)=$ 1.968 , n.s, that improved the least among the four components across the three groups. 
Table 6.6: Descriptive Statistics for Writing Components across Three Groups

\begin{tabular}{|c|c|c|c|c|c|}
\hline & & $\mathbf{N}$ & Mean & Std. Deviation & Std. Error \\
\hline \multirow[t]{4}{*}{ Pre-test Content } & EG & 37 & 1.649 & .4694 & .0772 \\
\hline & $\mathrm{C} 1$ & 26 & 1.558 & .4081 & .0800 \\
\hline & $\overline{\mathrm{C} 2}$ & 28 & 1.518 & .3465 & .0655 \\
\hline & $\overline{\text { Total }}$ & 91 & 1.582 & .4168 & .0437 \\
\hline \multirow[t]{4}{*}{ Post-test Content } & EG & 37 & 2.027 & .4401 & .0724 \\
\hline & $\overline{\mathrm{C} 1}$ & 26 & 1.808 & .4707 & .0923 \\
\hline & $\mathrm{C} 2$ & 28 & 1.696 & .5153 & .0974 \\
\hline & Total & 91 & 1.863 & .4891 & .0513 \\
\hline \multirow[t]{4}{*}{ Pre-test Organisation } & EG & 37 & 1.500 & .3909 & .0643 \\
\hline & $\overline{\mathrm{C} 1}$ & 26 & 1.308 & .4261 & .0836 \\
\hline & $\mathrm{C} 2$ & 28 & 1.500 & .4907 & .0927 \\
\hline & Total & 91 & 1.445 & .4375 & .0459 \\
\hline \multirow[t]{4}{*}{ Post-test Organisation } & EG & 37 & 2.027 & .4556 & .0749 \\
\hline & $\mathrm{C} 1$ & 26 & 1.635 & .4595 & .0901 \\
\hline & $\overline{\mathrm{C} 2}$ & 28 & 1.768 & .4997 & .0944 \\
\hline & Total & 91 & 1.835 & .4947 & .0519 \\
\hline \multirow[t]{4}{*}{ Pre-test Language } & EG & 37 & 1.743 & 2.2780 & .3745 \\
\hline & $\overline{\mathrm{C} 1}$ & 26 & 1.231 & .3803 & .0746 \\
\hline & $\mathrm{C} 2$ & 28 & 1.411 & .3059 & .0578 \\
\hline & Total & 91 & 1.495 & 1.4804 & .1552 \\
\hline \multirow[t]{4}{*}{ Post-test Language } & EG & 37 & 1.757 & .4506 & .0741 \\
\hline & $\mathrm{C} 1$ & 26 & 1.327 & .3726 & .0731 \\
\hline & $\overline{\mathrm{C} 2}$ & 28 & 1.518 & .3186 & .0602 \\
\hline & Total & 91 & 1.560 & .4271 & .0448 \\
\hline \multirow[t]{4}{*}{ Pre-test Accuracy } & EG & 37 & 1.122 & .4917 & .0808 \\
\hline & $\overline{\mathrm{C} 1}$ & 26 & 1.035 & .5130 & .1006 \\
\hline & $\mathrm{C} 2$ & 28 & 1.125 & .4436 & .0838 \\
\hline & Total & 91 & 1.098 & .4800 & .0503 \\
\hline \multirow[t]{4}{*}{ Post-test Accuracy } & EG & 37 & 1.270 & .5477 & .0900 \\
\hline & $\overline{\mathrm{C} 1}$ & 26 & 1.015 & .4839 & .0949 \\
\hline & $\mathrm{C} 2$ & 28 & 1.179 & .4557 & .0861 \\
\hline & Total & 91 & 1.169 & .5083 & .0533 \\
\hline
\end{tabular}


Table 6.7: ANOVA for Writing Components across Three Groups

\begin{tabular}{|c|c|c|c|c|c|c|}
\hline \multirow{2}{*}{ Pre-test Content } & \multirow[b]{2}{*}{ Between Groups } & \multicolumn{2}{|c|}{ Sum of Squares df } & \multirow{2}{*}{$\begin{array}{l}\text { Mean Square } \\
.147\end{array}$} & \multirow{2}{*}{$\begin{array}{l}\mathbf{F} \\
.846\end{array}$} & \multirow{2}{*}{$\begin{array}{l}\text { Sig. } \\
.433\end{array}$} \\
\hline & & .295 & 2 & & & \\
\hline & Within Groups & 15.337 & 88 & .174 & & \\
\hline & Total & 15.632 & 90 & & & \\
\hline \multirow[t]{3}{*}{ Post-test Content } & Between Groups & 1.852 & 2 & .926 & 4.140 & .019 \\
\hline & Within Groups & 19.681 & 88 & .224 & & \\
\hline & Total & 21.533 & 90 & & & \\
\hline \multirow[t]{3}{*}{ Pre-test Organisation } & Between Groups & .687 & 2 & .343 & 1.827 & .167 \\
\hline & Within Groups & 16.538 & 88 & .188 & & \\
\hline & Total & 17.225 & 90 & & & \\
\hline \multirow[t]{3}{*}{ Post-test Organisation } & Between Groups & 2.535 & 2 & 1.267 & 5.721 & .005 \\
\hline & Within Groups & 19.493 & 88 & .222 & & \\
\hline & Total & 22.027 & 90 & & & \\
\hline \multirow[t]{3}{*}{ Pre-test Language } & Between Groups & 4.294 & 2 & 2.147 & .979 & .380 \\
\hline & Within Groups & 192.953 & 88 & 2.193 & & \\
\hline & Total & 197.247 & 90 & & & \\
\hline \multirow[t]{3}{*}{ Post-test Language } & Between Groups & 2.895 & 2 & 1.447 & 9.418 & .000 \\
\hline & Within Groups & 13.523 & 88 & .154 & & \\
\hline & Total & 16.418 & 90 & & & \\
\hline \multirow[t]{3}{*}{ Pre-test Accuracy } & Between Groups & .146 & 2 & .073 & .311 & .734 \\
\hline & Within Groups & 20.594 & 88 & .234 & & \\
\hline & Total & 20.740 & 90 & & & \\
\hline \multirow[t]{3}{*}{ Post-test Accuracy } & Between Groups & .996 & 2 & .498 & 1.968 & .146 \\
\hline & Within Groups & 22.258 & 88 & .253 & & \\
\hline & Total & 23.254 & 90 & & & \\
\hline
\end{tabular}

The differences in the four writing components were identified on the basis of the post hoc tests. It is clearly seen from Table 6.8 that no statistical difference in the mean scores of the pre-test was found among the three groups on the measures of content, organisation, language, and accuracy. The significance value for each of these elements was greater than .05. In the post-test, however, the mean scores of each element for the EG differed from those of $\mathrm{C} 1$ and $\mathrm{C} 2$ not only numerically but also statistically. Specifically, in terms of content, the EG showed significant differences over $\mathrm{C} 1$. Although the $\mathrm{EG}$ performed better than $\mathrm{C} 2$, the difference between them was not significant. In the organisation and language aspects, the results of the EG significantly differed from those of $\mathrm{C} 1$ and $\mathrm{C} 2$. Regarding the accuracy, the score for the EG was significantly different from that of $\mathrm{C} 1$, but not of $\mathrm{C} 2$. It was interesting to find out that, in the post-test, $\mathrm{C} 2$ and $\mathrm{C} 1 \mathrm{did}$ not differ from 
each other in the writing components except for the language aspect. In fact, C2 performed almost significantly better than $\mathrm{C} 1$ in the language aspect (it nearly reached the significance value of less than .05).

Table 6.8: Differences in Writing Components across Three Groups

\begin{tabular}{|c|c|c|c|c|c|}
\hline Dependent Variable & (I) Group & (J) Group & $\begin{array}{l}\text { Mean Difference (I- } \\
\text { J) }\end{array}$ & Std. Error & Sig. \\
\hline \multirow[t]{6}{*}{ Pre-test Content } & \multirow[t]{2}{*}{ EG } & $\mathrm{C} 1$ & .0910 & .1068 & .397 \\
\hline & & $\overline{\mathrm{C} 2}$ & .1308 & .1046 & .214 \\
\hline & \multirow[t]{2}{*}{$\mathrm{C} 1$} & EG & -.0910 & .1068 & .397 \\
\hline & & $\mathrm{C} 2$ & .0398 & .1137 & .727 \\
\hline & \multirow[t]{2}{*}{$\mathrm{C} 2$} & EG & -.1308 & .1046 & .214 \\
\hline & & $\overline{\mathrm{C} 1}$ & -.0398 & .1137 & .727 \\
\hline \multirow[t]{6}{*}{ Post-test Content } & \multirow[t]{2}{*}{ EG } & $\mathrm{C} 1$ & .2193 & .1210 & .073 \\
\hline & & $\mathrm{C} 2$ & $.3306^{*}$ & .1185 & .006 \\
\hline & \multirow[t]{2}{*}{$\overline{\mathrm{C} 1}$} & EG & -.2193 & .1210 & .073 \\
\hline & & $\mathrm{C} 2$ & .1113 & .1288 & .390 \\
\hline & \multirow[t]{2}{*}{$\overline{\mathrm{C} 2}$} & EG & $-.3306^{*}$ & .1185 & .006 \\
\hline & & $\mathrm{C} 1$ & -.1113 & .1288 & .390 \\
\hline \multirow[t]{6}{*}{ Pre-test Organisation } & \multirow[t]{2}{*}{ EG } & $\mathrm{C} 1$ & .1923 & .1109 & .087 \\
\hline & & $\overline{\mathrm{C} 2}$ & .0000 & .1086 & 1.000 \\
\hline & \multirow[t]{2}{*}{$\mathrm{C} 1$} & EG & -.1923 & .1109 & .087 \\
\hline & & $\overline{\mathrm{C} 2}$ & -.1923 & .1181 & .107 \\
\hline & \multirow[t]{2}{*}{$\overline{\mathrm{C} 2}$} & EG & .0000 & .1086 & 1.000 \\
\hline & & $\overline{\mathrm{C} 1}$ & .1923 & .1181 & .107 \\
\hline \multirow[t]{6}{*}{ Post-test Organisation } & \multirow[t]{2}{*}{ EG } & $\mathrm{C} 1$ & $.3924^{*}$ & .1204 & .002 \\
\hline & & $\overline{\mathrm{C} 2}$ & $.2592^{*}$ & .1179 & .031 \\
\hline & \multirow[t]{2}{*}{$\overline{\mathrm{C} 1}$} & EG & $-.3924^{*}$ & .1204 & .002 \\
\hline & & $\overline{\mathrm{EG}}$ & -.1332 & .1282 & .301 \\
\hline & \multirow[t]{2}{*}{$\overline{\mathrm{C} 2}$} & EG & $-.2592^{*}$ & .1179 & .031 \\
\hline & & $\overline{\mathrm{C} 1}$ & .1332 & .1282 & .301 \\
\hline \multirow[t]{6}{*}{ Pre-test Language } & \multirow[t]{2}{*}{ EG } & $\mathrm{C} 1$ & .5125 & .3789 & .180 \\
\hline & & $\overline{\mathrm{C} 2}$ & .3325 & .3709 & .372 \\
\hline & \multirow[t]{2}{*}{$\mathrm{C} 1$} & EG & -.5125 & .3789 & .180 \\
\hline & & $\overline{\mathrm{C} 2}$ & -.1799 & .4033 & .657 \\
\hline & \multirow[t]{2}{*}{$\overline{\mathrm{C} 2}$} & EG & -.3325 & .3709 & .372 \\
\hline & & $\mathrm{C} 1$ & .1799 & .4033 & .657 \\
\hline \multirow[t]{6}{*}{$\begin{array}{l}\text { Post-test Language } \\
\text {. }\end{array}$} & \multirow[t]{2}{*}{ EG } & $\mathrm{C} 1$ & $.4298^{*}$ & .1003 & .000 \\
\hline & & $\overline{\mathrm{C} 2}$ & $.2389^{*}$ & .0982 & .017 \\
\hline & \multirow[t]{2}{*}{$\overline{\mathrm{C} 1}$} & EG & $-.4298^{*}$ & .1003 & .000 \\
\hline & & $\overline{\mathrm{C} 2}$ & -.1909 & .1068 & .077 \\
\hline & \multirow[t]{2}{*}{$\overline{\mathrm{C} 2}$} & EG & $-.2389^{*}$ & .0982 & .017 \\
\hline & & $\overline{\mathrm{C} 1}$ & .1909 & .1068 & .077 \\
\hline
\end{tabular}




\begin{tabular}{llllll}
\hline Pre-test Accuracy & EG & $\mathrm{C} 1$ & .0870 & .1238 & .484 \\
\cline { 3 - 6 } & & $\mathrm{C} 2$ & -.0034 & .1212 & .978 \\
\cline { 2 - 6 } & $\mathrm{C} 1$ & $\mathrm{EG}$ & -.0870 & .1238 & .484 \\
\cline { 2 - 5 } & & $\mathrm{C} 2$ & -.0904 & .1318 & .495 \\
\cline { 2 - 6 } & $\mathrm{C} 2$ & $\mathrm{EG}$ & .0034 & .1212 & .978 \\
\cline { 3 - 6 } & & $\mathrm{C} 1$ & .0904 & .1318 & .495 \\
\hline Post-test Accuracy & $\mathrm{EG}$ & $\mathrm{C} 1$ & .2549 & .1287 & .051 \\
\cline { 2 - 6 } & & $\mathrm{C} 2$ & .0917 & .1260 & .469 \\
\cline { 2 - 6 } & $\mathrm{C} 1$ & $\mathrm{EG}$ & -.2549 & .1287 & .051 \\
\cline { 2 - 6 } & & $\mathrm{C} 2$ & -.1632 & .1370 & .237 \\
\cline { 2 - 6 } & $\mathrm{C} 2$ & $\mathrm{EG}$ & -.0917 & .1260 & .469 \\
\cline { 2 - 5 } & & $\mathrm{C} 1$ & .1632 & .1370 & .237 \\
\hline
\end{tabular}

In summary, the statistical analyses demonstrate that after the MT the EG performed significantly better than $\mathrm{C} 1$ and $\mathrm{C} 2$. This indicates the usefulness of the MT which was delivered to students in the EG only.

The gains students obtained in each component, however, varied among the three groups. Regarding the writing component in which students made the most progress, it is evident from Table 6.9 that organisation topped the list, followed by content, language and grammatical accuracy. Most importantly, it was the EG that made the most gains in all writing elements except for the language one. The $F$ ratios (Table 6.10) for organisation and content were $F(2,88)=5.825, p<.05$, and $F(2$, $88)=3.71, p<.05$, respectively, indicating that the gains the three groups made in these aspects were significant. Although gains were made in the accuracy $[F(2,88)=$ $2.201, n . s]$ and language $[F(2,88)=.039, n . s]$ elements, they did not reach the significance value of .05 . Table 6.11 shows the location of differences in gains for each writing element across the three groups. Basically, the results of the post-test show, both numerically and statistically, that the EG performed significantly better than $\mathrm{C} 1$ and $\mathrm{C} 2$ in other elements except for language. In fact, the EG made negative gains in language though the significance value was greater than .05 . As far as the content was concerned, although the EG differed numerically from $\mathrm{C} 1$ (n.s), it differed both numerically and statistically from C2 ( $p$ <.05). Regarding the accuracy, the EG displayed numerical and statistical difference from $\mathrm{C} 1(p<.05)$ but only numerical difference from C2 (n.s). Organisation was the only component in which the EG differed numerically and statistically from $\mathrm{C} 1$ and $\mathrm{C} 2(p<.05)$. 
Table 6.9: Gains in Writing Components across Three Groups

\begin{tabular}{|c|c|c|c|c|c|}
\hline & & $\mathbf{N}$ & Mean & Std. Deviation & Std. Error \\
\hline \multirow{4}{*}{ Gains in Content } & EG & 37 & .3784 & .32071 & .05272 \\
\hline & $\overline{\mathrm{C} 1}$ & 26 & .2500 & .29155 & .05718 \\
\hline & $\mathrm{C} 2$ & 28 & .1786 & .27936 & .05279 \\
\hline & Total & 91 & .2802 & .30920 & .03241 \\
\hline \multirow{4}{*}{ Gains in Organisation } & EG & 37 & .5270 & .35249 & .05795 \\
\hline & $\mathrm{C} 1$ & 26 & .3269 & .28080 & .05507 \\
\hline & $\mathrm{C} 2$ & 28 & .2679 & .31862 & .06021 \\
\hline & Total & 91 & .3901 & .33995 & .03564 \\
\hline \multirow{4}{*}{ Gains in Language } & EG & 37 & .0135 & 2.30786 & .37941 \\
\hline & $\mathrm{C} 1$ & 26 & .0962 & .24573 & .04819 \\
\hline & $\mathrm{C} 2$ & 28 & .1071 & .24934 & .04712 \\
\hline & Total & 91 & .0659 & 1.47235 & .15434 \\
\hline \multirow{4}{*}{ Gains in Accuracy } & $\mathrm{EG}$ & 37 & .1486 & .28541 & .04692 \\
\hline & $\mathrm{C} 1$ & 26 & -.0192 & .30069 & .05897 \\
\hline & $\mathrm{C} 2$ & 28 & .0536 & .36866 & .06967 \\
\hline & Total & 91 & .0714 & .32155 & .03371 \\
\hline
\end{tabular}

Table 6.10: ANOVA for Gains in Writing Components across Three Groups

\begin{tabular}{|c|c|c|c|c|c|c|}
\hline & & $\begin{array}{l}\text { Sum of } \\
\text { Squares }\end{array}$ & df & Mean Square & $\mathbf{F}$ & Sig. \\
\hline \multirow[t]{3}{*}{ Gains in Content } & Between Groups & .670 & 2 & .335 & 3.713 & .028 \\
\hline & Within Groups & 7.935 & 88 & .090 & & \\
\hline & Total & 8.604 & 90 & & & \\
\hline \multirow{3}{*}{$\begin{array}{l}\text { Gains in } \\
\text { Organisation }\end{array}$} & Between Groups & 1.216 & 2 & .608 & 5.825 & .004 \\
\hline & Within Groups & 9.185 & 88 & .104 & & \\
\hline & Total & 10.401 & 90 & & & \\
\hline \multirow[t]{3}{*}{ Gains in Language } & Between Groups & .173 & 2 & .086 & .039 & .962 \\
\hline & Within Groups & 194.931 & 88 & 2.215 & & \\
\hline & Total & 195.104 & 90 & & & \\
\hline \multirow[t]{3}{*}{ Gains in Accuracy } & Between Groups & .443 & 2 & .222 & 2.201 & .117 \\
\hline & Within Groups & 8.862 & 88 & .101 & & \\
\hline & Total & 9.306 & 90 & & & \\
\hline
\end{tabular}


Table 6.11: Differences in Gains in Writing Components across Three Groups

\begin{tabular}{|c|c|c|c|c|c|}
\hline $\begin{array}{l}\text { Dependent } \\
\text { Variable }\end{array}$ & (I) Group & (J) Group & $\begin{array}{l}\text { Mean } \\
\text { Difference (I- } \\
\text { J) }\end{array}$ & Std. Error & Sig. \\
\hline \multirow[t]{6}{*}{ Gains in Content } & \multirow[t]{2}{*}{$\mathrm{EG}$} & $\mathrm{C} 1$ & .12838 & .07684 & .098 \\
\hline & & $\mathrm{C} 2$ & $.19981^{*}$ & .07522 & .009 \\
\hline & \multirow[t]{2}{*}{$\overline{\mathrm{C} 1}$} & $\mathrm{EG}$ & -.12838 & .07684 & .098 \\
\hline & & $\mathrm{C} 2$ & .07143 & .08178 & .385 \\
\hline & \multirow[t]{2}{*}{$\mathrm{C} 2$} & $\mathrm{EG}$ & $-.19981^{*}$ & .07522 & .009 \\
\hline & & $\mathrm{C} 1$ & -.07143 & .08178 & .385 \\
\hline \multirow{6}{*}{$\begin{array}{l}\text { Gains in } \\
\text { Organisation }\end{array}$} & \multirow[t]{2}{*}{ EG } & $\mathrm{C} 1$ & $.20010^{*}$ & .08268 & .018 \\
\hline & & $\mathrm{C} 2$ & $.25917^{*}$ & .08092 & .002 \\
\hline & \multirow[t]{2}{*}{$\mathrm{C} 1$} & EG & $-.20010^{*}$ & .08268 & .018 \\
\hline & & $\overline{\mathrm{C} 2}$ & .05907 & .08799 & .504 \\
\hline & \multirow[t]{2}{*}{$\mathrm{C} 2$} & EG & $-.25917^{*}$ & .08092 & .002 \\
\hline & & $\mathrm{C} 1$ & -.05907 & .08799 & .504 \\
\hline \multirow[t]{6}{*}{ Gains in Language } & \multirow[t]{2}{*}{ EG } & $\mathrm{C} 1$ & -.08264 & .38087 & .829 \\
\hline & & $\mathrm{C} 2$ & -.09363 & .37280 & .802 \\
\hline & \multirow[t]{2}{*}{$\mathrm{C} 1$} & EG & .08264 & .38087 & .829 \\
\hline & & $\mathrm{C} 2$ & -.01099 & .40535 & .978 \\
\hline & \multirow[t]{2}{*}{$\mathrm{C} 2$} & $\mathrm{EG}$ & .09363 & .37280 & .802 \\
\hline & & $\mathrm{C} 1$ & .01099 & .40535 & .978 \\
\hline \multirow[t]{6}{*}{ Gains in Accuracy } & \multirow[t]{2}{*}{ EG } & $\mathrm{C} 1$ & $.16788^{*}$ & .08121 & .042 \\
\hline & & $\mathrm{C} 2$ & .09508 & .07949 & .235 \\
\hline & \multirow[t]{2}{*}{$\mathrm{C} 1$} & $\mathrm{EG}$ & $-.16788^{*}$ & .08121 & .042 \\
\hline & & $\mathrm{C} 2$ & -.07280 & .08643 & .402 \\
\hline & \multirow[t]{2}{*}{$\mathrm{C} 2$} & $\mathrm{EG}$ & -.09508 & .07949 & .235 \\
\hline & & $\mathrm{C} 1$ & .07280 & .08643 & .402 \\
\hline
\end{tabular}

It was interesting to find out that the control groups followed the same pattern (Figure 6.2) closely in component improvements (organisation, content, language, and accuracy) even though they were not given any metacognitive treatment. C1 was slightly better than $\mathrm{C} 2$ in organising ideas and planning for content for an essay. However, the opposite trend was true for the language and accuracy elements. In fact, $\mathrm{C} 2$ improved the language aspect more than $\mathrm{C} 1$. Also, it was $\mathrm{C} 2$ that made progress in grammatical accuracy while the accuracy improvement of the EG was minimal. $\mathrm{C} 1$, on the other hand, made a negative improvement on accuracy. 
Figure 6.2: Gains Made in Writing Components across Three Groups

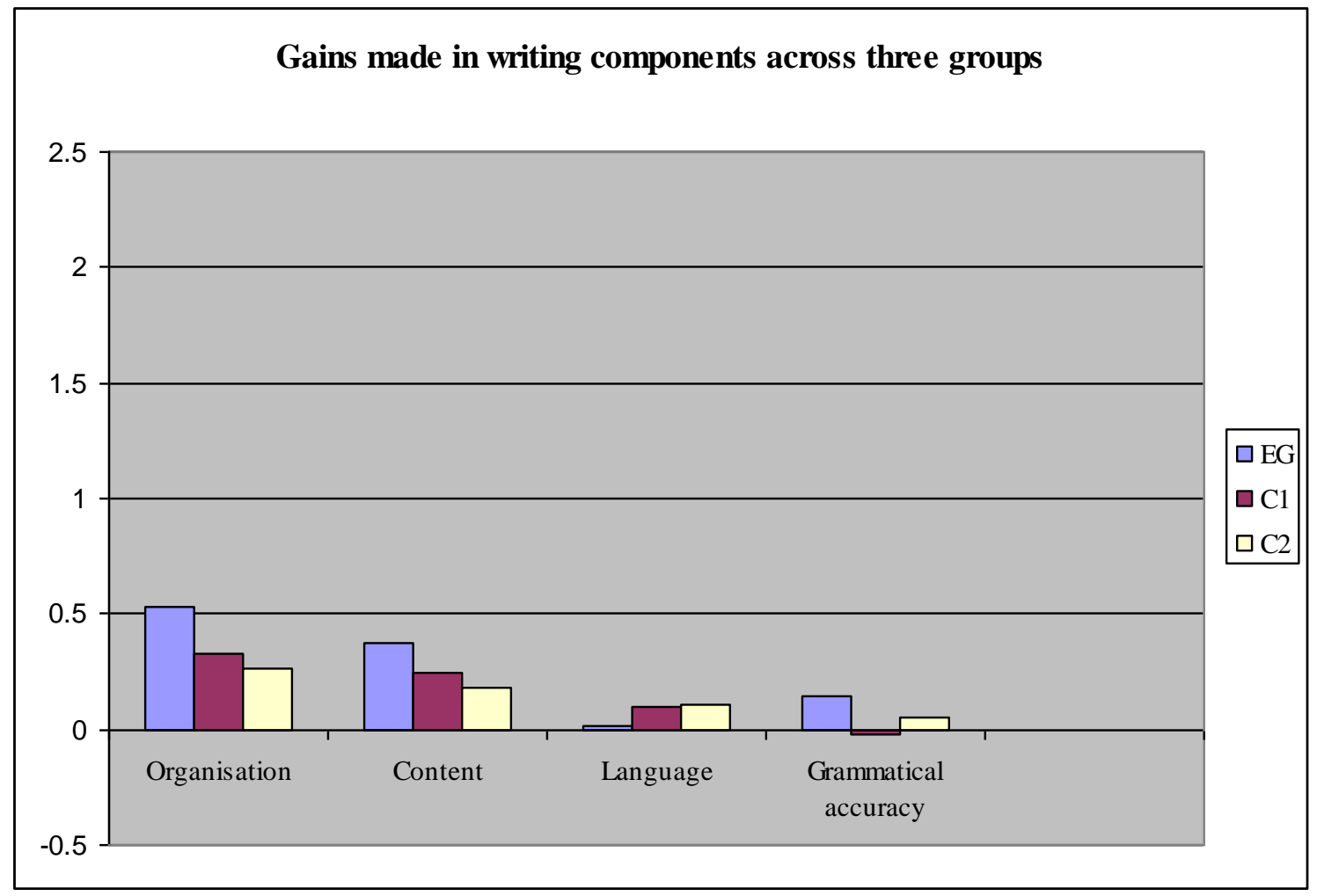

On the basis of the statistical analyses, it can be concluded that after the EG had received training in metacognitive skills of planning, monitoring, and evaluating, it achieved large gains in organisation, content, and accuracy though not much in language. Explanation and further discussion of these aspects will be presented next.

\subsubsection{Organisation}

The most remarkable improvement students across the three groups made in their essay was in organisation. However, the EG was the best among them. Triangulation of data from classroom observation, teacher interview and the follow-up interview with students provided interesting insights as to why organisation was the most enhanced aspect among the four.

It was shown that in $\mathrm{C} 1$ and $\mathrm{C} 2$ both teachers placed a lot of emphasis on the organisation of the essay. Firstly, both teachers viewed making an outline as a way to plan for an essay organisation. Both spent two hours (out of the 36 hours of writing lessons) teaching students how to make an outline for their essay. Secondly, both paid a lot of attention to organisation when they were teaching. For example, in answering 
the question about the focus of her lesson and how she actually conducted the lesson on an argument essay, Ms Loc claimed:

The first thing I taught when I started a new kind of essay was its organisation. I always told students about the organisation of an essay so that they knew how to organise their essay. At the same time I gave them a sample essay for reference... (from Interview L, Q3, P2).

Ms Loc's choice of organisation as a focal point of an essay was confirmed by classroom observation two. As observed by the researcher, when students were writing a concluding paragraph for an essay, Ms Loc constantly asked students to pay attention to the organisation of the essay for which they wrote a concluding paragraph. For example, after she explained the task of writing a concluding sentence for an essay she explained the organisation of an essay:

\footnotetext{
You see, in the thesis statement the author mentions about taking a nap in the afternoon and organising extracurricular activities for the staff as ways to enhance productivity, therefore in the body of his essay he writes two different paragraphs about those two things. So, in your concluding paragraph you should not write anything new. Instead, you should mention about those two things using your own words (from Classroom observation 2, C2, L5).
}

For the task, students were supposed to write the concluding paragraph only, Ms Loc, however, called students attention to the organisation of the essay. After students performed peer-correction for their concluding paragraphs that they had written on the board, Ms Loc once again said:

You have to make sure that your concluding paragraph covers all the ideas that you have stated in your thesis statement and have developed in your body paragraphs (from Classroom observation 2, C2, L19).

It was noticeable that Ms Loc always reminded her students about the organisation of the essay. This was consistent with students' responses in the follow-up interviews:

Ms Loc often teaches students how to organise ideas so that we would not be off the track when we are writing (Student 1, Q9, follow-up interview, P2).

She paid attention to all aspects but she focuses the most on organisation (Student 10, Q9, follow-up interview, P2). 
Likewise, Ms Phuoc put considerable emphasis on the organisation of an essay through teaching students how to make an outline and to organise ideas for their essay. Her reasons for doing so included students' lack of background knowledge which resulted in their failure to differentiate between general and specific ideas (Interview P, Q11, P2). In addition, Ms Phuoc provided students with sample outlines for different kinds of essay as a framework for her students to follow. Her focus on organisation was reinforced when she was correcting students' essays:

...I always correct mistakes on idea organisation, then sentence structure, vocabulary, spelling... (from Interview P, Q10, P2)

Although Ms Phuoc's attention to the organisation of the essay was not clearly captured in classroom observations, it was reflected in the follow-up interview with students. Many students stated the same opinion:

\footnotetext{
Organisation of essay (Student 9, Q9, follow-up interview, P2).

Grammar and organisation (Student 8, Q9, follow-up interview, P2).

Vocabulary and organisation (Student 7, Q9, follow-up interview, P2).

Grammar and organisation (Student 3, Q9, follow-up interview, P2).
}

In session four of the MT, the researcher attempted to expand students' understanding of how to organise their essays by helping them activate their world knowledge and rhetorical knowledge about the topic as well arrange the ideas they had generated. Specifically, students learned how to ask themselves some sets of questions to assess the knowledge, beliefs and values they had about the topic. For example, they answered the following sets of questions when choosing and structuring a topic:

- what shall I write about?

- what do I think about this topic?

- what is my opinion? 
and when developing and specify ideas:

- what can I say to show that.../to support this idea/to develop this point in my essay?

- what more can I add?

- what facts can I give to support my example?

- what other examples can I add?

- what can I say to explain?

- what's a related idea? A more appropriate idea?

After they had decided the ideas and their views about them, they organised their essay by considering firstly, the overall plan:

- how shall I organise the ideas that I have chosen to write about in my essay?

- how many points should I include in my thesis statement?

- which ideas from my thesis need elaboration?

- which one of these ideas do I discuss first, second, next?

- where does this idea fit best? How do I start?

- what shall I say in my introduction?

- when is it appropriate to conclude? What kind of information goes into the conclusion?

secondly, paragraph plan:

- how do I go about writing a paragraph?

- how do I start: with a general idea or a specific idea?

- how can I present my main idea? How many ideas have to be developed in a paragraph?

and thirdly, specifying techniques:

- how do I develop and/or specify...?

- $\quad$ should I add a fact/an example?

- what kind of information is needed?

On top of that, students were told to follow three steps to do both specific and general organisation for their essays. The first step was establishing main ideas to 
focus their analysis in which students had to consider selecting the ideas that they knew best and for which they could provide illustrative examples. They would write one paragraph for each main idea. In the second step, students arranged specific ideas to support the main ideas. To do this, students had to find more specific ideas from what they had brainstormed to support the main idea of each paragraph. In the third step students assembled their analysis by examining the points they had made and compiled their specific ideas into different paragraphs. They had to write a topic sentence which stated their subjects and the claim they wanted to make about them as a result of their analysis. Apart from promoting the activation of world knowledge and rhetorical knowledge to organise essays, during the training sessions the researcher also gave a lot of examples to illustrate the possible organisation of the essays that students were going to write by drawing the organisation outlines on the board. Additionally, she went around the classroom to help students with their essay organisation. Teaching students a combination of general and specific organisational planning thus explained the EG's best scores on the organisation aspect.

Apart from organisation, content is another area in which the EG achieved a better result than the two control classes. The content aspect will be presented in the following section.

\subsubsection{Content}

It seemed that it was more difficult for students to learn how to generate ideas for their essays than to learn how to organise their ideas into their essays. This was possibly because organisation had a lot more to do with arranging things that were already there while planning for content involved creating what to put in an essay. To be able to do so, students would necessarily produce their ideas based on their background knowledge, a much more difficult step than just arranging ideas. However, it was revealed that students in the study possessed poor background knowledge. In fact, both teachers complained that their students "don't have ideas to write about" (Interview P, Q12, P2) or "usually have difficulty finding ideas for their essays" (Interview L, Q11, P2). Ms Phuoc, furthermore, saw students' poor background knowledge as the most pressing problem her students experienced while writing an essay (Interview P, Q11, P2). Likewise, many students were aware that their weakness was finding ideas for their essays. For instance, one student said: 
I often lost ideas so I forced myself to sit there for a very long time to generate ideas. That is why, it consumed a lot of my time. When the time was nearly up, I was writing the conclusion. I ended up having no time to check my work after I finished it (Student 8, Q10, follow-up interview, P2).

Others stated:

... Finding ideas for an essay is difficult (Student 2, Q10, follow-up interview, P2).

... My ideas are so poor (Student 3, Q10, follow-up interview, P2).

Content of the essay thus was an area that needed developing among students, yet they did not receive sufficient support from their teachers. Classroom observations and interviews suggested that group and class discussion were the most common activities used to help students brainstorm for the content of their essay. For example, Ms Loc said that:

For topics which students have limited background for I often get all of them involved in the brainstorming activity by putting questions related to the topic (from Interview L, Q4, P2)

Similarly, Ms Phuoc made a very good use of group discussion as a means through which students brainstormed, gathered and selected ideas for their essays. In the follow-up interview students pointed out that making an outline in group was the first thing they needed to do in class for their essay. Apart from group and class discussion, the interview reported that Ms Loc had always provided students with reading materials on the topics she asked them to write about.

Both Ms Loc and Ms Phuoc found ways to help their students generate ideas for their essays: either the teacher did the job by providing them materials related to the topic, as in the case of Ms Loc, or letting students rely on each other for finding ideas for their essays. Although students maintained that group work and class discussion were of value to them because of the range of ideas generated together, classroom observations conducted by the researcher at both classes demonstrated that the teachers did not teach them any strategies that might assist them in generating ideas and testing the usefulness of ideas generated. All students did in groups was to think of as many ideas as possible. They seemed to be happy because they benefited 
from each other's ideas. If they failed to come up with an idea, they could rely on the ideas created by their group's members. Nevertheless, they expressed their great concern when it came to writing their essay on their own, especially when they had a test or sat a writing exam:

Working in groups is good for me because I can have many ideas from my friends but I am worried when I take an exam...(Student 1, Q17, follow-up interview, P2).

This was because when students took an exam, they would need to brainstorm ideas on an individual basis. Using group work or class discussion for generating ideas thus would not be appropriate anymore.

While the control classes made some improvement in the essay content, the improvement in the EG was greater. Explicitly teaching brainstorming steps to students appeared to make a positive difference in individual development of essay content. In addition to asking students to do group work for making an outline for "Being the only child in the family" or class discussion for generating ideas for "College uniforms" as Ms Loc reported doing (Interview L, Q7, P2), the researcher repeatedly and explicitly told students to follow three hints (adapted from the internet) in the brainstorming process which helped them create ideas for their essays.

The three hints included doing individual thinking, verbalising in pairs or groups, and classifying into proper categories. The first hint aimed to activate students' background about the topic, and to touch upon their imaginations for all the information or new ideas required for the topic. Specifically, they learned to ask questions to develop a perspective on a subject such as "who," "what," "when," "where," "why," and "how" in order to get a sense of the subject's scope and of the way in which they might want to approach the subject - the angle that made sense for them to take when thinking about the subject. The second hint allowed students to discuss and exchange the information and ideas obtained by individual thinking with their desk-mates or with other students in class. They were taught to ask questions to determine a subject's feasibility once they had a few ideas that they thought might be appropriate for further development in their essay by answering such questions as: What exactly do I know about this subject? Where did I get my knowledge (first-hand experience, books, television, newspapers, or discussions with others)? Will my knowledge yield sufficient examples and details for me to write in some depth about 
this subject, or will I have to do some additional research and reading? That is, if I want to write about this subject, what else do I need to know? Where can I find additional information if I need more? Books? Magazines? Journals? Talking with peers? Family members? Personal observations? Are these information sources readily available to me? The third hint let students sort out their generated ideas according to their intrinsic nature. For example, after students generated their ideas for an essay which asked them to contrast differences between going to the city and going to the beach on vacation, they were told to group the ideas according to activities to do, clothes to bring, expenses to pay at each place. They might also categorise their ideas around the pros and cons of each place.

In short, the students' understanding of generating ideas and testing the usefulness of their ideas seemed to be deepened by engaging in individual thinking, group discussion and searching information needed from different sources. Most importantly, during all the training sessions the students were frequently given time to practise the hints mentioned and overtly told that using those hints would help.

Providing scaffolding seemed to contribute to making a difference between the EG and $\mathrm{C} 1$ and $\mathrm{C} 2$. The EG students were encouraged to ask themselves sets of questions learned from the training session, to talk to their classmates, or to search for the information on the internet or from other sources when they got stuck and failed to find ideas for their essays. The value of the strategy for generating content was reinforced by student diary entries:

I can improve my writing skill, especially about content, organisation (LTY, Diary, Week 6).

And the part I like most is planning for content. Before learning this planning skill I just wrote down everything happened in my mind and then messed up by those. Fortunately, I knowed to categorise ideas and arrange them logically (HNN, Diary, Week 8).

In brief, the success in content improvement of the EG could be attributed to the three hints provided for students to generate ideas not only by working in groups but also by working independently.

While content and organisation were the two areas in which students made significant developments, language and accuracy were the ones in which students reported little progress. The following section is devoted to discussing the language aspect. 


\subsubsection{Language}

It was interesting to find out that language was the single aspect in which the EG lost ground to $\mathrm{C} 1$ and $\mathrm{C} 2$. According to Table 6.9 both control classes achieved a better growth in the language element than the EG. Specifically, C1 and C2 reached almost the same level of gain in the language aspect: 0.0962 and 0.1071 respectively while the EG obtained nearly no gain at all (0.0135). However, these figures did not indicate that the two control classes outperformed the EG. In fact, the pre-test mean score of the language aspect of the EG was 1.7432 and that of the post-test was 1.7568, both of which were higher than the post-test scores of C1 (1.3269) and C2 (1.5179). The reason the EG did not make much progress in the language aspect after the MT could be because it had already practised the language aspect before. To get the maximum of 2.5 marks for the language aspect (out of 10 marks as a total) for their essay, students had to be able to use cohesive devices, descriptive words, a variety of sentence structures, and the appropriate choice of vocabulary. While some aspects of language acquisition such as the use of cohesive devices can be mastered by employing rote learning, other elements such as sentence structure or the right choice of vocabulary require more time and practice. For example, it would be much easier and faster for students to learn by heart and to use such connective words as: concerning, as for, with regard to, with respect to, regarding in order to introduce a topic while writing their essay than to learn how to use a sentence structure or appropriate vocabulary in their essay without practice.

Following this line of thinking, it was understandable why the two control classes made more progress than the EG. Firstly, the main focus of session five on Planning for the language of the MT was put on cohesive devices aimed at helping students string their ideas together to make a cohesive piece of writing. Although the researcher told her students to consider different sentence structures or vocabulary for their essays, she did not spend enough time for them to further practise those elements. However, after a count of the cohesive devices used in the pre- and posttests of EG, it was discovered that students in the EG made significant progress in their post-test (Table 6.12). 
Table 6.12: Number of Cohesive Devices Used by Students in EG

\begin{tabular}{lll}
\hline & Pre-test $(\mathbf{N}=37)$ & Post-test $(\mathbf{N}=37)$ \\
\hline Total number of cohesive devices used & 42 & 153 \\
\hline $\begin{array}{l}\text { Average number of cohesive devices } \\
\text { used }\end{array}$ & 1.1 & 4.1 \\
\hline
\end{tabular}

To illustrate, the number of cohesive devices used in all 37 pre-tests was 42 . The figure rose dramatically reaching 153 in 37 post-tests. To put it more simply, on average in the pre-test each student in the EG used only 1.1 cohesive devices while in the post-test each used four times as many, 4.1 connectives devices. In addition to the increased number of cohesive devices used, it was discovered that in their post-test students in the EG included a range of new cohesive devices learned from session five on language planning. For instance, the most commonly used cohesive device for the purpose of adding found in the pre-test was besides. Out of the 42 devices used, there were six tokens of this word. However, in the post-test its equivalents such as furthermore, in addition, additionally were found. Another example was the presence of such words as in brief, to conclude, to sum up in the post-test instead of in general and in conclusion in the pre-test. Students also successfully incorporated into their essays devices showing contrast such as on the one hand, on the other hand, while, meanwhile, whereas, on the contrary, in contrast. These words were totally absent in their pre-test though both pre-and post-tests asked them to write a comparison and contrast essay. In other words, the EG did make progress in the language aspect, especially in the use of cohesive devices. However, the improvements students made in the use of cohesive devices were not sufficient to compensate for the low improvement of other elements involved in the language aspect.

Secondly, concerning the in-class time assigned for learning cohesive devices, there was no difference between the EG and $\mathrm{C} 1$. Classroom observations and interviews revealed that Ms Phuoc devoted one 1-hour lesson out of 36 lessons to teaching $\mathrm{C} 1$ cohesive devices. In addition to that, for each type of essay, she provided students with useful cohesive devices. Thirdly, both control classes had more in-class contact hours than the EG: 36 hours against 27 hours respectively, which meant they had more time for improving other elements such as vocabulary or sentence structures through practice and correction sessions. 
In summary, students in the EG failed to enhance the language aspect due to less in-class time for learning and practice. Although they might not succeed in improving vocabulary or sentence structures, which were part of the assessment criteria for the language component, they, nevertheless, used more cohesive devices in their post-test. The control groups, on the other hand, were able to improve not only the cohesive devices but also other language elements thanks to the greater number of in-class contact hours which enabled them to have more practice and feedback from their teachers on the use of vocabulary and a variety of sentence structures.

Next to the language aspect was grammatical accuracy in which students also reported insignificant enhancements. This feature is reported in the following section.

\subsubsection{Grammatical accuracy}

In order to obtain a score of 2.5 marks for the grammatical accuracy component, students had to write grammatically correct sentences, including subject-verb agreement, verb tense, verb form, active/passive, punctuation, number, article, pronoun, preposition, word order, idiomatic expression, and spelling.

Compared to other aspects, grammatical accuracy improved the least. In this regard, the story was different among the three groups. While the EG and C2 made positive though slight gains: 0.1486 for the former and 0.0536 for the latter (Table 6.9), it was unexpected that the opposite trend applied to $\mathrm{C} 1$. There were a number of factors involved in the interpretation of the results.

Firstly, it was reasonable that the EG obtained a good score in the grammatical accuracy aspect. In addition to the diary entries that students in the three classes were asked to write by Ms Phuoc and Ms Loc, students in the EG were invited by the researcher to write another set of diary entries. The primary purpose of asking students to write diaries was for the researcher to gather information on the application of metacognitive skills of planning, monitoring and evaluating in learning writing and in learning other subjects. However, students wanted to write their diaries in English and to get them corrected by the researcher. To encourage their motivation, the researcher corrected any grammatical mistakes they made in their weekly diary entries. At the beginning of each metacognitive session, the researcher returned diaries to students and wrote on the board commonly-made grammar mistakes and 
asked students to correct so that they would not make the same errors again. This may explain why the EG did slightly better in grammatical accuracy than the two control classes.

One reason connected to the negative improvement of $\mathrm{C} 1$ could be the students' existing low level of grammatical proficiency. Both Ms Loc and Ms Phuoc complained about their students' poor grammar as one of the most pressing problems their students were facing. For instance, Ms Phuoc said:

$\ldots$ they make too many grammatical errors (from Interview P, Q2, P2)

and:

... the grammatical knowledge of many students is very poor, especially the syntax. Vocabulary knowledge is indeed very important for their essay but it was overwhelmed by grammatical mistakes. In the two classes that I am teaching (experimental and Control 1), there are 10 students whom I have no idea how help. I am sort of giving up. There is no way to help them but giving private tutoring... (from Interview P, Q11, P2)

Because of poor grammar, the more students wrote, the more errors they would make, which would negatively affect the teachers' impression of students' accuracy. An investigation into the text length of the three groups displayed a significantly increased length in the post-test compared with that of the pre-test. For this reason, students had the tendency to make more grammatical mistakes when they wrote longer texts. The other interpretation was that some students might make grammatical errors in one area but not necessarily in the other. For example, some might make spelling mistakes in their post-test, but not in the pre-rest. Maybe, it was in the posttest that students in $\mathrm{C} 1$ made more errors. Another possibility could be the fact that the writing proficiency level of $\mathrm{C} 2$ was higher than that of $\mathrm{C} 1$ as shown by the writing score of the previous semester (6.8 against 6.3). Understandably, C2 outperformed Control 1 in the accuracy aspect.

In short, the MT project contributed to fostering grammatical accuracy for the EG. While it takes time for students to acquire grammar of the target language, writing diaries in English and having them corrected by both Ms Phuoc and the researcher could have been one of the ways that helped students improve grammatical accuracy. 


\subsubsection{Samples of students' writing texts}

To illustrate findings on the improvements in the four aspects discussed above, samples of pre-and post-tests written by three students from the EG, C1 and C2 are presented.

Table 6.13: Scores of English-Related Subjects for Three Average Students

\begin{tabular}{lllllllll}
\hline \multirow{2}{*}{ Student } & \multirow{2}{*}{ Group } & \multicolumn{2}{c}{$\begin{array}{c}\text { Translation Listening } \\
\text { theory }\end{array}$} & $\begin{array}{l}\text { Writing } \\
\text { translation }\end{array}$ & translation & Reading 3 & Writing 3 & Average \\
\hline Student 1 & EG & 7 & 6 & 8 & 7 & 7 & 7.0 \\
\hline Student 2 & C1 & 8 & 7 & 7 & 8 & 7 & 7.4 \\
\hline Student 3 & C2 & 6 & 8 & 7 & 7 & 7 & 7.0 \\
\hline
\end{tabular}

The three students had a similar writing test score from the previous semester and their average score for English-related subjects, including writing, compatibly ranged from 7.00 to 7.4 out of the 10 -mark scale (Table 6.13). As for the test instruction, for the 60-minute pre-test students wrote an essay of 150-200 words comparing and contrasting going on holiday by car and by train. In the post-test, within a similar time limit, they were given two choices. There were two topics for them to choose from. For the first topic they wrote about similarities and differences in studying at a high school and at a university in Vietnam. Their second choice asked them to write about spending a weekend indoors and spending a weekend outdoors. 


\section{Pre-test written by Student 1 from the EG (Essay 1):}

"Going on holiday is one of the ways that most of families choose to relax at the weekend or on the special occasions. There are many means of transportation such as car, train. I think that nowadays will have many people choose to going on holiday by car because of its advantages such as a fast speed and stopping whenever you need, have a active time.

The first thing I want to mention is that you can sane time. So you can have time to discover the place you set down. For example, at Quang Binh you want to visit Danang, you will spend at least 8 hours with a normal train, but you only spend 5 hours to go there by car. It is the first convenience if you go on holiday by car.

You can be active about time if you go on holiday by car. You can catch the car whenever you like instead of waiting to buy the ticket a lot of hours. Besides, on your way you can stop to see interesting places. So, going on holiday by car is a first choice to go on holiday.

In short, more people choose car to go on holiday because of its conveniences, I hope that you will have a comforfigure holiday if you go by car." (220 words)

\section{Post-test written by Student 1 from the EG (Essay 2):}

"Everyone wants to have a weekend after a busy work with work. Some people will spend a weekend indoors, while others like to spend a weekend outdoors. Besides some similarities, the differences are shown clearly. We will look at the atmosphere, the activities you are able to do.

There are similarities between spending a weekend indoors and spending a weekend outdoors. Both are a rest day. Like spending a weekend outdoors, spending a weekend indoors makes you comforfigure.

The first difference between spending a weekend indoors or outdoors is the activities you are able to do. I think that when you go out, you will have a lot of activities to do. For example, you can go shopping to buy something that you need all week. If you want to take your children to the zoo, this is a wonderful opportunity. Your family will very happy. Besides, you can to the beach, the cinema. On the contrary, you only watch TV or listen music all day without doing something if you stay at home. So, you can do lot of activities in your rest-day if you go out.

Another difference between spending a weekend indoors or outdoors is the atmosphere. If you are a person who likes peaceful atmosphere, maybe you can sleep all day but I think it is very boring. Nevertheless, you will meet your friends, talk to them when you go out. And this makes you fun comforfigure. While spending a weekend indoors, you will not have such a feeling.

In conclusion, except for similarities, to have a wonderful weekend indoors or outdoors, you are always concerned about the feeling as well as that you can do in your weekend. I think that people will have a choice that fits their hobby." (295 words) 


\section{Pre-test written by Student 2 from C1 (Essay 3):}

"Car and train are types of transport that we often use to go on holiday. When we travel by car and train, we can see scene outside during the trip.

However, going on holiday by train, it is seem to be more safe than car Because train have a particular railway system. In our country, car and bicycle, motobike move on general way. Especially, drivers don't work out law truly so accidents usually take place. On the other hand, if we travel by car, we can go anywhere Because the railway system is limited compared with ways for car." (99 words)

\section{Post-test written by Student 2 from C1 (Essay 4):}

"After doing work a busy week, you have two day at weekend. You can spend a weekend outdoors to relax with your family and friends. You can do anything you want. But spending a weekend indoors and spending a weekend outdoors have differences such as activities, atmosphere, so you have different feelings.

A weekend outdoors will help you to reduce stress and to relax after busy work; a weekend indoors will, too. You can do your favourite things such listen to music, eat with family. Those things make your mood better to continue work on Monday.

However, A weekend outdoors has more activities than a weekend indoors. When you spend free time at home, you can only do things such as watching television, reading or cooking. But you can do it and more, when you spend a weekend outdoors such sightseeing, playing sports, fishing. These activities you can not do at home.

Besides, atmosphere of a weekend outdoors is more fresh than a weekend indoors.

To sum up, spending a weekend indoor or a weekend outdoor both help you comforfigure. However, each activity have advantage and disadvantage." (187 words)

\section{Pre-test written by Student 3 from C2 (Essay 5):}

\footnotetext{
“Almost people enjoy going on holiday by car or train. You feel more comforfigure and convenient if going on holiday by car and if you want save money, you should going by train. But it is interesting to spend your holiday with two transportation.

When you go with your family or your friend, you should choose a car. It helps you sightseeing and take photograph anywhere. With a quality car such as taxi enough for your family, you feel more convenient. However, if you don't have enough money for your trip, you can going by train. It is a best way to save money. We must buy ticket before starting. You have a problem about your health such as scasick, a train is a good choice for you.
} 
Nowadays, more and more transportation with technology moden but someone enjoy strating their trip by car or train. Maybe they are best choice”. (151 words)

\title{
Post-test written by Student 3 from C2 (Essay 6):
}

\begin{abstract}
"There are many things on where to choose spending a weekend. Some people like to spend a weekend indoors but others spend a weekend outdoors. Both places offer a variety of things. In fact as places for weekend indoors and outdoors are different in some ways.

The two main idea lead to spend a weekend indoors are climate and activities. Climate is always important to take part in your free times. The cook climate outdoors is the first factors to enjoying your weekend.

In contrast, the warm climate in indoors helps you fell more comforfigure. If you dislikes cold or cool weather, spending a weekend is the best your choice. The climate and the temperature are also determine the types of activities you want. Setting up tent, swimming, and go fishing are some activities you can enjoy when spending a weekend outdoors.
\end{abstract}

During your weekend, cooking, watching television and playing chess are some activities you will prefer when spending a weekend indoors.

Your choice can be either outdoors or indoors depend on weather you like and the activities you enjoy. It is interesting for you to choose any places you want if its can bring happiness to you. You might prefer the outdoors to spend you weekend, but sometimes it is better to take a risk and find a different place to enjoy." (223 words)

Several comments could be made about the students' samples of writing texts. The remarks around length, organisation, content, language, and grammatical accuracy are discussed on the basis of the marking scheme (Table 3.8).

First of all, at the post-test students wrote more than at the pre-test indicating that they had more ideas for their essays by the end of the Writing Four course. In terms of organisation, all three students made considerable achievements in the posttest. To illustrate, in the introduction of two (out of three) essays, a thesis statement was included. Also, a concluding sentence was present in their essay. Moreover, in every paragraph, there was a topic sentence. Most importantly, each paragraph discussed one main point mentioned in the thesis statement. Some examples and personal experiences were incorporated to illustrate the point.

However, it was Essay 2 by the student from the EG that neatly and in a balanced way developed the two points into two different paragraphs: one about 
activities to do at weekend and the other about the atmosphere. Essay 6 by a student from C2 was pretty good; however the thesis statement was combined in the body of the essay. On top of that three arrows were employed as signs for introduction, body and conclusion of the essay instead indenting the first letter of a paragraph. Essay 4 by a student from $\mathrm{C} 1$ would have been almost perfect if there had not been a fourth paragraph comprising of only one sentence discussing the atmosphere.

As far as the content is concerned, the information given in Essay 2, Essay 4, and Essay 6 was relevant to the topic and appropriate. None of them was too short or too long. Nevertheless, Essay 4 (by a student from C1) should have provided more information on the atmosphere. Regarding the language, cohesive devices were integrated in all essays. In fact, the number of cohesive devices was five (for example, on the contrary, so, nevertheless, in conclusion) for Essay 2; four (so, however, besides, to sum up) for Essay 4; and two (in fact, in contrast) for Essay 6. Still Essay 2 (by a student from the EG) was the most cohesive because several sentence structures and words were employed to reflect the similarities and difference such as: the first difference is..., another difference is..., both are..., like .... With respect to grammatical accuracy, fewer errors were made in Essay 2. The number of errors for Essay 2, Essay 4, and Essay 6 was four, nine, and twelve respectively.

To conclude, the six sample essays were not representative of each group as a whole. They only represented the writing by students of the average level of each group. Nonetheless, Essay 2 by a student from the EG could be considered the best among the others. The MT, hence, seems to have proved to be worthwhile.

\subsubsection{MT and improvements for students of different academic achievement}

This section presents writing improvements made by top, average and bottom students in the EG. The top, average, and bottom students were defined on the basis of the student academic classification made by the university where the MT was conducted (Table 3.15). Out of 37 students in the EG, 34 took all three tests. The numbers of top, average, and bottom students were eight, 20, and five respectively. In order to find out about the category of students who gained the most from the MT, the gains were calculated by obtaining the difference between pre- and post-test mean scores. 
Table 6.14 shows that average students made the most gains (1.700), followed by top (1.312) and bottom (1.100) students. The $F$ ratio for the gains was $F(2,30)=$ 1.573, n.s (Table 6.15). This indicates that the gains the three types of students made did not statistically differ from each other, though there was a numerical difference among them. The post-hoc tests (Table 6.16) show how each category of students differed from the other in terms of the gains they had made. The mean difference between average students and bottom students is .6000. The figure for average and top students is .3850 . These numerical differences were an indication of average students making more gains in writing than bottom and top students. However, in both cases, the significance value was greater than .05 , which means the gains the average students made over the other groups of students were not significantly different from the gains made by bottom and top students. Similarly, no statistical difference was found between top and bottom students (n.s).

Table 6.14: Descriptive Statistics for Writing Improvements for EG

\begin{tabular}{llllll} 
& & N & Mean & Std. Deviation & Std. Error \\
\hline Post-test - Pre-test & Bottom student & 5 & 1.1000 & .82158 & .36742 \\
\cline { 2 - 6 } & Average student & 20 & 1.7000 & .83351 & .18638 \\
\cline { 2 - 6 } & Top student & 8 & 1.3125 & .53033 & .18750 \\
\cline { 2 - 5 } & Total & 33 & 1.5152 & .78546 & .13673 \\
\hline
\end{tabular}

Table 6.15: ANOVA for Writing Improvements for EG

\begin{tabular}{lllllll}
\hline & & Sum of \\
& & Squares & df & Mean Square & F & Sig. \\
\hline Post-test - Pre-test & Between Groups & 1.874 & 2 & .937 & 1.573 & .224 \\
\cline { 2 - 7 } & Within Groups & 17.869 & 30 & .596 & & \\
\cline { 2 - 7 } & Total & 19.742 & 32 & & & \\
\hline
\end{tabular}

Table 6.16: Differences in Writing Improvements for EG

\begin{tabular}{llllll}
\hline \multirow{2}{*}{ Dependent Variable } & (I) Academic & (J) Academic & \multicolumn{2}{l}{$\begin{array}{l}\text { Mean } \\
\text { Difference }(\mathbf{I}-\text { Std. }\end{array}$} \\
\hline Post-test - Pre-test & Rating & Rating & J) & Error & Sig. \\
\cline { 2 - 6 } & Bottom student & Average student & -.60000 & .38588 & .130 \\
\cline { 2 - 6 } & Average student & Bop student & -.21250 & .43998 & .633 \\
\cline { 2 - 6 } & & Top student & .38750 & .32285 & .239 \\
\cline { 2 - 6 } & Top student & Bottom student & .21250 & .43998 & .633 \\
\cline { 2 - 6 } & & Average student & -.38750 & .32285 & .239 \\
\hline
\end{tabular}


Only numerical difference was found among top, average, and bottom students in the EG in terms of the gains they made in their writing after they had received the training in metacognition, the finding suggested that the MT package was of some benefit to 20 average students, the largest proportion of the student population in the EG. The result was encouraging because the MT was useful to a large number of students.

In summary, the MT package was valuable to students of different levels of writing proficiency. It could be claimed that the package was considerably worthwhile since average students, the largest number of students in the EG, proved to be the major beneficiaries. However, due to the small number of subjects involved in this section, these findings are very tentative.

\subsubsection{MT and maintaining of English writing improvements}

The delayed test was conducted six weeks after the MT had been completed. The delayed test was the end-of-term writing examination set by teachers at the Department of English, not by the researcher. All three groups sat the delayed test after they had finished the Writing Four course. Unlike the pre- and post-tests which required students to write comparison and contrast essays, the delayed test requested students to compose an argument essay which was not practised during the MT sessions. The marking criteria applied to marking the delayed test were not as detailed as those used for the pre- and post-tests (Table 3.14). The markers followed three main components, including content, organisation, and grammatical accuracy. They combined the language aspect with accuracy. Both one-way ANOVA and repeatedmeasures ANOVA were performed to compare means of three writing tests across the three groups.

Table 6.17 clearly demonstrates that in the delayed test, scores dropped across the three groups. Nevertheless, the EG managed to keep the highest score among the three groups. Its mean score was 6.2727. The figures for $\mathrm{C} 1$ and $\mathrm{C} 2$ were 4.8800 and 6.2400 respectively. The EG gained the highest score among the three groups. C1 obtained the lowest score, yet it showed the highest standard deviation indicating a considerable gap among students. Although the score of C2 was slightly lower than that of the EG, its having the smallest standard deviation showed that the difference among students was the least significant. The $F$ ratio $(2,80)=6.930, p<.05$ (Table 
6.18) shows that the three groups statistically and significantly differed from each other on the means of the delayed test. The significant difference in the three tests and among the three groups is clearly seen in the $F$ ratios for within-subject and betweensubject effects (Tables 6.19 and 6.20). The significance value for both cases was less than .001 .

Table 6.17: Descriptive Statistics for Three Tests across Three Groups

\begin{tabular}{lllll}
\hline & Group & Mean & SD & N \\
\hline Pre-test & EG & 5.833 & 1.4878 & 33 \\
\cline { 2 - 5 } & $\mathrm{C} 1$ & 5.120 & 1.5294 & 25 \\
\cline { 2 - 5 } & $\mathrm{C} 2$ & 5.860 & 1.1413 & 25 \\
\cline { 2 - 5 } Post-test & Total & 5.627 & 1.4289 & 83 \\
\cline { 2 - 5 } & $\mathrm{EG}$ & 7.348 & 1.5983 & 33 \\
\cline { 2 - 5 } & $\mathrm{C} 1$ & 5.760 & 1.5487 & 25 \\
\hline Delayed Test & Total & 6.500 & 1.2829 & 25 \\
\cline { 2 - 5 } & EG & 6.614 & 1.6199 & 33 \\
\cline { 2 - 5 } & $\mathrm{C} 1$ & 6.2727 & 1.54662 & 25 \\
\cline { 2 - 5 } & $\mathrm{C} 2$ & 4.8800 & 1.83303 & 25 \\
\cline { 2 - 5 } & Total & 6.2400 & 1.20000 & 33 \\
\hline
\end{tabular}

Table 6.18: ANOVA for Three Tests across Three Groups

\begin{tabular}{lllllll}
\hline & \multicolumn{1}{c}{ Sum of Squares } & df & Mean Square & F & Sig. \\
\hline \multirow{2}{*}{ Pre-test } & Between Groups & 9.188 & 2 & 4.594 & 2.323 & .105 \\
\cline { 2 - 7 } & Within Groups & 158.233 & 80 & 1.978 & & \\
\cline { 2 - 7 } & Total & 167.422 & 82 & & & \\
\hline \multirow{2}{*}{ Post-test } & Between Groups & 36.360 & 2 & 18.180 & 8.134 & .001 \\
\cline { 2 - 7 } & Within Groups & 178.802 & 80 & 2.235 & & \\
\cline { 2 - 7 } & Total & 215.163 & 82 & & & \\
\hline
\end{tabular}

Table 6.19: Within-Subjects Effects for Three Tests across Three Groups

\begin{tabular}{llllll}
\hline Source & Sum of Squares & df & Mean Square & F & Sig. \\
\hline Tests & 39.461 & 2 & 19.731 & 27.847 & .000 \\
\hline Tests * Group & 10.878 & 4 & 2.719 & 3.838 & .005 \\
\hline Error(Tests) & 113.367 & 160 & .709 & & \\
\hline
\end{tabular}


Table 6.20: Between-Subjects Effects for Three Tests across Three Groups

\begin{tabular}{llllll}
\hline Source & Sum of Squares & df & Mean Square & F & Sig. \\
\hline Intercept & 8751.664 & 1 & 8751.664 & 1685.387 & .000 \\
\hline Group & 67.889 & 2 & 33.945 & 6.537 & .002 \\
\hline Error & 415.414 & 80 & 5.193 & & \\
\hline
\end{tabular}

Table 6.21: Differences in Three Tests across Three Groups

\begin{tabular}{|c|c|c|c|c|c|}
\hline Tests & (I) Group & (J) Group & $\begin{array}{l}\text { Mean } \\
\text { difference (I- } \\
\text { J) }\end{array}$ & $\begin{array}{l}\text { Standard } \\
\text { error }\end{array}$ & Significance \\
\hline \multirow[t]{6}{*}{ Pre-test } & \multirow{2}{*}{$\mathrm{EG}$} & $\mathrm{C} 1$ & .5140 & .3748 & .174 \\
\hline & & $\mathrm{C} 2$ & .0594 & .3668 & .872 \\
\hline & \multirow{2}{*}{$\mathrm{C} 1$} & EG & -.5140 & .3748 & .174 \\
\hline & & $\mathrm{C} 2$ & -.4547 & .3989 & .257 \\
\hline & \multirow[t]{2}{*}{$\mathrm{C} 2$} & EG & -.0594 & .3668 & .872 \\
\hline & & $\mathrm{C} 1$ & .4547 & .3989 & .257 \\
\hline \multirow[t]{6}{*}{ Post-test } & \multirow[t]{2}{*}{$\mathrm{EG}$} & $\mathrm{C} 1$ & $1.2791^{*}$ & .4158 & .003 \\
\hline & & $\mathrm{C} 2$ & $.8890^{*}$ & .4069 & .032 \\
\hline & \multirow[t]{2}{*}{$\mathrm{C} 1$} & EG & $-1.2791^{*}$ & .4158 & .003 \\
\hline & & $\mathrm{C} 2$ & -.3901 & .4425 & .380 \\
\hline & \multirow[t]{2}{*}{$\mathrm{C} 2$} & EG & $-.8890^{*}$ & .4069 & .032 \\
\hline & & $\mathrm{C} 1$ & .3901 & .4425 & .380 \\
\hline \multirow{6}{*}{$\begin{array}{l}\text { Delayed } \\
\text { test }\end{array}$} & \multirow[t]{2}{*}{ EG } & $\mathrm{C} 1$ & $1.39273^{*}$ & .41049 & .001 \\
\hline & & $\mathrm{C} 2$ & .03273 & .41049 & .937 \\
\hline & \multirow[t]{2}{*}{$\mathrm{C} 1$} & EG & $-1.39273^{*}$ & .41049 & .001 \\
\hline & & $\mathrm{C} 2$ & $-1.36000^{*}$ & .43789 & .003 \\
\hline & \multirow[t]{2}{*}{$\mathrm{C} 2$} & EG & -.03273 & .41049 & .937 \\
\hline & & $\mathrm{C} 1$ & $1.36000^{*}$ & .43789 & .003 \\
\hline
\end{tabular}

Information as to which groups differed from each other is found in the post hoc tests in Table 6.21. The mean of the EG was statistically different from that of $\mathrm{C} 1$ at the 0.5 level. While the EG also had a higher mean than $\mathrm{C} 2$, the difference was not statistically significant. In other words, the EG only numerically differed from $\mathrm{C} 2$ on the mean of the delayed test. Overall, the EG maintained its advantage over the two control groups in English writing (Figure 6.3). 
Figure 6.3: Writing Scores of Three Groups across Three Tests

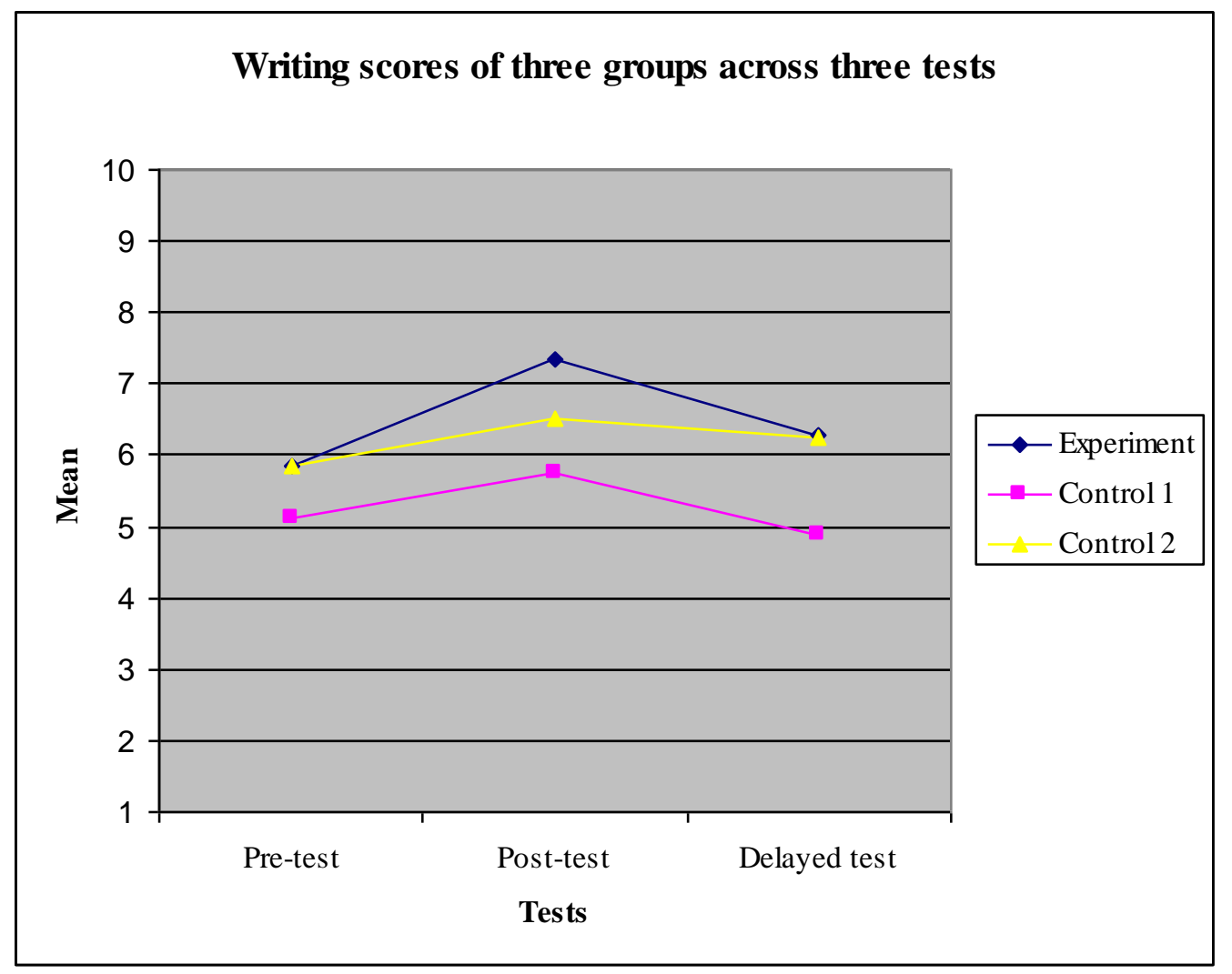

The results of the delayed test coincided with the data from the group interview. Responding to question three (Q3) of the group interview about whether or not in the future they would continue to use the planning, monitoring, and evaluating strategies learned from the metacognitive sessions, all five students (four top students and one average student) in the EG talked about their future use of these metacognitive skills. Their responses included:

Absolutely! I will (Student 1, Q3, group interview, P2).

Of course! They are so useful for me. When I write my thesis next year, I will use these strategies (Student 2, Q3, group interview, P2).

There is no need to ask this question! I feel more confident when I am writing an essay now (Student 3, Q3, group interview, P2).

I am positively sure I will use them (Student 4, Q3, group interview, P2).

Yes, yes, yes!!! You can check when you return next year (Student 5, Q3, group interview, $\mathrm{P} 2)$. 
It was unknown how often and for what kind of writing tasks they used the metacognitive skills. However, the two sources of data presented above provided some evidence that students in the EG continued to use the metacognitive skills of planning, monitoring, and evaluating after the MT intervention.

Generally, six weeks after the completion of the MT, students in the EG still used the skills of planning, monitoring, and evaluating in their writing. However, they did not practise the metacognitive skills as much as they had right after they received the training. It would be interesting to find out which types of student (top, average, or bottom) in the EG were least likely to use the metacognitive skills six weeks after the MT. In order to do this, the difference in the mean scores between the post- and delayed tests was calculated.

Table 6.22: Descriptive Statistics for Writing Loss for Students in EG

\begin{tabular}{llllll} 
& & $\mathbf{N}$ & Mean & Std. Deviation & Std. Error \\
\hline \multirow{3}{*}{ Post-test - Delayed test } & Bottom student & 5 & .2000 & .83666 & .37417 \\
\cline { 2 - 6 } & Average student & 20 & 1.5500 & 1.22367 & .27362 \\
\cline { 2 - 6 } & Top student & 8 & .4375 & 1.17830 & .41659 \\
\cline { 2 - 6 } & Total & 33 & 1.0758 & 1.28161 & .22310 \\
\hline
\end{tabular}

Table 6.23: ANOVA for Writing Loss for Students in EG

\begin{tabular}{|c|c|c|c|c|c|c|}
\hline & & $\begin{array}{l}\text { Sum of } \\
\text { Squares }\end{array}$ & df & Mean Square & $\mathbf{F}$ & Sig. \\
\hline \multirow[t]{3}{*}{ Post-test - Delayed test } & Between Groups & 11.592 & 2 & 5.796 & 4.244 & .024 \\
\hline & Within Groups & 40.969 & 30 & 1.366 & & \\
\hline & Total & 52.561 & 32 & & & \\
\hline
\end{tabular}

Table 6.24: Differences in Writing Loss for Students in EG

\begin{tabular}{|c|c|c|c|c|c|}
\hline Dependent Variable & $\begin{array}{l}\text { (I) Academic } \\
\text { Rating }\end{array}$ & $\begin{array}{l}\text { (J) Academic } \\
\text { Rating }\end{array}$ & $\begin{array}{l}\text { Mean } \\
\text { Difference (I- } \\
\text { J) }\end{array}$ & Std. Error & Sig. \\
\hline \multirow[t]{6}{*}{ Post-test - Delayed test } & Bottom student & Average student & $-1.35000^{*}$ & .58430 & .028 \\
\hline & & Top student & -.23750 & .66620 & .724 \\
\hline & Average student & Bottom student & $1.35000^{*}$ & .58430 & .028 \\
\hline & & Top student & $1.11250^{*}$ & .48886 & .030 \\
\hline & Top student & Bottom student & .23750 & .66620 & .724 \\
\hline & & Average student & $-1.11250^{*}$ & .48886 & .030 \\
\hline
\end{tabular}


The descriptive figures in Table 6.22 indicate that average students maintained the use of metacognitive skills the least. They were followed by top and bottom students. The $F$ ratio $F(2,30)=4.244, p<.05$ (Table 6.23) shows a significant difference among the three categories of students. Specifically, average students practised planning, monitoring, and evaluating statistically much less than both bottom students $(p<.05)$ and top students $(p<.05)$.

The results reported in section 6.3.3 revealed that average students made the most gains in the post-test of writing which was done immediately after they were trained in the metacognitive skills. Top students ranked second, followed by bottom students. However, by the time of the delayed test, the average students had become the most reluctant to use the metacognitive skills which had been taught to them six weeks before. This phenomenon could be explained in three ways. The first reason could be the difference in the number of students in each category. While there were 20 students in the average group, the bottom group and the top group had only five and eight students respectively. Any extreme score in the group of too few students would affect the mean of the whole group. Therefore, the results might not be the same if the bottom and top groups had more students. The second explanation might be top students already steadily practising the metacognitive skills and bottom students already failing to use these skills. For this reason, there was not much to be won or lost by these two groups of students. The third possibility could be linked to the MT. In order for average students to continue using the metacognitive skills, more training would be needed. The MT appeared to have a short-term effect on average students. Intensive training or a bottom-up form of SBI, which focuses on a specific group of learners (Butler, 2002), would possibly result in a longer-term effect for them.

\subsubsection{MT and improvement in LA}

LA is defined in this study as "learners' self-initiation plus their ability to selfregulate their own learning" (Nguyen 2008, p. 68). Learners' self-initiation involves their reasons for learning and effortful behaviours to learn. Learners' self-regulation is composed of planning (general and task-specific), monitoring and evaluating. Therefore, the LA aspects comprised reasons to learn English, making efforts to learn English, general planning, task-specific planning, monitoring, and evaluating. 
Firstly, in order to explore the improvement the EG made after the students had been trained in the metacognitive skills, the mean score of each element of LA was obtained from the pre-MT LA questionnaire ( $\mathrm{N}=91,1-5$ Likert scale). The purpose of this was to investigate the differences and to evaluate aspects of autonomy demonstrated by students among the three groups before they embarked on the MT. Secondly, means for aspects of LA from the post-MT questionnaires $(\mathrm{N}=91)$ were calculated to examine the effect the MT had on LA in the three groups and to get insights into how elements of LA differed among the three groups prior to and after the MT. Thirdly, a similar process was applied to evaluate LA demonstrated by students in the EG both prior to and after the MT. Finally, effects the MT had on students of different academic achievements in the EG was investigated.

\subsubsection{LA before MT}

It was revealed from Table 6.25 that the numerical differences among the means on most aspects of LA did not appear to be great. Before the MT, the gap in selfinitiation among the three groups was the least insignificant. The figures for reasons for learning English for all three groups fluctuated from 3.846 to 3.944. Students in C2 were slightly more motivated to learn English and made a little more effort to learn English than their counterparts. The other element of LA, self-regulation, however, varied among the three groups. It was found that the EG practised selfregulation skills of planning, monitoring and evaluating a little less than the two control groups. Regarding planning, $\mathrm{C} 1$ had the highest scores reaching around 3.830 for both general and task-specific planning. It was followed by $\mathrm{C} 2$ with the mean scores of roughly 3.700 for the same elements. Both groups spent the same amount of time on monitoring their work though not as much as on planning (3.405 against 3.830). However, $\mathrm{C} 2$ evaluated their written work (3.620) slightly more than $\mathrm{C} 1$ (3.437). The EG did not demonstrate the same level of self-regulation as the other two groups. In fact, they lost ground to their counterparts in every aspect of selfregulation. 
Table 6.25: Descriptive Statistics for LA before MT across Three Groups

\begin{tabular}{|c|c|c|c|c|c|}
\hline & & $\mathbf{N}$ & Mean & Std. Deviation & Std. Error \\
\hline \multirow{4}{*}{$\begin{array}{l}\text { Pre-MT Reasons for learning } \\
\text { English }\end{array}$} & EG & 37 & 3.8889 & .66046 & .10858 \\
\hline & $\overline{\mathrm{C} 1}$ & 26 & 3.8462 & .56313 & .11044 \\
\hline & $\mathrm{C} 2$ & 28 & 3.9444 & .49367 & .09330 \\
\hline & Total & 91 & 3.8938 & .58065 & .06087 \\
\hline \multirow{4}{*}{$\begin{array}{l}\text { Pre-MT Making efforts to } \\
\text { learn English }\end{array}$} & EG & 37 & 2.7629 & .47783 & .07855 \\
\hline & $\mathrm{C} 1$ & 26 & 2.8129 & .55243 & .10834 \\
\hline & $\mathrm{C} 2$ & 28 & 2.9318 & .46577 & .08802 \\
\hline & Total & 91 & 2.8292 & .49633 & .05203 \\
\hline \multirow[t]{4}{*}{ Pre-MT General planning } & EG & 37 & 3.4162 & .55253 & .09083 \\
\hline & $\mathrm{C} 1$ & 26 & 3.8308 & .61108 & .11984 \\
\hline & $\mathrm{C} 2$ & 28 & 3.7500 & .61010 & .11530 \\
\hline & Total & 91 & 3.6374 & .61022 & .06397 \\
\hline \multirow{4}{*}{$\begin{array}{l}\text { Pre-MT Task-specific } \\
\text { planning }\end{array}$} & EG & 37 & 3.6036 & .59622 & .09802 \\
\hline & $\mathrm{C} 1$ & 26 & 3.8397 & .56859 & .11151 \\
\hline & $\mathrm{C} 2$ & 28 & 3.7024 & .55806 & .10546 \\
\hline & Total & 91 & 3.7015 & .57869 & .06066 \\
\hline \multirow[t]{4}{*}{ Pre-MT Monitoring } & EG & 37 & 3.3563 & .54939 & .09032 \\
\hline & $\mathrm{C} 1$ & 26 & 3.4056 & .54741 & .10736 \\
\hline & $\overline{\mathrm{C} 2}$ & 28 & 3.4318 & .57048 & .10781 \\
\hline & Total & 91 & 3.3936 & .55016 & .05767 \\
\hline \multirow[t]{4}{*}{ Pre- MT Evaluating } & EG & 37 & 3.2826 & .57367 & .09431 \\
\hline & $\mathrm{C} 1$ & 26 & 3.4371 & .61712 & .12103 \\
\hline & $\mathrm{C} 2$ & 28 & 3.6201 & .46949 & .08872 \\
\hline & Total & 91 & 3.4306 & .56899 & .05965 \\
\hline
\end{tabular}

It is important to note that the $\mathrm{F}$ ratios (Table 6.26) for reasons for learning English $[\mathrm{F}(2,88)=.192, \mathrm{n} . \mathrm{s}]$, making efforts to learn English $[\mathrm{F}(2,88)=.941, \mathrm{n} . \mathrm{s}]$, task-specific planning $[\mathrm{F}(2,88)=1.279$, n.s], and monitoring $[\mathrm{F}(2,88)=.156$, n.s $]$ were very small and none of the elements reached the significance value of less than 0.5. This indicated that before the MT the three groups did not statistically differ from each other on these aspects of LA though there were slight numerical differences among them. However these groups were statistically different on general planning and evaluating aspects. The $\mathrm{F}$ ratios for them were $\mathrm{F}(2,88)=4.544, \mathrm{p}<.05$, and $\mathrm{F}(2$, $88)=2.928, p<.05$ respectively. The differences on these two measures are presented in Table 6.27. $\mathrm{C} 1$ and $\mathrm{C} 2$ performed significantly better than the EG $(\mathrm{p}<.05)$ in general planning. The two control groups also evaluated their writing more than the EG. It was $\mathrm{C} 2$ that practised evaluating significantly more than the EG $(\mathrm{p}<.05)$. To 
put it another way, before the MT, while the three groups performed almost equally in self-initiation, they differed in self-regulation. The two control groups used selfregulation skills more than the experimental one. The differences among them were significant on general planning, and evaluating elements of LA.

Table 6.26: ANOVA for LA before MT across Three Groups

\begin{tabular}{|c|c|c|c|c|c|c|}
\hline & & $\begin{array}{l}\text { Sum of } \\
\text { Squares }\end{array}$ & df & $\begin{array}{l}\text { Mean } \\
\text { Square }\end{array}$ & $\mathbf{F}$ & Sig. \\
\hline \multirow{3}{*}{$\begin{array}{l}\text { Pre-MT Reasons for } \\
\text { learning English }\end{array}$} & Between Groups & .132 & 2 & .066 & .192 & .826 \\
\hline & Within Groups & 30.212 & 88 & .343 & & \\
\hline & Total & 30.344 & 90 & & & \\
\hline \multirow{3}{*}{$\begin{array}{l}\text { Pre-MT Making efforts to } \\
\text { learn English }\end{array}$} & Between Groups & .464 & 2 & .232 & .941 & .394 \\
\hline & Within Groups & 21.706 & 88 & .247 & & \\
\hline & Total & 22.171 & 90 & & & \\
\hline \multirow[t]{3}{*}{ Pre-MT General planning } & Between Groups & 3.137 & 2 & 1.569 & 4.544 & .013 \\
\hline & Within Groups & 30.376 & 88 & .345 & & \\
\hline & Total & 33.513 & 90 & & & \\
\hline \multirow{3}{*}{$\begin{array}{l}\text { Pre-MT Task-specific } \\
\text { planning }\end{array}$} & Between Groups & .852 & 2 & .426 & 1.279 & .283 \\
\hline & Within Groups & 29.288 & 88 & .333 & & \\
\hline & Total & 30.140 & 90 & & & \\
\hline \multirow[t]{3}{*}{ Pre-MT Monitoring } & Between Groups & .096 & 2 & .048 & .156 & .856 \\
\hline & Within Groups & 27.144 & 88 & .308 & & \\
\hline & Total & 27.241 & 90 & & & \\
\hline \multirow[t]{3}{*}{ Pre-MT Evaluating } & Between Groups & 1.818 & 2 & .909 & 2.928 & .059 \\
\hline & Within Groups & 27.320 & 88 & .310 & & \\
\hline & Total & 29.138 & 90 & & & \\
\hline
\end{tabular}


Table 6.27: Differences in LA before MT across Three Groups

\begin{tabular}{|c|c|c|c|c|c|}
\hline Dependent Variable & (I) Group & (J) Group & $\begin{array}{l}\text { Mean } \\
\text { Difference (I-J) }\end{array}$ & Std. Error & Sig. \\
\hline \multirow{6}{*}{$\begin{array}{l}\text { Pre-MT Reasons for } \\
\text { learning English }\end{array}$} & \multirow[t]{2}{*}{ EG } & $\mathrm{C} 1$ & .04274 & .14994 & .776 \\
\hline & & $\overline{\mathrm{C} 2}$ & -.05556 & .14677 & .706 \\
\hline & \multirow[t]{2}{*}{$\mathrm{C} 1$} & EG & -.04274 & .14994 & .776 \\
\hline & & $\overline{\mathrm{C} 2}$ & -.09829 & .15958 & .540 \\
\hline & \multirow[t]{2}{*}{$\overline{\mathrm{C} 2}$} & EG & .05556 & .14677 & .706 \\
\hline & & $\overline{\mathrm{C} 1}$ & .09829 & .15958 & .540 \\
\hline \multirow{6}{*}{$\begin{array}{l}\text { Pre-MT Making efforts } \\
\text { to learn English }\end{array}$} & \multirow[t]{2}{*}{ EG } & $\mathrm{C} 1$ & -.05004 & .12710 & .695 \\
\hline & & $\mathrm{C} 2$ & -.16892 & .12440 & .178 \\
\hline & \multirow[t]{2}{*}{$\overline{\mathrm{C} 1}$} & EG & .05004 & .12710 & .695 \\
\hline & & $\mathrm{C} 2$ & -.11888 & .13526 & .382 \\
\hline & \multirow[t]{2}{*}{$\overline{\mathrm{C} 2}$} & EG & .16892 & .12440 & .178 \\
\hline & & $\overline{\mathrm{C} 1}$ & .11888 & .13526 & .382 \\
\hline \multirow[t]{6}{*}{ Pre-MT General planning } & \multirow[t]{2}{*}{ EG } & $\mathrm{C} 1$ & $-.41455^{*}$ & .15035 & .007 \\
\hline & & $\overline{\mathrm{C} 2}$ & $-.33378^{*}$ & .14716 & .026 \\
\hline & \multirow[t]{2}{*}{$\mathrm{C} 1$} & EG & $.41455^{*}$ & .15035 & .007 \\
\hline & & $\mathrm{C} 2$ & .08077 & .16001 & .615 \\
\hline & \multirow[t]{2}{*}{$\overline{\mathrm{C} 2}$} & EG & $.33378^{*}$ & .14716 & .026 \\
\hline & & $\mathrm{C} 1$ & -.08077 & .16001 & .615 \\
\hline \multirow{6}{*}{$\begin{array}{l}\text { Pre-MT Task-specific } \\
\text { planning }\end{array}$} & \multirow[t]{2}{*}{ EG } & $\mathrm{C} 1$ & -.23614 & .14763 & .113 \\
\hline & & $\mathrm{C} 2$ & -.09878 & .14450 & .496 \\
\hline & \multirow[t]{2}{*}{$\mathrm{C} 1$} & EG & .23614 & .14763 & .113 \\
\hline & & $\overline{\mathrm{C} 2}$ & .13736 & .15712 & .384 \\
\hline & \multirow[t]{2}{*}{$\overline{\mathrm{C} 2}$} & EG & .09878 & .14450 & .496 \\
\hline & & $\overline{\mathrm{C} 1}$ & -.13736 & .15712 & .384 \\
\hline \multirow[t]{6}{*}{ Pre-MT Monitoring } & \multirow[t]{2}{*}{ EG } & $\mathrm{C} 1$ & -.04933 & .14213 & .729 \\
\hline & & $\mathrm{C} 2$ & -.07555 & .13912 & .588 \\
\hline & \multirow[t]{2}{*}{$\overline{\mathrm{C} 1}$} & EG & .04933 & .14213 & .729 \\
\hline & & $\mathrm{C} 2$ & -.02622 & .15126 & .863 \\
\hline & \multirow[t]{2}{*}{$\overline{\mathrm{C} 2}$} & EG & .07555 & .13912 & .588 \\
\hline & & $\mathrm{C} 1$ & .02622 & .15126 & .863 \\
\hline \multirow[t]{6}{*}{ Pre-MT Evaluating } & \multirow[t]{2}{*}{ EG } & $\mathrm{C} 1$ & -.15451 & .14259 & .282 \\
\hline & & $\overline{\mathrm{C} 2}$ & $-.33757^{*}$ & .13956 & .018 \\
\hline & \multirow[t]{2}{*}{$\mathrm{C} 1$} & EG & .15451 & .14259 & .282 \\
\hline & & $\overline{\mathrm{C} 2}$ & -.18307 & .15175 & .231 \\
\hline & \multirow[t]{2}{*}{$\mathrm{C} 2$} & EG & $.33757^{*}$ & .13956 & .018 \\
\hline & & $\mathrm{C} 1$ & .18307 & .15175 & .231 \\
\hline
\end{tabular}




\subsubsection{LA after MT}

\subsection{LA after MT among Three Groups}

The descriptive statistics in Table 6.28 display some minimal numerical differences in the means for self-initiation. Some differences in self-regulation among the three groups were also found. The $F$ ratios for the two elements of self-initiation were $F$ (2, $88)=.067$, n.s and $F(2,88)=0.832$, n.s (Table 6.29), which indicates that the three groups did not change their reasons for learning English after the MT had been completed. Neither did they make additional efforts to learn English. The differences in self-regulation among the three groups found in Table 6.30 were not significant at all (n.s). While the figures for reasons for learning and making efforts to learn for $\mathrm{C} 1$ were stable, those for $\mathrm{C} 2$ and for the EG changed a little. Both $\mathrm{C} 2$ and the EG made numerically more efforts to learn English (3.0211 against 2.9318) and (2.8600 against 2.7629) respectively. $\mathrm{C} 2$, however, displayed a small change in their reasons for learning English. Table 6.31 reveals that fewer students in $\mathrm{C} 2$ chose an item from the Going abroad category such as 'emigrate to an English speaking country', 'seek better education or job opportunities overseas', and 'experience English-speaking culture abroad' as their reasons for learning English.

In terms of self-regulation, among the $\mathrm{EG}, \mathrm{C} 1$, and $\mathrm{C} 2$, there was almost no difference in the general planning element. Its $F$ ratio was $F(2,88)=.016$, n.s. Some numerical, not statistical differences among the three groups appeared in task-specific planning, monitoring, and evaluating. The $F$ ratios for them were $F(2,88)=1.511$, $n . s, F(2,88)=2.193, n . s$, and $F(2,88)=1.481, n . s$ respectively. It is important to note that in all these three elements of self-regulation, the EG achieved higher mean scores than the two control classes. In plain language, the EG used the skills of taskspecific planning, monitoring, and evaluating more than $\mathrm{C} 1$ and $\mathrm{C} 2$ after they had been trained in metacognition even though the differences were not significant. The EG performed significantly better than $\mathrm{C} 1$ in monitoring ( $p<.05$, Table 6.30). Among the three groups, it was the EG that managed to improve self-regulation. Although a statistically significant difference was found only in monitoring, the EG succeeded in numerically enhancing mean scores for task-specific planning and evaluating.

Compared with the LA figures before the MT, the two control groups did not develop their self-regulation as much as the EG. To illustrate, in $\mathrm{C} 1$ the mean score 
for general planning and evaluating remained stable at 3.8538 against 3.8308 , and 3.4755 against 3.4371 respectively. It was interesting to find out that $\mathrm{C} 1 \mathrm{did}$ a little less task-specific planning (3.7885 against 3.8397), and monitoring (3.3182 against 3.4056) at the end of their Writing Four course. It was clear that $\mathrm{C} 1$ did not improve their self-regulation at all.

The pattern for $\mathrm{C} 2$ differed from that of $\mathrm{C} 1$. According to Tables 6.25 and 6.28 , students in $\mathrm{C} 2$ showed a negative trend for evaluating. Their mean score was 3.5584. The before-MT figure was 3.6201. The students in $\mathrm{C} 1$ did not show any achievement in task-specific planning, the mean score of which stayed unchanged at 3.7144 against 3.7024. They, however, improved in general planning (3.8429 against 3.7500), and monitoring (3.5292 against 3.4318). Compared with $\mathrm{C} 1, \mathrm{C} 2$ displayed some achievement in their self-regulation. Still the achievement was not significant.

Table 6.28: Descriptive Statistics for LA after MT across Three Groups

\begin{tabular}{|c|c|c|c|c|c|}
\hline & & $\mathbf{N}$ & Mean & Std. Deviation & Std. Error \\
\hline \multirow{4}{*}{$\begin{array}{l}\text { Post-MT Reasons for learning } \\
\text { English }\end{array}$} & EG & 37 & 3.8408 & .69019 & .11347 \\
\hline & $\overline{\mathrm{C} 1}$ & 26 & 3.8718 & .53858 & .10562 \\
\hline & $\mathrm{C} 2$ & 28 & 3.8095 & .60470 & .11428 \\
\hline & Total & 91 & 3.8400 & .61758 & .06474 \\
\hline \multirow{4}{*}{$\begin{array}{l}\text { Post-MT Making efforts to } \\
\text { learn English }\end{array}$} & $\mathrm{EG}$ & 37 & 2.8600 & .50484 & .08300 \\
\hline & $\mathrm{C} 1$ & 26 & 2.8986 & .51943 & .10187 \\
\hline & $\mathrm{C} 2$ & 28 & 3.0211 & .50548 & .09553 \\
\hline & Total & 91 & 2.9206 & .50827 & .05328 \\
\hline \multirow[t]{4}{*}{ Post-MT General planning } & $\mathrm{EG}$ & 37 & 3.8270 & .59285 & .09746 \\
\hline & $\mathrm{C} 1$ & 26 & 3.8538 & .64883 & .12725 \\
\hline & $\mathrm{C} 2$ & 28 & 3.8429 & .54258 & .10254 \\
\hline & Total & 91 & 3.8396 & .58819 & .06166 \\
\hline \multirow{4}{*}{$\begin{array}{l}\text { Post-MT Task-specific } \\
\text { planning }\end{array}$} & EG & 37 & 3.9550 & .59790 & .09829 \\
\hline & $\mathrm{C} 1$ & 26 & 3.7885 & .64903 & .12729 \\
\hline & $\mathrm{C} 2$ & 28 & 3.7144 & .45540 & .08606 \\
\hline & Total & 91 & 3.8334 & .57731 & .06052 \\
\hline \multirow[t]{4}{*}{ Post-MT Monitoring } & EG & 37 & 3.6585 & .61074 & .10041 \\
\hline & $\mathrm{C} 1$ & 26 & 3.3182 & .64089 & .12569 \\
\hline & $\mathrm{C} 2$ & 28 & 3.5292 & .66208 & .12512 \\
\hline & Total & 91 & 3.5215 & .64380 & .06749 \\
\hline \multirow[t]{4}{*}{ Post-MT Evaluating } & EG & 37 & 3.7248 & .58857 & .09676 \\
\hline & $\mathrm{C} 1$ & 26 & 3.4755 & .68045 & .13345 \\
\hline & $\mathrm{C} 2$ & 28 & 3.5584 & .48969 & .09254 \\
\hline & Total & 91 & 3.6024 & .59206 & .06206 \\
\hline
\end{tabular}


Table 6.29: ANOVA for LA after MT across Three Groups

\begin{tabular}{|c|c|c|c|c|c|c|}
\hline & & $\begin{array}{l}\text { Sum of } \\
\text { Squares }\end{array}$ & df & $\begin{array}{l}\text { Mean } \\
\text { Square }\end{array}$ & $\mathbf{F}$ & Sig. \\
\hline \multirow{3}{*}{$\begin{array}{l}\text { Post-MT Reasons for } \\
\text { learning English }\end{array}$} & Between Groups & .052 & 2 & .026 & .067 & .935 \\
\hline & Within Groups & 34.274 & 88 & .389 & & \\
\hline & Total & 34.326 & 90 & & & \\
\hline \multirow{3}{*}{$\begin{array}{l}\text { Post-MT Making efforts to } \\
\text { learn English }\end{array}$} & Between Groups & .432 & 2 & .216 & .832 & .439 \\
\hline & Within Groups & 22.819 & 88 & .259 & & \\
\hline & Total & 23.250 & 90 & & & \\
\hline \multirow[t]{3}{*}{ Post-MT General planning } & Between Groups & .011 & 2 & .006 & .016 & .984 \\
\hline & Within Groups & 31.126 & 88 & .354 & & \\
\hline & Total & 31.138 & 90 & & & \\
\hline \multirow{3}{*}{$\begin{array}{l}\text { Post-MT Task-specific } \\
\text { planning }\end{array}$} & Between Groups & .996 & 2 & .498 & 1.511 & .226 \\
\hline & Within Groups & 29.000 & 88 & .330 & & \\
\hline & Total & 29.996 & 90 & & & \\
\hline \multirow[t]{3}{*}{ Post-MT Monitoring } & Between Groups & 1.771 & 2 & .885 & 2.193 & .118 \\
\hline & Within Groups & 35.532 & 88 & .404 & & \\
\hline & Total & 37.303 & 90 & & & \\
\hline \multirow[t]{3}{*}{ Post-MT Evaluating } & Between Groups & 1.027 & 2 & .514 & 1.481 & .233 \\
\hline & Within Groups & 30.521 & 88 & .347 & & \\
\hline & Total & 31.548 & 90 & & & \\
\hline
\end{tabular}


Table 6.30: Differences in LA after MT across Three Groups

\begin{tabular}{|c|c|c|c|c|c|}
\hline Dependent Variable & (I) Group & (J) Group & $\begin{array}{l}\text { Mean } \\
\text { Difference (I- } \\
\text { J) }\end{array}$ & Std. Error & Sig. \\
\hline \multirow{6}{*}{$\begin{array}{l}\text { Post-MT Reasons for } \\
\text { learning English }\end{array}$} & \multirow[t]{2}{*}{ EG } & $\mathrm{C} 1$ & -.03095 & .15971 & .847 \\
\hline & & $\overline{\mathrm{C} 2}$ & .03132 & .15632 & .842 \\
\hline & \multirow[t]{2}{*}{$\mathrm{C} 1$} & EG & .03095 & .15971 & .847 \\
\hline & & $\mathrm{C} 2$ & .06227 & .16997 & .715 \\
\hline & \multirow{2}{*}{$\overline{\mathrm{C} 2}$} & EG & -.03132 & .15632 & .842 \\
\hline & & $\mathrm{C} 1$ & -.06227 & .16997 & .715 \\
\hline \multirow{6}{*}{$\begin{array}{l}\text { Post-MT Making efforts to } \\
\text { learn English }\end{array}$} & \multirow[t]{2}{*}{ EG } & $\mathrm{C} 1$ & -.03865 & .13031 & .767 \\
\hline & & $\mathrm{C} 2$ & -.16115 & .12755 & .210 \\
\hline & \multirow[t]{2}{*}{$\overline{\mathrm{C} 1}$} & EG & .03865 & .13031 & .767 \\
\hline & & $\overline{\mathrm{C} 2}$ & -.12250 & .13869 & .379 \\
\hline & \multirow[t]{2}{*}{$\mathrm{C} 2$} & EG & .16115 & .12755 & .210 \\
\hline & & $\mathrm{C} 1$ & .12250 & .13869 & .379 \\
\hline \multirow[t]{6}{*}{ Post-MT General planning } & \multirow[t]{2}{*}{ EG } & $\mathrm{C} 1$ & -.02682 & .15220 & .861 \\
\hline & & $\mathrm{C} 2$ & -.01583 & .14897 & .916 \\
\hline & \multirow[t]{2}{*}{$\mathrm{C} 1$} & $\mathrm{EG}$ & .02682 & .15220 & .861 \\
\hline & & $\mathrm{C} 2$ & .01099 & .16198 & .946 \\
\hline & \multirow[t]{2}{*}{$\mathrm{C} 2$} & $E G$ & .01583 & .14897 & .916 \\
\hline & & $\mathrm{C} 1$ & -.01099 & .16198 & .946 \\
\hline \multirow{6}{*}{$\begin{array}{l}\text { Post-MT Task-specific } \\
\text { planning }\end{array}$} & \multirow[t]{2}{*}{ EG } & $\mathrm{C} 1$ & .16649 & .14691 & .260 \\
\hline & & $\mathrm{C} 2$ & .24055 & .14379 & .098 \\
\hline & \multirow[t]{2}{*}{$\mathrm{C} 1$} & $\mathrm{EG}$ & -.16649 & .14691 & .260 \\
\hline & & $\mathrm{C} 2$ & .07406 & .15635 & .637 \\
\hline & \multirow[t]{2}{*}{$\mathrm{C} 2$} & $\mathrm{EG}$ & -.24055 & .14379 & .098 \\
\hline & & $\mathrm{C} 1$ & -.07406 & .15635 & .637 \\
\hline \multirow[t]{6}{*}{ Post-MT Monitoring } & \multirow[t]{2}{*}{ EG } & $\mathrm{C} 1$ & $.34029^{*}$ & .16261 & .039 \\
\hline & & $\mathrm{C} 2$ & .12926 & .15917 & .419 \\
\hline & \multirow[t]{2}{*}{$\overline{\mathrm{C} 1}$} & $\mathrm{EG}$ & $-.34029^{*}$ & .16261 & .039 \\
\hline & & $\overline{\mathrm{C} 2}$ & -.21104 & .17306 & .226 \\
\hline & \multirow[t]{2}{*}{$\mathrm{C} 2$} & EG & -.12926 & .15917 & .419 \\
\hline & & $\overline{\mathrm{C} 1}$ & .21104 & .17306 & .226 \\
\hline \multirow[t]{6}{*}{ Post-MT Evaluating } & \multirow[t]{2}{*}{ EG } & $\mathrm{C} 1$ & .24929 & .15071 & .102 \\
\hline & & $\overline{\mathrm{C} 2}$ & .16637 & .14751 & .262 \\
\hline & \multirow[t]{2}{*}{$\mathrm{C} 1$} & $\mathrm{EG}$ & -.24929 & .15071 & .102 \\
\hline & & $\mathrm{C} 2$ & -.08292 & .16039 & .606 \\
\hline & \multirow[t]{2}{*}{$\overline{\mathrm{C} 2}$} & $\mathrm{EG}$ & -.16637 & .14751 & .262 \\
\hline & & $\overline{\mathrm{C} 1}$ & .08292 & .16039 & .606 \\
\hline
\end{tabular}


Table 6.31: Reasons for Learning English in C2

\begin{tabular}{llll}
\hline Elements of reasons for learning & N & Mean & Std. Deviation \\
\hline Pre-MT Individual development & 28 & 4.250 & .4938 \\
\cline { 2 - 4 } Post-MT Individual development & 28 & 4.2738 & .55964 \\
\hline Pre-MT Intrinsic interest & 28 & 4.190 & .6994 \\
\cline { 2 - 4 } Post-MT Intrinsic interest & 28 & 4.0357 & .93992 \\
\hline Pre-MT Going abroad & 28 & 3.3929 & 1.03857 \\
\cline { 2 - 4 } Post-MT Going abroad & 28 & 3.1190 & 1.03921 \\
\hline
\end{tabular}

In summary, at the end point of the MT, it was the EG that demonstrated improved self-regulation among the three groups of participants. Although the mean scores in each element of self-regulation in the EG were not significantly different from those of the two control classes (except for the monitoring element), it displayed the highest scores. Figure 6.4 displays changes in LA before and after the MT across the three groups.

Figure 6.4: Elements of LA prior to and after MT across Three Groups

\section{Learner autonomy across three groups before and after MT}

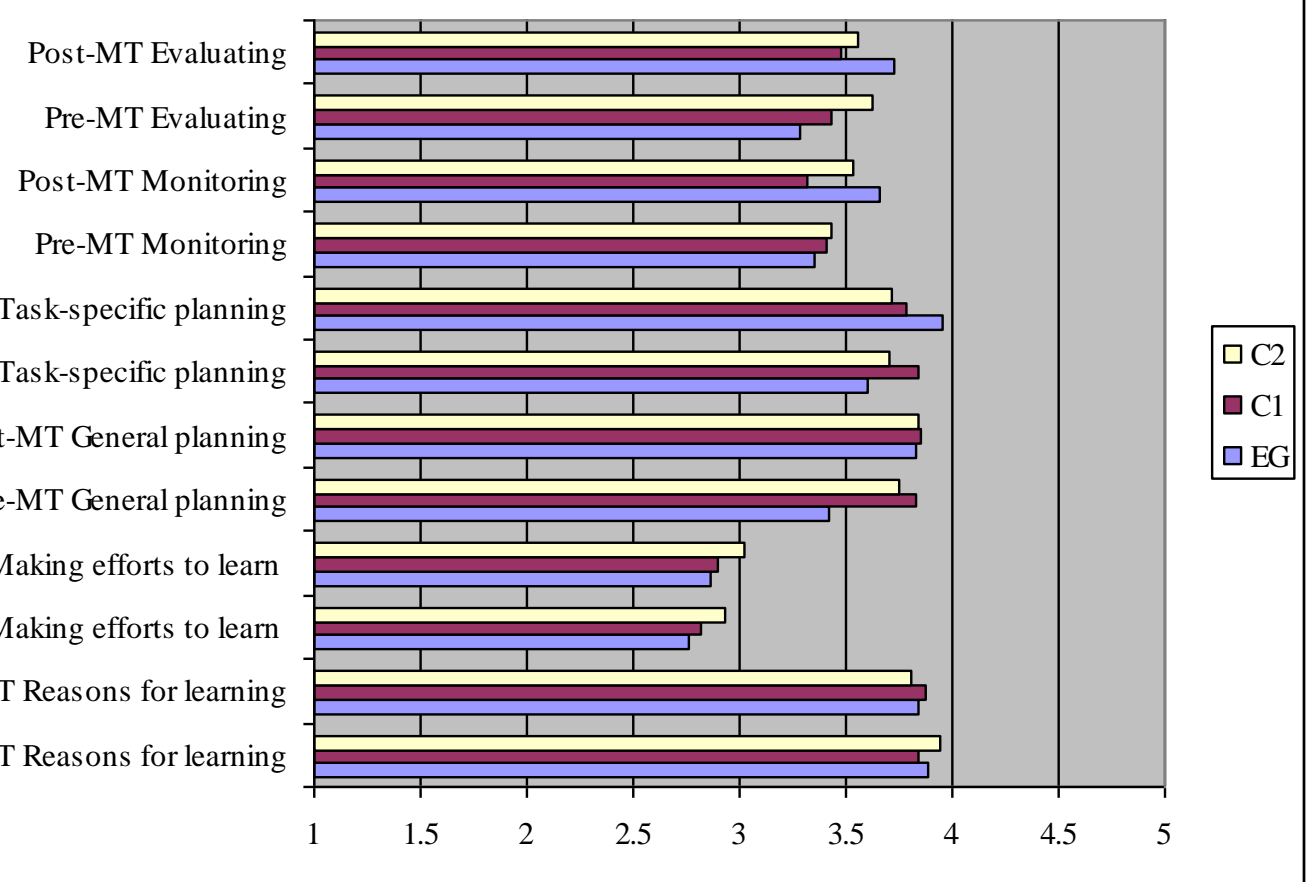




\subsection{LA after MT in EG}

One of the key concerns of the research was to investigate whether the MT would lead to greater LA among students in the EG. There was evidence that the EG students, after having been trained in metacognitive skills, developed LA. This section provides a detailed account of the improvements the EG students made in LA as a result of being taught the skills of planning, monitoring, and evaluating. Interpretations for the results found are also presented.

Regarding self-initiation, students' reasons for learning English remained almost unchanged at 3.8999 at the beginning and at 3.8408 at the end of the MT project. Students did not show much change in this respect mainly because they were English-major students, and reasons for their choice of English as their major would be expected to remain unaffected. For example, they chose English because they liked English itself, enjoyed language learning, or wanted to seek better education or job opportunities abroad. Since they were in their third year, they would no longer be able to choose a different major. As far as efforts were concerned, though students made some efforts to learn English both inside and outside classroom, the efforts made were minimal, staying at 2.7629 prior to the training and reaching 2.8600 after the training (Tables 6.25 and 6.28).

It is clear from Table 6.32 that students in the EG initiated more learning activities both outside and inside the classroom context after the MT than prior to it. Among the four elements of making efforts to learn English including learning English outside classroom, using English outside classroom, overt learning in class, and covert learning in class, it was revealed that by the end of the MT, students did more overt learning and covert learning in class than learning and using English outside class. The figures for overt learning in class prior to and after the training were 1.7730 and 1.9622 respectively. Those for covert learning were 3.9892 and 4.1081 confirming covert learning the most preferred mode of learning among Vietnamese students, which was also found from the first phase of the study. 
Table 6.32: Making Efforts to Learn English by Students in EG

\begin{tabular}{llll}
\hline Elements of making efforts to learn & N & M & SD \\
\hline Pre-MT Learning English outside classroom & 37 & 2.9640 & .49711 \\
\cline { 2 - 4 } Post-MT Learning English outside classroom & 37 & 3.0045 & .62914 \\
\hline Pre-MT Using English outside classroom & 37 & 2.3739 & .81404 \\
\cline { 2 - 4 } Post-MT Using English outside classroom & 37 & 2.4234 & .81327 \\
\hline Pre-MT Overt learning in class & 37 & 1.7730 & .64664 \\
Post-MT Overt learning in class & 37 & 1.9622 & .75842 \\
\hline Pre-MT Covert learning in class & 37 & 3.9892 & .70545 \\
\hline Post-MT Covert learning in class & 37 & 4.1081 & .63874 \\
\hline
\end{tabular}

To put it another way, while the MT did not lead to changes in students' reasons for learning English, it resulted in greater autonomy within the classroom, not outside it. For example, the post-MT questionnaire demonstrated that by the end point of the MT project, students in class engaged in such learning behaviours as encouraging their classmates to speak English so that they could practise English with them, asking their classmates to evaluate their English and giving feedback, and recording a lesson to listen to at home so that they could better understand the lesson, their teacher's English and their English as well. They also put a lot of effort into observing the way their classmates spoke and wrote in English in order to learn from them; trying to answer the teacher's questions in their mind; listening carefully to the teacher, to their classmates; and trying to think about how they would speak or write about the same thing in their own way.

In terms of self-regulation, it was found that the MT project led to students' greater ability to plan, monitor and evaluate their writing. The post-MT questionnaire displayed very positive changes. Specifically, before the training it was only "moderately true" that they: performed general planning (3.4126); carried out taskspecific planning (3.6036); monitored (3.3563); and evaluated a writing task (3.2826). After the training came to an end, however, it was "true" that they applied those metacognitive skills in their writing task. The most exercised skills were task-specific planning and evaluating, which gained the mean scores of 3.9550 and 3.7248 respectively. Nevertheless, it was evaluating (3.7248 for post-MT against 3.2826 for pre-MT) and general planning (3.9550 for post-MT against 3.6036 for pre-MT) skills in which students made the largest gains after the training in metacognition had been completed. This suggested that the MT resulted in students evaluating their writing 
tasks and doing general planning considerably more than before the MT was conducted. Monitoring, as shown by the study, was the least exercised aspect of the self-regulation element of LA.

The group interview conducted with five students from the EG right after the MT had been completed reinforced the findings about students' improved selfregulation. All of them said that the way they approached a writing task had changed since they embarked on the MT. All of them admitted that they did a lot more thinking before they wrote. One said:

Content is very important so I pay more attention to it now. I ask myself how much I know about the topic. I also ask my classmates to help me or I search information about the topic by myself (Student 1-1, Q1, group interview, P2)

Another pointed out that she learned how to organise her essay:

I did not put down so many 'small' ideas in my essay now. I choose only two 'big' ideas and write about them in one paragraph. I used to be very ambitious because I always wanted to write as much as I could (Student 4-1, Q1, group interview, P2)

One said she thought about the vocabulary as well:

I think about possible words that I can use for my essay. I like to put in my essay beautiful phrases that I learned from sample essays or other readings so I write down those phrases so that I will not forget them (Student 2-1, Q1, group interview, P2).

While planning, as illustrated by the questionnaire and the interview, was exercised pretty regularly, monitoring was not. Some students merged monitoring with evaluating because they did not have time for it:

You told us that we should check every sentence we have just finished to make sure it makes sense. Well, it is good but I don't have time while I am writing. Also, if I did that, I would be distracted. I would forget the next thing I want to write about. I normally check everything when I finish the paper (Student 3-1, Q1, group interview, P2).

Another shared the same opinion, saying that the time constraint prevented her from monitoring her writing text: 
When I write at home, I would check every paragraph that I have just finished. But when I write in class or write an exam paper, I only check my work when I am done (Student 5-1, Q1, group interview, P2)

One student, on the other hand, acknowledged that she monitored her writing by employing a writing strategy:

While I am writing, if I get stuck with one idea, I will just move on. I will come back to it later. It saves me time now because before I kept forcing myself to stick to it and by all means to finish what I wanted to write no matter how much time it took. I ended up not having enough time for the rest of the essay (Student 3-2, Q1, group interview, P2).

As for evaluation, most students associated it with checking spelling and grammatical mistakes:

Proof-reading my paper to find spelling and grammatical mistakes is useful. Now I set aside two or three minutes at the end of the paper to read my paper again (Student 2-2, Q1, group interview, P2).

Yeah, before this class, I often spent the last minutes of the paper adding up more ideas to my paper because it seemed to me that it was short of ideas. But now I use the last minutes to read my essay from the beginning to the end and correct the mistakes that I have found (Student 4-2, Q1, group interview, P2)

One student, however, said that she checked not only spelling and grammatical mistakes but also the development of ideas in her essay:

For me, I also check if I have provided enough examples or facts to illustrate my points. Sometimes I add connective words to make my essay better (Student 1-2, Q1, group interview, P2)

The group interview not only maintained the results of the post-MT questionnaire but also provided insights into the aspects of each metacognitive skill that students exercised. For example, it was known that they did a lot of planning such as content, organisation and language. However it seemed that they failed to properly plan time 
for their essay. The interview suggested that they were short of time which was a reason for not monitoring their writing. The Time-based element of SMART (Specific, Measurable, Achievable, Relevant, and Time-based) goals (McCoy \& Rubin, 2008) seemed not to be put into application by the students. The time shortage led to students' failure to sufficiently monitor their work. They monitored their strategies while writing, but not task performance. As far as evaluating was concerned, students focussed more on the narrow aspects of evaluation such as spelling and grammar rather than on broader ones such as organisation, language, idea development, or their strengths and weaknesses. The session allocation of the MT could be a possible explanation for this finding. Four training sessions on planning compared with one on monitoring and one on evaluating, understandably, caused more planning behaviours among the students. Figure 6.5 summarises improvements in all components of LA demonstrated by the EG.

Figure 6.5: LA Demonstrated by EG prior to and after MT

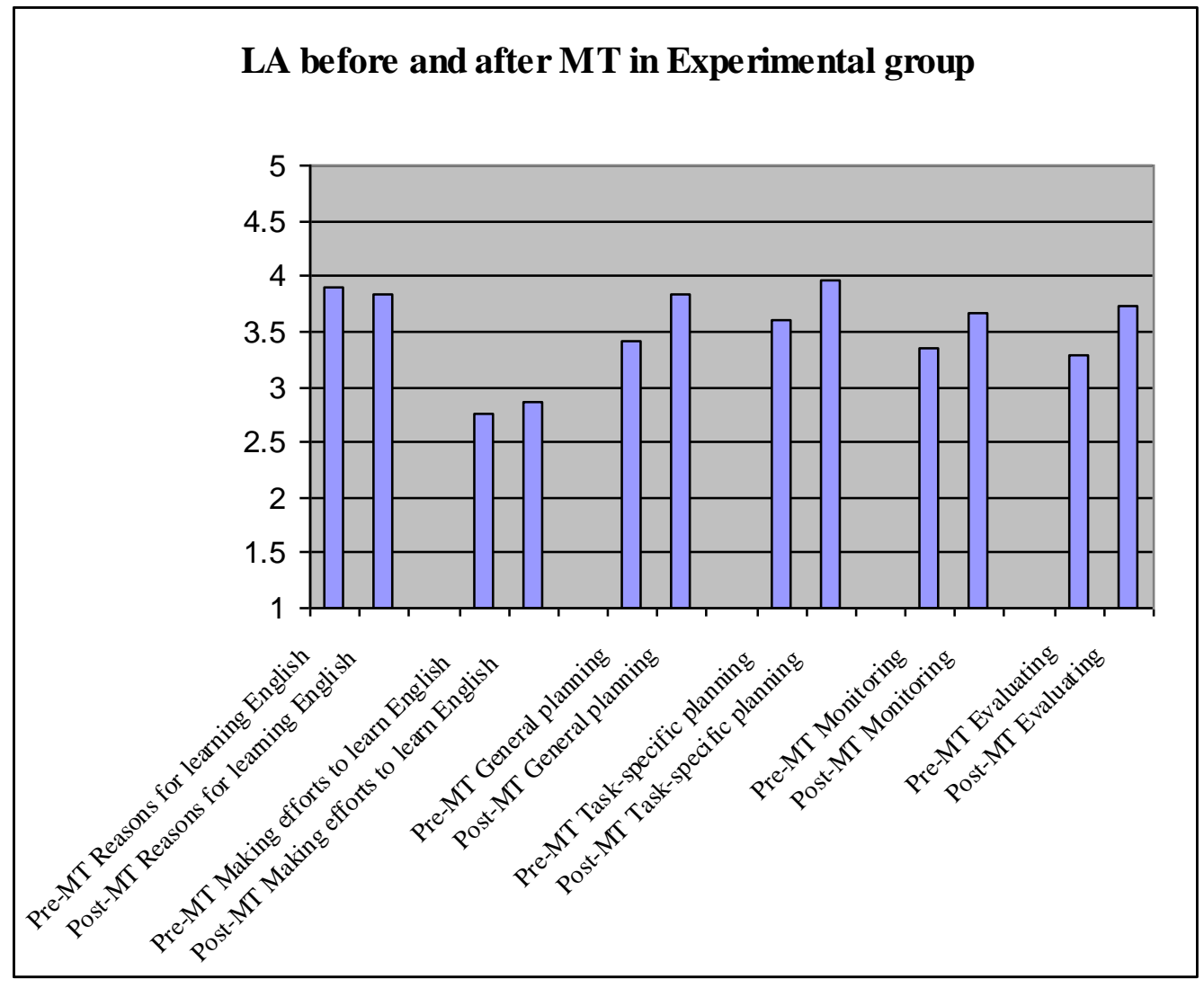

To sum up, the MT yielded different outcomes in the two main components of LA in the EG. While there was not much change seen in the students' self-initiation, 
namely their reasons for learning English and efforts to learn English, their selfregulation improved. From the self-initiation perspective of LA, the project demonstrably enhanced LA in the classroom. From the self-regulation angle, it significantly developed students' ability to evaluate, to do general and task-specific planning, and to monitor a writing task. Generally, students in the EG planned, monitored, and evaluated for their writing tasks more than before they had embarked on the MT.

\subsection{LA after MT for students in EG}

It was revealed that the MT had a positive but short-term effect on average students, who were able to improve their writing scores immediately after the MT though not six week afterwards. The following section examines the influence of the MT on learners' self- initiation and self-regulation for top, average, and bottom students in the EG. Since in the EG, the number of students who answered the LA questionnaires was 37, the data for all 37 students will be analysed. The numbers of top, average, and bottom students were eight, 23 , and six respectively.

\subsection{Comparisons for LA before MT}

According to Table 6.33, the mean scores for all elements of LA for top students were the highest. The $F$ ratios for the two components of self-initiation were less than 1: $F$ $(2,34)=.322$, n.s and $F(2,34)=.583$, n.s, indicating that the three categories of student did not differ from one another on their reasons for learning English and making effort to learn English. To put it another way, regardless of their academic achievement the students in the EG demonstrated almost the same level of selfinitiation for learning English before the start of the MT. As for self-regulation, in terms of general planning, there was no statistical difference among top, average, and bottom students $[F,(2,34)=.193$, n.s. However, they were different in the other aspects of self-regulation. The $F$ ratios for task-specific planning and evaluating were $F(2,34)=3.987, p<.05$ and $F(2,34)=3.214, p<.05$ respectively. This was indicative of a statistical difference among top, average, and bottom students. This shows that students' academic ability considerably affected their ability to plan specifically for a writing task and to evaluate it. The monitoring measure also had a 
big $F$ value: $F(2,34)=3.008$. Most importantly it almost reached the significance value of less than .05 (Table 4.34), which means that the three categories of student were also significantly different from each other on monitoring.

A detailed account as to which type of students self-regulated their learning more as well as which aspect of self-regulation was practised more by which category of students is easily found in Table 6.35. Top students statistically did a lot more taskspecific planning, monitoring, and evaluating for their essays than bottom students. Average students were also statistically significantly different from bottom students on the measures of monitoring and evaluating. Top students, however, only numerically performed better than average students in task-specific planning, monitoring and evaluating.

Table 6.33: Descriptive Statistics for LA before MT among Students in EG

\begin{tabular}{|c|c|c|c|c|c|}
\hline & & $\mathbf{N}$ & Mean & $\begin{array}{l}\text { Std. } \\
\text { Deviation }\end{array}$ & Std. Error \\
\hline \multirow{4}{*}{$\begin{array}{l}\text { Pre-MT Reasons for learning } \\
\text { English }\end{array}$} & Bottom student & 6 & 3.7222 & .63925 & .26097 \\
\hline & Average student & 23 & 3.8889 & .64528 & .13455 \\
\hline & Top student & 8 & 4.0139 & .77536 & .27413 \\
\hline & Total & 37 & 3.8889 & .66046 & .10858 \\
\hline \multirow{4}{*}{$\begin{array}{l}\text { Pre-MT Making efforts to } \\
\text { learn English }\end{array}$} & Bottom student & 6 & 2.7273 & .42055 & .17169 \\
\hline & Average student & 23 & 2.7154 & .44435 & .09265 \\
\hline & Top student & 8 & 2.9261 & .62321 & .22034 \\
\hline & Total & 37 & 2.7629 & .47783 & .07855 \\
\hline \multirow[t]{4}{*}{ Pre-MT General planning } & Bottom student & 6 & 3.3667 & .55737 & .22755 \\
\hline & Average student & 23 & 3.3913 & .57042 & .11894 \\
\hline & Top student & 8 & 3.5250 & .55485 & .19617 \\
\hline & Total & 37 & 3.4162 & .55253 & .09083 \\
\hline \multirow{4}{*}{$\begin{array}{l}\text { Pre-MT Task-specific } \\
\text { planning }\end{array}$} & Bottom student & 6 & 3.1944 & .28707 & .11719 \\
\hline & Average student & 23 & 3.5652 & .58547 & .12208 \\
\hline & Top student & 8 & 4.0208 & .58715 & .20759 \\
\hline & Total & 37 & 3.6036 & .59622 & .09802 \\
\hline \multirow[t]{4}{*}{ Pre-MT Monitoring } & Bottom student & 6 & 2.9091 & .53936 & .22019 \\
\hline & Average student & 23 & 3.3953 & .49914 & .10408 \\
\hline & Top student & 8 & 3.5795 & .57277 & .20251 \\
\hline & Total & 37 & 3.3563 & .54939 & .09032 \\
\hline \multirow[t]{4}{*}{ Pre-MT Evaluating } & Bottom student & 6 & 2.7879 & .42898 & .17513 \\
\hline & Average student & 23 & 3.3399 & .51950 & .10832 \\
\hline & Top student & 8 & 3.4886 & .66616 & .23552 \\
\hline & Total & 37 & 3.2826 & .57367 & .09431 \\
\hline
\end{tabular}


Table 6.34: ANOVA for LA before MT among Students in EG

\begin{tabular}{|c|c|c|c|c|c|c|}
\hline & & $\begin{array}{l}\text { Sum of } \\
\text { Squares }\end{array}$ & df & $\begin{array}{l}\text { Mean } \\
\text { Square }\end{array}$ & $\mathbf{F}$ & Sig. \\
\hline \multirow{3}{*}{$\begin{array}{l}\text { Pre-MT Reasons for } \\
\text { learning English }\end{array}$} & Between Groups & .292 & 2 & .146 & .322 & .727 \\
\hline & Within Groups & 15.412 & 34 & .453 & & \\
\hline & Total & 15.704 & 36 & & & \\
\hline \multirow{3}{*}{$\begin{array}{l}\text { Pre-MT Making efforts to } \\
\text { learn English }\end{array}$} & Between Groups & .273 & 2 & .136 & .583 & .564 \\
\hline & Within Groups & 7.947 & 34 & .234 & & \\
\hline & Total & 8.220 & 36 & & & \\
\hline \multirow[t]{3}{*}{ Pre-MT General planning } & Between Groups & .124 & 2 & .062 & .193 & .825 \\
\hline & Within Groups & 10.867 & 34 & .320 & & \\
\hline & Total & 10.990 & 36 & & & \\
\hline \multirow{3}{*}{$\begin{array}{l}\text { Pre-MT Task-specific } \\
\text { planning }\end{array}$} & Between Groups & 2.431 & 2 & 1.216 & 3.987 & .028 \\
\hline & Within Groups & 10.366 & 34 & .305 & & \\
\hline & Total & 12.797 & 36 & & & \\
\hline \multirow[t]{3}{*}{ Pre-MT Monitoring } & Between Groups & 1.634 & 2 & .817 & 3.008 & .063 \\
\hline & Within Groups & 9.232 & 34 & .272 & & \\
\hline & Total & 10.866 & 36 & & & \\
\hline \multirow[t]{3}{*}{ Pre-MT Evaluating } & Between Groups & 1.884 & 2 & .942 & 3.214 & .053 \\
\hline & Within Groups & 9.964 & 34 & .293 & & \\
\hline & Total & 11.848 & 36 & & & \\
\hline
\end{tabular}


Table 6.35: Differences in LA before MT among Students in EG

\begin{tabular}{|c|c|c|c|c|c|}
\hline Dependent Variable & $\begin{array}{l}\text { (I) Academic } \\
\text { Rating }\end{array}$ & $\begin{array}{l}\text { (J) Academic } \\
\text { Rating }\end{array}$ & $\begin{array}{l}\text { Mean } \\
\text { Difference (I-J) }\end{array}$ & Std. Error & Sig. \\
\hline \multirow{6}{*}{$\begin{array}{l}\text { Pre-MT Reasons for } \\
\text { learning English }\end{array}$} & \multirow[t]{2}{*}{ Bottom student } & Average student & -.16667 & .30864 & .593 \\
\hline & & Top student & -.29167 & .36361 & .428 \\
\hline & \multirow[t]{2}{*}{ Average student } & Bottom student & .16667 & .30864 & .593 \\
\hline & & Top student & -.12500 & .27635 & .654 \\
\hline & \multirow[t]{2}{*}{ Top student } & Bottom student & .29167 & .36361 & .428 \\
\hline & & Average student & .12500 & .27635 & .654 \\
\hline \multirow{6}{*}{$\begin{array}{l}\text { Pre-MT Making efforts } \\
\text { to learn English }\end{array}$} & \multirow{2}{*}{ Bottom student } & Average student & .01186 & .22163 & .958 \\
\hline & & Top student & -.19886 & .26110 & .452 \\
\hline & \multirow[t]{2}{*}{ Average student } & Bottom student & -.01186 & .22163 & .958 \\
\hline & & Top student & -.21072 & .19844 & .296 \\
\hline & \multirow[t]{2}{*}{ Top student } & Bottom student & .19886 & .26110 & .452 \\
\hline & & Average student & .21072 & .19844 & .296 \\
\hline \multirow{6}{*}{$\begin{array}{l}\text { Pre-MT General } \\
\text { planning }\end{array}$} & \multirow[t]{2}{*}{ Bottom student } & Average student & -.02464 & .25916 & .925 \\
\hline & & Top student & -.15833 & .30532 & .607 \\
\hline & \multirow[t]{2}{*}{ Average student } & Bottom student & .02464 & .25916 & .925 \\
\hline & & Top student & -.13370 & .23205 & .568 \\
\hline & \multirow[t]{2}{*}{ Top student } & Bottom student & .15833 & .30532 & .607 \\
\hline & & Average student & .13370 & .23205 & .568 \\
\hline \multirow{6}{*}{$\begin{array}{l}\text { Pre-MT Task-specific } \\
\text { planning }\end{array}$} & \multirow[t]{2}{*}{ Bottom student } & Average student & -.37077 & .25312 & .152 \\
\hline & & Top student & $-.82639^{*}$ & .29821 & .009 \\
\hline & \multirow[t]{2}{*}{ Average student } & Bottom student & .37077 & .25312 & .152 \\
\hline & & Top student & -.45562 & .22664 & .052 \\
\hline & \multirow[t]{2}{*}{ Top student } & Bottom student & $.82639^{*}$ & .29821 & .009 \\
\hline & & Average student & .45562 & .22664 & .052 \\
\hline \multirow[t]{6}{*}{ Pre-MT Monitoring } & \multirow[t]{2}{*}{ Bottom student } & Average student & $-.48617^{*}$ & .23888 & .050 \\
\hline & & Top student & $-.67045^{*}$ & .28142 & .023 \\
\hline & \multirow[t]{2}{*}{ Average student } & Bottom student & $.48617^{*}$ & .23888 & .050 \\
\hline & & Top student & -.18429 & .21389 & .395 \\
\hline & \multirow[t]{2}{*}{ Top student } & Bottom student & $.67045^{*}$ & .28142 & .023 \\
\hline & & Average student & .18429 & .21389 & .395 \\
\hline \multirow[t]{6}{*}{ Pre-MT Evaluating } & \multirow[t]{2}{*}{ Bottom student } & Average student & $-.55204^{*}$ & .24816 & .033 \\
\hline & & Top student & $-.70076^{*}$ & .29236 & .022 \\
\hline & \multirow[t]{2}{*}{ Average student } & Bottom student & $.55204^{*}$ & .24816 & .033 \\
\hline & & Top student & -.14872 & .22220 & .508 \\
\hline & \multirow[t]{2}{*}{ Top student } & Bottom student & $.70076^{*}$ & .29236 & .022 \\
\hline & & Average student & .14872 & .22220 & .508 \\
\hline
\end{tabular}

In summary, some important findings about before-the-MT LA among top, average, and bottom students in the EG were revealed. First, all the students were not statistically different from each other in their reasons for learning English and 
making efforts to learn it. However, top students had the highest level of selfinitiation. Second, top students significantly outperformed bottom students in taskspecific planning, monitoring, and evaluating. Third, average students were considerably better than bottom students in monitoring and evaluating. Therefore, it can be concluded that top students were the most autonomous learners who had already planned, monitored, and evaluated their essays before the metacognitive skills were taught to them. Average students ranked the second, followed by bottom students. Students' level of proficiency seemed to be linked to their level of autonomy. The more proficient they were, the more autonomous they were.

\subsection{Comparisons for $L A$ after MT}

Table 6.36 reveals that, after the MT, the numerical difference in the means for the five elements of LA among top, average, and bottom students does not appear to be great. The $F$ values for all LA aspects except for evaluating were very small, raging from $F(2,34)=.006$ to $F(2,34)=1.516$, and their significance values were all greater than .05 (Table 6.37). While the three categories of students performed almost equally in reasons for learning English, making efforts to learn English, general planning, task-specific planning, and monitoring, they differed significantly in evaluating with the $F$ ratio of $F(2,34)=3.291, p<.05$. The specific differences are located in Table 6.38. In terms of self-initiation, top students did not improve at all after the MT. In fact, the mean scores for the self-initiation aspect for top students were a little smaller than the scores they had before they had received the MT. Average students were slightly better than bottom students in reasons for learning but they did not invest as much effort to learn English as bottom students did. It seemed that the MT resulted in better self-initiation for bottom and average students but not for top students. This is understandable because top students had already showed their slightly greater self-initiation over average and bottom students before the MT had begun. It was encouraging to find out that bottom students became more aware of the importance of the efforts they made to improve English writing both inside and outside the classroom context. They were the best in this measure. 
Table 6.36: Descriptive Statistics for LA after MT among Students in EG

\begin{tabular}{|c|c|c|c|c|c|}
\hline & & $\mathbf{N}$ & Mean & $\begin{array}{l}\text { Std. } \\
\text { Deviation }\end{array}$ & Std. Error \\
\hline \multirow{4}{*}{$\begin{array}{l}\text { Post-MT Reasons for } \\
\text { learning English }\end{array}$} & Bottom student & 6 & 3.8333 & .56547 & .23085 \\
\hline & Average student & 23 & 3.8502 & .62281 & .12986 \\
\hline & Top student & 8 & 3.8194 & 1.00077 & .35383 \\
\hline & Total & 37 & 3.8408 & .69019 & .11347 \\
\hline \multirow{4}{*}{$\begin{array}{l}\text { Post-MT Making efforts to } \\
\text { learn English }\end{array}$} & Bottom student & 6 & 2.8788 & .42898 & .17513 \\
\hline & Average student & 23 & 2.8656 & .43824 & .09138 \\
\hline & Top student & 8 & 2.8295 & .75778 & .26792 \\
\hline & Total & 37 & 2.8600 & .50484 & .08300 \\
\hline \multirow[t]{4}{*}{ Post-MT General planning } & Bottom student & 6 & 3.5333 & .39328 & .16055 \\
\hline & Average student & 23 & 3.8435 & .54257 & .11313 \\
\hline & Top student & 8 & 4.0000 & .81416 & .28785 \\
\hline & Total & 37 & 3.8270 & .59285 & .09746 \\
\hline \multirow{4}{*}{$\begin{array}{l}\text { Post-MT Task-specific } \\
\text { planning }\end{array}$} & Bottom student & 6 & 3.5833 & .50277 & .20526 \\
\hline & Average student & 23 & 4.0000 & .58171 & .12129 \\
\hline & Top student & 8 & 4.1042 & .66629 & .23557 \\
\hline & Total & 37 & 3.9550 & .59790 & .09829 \\
\hline \multirow[t]{4}{*}{ Post-MT Monitoring } & Bottom student & 6 & 3.4697 & .45787 & .18692 \\
\hline & Average student & 23 & 3.6403 & .48993 & .10216 \\
\hline & Top student & 8 & 3.8523 & .96935 & .34272 \\
\hline & Total & 37 & 3.6585 & .61074 & .10041 \\
\hline \multirow[t]{4}{*}{ Post-MT Evaluating } & Bottom student & 6 & 3.2424 & .52591 & .21470 \\
\hline & Average student & 23 & 3.7549 & .52183 & .10881 \\
\hline & Top student & 8 & 4.0000 & .66272 & .23431 \\
\hline & Total & 37 & 3.7248 & .58857 & .09676 \\
\hline
\end{tabular}

Regarding self-regulation, top students, in contrast, were the best among the three types of student. They practised general planning, task-specific planning, monitoring, and evaluating more than average and bottom students. However, top students performed significantly better than bottom students in evaluating. Average students also used the metacognitive skills for their writing more frequently than bottom students. Again, after the metacognitive skills were incorporated in the writing curriculum of the EG, it appeared that top students still outperformed the other two types of student. Although, all students used the metacognitive skills a little more than before they engaged in the MT, it was top students that showed more improvement in self-regulation. It might be because they had already had a background in metacognition, which enabled them to perform even better after they were trained in this aspect of LA. In order for average and bottom students to make 
more progress in the self-regulation component of LA, more training might be necessary. Students might need to be grouped according to their level of proficiency, which would determine what specific metacognitive skills and how much training time each group should receive.

Table 6.37: ANOVA for LA after MT among Students in EG

\begin{tabular}{|c|c|c|c|c|c|c|}
\hline & & $\begin{array}{l}\text { Sum of } \\
\text { Squares }\end{array}$ & df & $\begin{array}{l}\text { Mean } \\
\text { Square }\end{array}$ & $\mathbf{F}$ & Sig. \\
\hline \multirow{3}{*}{$\begin{array}{l}\text { Post-MT Reasons for } \\
\text { learning English }\end{array}$} & Between Groups & .006 & 2 & .003 & .006 & .994 \\
\hline & Within Groups & 17.143 & 34 & .504 & & \\
\hline & Total & 17.149 & 36 & & & \\
\hline \multirow{3}{*}{$\begin{array}{l}\text { Post-MT Making efforts to } \\
\text { learn English }\end{array}$} & Between Groups & .010 & 2 & .005 & .019 & .981 \\
\hline & Within Groups & 9.165 & 34 & .270 & & \\
\hline & Total & 9.175 & 36 & & & \\
\hline \multirow[t]{3}{*}{ Post-MT General planning } & Between Groups & .763 & 2 & .382 & 1.091 & .347 \\
\hline & Within Groups & 11.890 & 34 & .350 & & \\
\hline & Total & 12.653 & 36 & & & \\
\hline \multirow{3}{*}{$\begin{array}{l}\text { Post-MT Task-specific } \\
\text { planning }\end{array}$} & Between Groups & 1.053 & 2 & .527 & 1.516 & .234 \\
\hline & Within Groups & 11.816 & 34 & .348 & & \\
\hline & Total & 12.869 & 36 & & & \\
\hline \multirow[t]{3}{*}{ Post-MT Monitoring } & Between Groups & .522 & 2 & .261 & .687 & .510 \\
\hline & Within Groups & 12.906 & 34 & .380 & & \\
\hline & Total & 13.428 & 36 & & & \\
\hline \multirow[t]{3}{*}{ Post-MT Evaluating } & Between Groups & 2.023 & 2 & 1.011 & 3.291 & .049 \\
\hline & Within Groups & 10.448 & 34 & .307 & & \\
\hline & Total & 12.471 & 36 & & & \\
\hline
\end{tabular}


Table 6.38: Differences in LA after MT among Students in EG

\begin{tabular}{|c|c|c|c|c|c|}
\hline Dependent Variable & $\begin{array}{l}\text { (I) Academic } \\
\text { Rating }\end{array}$ & (J) Academic Rating & $\begin{array}{l}\text { Mean } \\
\text { Difference (I- } \\
\text { J) }\end{array}$ & $\begin{array}{l}\text { Std. } \\
\text { Error }\end{array}$ & Sig. \\
\hline \multirow{6}{*}{$\begin{array}{l}\text { Post-MT Reasons for } \\
\text { learning English }\end{array}$} & \multirow{2}{*}{ Bottom student } & Average student & -.01691 & .32551 & .959 \\
\hline & & Top student & .01389 & .38349 & .971 \\
\hline & \multirow[t]{2}{*}{ Average student } & Bottom student & .01691 & .32551 & .959 \\
\hline & & Top student & .03080 & .29146 & .916 \\
\hline & \multirow[t]{2}{*}{ Top student } & Bottom student & -.01389 & .38349 & .971 \\
\hline & & Average student & -.03080 & .29146 & .916 \\
\hline \multirow{6}{*}{$\begin{array}{l}\text { Post-MT Making } \\
\text { efforts to learn } \\
\text { English }\end{array}$} & \multirow[t]{2}{*}{ Bottom student } & Average student & .01318 & .23800 & .956 \\
\hline & & Top student & .04924 & .28039 & .862 \\
\hline & \multirow[t]{2}{*}{ Average student } & Bottom student & -.01318 & .23800 & .956 \\
\hline & & Top student & .03607 & .21311 & .867 \\
\hline & \multirow[t]{2}{*}{ Top student } & Bottom student & -.04924 & .28039 & .862 \\
\hline & & Average student & -.03607 & .21311 & .867 \\
\hline \multirow{6}{*}{$\begin{array}{l}\text { Post-MT General } \\
\text { planning }\end{array}$} & \multirow[t]{2}{*}{ Bottom student } & Average student & -.31014 & .27109 & .261 \\
\hline & & Top student & -.46667 & .31937 & .153 \\
\hline & \multirow[t]{2}{*}{ Average student } & Bottom student & .31014 & .27109 & .261 \\
\hline & & Top student & -.15652 & .24273 & .523 \\
\hline & \multirow[t]{2}{*}{ Top student } & Bottom student & .46667 & .31937 & .153 \\
\hline & & Average student & .15652 & .24273 & .523 \\
\hline \multirow{6}{*}{$\begin{array}{l}\text { Post-MT Task- } \\
\text { specific planning }\end{array}$} & \multirow[t]{2}{*}{ Bottom student } & Average student & -.41667 & .27024 & .132 \\
\hline & & Top student & -.52083 & .31837 & .111 \\
\hline & \multirow[t]{2}{*}{ Average student } & Bottom student & .41667 & .27024 & .132 \\
\hline & & Top student & -.10417 & .24197 & .670 \\
\hline & \multirow[t]{2}{*}{ Top student } & Bottom student & .52083 & .31837 & .111 \\
\hline & & Average student & .10417 & .24197 & .670 \\
\hline \multirow[t]{6}{*}{ Post-MT Monitoring } & \multirow[t]{2}{*}{ Bottom student } & Average student & -.17062 & .28244 & .550 \\
\hline & & Top student & -.38258 & .33274 & .258 \\
\hline & \multirow[t]{2}{*}{ Average student } & Bottom student & .17062 & .28244 & .550 \\
\hline & & Top student & -.21196 & .25289 & .408 \\
\hline & \multirow[t]{2}{*}{ Top student } & Bottom student & .38258 & .33274 & .258 \\
\hline & & Average student & .21196 & .25289 & .408 \\
\hline \multirow[t]{6}{*}{ Post-MT Evaluating } & \multirow[t]{2}{*}{ Bottom student } & Average student & -.51252 & .25412 & .052 \\
\hline & & Top student & $-.75758^{*}$ & .29938 & .016 \\
\hline & \multirow[t]{2}{*}{ Average student } & Bottom student & .51252 & .25412 & .052 \\
\hline & & Top student & -.24506 & .22753 & .289 \\
\hline & \multirow[t]{2}{*}{ Top student } & Bottom student & $.75758^{*}$ & .29938 & .016 \\
\hline & & Average student & .24506 & .22753 & .289 \\
\hline
\end{tabular}

To sum up, the MT benefited students of different academic achievements in different ways. Although no significant difference was found among top, average, and bottom students on all the LA measures, except for evaluating, there were numerical 
differences among them. From the perspective of self-initiation, top students did not become more motivated to learn English after the MT. Neither did they initiate additional inside-the-classroom and outside-the-classroom learning activities. In terms of self-regulation, top students managed to further improve the skills of planning, monitoring, and evaluating. The level of students' proficiency still seemed to determine the level of their autonomy. Therefore, it could be concluded that the more proficient students were, the more likely they were to improve their metacognitive skills. However, it is important to keep in mind that these results only have a relative value because of the differences in the number of students representing each type of top, average, and bottom students. All in all, an important conclusion can be drawn from the two components of LA. The self-initiation aspect of LA seemed to progress less than the self-regulation element. The results show that self-regulation was teachable to students. Nevertheless, it would be immature to conclude that self-initiation is non-teachable. The question of how it can be taught is as important as the question of whether it can be taught to students.

\subsubsection{MT and transfer of metacognitive skills}

Students' diary entries, student interviews, and teacher interviews revealed that there was not much transfer of metacognitive skills done by students in the EG. It was discovered from students' diary entries that they found it hard to apply the metacognitive skills to the learning of other subjects:

The teacher also told us to apply the strategies in learning other skills of learning English but I was a little confused how to apply them. I will try tomorrow's class and the next ones to see if I find some advantages (LHA, Diary, Week 2).

However how to apply those strategies is difficult (HTML, Diary, Week 4).

I think I will write well. But I don't know whether how can I apply this strategy in other skills (TTHT, Diary, Week 5).

I still don't know how these strategies help me in learning other skill of reading, speaking, and listening (BH, Diary, Week 2). 
Applying the things what the teacher gave me for writing is easy, I think, but it's a little difficult to apply them for other subjects. That's still my problem (LHA, Diary, Week 3).

However, some students admitted that they practised the metacognitive skills in learning speaking. They seemed to plan carefully for their presentation which was the main focus of their current speaking course. For example, they searched for more information on the topic, defined their audience, organised their ideas so that the audience could follow their presentation easily, planned the time for each point in their presentation, and talked extensively about what they knew best:

“... I apply the strategies you taught me in learning speaking. To speak well, first I also need to write content on the paper and organise the ideas in logical so that my listener can easily understand..." (NTCP, Diary, Week 4).

“... in speaking, before presentation, you should define your audience to esay/advantage in using language, and give them the informations suit their knowledge. I should set the time to carry my goals. In a presentation, such part has each different important and they are not equal so I should set much time for the important part and parts I know well" (DTML, Diary, Week 3).

“... For examples, in speaking English, I will arrange these ideas follow the time and the space. If I didn't have information about this topic, I will get information in book, on web..." (NTH, Diary, Week 6).

One student self-evaluated after she finished her presentation:

\begin{abstract}
And in speaking and writing is not different so much. Writing is write on the paper and speaking is speak out so the strategies is also important. When you prepare your presentation about any topics, you also have to plan what you say, organise the ideas in logical so your audience easy to understand. After finish your presentation you should evaluate what you did to draw experience, whether what you did got a best result? Can you make it better? What is you missing? If you answer that questions you can make your presentation better after and improve your speaking skill (LHN, Diary, Week 5).
\end{abstract}

Others said they not only applied the skills of planning, monitoring, and evaluating in learning speaking, but also in learning reading and listening comprehension: 
I applied the strategies you taught me in learning other skills of reading, speaking and listening because I can practice these skills more quickly and get main ideas better $(\mathrm{CNH}$, Diary, Week 4).

And I applied the strategies in learning other skills of reading, speaking and listening. In reading, before I read a topic or an essay, a paragraph, I should look at the topic and think or imagine them then read it and compare or contrast with my opinion; think about something which the author gave in essay or that paragraph. In speaking, when I speak a topic, I should talk all, don't be shy because when I speak the teacher and other students will listen to me and correct my mistakes for me. Then I will compare and contrast with others to find some good thing for me. In listening, this is a difficult subject to me. I don't know what I have to do to listen well, I tried some methods such as listening to radio, some news on $T V, B B C, A B C$ but it not useful. To apply them on listening for me is also a problem (NTH, Diary, Week 4).

In reading, each text has a title, before you read the text you should read the title and then stop to brainstorm something about the topic and think what the author will give you. During process you read you can monitor what you read similar what you thought before. In listening, the strategies is quite important. Listening to spoken English is much easier when you have some ideas about what you are going to hear (DTML, Diary, Week 3).

The group interview with five students from the EG maintained the above finding. One student said that she found it hard to employ the metacognitive skills in reading:

When I am reading, I want to plan, to monitor and to evaluate but I don't know how. I cannot plan for the content because it is there already. I don't know. It is so hard (Student 3, Q4, group interview, P2).

Another did not say anything. However, the other three reported making use of planning skills in learning listening comprehension:

Before I listen I often think about the words that might be used in the topic given. I try to recall the words that I know about the topic (Student 4, Q4, group interview, P2).

Me too. I get myself prepared by thinking about the words that I might hear. I write them down. Sometimes I spell them wrong but it does not matter (Student 4, Q4, group interview, P2).

I ask myself what I know about the topic and try to recall the information on the topic that I have read before (Student 1, Q4, group interview, P2). 
The use of metacognitive skills in listening comprehension by students was backed up by the interview with the teacher who taught listening comprehension in the EG. She stated that she witnessed a small change in the way students approached a listening task:

They actually brainstormed before they listened. For example, they guessed what they would hear on the topic about earthquakes. I gave them some clues though, but they did guess words they thought would appear in the listening text (from Interview DT, Q1, P2).

However she claimed that she did not notice students employing any other strategies in learning listening comprehension (Interview DT, Q6, P2).

It was interesting to find out that one student put the metacognitive skills into practice in her daily life:

Beside that, we are not only using in writing, but also in our life. That are when we do something, we also have to think carefully, then preparing ideas exactly (HTT, Diary, Week 2).

In this respect, Ms Phuoc reported hat students in the EG had become more likely to take the initiative, namely, they asked a lot more questions during the lesson. Ms Phuoc also observed that her students had developed critical thinking. They tended to express strong opinions on the issue about which they were writing:

The students asked a lot more questions now when they were writing the outline for their essay... For example, they asked if they could organise their essay in a certain way. They showed their critical thinking as well. For instance, they did not agree with some of the information I provided and wanted to write in their own way... (from Interview P1, Q2, P2).

She also stated that her students composed their essays faster then before:

...But one very obvious thing was that they edited their essay more quickly than before ... Normally, when I asked them to do any writing in class, they always asked for more time to get the work done. Now, they were faster. They managed to submit their work within the time limit (from Interview DT, Q1, P2). 
Although Ms Phuoc did not provide many comments about the changes students made in her writing class, her remarks about the effectiveness of the training package were positive. It could be argued that students in the EG developed their ability to plan for their essay by asking different sets of questions to generate ideas or to organise their essay, the skills learned from the metacognitive sessions. This could be one of the reasons why they became more inquisitive and more critical. Ms Phuoc's observation about students editing their essays faster indicated that they were able to plan time for their essay. Setting the time for an essay was also one of the SMART goals they had learned from the metacognitive sessions. To some extent, students in the EG managed to transfer the metacognitive skills into learning writing.

Little (1991) argues that "autonomy is likely to be hard-won and its permanence cannot be guaranteed" (p. 5). It was, therefore, not surprising that the transfer of metacognitive skills, basically, failed. Due to the time limit, during the metacognitive sessions, the researcher focussed on teaching students how to plan, monitor, and evaluate for a writing task only. Although she sometimes explained and provided examples on how the metacognitive skills could be applied in learning other subjects, she only did so when she felt that the students could make a direct link with other subjects. To illustrate, in session three on planning for content, the researcher asked students to use the technique for generating the content for their oral presentations. As a requirement of the speaking course, students were asked to make oral presentations on topics decided upon by themselves. On any given topic, they were divided into for or against groups and worked closely with their group members to prepare for their presentation. Since the researcher felt that the strategy of content planning might be of value to students, she spent about five minutes explaining how they could find ideas and organise them in their oral presentations. This might be the explanation for the transfer of the planning technique into the speaking course but not into other skills.

Another explanation for the failure could be the fact that the metacognitive skills were explicitly incorporated into the writing curriculum for the first time; it would take time for students to master them in writing before they could apply them in learning other subjects. This reason is mentioned in Benson's (2002, p. 53) explanation: 
...we know that the capacity to control an aspect of learning in one domain of learning is not readily transferred to others. Since the exercise of control over certain aspects of learning appears to be influenced by subject matter competence, lack of competence in a new domain may be one factor influencing transfer.

Therefore, it would be reasonable to suggest that in order for students to be able to use the metacognitive skills in other areas of language learning, similar MT packages should be incorporated across all language skill curricula, not only the writing curriculum.

\subsubsection{Feedback about MT}

The researcher managed to gather feedback on the MT sessions from both the students and Ms Phuoc. Basically, the remarks were very encouraging. As has been illustrated in previous sections, students' diary entries and interviews showed very positive comments about the MT sessions. However, some students noted in their diary entries the weaknesses of the sessions. The drawbacks included the researcher speaking too fast:

Today's lesson which you taught me is very interesting and useful. But I think you taught quite quickly, it is difficult for me to catch up with lesson. I hope next time you can teach slowlier than the lesson before (NTCP, Diary, Week 3).

or providing insufficient examples:

Although it's very clear, I feel difficult. So there are a little example that I don't understand. I think I need to make many homework to know clearly (NTMH, Diary, Week 4).

One student had difficulty using connective words and generating ideas for her essay:

Although you teachs good, talk English clearly, slowly, your lesson understand easily, but I don't still excitement. Occasionally understand and little vague how use words? How use ideas that it isn't clumsily with your lesson (LTKL, Diary, Week4).

During the sessions, when being asked about their failure to get their homework done, many students blamed the incorporation of this training package 
into their Writing Four curriculum. Informal conversations with students in the classroom revealed that students could not find enough time to do homework given by both the researcher and Ms Phuoc. This also explained the drop in the number of students submitting their weekly diary entries from week four towards the ending point of the project.

From a teacher perspective, Ms Phuoc who taught the Writing Four course felt that the MT should be incorporated into each writing lesson of the course rather than be taught separately by the researcher as it had been done. She stated that it would save time and be easier for her to teach the course if the teaching was done by herself. She expressed her worries about not having enough time for the EG to practise writing in class (Interview $\mathrm{P}, \mathrm{Q} 5, \mathrm{P} 2$ ).

\subsection{Discussion}

This section presents detailed discussions on strong points of the MT project including improvements in self-initiation, self-regulation, and writing score. It also discusses the most distinguishing features of LA in Vietnam.

\subsubsection{MT project}

According to Little (1996) in developmental learning, autonomy begins implicitly and the levels at which it becomes explicit vary, depending on learners' endowments and the environmental influences. In formal learning there is always explicitness in planning, implementation and evaluation of learning, the important elements of selfregulation. Explicit strategy training explains the EG's improved autonomy after the students embarked on the MT.

Results of the second phase proposed that the MT project was a success. McGarry (1995) states that "if students are to become autonomous learners, it is selfevident that they will need to exert some measure of control over their learning" (p. 6). He emphasises that it is not a question of less control being applied in the course, but it is a question of how the control is exercised and how the responsibility is shared among learners and between learners and the teacher. He claims that generally the teacher makes a decision on the overall direction of the term work but leaves the details to be worked out by learners. He argues that "autonomy is promoted by 
providing a framework within which students can take an increasing amount of responsibility" (p. 34). The SBI framework developed by Chamot et al. (1999) proved to be the right choice for the MT. The shift of responsibilities from teachers to learners was best facilitated and achieved through the application of the SBI structure. The value of the MT was seen in the EG's improved self-initiation, enhanced selfregulation, and better writing scores.

\subsubsection{Enhanced self-initiation}

Greater autonomy in the EG was attributed to the MT project. The learners manifested both quantitative and qualitative changes in their self-initiation and selfregulation. While it was expected that after the training students would improve their self-regulatory skills of planning, monitoring and evaluating, it was encouraging to discover that they also developed (though not statistically significantly) their selfinitiation, a more autonomy-focused element of LA. Although the MT led to greater development of self-regulation than self-initiation, the learners nonetheless invested more effort in learning English both outside and inside the classroom than they had before they embarked on the training. In fact, improvement was made in all aspects of self-initiation including learning English outside class (3.0 against 2.9), using English outside class (2.4 against 2.3), overt learning in class (1.9 against 1.7), and covert learning in class (4.1 against 3.9). Additionally, qualitative data from interviews and learners' diary entries provided sound evidence about the changes. Qualitative insights into autonomy were revealed. These included learners engaging more actively and becoming more interested in the writing subject than before, and recognising their weaknesses not only in English writing but also in other subjects. Learners, according to the researcher's observations, showed regular class attendance, interaction and active participation in classroom activities. This phase of the study resonated with a range of LA descriptive studies such as Mizuki (2003), and Tagaki (2003) on the use of cooperative learning; Nunes (2004), Shimo (2003), and Rao (2005) on the use of portfolios; Natri (2007) and Thomson (1996) on the use of selfand peer-assessment. Similar to other approaches to fostering LA, the learner-based approach with its focus on MT produced positive results.

Similar to the first phase, this phase of the study further established that LA developed more effectively in a covert manner within the classroom, where learners 
were more readily able to collaborate with other learners and draw on the support of teachers, than outside it. Autonomy being exercised more within the classroom than outside it further supported the idea that interdependence was important for LA (Little, 1999). However, it was interesting to discover that the majority of the participants in this study voted for individual learning in the classroom setting. It was found that they did not like writing their essay in groups and wrote better when working individually. This finding bears out the results of Smith's (2001) study which reported advocacy for individual learning by Japanese learners. His study revealed that the majority of outside-classroom learning involved individual, not cooperative study arrangements. Inside the class, individual learning was feasible, appropriate and also required by some Japanese learners. This was different from the existing stereotypes or other generalisations held about Japanese as group-oriented learners. It is clear that learners need time on their own for reflection. In-class individual learning rather than group work would reinforce autonomy among some learners.

The relationship between LA and motivation proved to be close. Ushioda (1996) believes that "while motivation is principally regarded as a causal variable influencing outcomes, motivation is also now seen to be potentially affected by those language learning outcomes, subject to change..." (p. 10). To put it more simply, there is now perceived to be a mutual relationship between motivation and language outcomes. If we can aid learners in obtaining good language learning results, they will become more motivated to learn. More importantly, since motivation and LA are evidently closely related, the achievement of better learning outcomes will yield greater LA. In summary, self-initiation, the less teachable aspect of LA, improved quantitatively and qualitatively thanks to the MT, which strengthens the claim about the significance of the MT.

\subsubsection{Enhanced self-regulation}

The MT resulted in more development in the area of self-regulation than in that of self-initiation. It was encouraging that the MT led to improved skills for the learners. While some learners who had not exercised metacognitive skills before started to plan, monitor, and evaluate a writing task, some others learners who were familiar with metacognitive skills managed to widen the repertoire of each skill. For instance, in addition to content planning that learners had already undertaken before the MT, they, 
after the MT, thought about vocabulary used in their writing (Student 5, Q4, group interview). Others evaluated the provision of examples and facts, and cohesive devices in their essays as well as, in most cases, checking spelling and grammar errors (Student 3, Q5, group interview).

Learners in the EG engaged in evaluating significantly more after the MT. They also practised planning more. However, they exhibited little improvement in monitoring skill. This finding adds to the evidence that monitoring is the least popular aspect of self-regulation. Not only were Vietnamese learners reluctant to practise monitoring, learners from other countries demonstrated the same trend. For example, in Turkey, Sert (2006) found that Turkish learners failed to monitor their own learning. Learners' failure to monitor their learning is consistent with White (1995) who examined the use of metacognitive strategies by classroom and distance learners and found that learners in both instructional contexts did not monitor as much as they planned and evaluated. The Vietnamese learners also employed a lot more planning and evaluating than monitoring strategies partly because they equated monitoring with evaluating. They tended to focus more on monitoring language problems rather than on other aspects such as monitoring task progress, task concentration, task performance or feelings. Since monitoring was the least exercised among the three metacognitive skills, it is suggested that more monitoring-focused training should be provided in order to help learners master and execute monitoring skills in their learning.

It was motivating to know that the learners transferred the metacognitive skills to the speaking subject though not to others. Transfer is said to occur when learners apply a skill learned in one situation in another situation. Woolfolk (2004) distinguishes between low-road and high-road transfer. The former involves "spontaneity and automaticity in familiar situations" (p. 309). The latter involves "consciously applying abstract knowledge in one situation to a different situation" (p. 303). Whatever transfer learners in the EG made was the low-road, not the high-road transfer. To facilitate high-road transfer, long-term SBI training and practice would be required, especially training in monitoring skills. 


\subsubsection{Enhanced writing score}

The EG's accomplishment in writing in both the post- and delayed tests is in tune with the results of studies on SBI such as those by Butler (1997), Goh and Taib (2006), Gu (2007), Rubin and McCoy (2008). These research projects indicated the usefulness of strategy training to learners' improved learning results. Gu's (2007) study provided the inspiration for the design and structure of the MT for this phase. In essence, the researcher followed the SBI framework further developed by Gu (2007) in Singapore. The SBI worked well and yielded positive results not only in Singaporean primary schools but also in a Vietnamese university. The flexibility of SBI is a strength that makes it work effectively irrespective of the setting and the level of learners. Literature in the field of LA has suggested that LA is useful. However, little data-based evidence about how useful LA is for learners has been provided. Most language teachers and learners focus on the language learning outcomes. This study has demonstrated the positive relationship between LA and language learning results. In the LA field, some studies managed to demonstrate improved learning results such as Champagne et al. (2001), Dam and Legenhausen's (1996), and Vickers and Ene's (2006). However, they all faced problems which prevented them from producing convincing and sound empirical results. The weak points of these research projects respectively involved the difficulty of standardising a test, the lack of comparability between experimental and control groups, and the absence of authenticity of the texts used in the tests. Since the subjects of this phase of the study were compatible in terms of language proficiency and LA, the improved writing scores the EG achieved were persuasive and trustworthy.

To sum up, the success of the MT suggests that LA is teachable despite Dam's (1995) belief that LA cannot be taught (p. 6). It is congruent with Holec's (1981) view that LA is most often acquired through a systematic and intentional process (p. $3)$.

\subsubsection{Popular model of LA in Vietnam}

In the researcher's own experience, the psychological model of LA with its emphasis on the internal modification within each learner is the most well-known in the Vietnamese educational context. In the Vietnamese classroom, learners do not have the right to make decisions on what to learn because it is predetermined by the school 
curriculum and their teachers. However, they are empowered to make decisions on how to learn. Although this is a constraint, it is at the same time a facilitating factor that reinforces the inner transformation inside learners. There may be limits to what students can do in the classroom but this encourages them to exploit what they are currently entitled to. In essence, when learners were receiving MT, they became more involved in their learning by creating learning environments for themselves outside the classroom, interacting with peers and teachers, and actively used planning, monitoring, and evaluating skills to complete their writing tasks. It was evident that they became more responsible for their learning by employing the metacognitive skills they had been taught. In this regard, autonomy could be seen as "something which is internal to the learner and which is not necessarily tied to any particular learning circumstances" (White, 1995, p. 209). Irrespective of the limited freedom of the educational context of Vietnam, learners managed to make changes in the way they approached writing tasks to attain better writing results.

Other models of LA such as political or critical seemed to be less relevant in the Vietnamese educational setting. The five suggestions made by Benson (1997) about the right stance on the political version of LA are worth considering. These ideas included authentic communication with users of the target language, collaboration and collective decision making, engagement in open-ended learning tasks, learning about the target language and its social contexts of use, and exploration of collective and personal goals. Basically, because of the bureaucratic constraints in the Vietnamese educational system, neither teachers nor learners would be able to make changes in the classroom even if they were interested in doing so. Because they perceive they are not allowed to implement the changes, they are not interested in the political model of LA. As a result, they are more concerned with language learning techniques which enable them to initiate changes to improve the English language learning outcomes. Learning about the English language and the social contexts of its use would not be as important as learning how to learn in order to become better language learners and users. Additionally, the EFL environment in Vietnam where interactions in English are more likely to happen between Vietnamese and interlocutors from other non English-speaking countries does not seem to be a good place for the promotion of the political model. In the Vietnamese context the political version of LA seems to offer indirect, insubstantial, and out-of-reach benefits. 
Similarly, the critical model of LA has been irrelevant due to learners' and teachers' exceeding interest in teaching and learning outcomes. The critical autonomy proposed by Pennycook (1997), who encouraged learners to speak against the local and global discourses that might hinder or create the possibilities for shaping their lives, appeared the least relevant to Vietnamese learners. Although this is a worthy awareness to be raised among learners, within the educational environment of Vietnam, it is difficult for learners to express their opposition to any discourse that might constrain their lives. This is because it would be too serious an issue for them to deal with by themselves. Raising a problem without being able to attend to it is not worth the effort. In the Vietnamese context, learners are not in a position to make radical changes to the way their lives are shaped due to the power relations in society. Before any fundamental alterations occur, learners should formulate small-scale aims which they can attain themselves without relying too much on other people. In short, the critical model of LA, on the one hand, is not applicable in the Vietnamese setting. On the other hand, it would make learners heavily dependent on external resources to have favourable changes made, which is against the core meaning of LA. Too much dependence will definitely destroy LA.

While the psychological aspect of autonomy is both relevant and feasible in Vietnam, the social model of autonomy developed by Holliday (2003) makes it clear that Vietnamese learners bring their own autonomy in the classroom. In fact, Holliday's (2003) concept of social autonomy calls for the avoidance of essential cultural descriptions of learners, the examination of learners' worlds, the fair treatment of all people, and the universalisation of the notion of LA. This notion of autonomy certainly suggests that LA is positively appropriate in Vietnam. LA is not only suitable but also beneficial to Vietnamese learners.

Schmenk (2005) criticises the psychological aspect of autonomy for being homogenised in the global context. She argues against the idea that learners attain autonomy as a result of mastery and use of learning strategies. Her argument is for the glocalised model of autonomy which takes into consideration the cultural and political background of the local learning environment. This study has shown that the internal modification which Schmenk (2005) argues against seemed to be useful in the Vietnamese educational context. The psychological model of autonomy, in essence, is an excellent response to her proposal for the glocalisation of autonomy. Since the cultural and social backgrounds of Vietnam are not favourable for other 
versions of autonomy, teachers and learners should glocalise it by putting endeavours into teaching and learning the strategies that are useful to them. They should explore and make use of their internal resources to accomplish their learning goals rather than rely on radical educational and social changes that are other-dependent. It follows that, employing metacognitive strategies to promote LA is aligned with the need to glocalise autonomy as argued by Schmenk (2005).

\subsection{Conclusion}

The second phase of the study revealed some important findings about improved written English among students in the EG.

Firstly, the MT resulted in the EG outperforming $\mathrm{C} 1$ and $\mathrm{C} 2$ in both the postand the delayed tests. The EG obtained significantly higher scores than $\mathrm{C} 1$ for the post- and the delayed tests. It performed significantly better than $\mathrm{C} 2$ in the post-test but only numerically better than $\mathrm{C} 2$ in the delayed test. The triangulation of data indicated that the procedures of the metacognitive lessons, the explicitness of strategy teaching, the teacher rapport, and the interesting and to-the-point content of the metacognitive project were the main contributing factors. Additionally, it was found that organisation and content were the two components in which students across the three groups made the most progress. Language and grammatical accuracy aspects, on the other hand, witnessed the least progress made by the students. Most importantly, it was the EG that made the most progress in all aspects except for the language component. In the language element, however, it was revealed that the MT led to students in the EG using a lot more connective words after the MT had been conducted than their counterparts in the other two control classes. Furthermore, the study demonstrated better writing scores for those who had attended all the training sessions compared with those who did not come to the training sessions on a regular basis.

Secondly, the study showed the maintenance of improvements in written English made by students in the EG. Among the three groups of participants, students in the EG achieved the highest writing score for the delayed test taken six weeks after the training had been completed. When considering the influence that the MT had on the writing score for students of different academic achievement, it can be seen that average students made the most gains in their writing scores right after they engaged 
in the MT. However, they were not able to maintain these gains six weeks after the MT had been completed.

Thirdly, greater LA was reported as a result of students being trained in metacognitive techniques of planning, monitoring, and evaluating. Regarding selfinitiation, the MT did not result in changes in students' reasons for learning English, but it led to greater autonomy inside the classroom, although not outside it. More importantly, covert learning was confirmed as the most favoured method of learning among the participants of the study. Concerning self-regulation, students in the EG improved their ability to plan, monitor and evaluate a writing task more than students in the other two control groups. Planning became the most often exercised skill, followed by evaluating. Monitoring was the least practised skill among the three metacognitive skills. In terms of the influence of the MT on different aspects of LA for students of different academic achievement in the EG, it was found that the MT did not result in changes in self-initiation for top students. Nonetheless, it encouraged average and bottom students to invest more effort in learning English. As for selfregulation, the MT led to top students performing better than the other types of students in general planning, task-specific planning, monitoring, and evaluating. Because of their level of proficiency, average students, after having attended the MT, demonstrated greater ability to practise the metacognitive skills than bottom students.

Finally, it was discovered that students were not able to successfully transfer the metacognitive skills into other language learning areas. They managed to apply the skills they had learned in learning speaking. However, they failed to do so in learning in most other language areas.

Overall, the results of the second phase of the study indicated that, with intensive instruction, learners can improve their ability to self-regulate a writing task. The self-regulation element of LA, thus, could be taught to students. 


\section{IMPLICATIONS AND CONCLUSION}

\subsection{Introduction}

This study first investigated the relationship between LA and language learning outcomes through an exploratory correlational design. It next examined the causal relationship between the MT and writing results as well as the relationship between MT and LA through an intervention study. The study also advanced the understanding of LA in Vietnam. Like other Asian learners from Hong Kong and Japan, Vietnamese learners were autonomous. The Vietnamese culture did not inhibit but facilitated LA. While the first phase of the study established that LA was related to learners' language proficiency, the second phase further confirmed that learners could enhance their autonomy through engagement in SBI with a focus on metacognitive strategies. Being supported by both direct and indirect evidence, the study has demonstrated that LA is useful for language learners. This chapter discusses specific theoretical, methodological, and pedagogical contributions this study has made to the field of LA. It then outlines the limitations of the study. Finally, it draws some conclusions and suggests some directions for future research.

\subsection{Theoretical contribution}

On the theoretical ground this study has successfully conceptualised LA, proved the importance of LA for language acquisition, measured LA, and exhibited the convergence between LA and LS.

\subsubsection{Conceptualisation of LA}

In this study, LA is pinned down as consisting of self-initiation and self-regulation. According to this definition, self-initiation included learner reasons for learning and making effort to learn. More specifically, reasons for learning consisted of individual development, intrinsic interest and going abroad. Making effort to learn consisted of learning English outside class, using English outside class, overt language learning 
in class, and covert language learning in class. Self-regulation comprised selfmanagement learning skills of planning, monitoring, and evaluating.

This conception of LA reinforces Benson's (1997) psychological version of LA which focuses on learners initiating internal changes to improve their learning. This is both feasible and suitable in a learning environment where constraints on decision making exist. The operationally defined concept also contributes to current understanding of aspects and dimensions of LA. Following this new conceptualisation, LA comprises the three dimensions of learner independence, learner agency, and learner self-control. The extent to which these dimensions are exhibited depends on the setting where the learning takes place. In addition, the task and learning strategies are important elements in learners' ability to exercise LA. This research has developed LA as a concept coordinating a range of elements related to learners' control of their learning. Self-regulation, a task-focused element of LA, can be achieved through training. Self-initiation, the learner-focused element of LA, seems to be more or less dependent on learners' natural endowments. However, there are not sufficient grounds to claim that self-initiation is not teachable.

\subsubsection{LA and language acquisition}

This study demonstrates that LA is worth promoting to a considerable extent because it yielded tangible results. The study has established an empirical ground for a claim about the practical values of LA. Empirical evidence of the efficacy of LA is added to the existing descriptive evidence of the importance of LA. The positive relationship between LA and language learning results has provided credible evidence for practitioners and researchers who aim to foster LA in language teaching and learning. It is evident that LA facilitates language acquisition.

\subsubsection{LA and its assessment}

It was evident that LA could be quantified and measured. After LA had been defined and broken down into constructs and subconstructs, it was easily measured. The employment of a combination of methods also contributed to the success of LA being measured quantitatively and qualitatively. The study used three out of the four ways proposed by Sinclair (1999) to measure LA including monitoring learners' gains in 
proficiency in the target language, gathering feedback from teachers and learners, and researching the effects of strategy training. The application of all three approaches rather than of a single one proved to be the right way to assess LA. This method of evaluating and measuring LA was, to a certain extent, more comprehensive and credible than the way LA was assessed by Lai (2001) who measured LA at the task and the self-direction levels. When looking at the task, Lai (2001) only considered task aims and self-assessment components. The other elements of LA such as learners' ability to identify problems and to use appropriate strategies to solve their problems were ignored. In other words, while Lai (2001) operationally defined LA as learners' ability to plan, monitor and evaluate the learning task, she failed to assess the monitoring component of the metacognitive knowledge. In terms of self-direction, her study showed high internal consistency of items in the rating scale for process control and the inter-rater reliability of the rating scale for self-direction. Still, learners did not receive any training in self-direction. The learners were given the framework to follow but it was unidentified whether and how much training and instruction they had received. Without doubt, Lai (2001) has made a contribution to providing an instrument to evaluate LA at both micro and macro levels. Nonetheless, the way LA was measured needed improving. Therefore, it is argued that the operational definition of LA identified by this study has made it possible to assess LA quantitatively and qualitatively.

\subsubsection{Inter-relation between LA and LS}

White's (1995, p. 207) statement that mutual benefits would be brought about by closer research endeavours between the LA movement and learning strategy research was tested in the second phase of this study. Strategy training resulted in tangible benefits including increased strategy use, learning outcomes, and most importantly, LA. Hence, it is logical to argue that strategy training is of importance to the fostering of LA. Metacognitive strategies, which are more learner-dependent, are at the core of the overlap between LA and LS. When learners master the metacognitive strategies, the self-regulation aspect of their autonomy will be enhanced. The positive learning results and reflections achieved by learners in the EG made it crystal clear that LS can be employed to foster this element of LA. This study supports Cohen (1998, 2007), Wenden (1998), and White (1995) who strongly believe in the interconnectedness of 
LS and LA. The study demonstrates that LA could be best promoted by explicitly training learners in metacognitive strategies. SBI proved to be a right approach to fostering LA. The gap between LS and LA appeared to be narrowed. Hence, learnerbased approach to developing LA can be used as a way of coming to know more about both LA and LS. This requires methodological shifts which can be a means of widening the repertoire of tools and practice for LA research.

\subsection{Methodological contributions}

Another major contribution of this study involved research design and data analysis approaches.

\subsubsection{Research design}

This study made use of both qualitative and quantitative designs which have provided research evidence on the basis of not only subjective descriptions but also objective statistics. The combination has been important in producing credible results. This has also been an essential contribution of the study because so far most studies have taken the descriptive approach. Another quality of this research project was its longitudinal characteristics. The pilot study was conducted in the first year of the study. It aimed to test the research instruments and to gather comprehensive information about the context and the setting where data collection took place. The first phase of the research was performed in the second year. Its purpose was to collect empirical evidence on the relationship between LA and language proficiency. The second phase occurred in the third year when an intervention package was integrated into the writing curriculum. The aim of this phase was to investigate the effects of the MT on learners' language proficiency and LA. The three stages stretching over a period of three years made it possible for the researcher to develop, design, revise, and to validate the research instruments in the context of the study.

\subsubsection{Data analysis approach}

The strengths of the data analysis process included triangulation of different sources of data, consideration of inter-rater reliability, validation of the questionnaire through 
factor analysis and internal consistency analysis, and the operationalisation of the LA construct. Firstly, research questions were addressed on the basis of not only the questionnaires but also various sources of information. The triangulation of data has contributed to valid interpretation and the production of sound and persuasive results. Secondly, inter-rater reliability was taken into consideration. In both phases of the study, the learners' writing tasks were marked by two different writing teachers. They were not advised if the writing tasks they were marking were from the pre-tests or post-tests. In tasks where discrepancies in score were found, the final score was the average of the two. Thirdly, the questionnaires used in this study have gone through many rounds of revision to ensure their suitability to the Vietnamese context. The questionnaires were also validated by running SPSS inter-item reliability and factor analysis. Hence, the reliability of the scores of the questionnaires was ensured. Of equal importance was the fact that both top down and bottom up approaches to developing the questionnaires were taken. Fourthly, at the early start of the research a clear concept of LA, which guided the research, was explicitly indicated. Once the construct of LA was operationally defined, this operationalisation was strictly followed in the data analysis. Because "operationalizations allow measurement" (Mackey \& Gass, 2005, p. 105), LA was successfully quantified and measured.

Taken together, the way this study was designed and the way the data were analysed made it possible to answer the research questions set out at the beginning of the study. Most importantly, in this regard, a message that this study aimed to convey was the feasibility of conducting quantitative research in LA.

\subsection{Pedagogical contributions}

This study demonstrates that LA is worthwhile and in need of promotion in the Vietnamese educational setting. It also provided insights into how LA can be fostered.

\subsubsection{How to promote LA}

The operationalisation of LA, i.e., 'taking control of the learning process' (Benson, 2001), as both learners' self-initiation and self-management, can be extended to its promotion. For example, self-initiation, the arguably less teachable element of LA, could be promoted by encouraging students to use English outside the classroom as 
much as possible. Such activities as sending emails in English, talking to foreigners, chatting in English online, making friends with foreigners and communicating with them orally or in writing, spending time with a volunteer teacher of English, and writing blogs in English, should prove to be very useful to students. Self-regulation should be taught to Vietnamese students so that they will become more autonomous learners of English. This is especially true in view of the finding that the students who received training in metacognition were able to improve their metacognitive skills. In other words, learners need training in order to develop their autonomy in learning. This is in tune with the view that "learner autonomy now seemed to be a matter of learners doing things not necessarily on their own but for themselves" (Little, 2007, p. $14)$.

While the self-initiation of learners is not easily either changed or improved considerably through teaching, it is possible to enhance LA through teaching learners the metacognitive skills of planning, monitoring, and evaluating. Hence, it is argued that the development of LA depends upon learners making efforts to learn and their ability to use metacognitive strategies in a learning task. Learner-based approaches focussing on SBI proved to be efficient in fostering LA. To put it another way, learners need to be trained in learning strategies in order to become more autonomous, and more importantly to achieve higher learning results in language learning.

To develop and maintain LA and language learning results, SBI should be synchronously integrated into other language learning areas such as listening, speaking and reading. It is suggested that language teachers be trained in SBI and incorporate it into the curriculum of each subject they are teaching. Since the SBI steps are flexible, teachers can reshape them to suit their classroom context. More importantly, they can adopt either the top-down model (Chamot et al., 1999) or the bottom-up approach (Butler, 2002) for their own classroom. The integration of SBI across language subjects would make learners more aware of the use of strategies, and enable them to grasp opportunities to practise them.

While SBI top-down group instruction might be more suitable for learners who have little knowledge of learning strategies, Butler's (2002) bottom-up model of strategy-based instruction could be applied for learners who are able to co-construct learning strategies with the teacher. It is recommended that learners of different proficiency levels be given a particular focus during the MT in order to achieve similar growth. For example, more emphasis should be placed on the self-regulation 
component of LA for bottom and average students while the self-initiation aspect of LA would be the focus for top students. In other words, learners should be preassessed and split out according to their level of performance before MT is conducted. Of equal importance is the suggestion that learners should be trained in aspects of language they are weak at. For example, after an analysis of aspects of an essay (organisation, content, language, and grammatical accuracy) is completed, particular learners should be trained only in those areas of language where improvement is most needed in order to compensate for their weaknesses. To put it differently, the MT training must necessarily be based on individual needs to yield the best results. For practical purposes, learners should be grouped according to the weaknesses in each language skill, and the group training will start from there. Group SBI might be a feasible model which would be a more learner-derived and learner-focussed approach to developing LA.

\subsubsection{Implications for classroom teaching}

Several practical pedagogical implications were drawn from the comparison of performance between the EG and $\mathrm{C} 1$. These included transfer of responsibility from the teacher to the learner, explicit statement of lesson objectives, structure of groupwork, and error correction.

Structuring lessons in such a way as to shift responsibilities from the teacher to learners seemed to be beneficial. The success of the MT appeared to be closely linked to the gradual transfer of responsibility from the teacher to learners, one of the most rigorous strengths of SBI acknowledged by Gu (2007). The responsibility was shared with learners by the teachers who engaged them in the stages of which the Vietnamese teacher is normally in charge, such as giving new inputs or theoretical background for an item. Acceptance of responsibility, which facilitates the management of learning and the right to make decisions in learning, is fundamental in the exercise of LA (Little, 1999; Scharle \& Szabo, 2000). In the LA literature, there has been ample evidence that a well-balanced lesson where the responsibility is shared and is gradually shifted from the teacher to learners would be beneficial (Cunningham \& Carlton, 2003; Dam, 1995; Nix, 2003; Stephenson \& Kohyama, 2003). It is vital that there be a proper transfer of responsibility from teachers to learners (Chan, Spratt \& Humphreys, 2002). Hence, while planning their lessons, 
teachers should keep in mind that learners need to be involved and have 'a job to do' in every stage of a lesson.

Having articulated the objectives of the lessons explicitly seemed to make a contribution to enhanced LA in the EG. According to the educational psychology of learning (Gagne, 1974), statements of learning objectives are essential not only for the teacher but also for the learner. He argues that "for the students, appropriate communication of learning objectives may be an important element in the establishment of motivation and the feedback from completed learning" (p. 74). This suggests that explicit articulation of objectives was crucial for learners. It is commonly observed that in the Vietnamese classroom, especially at a tertiary level, teachers do not tell their students about the objectives of each lesson. They might either perceive this to be a point for students to think about, or be influenced by the implicitness of the Vietnamese culture where most people prefer their interlocutors to arrive at conclusions or draw implications from what is said or taught by themselves. It is explicitness rather than implicitness that would orient the students to the main points of the lessons and "push" them towards the objectives of a lesson. For this reason, irrespective of learners' level of maturity and proficiency, it is suggested that teachers openly and repetitively state the objectives of each lesson as well as of each new item.

Group-work was found to be the most popular type of class activity employed by the teachers. While it enabled learners to generate ideas for their essay, most learners, who took part in the follow-up interviews, opted for it being used at the initial stage of planning for their essays only. When it came to actual writing, individual work was preferred. Some learners did not like group-work at all. Teachers, consequently, should make a decision whether to engage all their students in the same sort of activities. In this regard, it is more useful if teachers learn how to "let go" by which Dam (1995) implies teachers accepting learners' choices rather than imposing their choices on the learners. Learners, who do not enjoy the interdependence, which is perceived by Little (1991) to be a crucial element of LA, should be allowed to pursue activities they are comfortable with.

Regarding error correction, giving learners opportunities for self- and peercorrection seemed to motivate learners effectively. The positive correlation found between LA and motivation implies encouragement being given to learners so that they will participate in both self- and peer-correction and evaluation. Previous studies 
have endorsed practical values of peer- and self-evaluation (Miller \& $\mathrm{Ng}, 1996$; Nachi, 2003; Natri, 2007; Thomson, 1996). Empowering learners with the right to correct themselves and others is, in essence, giving them a chance to evaluate themselves and others. Teachers, by doing so, will create opportunities for their students to practise and to improve evaluation, an essential aspect of metacognition.

It is hoped that autonomy achieved in the domain of learning will be transferred to the domain of personal life. The three different domains of LA described by Littlewood (1996a) will be reinforced by each other, which in turn will contribute to autonomously well-rounded people.

\subsection{Limitations}

Some limitations of this study included the Writing Four course being co-taught, the questionnaires being repeatedly used, the self-report nature of the questionnaires, the participants being invited to take part in the three phases of the study, and the researcher being granted more privileges than other teachers.

Due to the fact that Ms Phuoc and the researcher shared the teaching of the Writing Four course, the amount of homework assigned by them to the learners in the EG, to some extent, contributed to the improvement in writing. Although no comparison was made between the EG and the two control groups in terms of the amount of homework given during the Writing Four course, complaints from learners in the EG about the workload made it clear that they had to invest more time in writing at home. More time devoted to writing homework must have enhanced the EG's post-test scores of writing.

The fact that the LA questionnaires were distributed to the same subjects prior to and after the MT might have raised learners' awareness about LA. One case could be that the participants in the study including learners in $\mathrm{C} 1$ and $\mathrm{C} 2$ might put on a mask of LA. They might not have exhibited autonomous behaviours prior to the MT, however they could have reported them after the MT, even though they did not actually perform such autonomous acts in their learning. They might want to meet the researcher's expectations. Another reason could be the lack of anonymity of the questionnaires. Since the participants were required to put their names on the questionnaire, some could have self-reported their improved LA because they wanted to maintain their face. 
The quantitative data came from learners' self-reports. It was not certain whether they actually performed self-initiated and self-regulated learning activities as they claimed in the questionnaires. In addition to the triangulation of data sources, the match between what learners report engaging in and what they in fact undertake could further be monitored by looking at learners' actual performance. Future research could use close observation and if possible video-tape learners' learning behaviours exhibited both inside and outside the classroom.

The longitudinal characteristic of the study could have triggered improved LA among the learners in the EG. Most of them volunteered their participation in the first phase of the study and two of them even wrote the learning logs in the pilot study. They could have become more autonomous because they had answered the questionnaires many times and had realised what would be good for them, not because they received the MT. The validation of the LA questionnaires should have been performed on different learners rather than on the same learners at the same institution.

The researcher's status might have influenced the learners' attitude and their commitment to the MT. First, she used to work as the Dean of the Department of English of the university where the participants were studying for their Bachelor's degree in English. Second, as stated by one of the teachers in her interview, the fact that the researcher was doing her $\mathrm{PhD}$ overseas made learners in the $\mathrm{EG}$ put more effort into the MT sessions than into the Writing Four content sessions delivered by the co-teacher. If the MT was taught by a different teacher, not the researcher, the results might not have been the same.

\subsection{Conclusion and directions for further research}

Research on LA could be further developed on the basis of the concept of LA constructed by this study. The notion of LA involves learners' self-initiation to make an effort to learn and their self-regulation through planning, monitoring, and evaluating a learning task. SBI which enhances learners' acquisition in English writing proved to be an effective instrument in the promotion of LA. Hence, it needs attention in future research into LA.

Like most SBI research, this study followed the top-down approach. It would be interesting for future research into LA promotion to employ the SBI bottom-up 
model suggested by Butler (2002). The participants in Butler's (2002) studies were disabled learners. It would be fascinating to discover if and to what extent her framework works for physically unchallenged learners. It would especially be intriguing to compare the efficacy of the two models of SBI. In this regard, a study which involves two experimental groups instead of one is worth trying. For example, one experimental group receives top-down SBI while the other focuses on bottom-up SBI. A comparison between the two models could be made accordingly. Of equal interest would be the application of the three different versions of the bottom-up SBI. An experiment of three groups of participants who are trained in one-on-one, group, and whole class learning strategies respectively would yield evidence of the effectiveness of a particular intervention in the fostering of LA.

This study focused on learners' self-regulation, a more teachable and taskfocused element of LA. It would be illuminating to gain insights into learners' selfinitiation, a less teachable and more learner-focussed part of LA. The study found preferred learning activities that Vietnamese learners undertook to improve their English, however it did not look for learners' reasons for such activities. Neither did it look for the correlation between a particular favoured activity and language learning outcomes. A correlational design aimed at investigating this relationship could further provide directions in exploring specific ways to enhance learners' self-initiation.

The subjects of this study were English-major learners. A different research project which recruits participants from other backgrounds who have dissimilar types of motivation would be interesting. Such a focus would help further identify the relationship between LA and motivation types triggered by differences in learners' backgrounds.

Furthermore for generalisation about the measurability of LA to be made in other contexts, the version of the LA questionnaire used in the second phase of this study should be further validated at other educational institutions, not only in Vietnam but also in other countries.

Finally, the intervention in this study merely focused on the writing skill. Future research projects could look for evidence about the relationship between LA and language acquisition in other language areas such as listening, speaking, and reading. In short, many other issues should be attended to in future LA research. Most important for researchers is the consideration of integrating into their research 
approaches borrowed from other fields, especially from the LS area, for the promotion of LA.

To conclude, the learner-based approach with a focus on SBI represents an important means of reinforcing LA. This study, demonstrating the ongoing relevance of LA research, has strengthened the often tenuous link between theory, research, and practice in the field of LA. The study has contributed to the refinement of LA research tools and methods. It has also advanced an understanding of how learners, teachers, and researchers can come to learn more about LA, promote and improve it through LS. 


\section{REFERENCES}

Allwright, D. (1988). Autonomy and individualisation in whole-class instruction. In A. Brookes \& P. Grundy (Eds.), Individualization and autonomy in language learning (pp. 35-44). Basingstoke: Modern English Publications in association with the British Councils.

Aoki, N. (2001). The institutional and psychological context of learner autonomy. AILA Review, 15, 72-90.

Aoki, N. (2002). Aspects of teacher autonomy: Capacity, freedom, and responsibility. In P. Benson \& S. Toogood (Eds.), Challenges to research and practice (Vol. 7, pp. 111-124). Dublin: Authentik.

Aoki, N., \& Smith, R. C. (1999). Learner autonomy in cultural context: The case of Japan. In S. Cotterall \& D. Crabbe (Eds.), Learner autonomy in language learning: Defining the field and effecting change (pp. 19-27). Frankfurt am Main: Peter Lang.

Aston, G. (1997). Involving learners in developing learning methods: Exploiting text corpora in self-access. In P. Benson \& P. Voller (Eds.), Autonomy and independence in language learning (Vol. 204-214). London: Longman.

Bachman, L. F. (2004). Statistical analyses for language assessment. Cambridge: Cambridge University Press.

Benson, P. (1997). The philosophy and politics of learner autonomy. In P. Benson \& P. Voller (Eds.), Autonomy and independence in language learning (pp. 1834). New York: Longman.

Benson, P. (2000). Autonomy as learners' and teachers' right. In B. Sinclair, I. McGrath \& T. Lamb (Eds.), Learner autonomy, teacher autonomy: Future directions (pp. 111-117). London: Longman.

Benson, P. (2001). Teaching and researching autonomy in language learning. Harlow, England: Longman.

Benson, P. (2002). Autonomy and communication. In P. Benson \& S. Toogood (Eds.), Challenges to research and practice (Vol. 7, pp. 10-29). Dublin: Authentik.

Benson, P. (2007). State-of-the-art article. Language Teaching, 40(1), 21-40. 
Benson, P., \& Voller, P. (1997). Autonomy and independence in language learning. New York: Longman.

Bialystok, E. (1978). A theoretical model of second language learning. Language Learning 28, 69-83.

Bialystok, E. (1981). The role of conscious strategies in second language proficiency. Modern Language Journal, 65(1), 25-35.

Boekaerts, M. (1999). Self-regulated learning: Where we are today. International Journal of Educational Research, 31, 445-457.

Boud, D. (1981). Toward student responsibility for learning. In D. Boud (Ed.), Developing student autonomy in learning (pp. 21-37). New York: Nichols Publishing Company.

Brammerts, H. (2003). Autonomous language learning in tandem. In T. Lewis \& L. Walker (Eds.), Autonomous learning in tandem (pp. 27-36). Sheffield: Academy Electronic Publications.

Brammerts, H., \& Calvert, M. (2003). Learning by communicating in tandem. In T. Lewis \& L. Walker (Eds.), Autonomous language learning in tandem (pp. 4560). Sheffield: Academy Electronic Publications.

Breen, M. P. (2001). Overt participation and covert acquisition in the language classroom. In M. P. Breen (Ed.), Learner contributions to language learning: New directions in research (pp. 112-140). Harlow: Longman.

Breen, M. P., \& Mann, S. J. (1997). Shooting arrows at the sun: Perspectives on a pedagogy for autonomy. In P. Benson \& P. Voller (Eds.), Autonomy and independence in language learning (pp. 132-149). New York: Longman.

Broady, E. (1996). Learner autonomy: An introduction to the issues. In E. Broady \& M.-M. Kenning (Eds.), Promoting learner autonomy in university language teaching (pp. 9-21). London: Association for French Language Studies in association with the Centre for Information on Language Teaching and Research.

Brown, A. (1987). Metacognition, executive control, self-regulation, and other more mysterious mechanisms. In F. E. Weinert \& R. H. Kluwe (Eds.), Metacognition, motivation, and understanding (pp. 65-116). Hillsdale, NJ: Lawrence Erlbaum Associates Publishers.

Brown, J. D. (2001). Using surveys in language programs. New York: Cambridge University Press. 
Butler, D. L. (1997). The roles of goal setting and self-monitoring in students' selfregulated engagement in tasks. Paper presented as part of a symposium on goal setting and monitoring coordinated by Dale Schunk and Barry Zimmerman at the annual meeting of the American Educational Research Association. Chicago, IL.

Butler, D. L. (2002). Individualizing instruction in self-regulated learning. Theory into Practice, 41(2), 81-92.

Candy, P. C. (1991). Self-direction for life long learning. San Francisco: Jossey-Bass.

Carrell, P. L. (1992). Awareness of text structure: Effects on recall. Language Learning, 42(1), 1-20.

Carter, B. A. (2001). From awareness to counselling in learner autonomy. AILA Review, 15, 26-33.

Chamot, A. U. (2001). The role of learning strategies in second language acquisition. In P. B. Michael (Ed.), Learner contributions to language learning (pp. 2543). Harlow, England: Longman.

Chamot, A. U., Barnhardt, S., El-Dinary, P. B., \& Robbins, J. (Eds.). (1999). The learning strategies handbook. New York: Longman.

Chamot, A. U., \& Rubin, J. (1994). Comments on Janie Rees-Miller's: A critical appraisal of learner training: Theoretical bases and teaching implications: Two readers react... TESOL Quarterly, 28(4), 771-776.

Champagne, M.-F., Clayton, T., Dimmitt, N., Laszewski, M., Savage, W., Shaw, J., et al. (2001). The assessment of learner autonomy and language learning. AILA Review, 15, 45-54.

Chan, V. (2001). Readiness for learner autonomy: What do our learners tell us? Teaching in Higher Education, 6(4), 505-518.

Chan, V. (2003). Autonomous language learning: The teachers' perspectives. Teaching in Higher Education, 8(1), 33-54.

Chan, V., Spratt, M., \& Humphreys, G. (2002). Autonomous language learning: Hong Kong tertiary students. Teaching in Higher Education, 16(1), 1-18.

Clemente, M. de los Angeles. (2003). Learning cultures and counselling: Teacher/learner interaction within a self-directed scheme. In D. Palfreyman \& R. C. Smith (Eds.), Learner autonomy across cultures: Language education perspectives (pp. 201-219). New York: Palgrave Macmillan. 
Cohen, A. D. (1984). Studying second-language learning strategies: How do we get information ? Applied Linguistics, 5, 101-112.

Cohen, A. D. (1998). Strategies in learning and using a second language. London: Longman.

Cohen, A. D. (2007). Coming to terms with language learner strategies: Surveying the experts. In A. D. Cohen \& E. Macaro (Eds.), Language learner strategies (pp. 29-46). Oxford: Oxford University Press.

Cohen, A. D., \& Macaro, E. (Eds.). (2007). Language learner strategies: Thirty years of research and practice. Oxford: Oxford University Press.

Cohen, L., \& Manion, L. (1994). Research methods in education. London and New York: Routledge.

Cohen, L., Manion, L., \& Morrison, K. (2000). Research methods in education (5th ed.). New York: Routledge Falmer.

Cotterall, S. (2008). Autonomy and good language learners. In C. Griffths (Ed.), Lessons from good language learners (pp. 110-120). Cambridge: Cambridge University Press.

Cotterall, S., \& Crabbe, D. (2008). Learner talking: From problem to solution. In T. Lamb \& H. Reinders (Eds.), Learner and teacher autonomy: Concepts, realities, and responses (pp. 125-140). Amsterdam: John Benjamins Publishing Company.

Crabbe, D. (1993). Fostering autonomy within classroom: The teacher's responsibility. System, 21(4), 443-452.

Creswell, J. W. (2005). Educational research: Planning, conducting, and evaluating quantitative and qualitative research (2nd Ed.). Upper Saddle River, N.J.: Merrill.

Cunningham, J., \& Carlton, W. (2003). Collaborative newsletters. In A. Barfield \& M. Nix (Eds.), Autonomy you ask! (pp. 113-128). Tokyo: Learner Development Special Interest Group of the Japan Association for Language Teaching.

Cuypers, S. E. (1992). Is personal autonomy the first principle of education? Journal of Philosophy of Education, 26(1), 5-17.

Dam, L. (1995). Learner autonomy: From theory to classroom practice (Vol. 3). Dublin: Authentik Language Learning Resources.

Dam, L., \& Legenhausen, L. (1996). The acquisition of vocabulary in an autonomous learning environment - the first months of beginning English. In R. Pemberton, 
E. S. L. Li, W. W. F. Or \& H. D. Pierson (Eds.), Taking control: Autonomy in language learning (pp. 265-280). Hong Kong: Hong Kong University Press.

Dearden, R. F. (1972). Autonomy and education. In R. F. Dearden, P. H. Hirst \& R. S. Peters (Eds.), Education and the development of reason (pp. 448-465). London: Routledge \& Kegan Paul.

Dearden, R. F. (1975). Autonomy as an educational ideal I. In S. C. Brown (Ed.), Philosophers discuss education (pp. 3-18). London: Macmillan Press.

Deci, E. L., \& Ryan, R. M. (1985). Intrinsic motivation and self-determination in human behavior. New York: Plenum.

Devine, N., \& Irwin, R. (2005). Autonomy, agency and education: He tangata, he tangata, he tangata. Educational Philosophy and Theory, 37(3), 317-331.

Dickinson, L. (1987). Self-instruction in language learning. Cambridge: Cambridge University Press.

Dickinson, L. (1992). Learner training for language learning (Vol. 2). Dublin: Authentik.

Dickinson, L. (1995). Autonomy and motivation: A literature review. System, 23(2), 165-175.

Dickinson, L. (1996). Culture, autonomy and common sense. Paper presented at AUTONOMY 2000: The development of learning independence in language learning, Bangkok.

Dingle, S., \& McKenzie, P. (2001). Establishing a language-learning advisory service. In M. Mozzon-McPherson \& R. Vismans (Eds.), Beyond language teaching towards language advising (pp. 104-114). London: Centre for Information on Language Teaching and Research.

Dornyei, Z. (2007). Research methods in applied linguistics. Oxford: Oxford University Press.

Dworkin, G. (1988). The theory and practice of autonomy. Cambridge: Cambridge University Press.

Englert, C. S., Raphael, T. E., Fear, K. L., \& Anderson, L. M. (1988). Students' metacognitive knowledge about how to write informational texts. Learning Disability Quarterly, 11(1), 18-46.

Esch, E. (1996). Promoting learner autonomy: Criteria for the selection of appropriate methods. In R. Pemberton, E. S. L. Li, W. W. F. Or \& H. D. Pierson (Eds.), 
Taking control: Autonomy in language learning (pp. 35-48). Hong Kong: Hong Kong University Press.

Field, A. (Ed.). (2005). Discovering statistics using SPSS. London: SAGE.

Flannery, J. L. (1994). Teacher as co-conspirator: Knowledge and authority in collaborative learning. In K. Bosworth \& S. J. Hamilton (Eds.), Collaborative learning: Underlying processes and effective techniques (pp. 15-23). San Francisco, CA: Jossey-Bass.

Fu, G. S. (1999). Guidelines for productive language counselling - tools for implementing autonomy. In S. Cotterall \& D. Crabbe (Eds.), Learner autonomy in language learning: Defining the field and effecting change (pp. 105-110). Frankfurt am Main: Peter Lang.

Gagne, R. M. (Ed.). (1974). Essentials of learning for instruction. Hinsdale, IL: The Dryden Press.

Gao, Y., Zhao, Y., Cheng, Y., \& Zhou, Y. (2004). Motivation types of Chinese university undergraduates. Asian Journal of English Language Teaching, 14, 45-64.

Gao, Y., Zhao, Y., Cheng, Y., \& Zhou, Y. (2007). Relationship between English learning motivation types and self-identity changes among Chinese students TESOL Quarterly, 41(1), 133-155.

Gardner, D., \& Garcia, R. (1996). Interactive video as self-access support for language-learning beginners. In R. Pemberton, E. S. L. Li, W. W. F. Or \& H. D. Pierson (Eds.), Taking control: Autonomy in language learning (pp. 219232). Hong Kong: Hong Kong University Press.

Gardner, R. C., \& Lambert, W. E. (1972). Attitudes and motivation in second language learning. Rowley, MA: Newbury House Publishers, inc.

Gibbs, B. (1979). Autonomy and authority in education. Journal of Philosophy of Education, 13, 119-132.

Gibbs, B. (Ed.). (1976). Freedom and liberation. London: Chatto and Windus for Sussex University Press.

Goh, C., \& Taib, Y. (2006). Metacognitive instruction in listening for young learners. ELT Journal, 60(3), 222-232.

Gremmo, M.-J., \& Riley, P. (1995). Autonomy, self-direction and self access in language teaching and learning: The history of an idea. System, 23(2), 151164. 
Gu, Y. (1994). Vocabulary learning strategies of good and poor Chinese EFL learners. In N. Bird, P. Falvey, A. Tsui, D. Allison \& A. McNeill (Eds.), Language and Learning (pp. 376-401). Hong Kong: Government Printer.

Gu, Y. (1996). Robin Hood in SLA: What has the learning strategy researcher taught us? Asian Journal of English Language Teaching, 6, 1-29.

Gu, Y. (2007). Strategy-based instruction. In T. Yashima \& T. Nabei (Eds.), Proceedings of the International Symposium on English Education in Japan: Exploring New Frontiers (pp. 21-38). Osaka: Yubunsha.

Gu, Y. (2009). LALS 516 Learner Autonomy and Learning Strategies course notes. School of Linguistics and Applied Language Studies, Victoria University of Wellington, NZ.

Hamp-Lyons, L., \& Condon, W. (2000). Assessing the portfolio: Principles for practice, theory, and research. Cresskill, N.J.: Hampton Press.

Hand, M. (2006). Against autonomy as an educational aim. Oxford Review of Education, 32(4), 535-550.

Harmer, J. (2001). The practice of English language teaching (3rd ed.): Harlow: Longman.

Harris, V. (2001). Helping learners learn: Exploring strategy instruction in language classroom across Europe. Graz: European Centre for Modern Languages, Council of Europe.

Hatch, E., \& Lazaraton, A. (Eds.). (1991). The research manual: Design and statistics for applied linguistics. Boston, MA: Heinle \& Heinle Publishers.

Hedge, T. (2000). Teaching and learning in the language classroom. Oxford: Oxford University Press.

Ho, J., \& Crookall, D. (1995). Breaking with the Chinese cultural traditions: Learner autonomy in English language teaching. System, 23(2), 235-243.

Holec, H. (1981). Autonomy and foreign language learning. Oxford: Pergamon Press. Holliday, A. (2003). Social autonomy: Addressing the dangers of culturalism in TESOL. In D. Palfreyman \& R. C. Smith (Eds.), Learner autonomy across Cultures: Language education perspectives (pp. 110-126). New York: Palgrave Macmillan.

Holly, M. L. (1987). Keeping a personal-professional journal. Waurn Ponds, Vic.: Deakin University. 
Hyland, F. (2004). Learning autonomously: Contextualising out-of-class language learning. Language Awareness, 13(3), 180-202.

Jing, H. (2006). Learner resistance in metacognition training? An exploration of mismatches between learner and teacher agendas. Language Teaching Research, 10(1), 95-117.

Kehr, M. H., Bles, P., \& Rosenstiel, L. V. (1999). Self-regulation, self-control, and management training transfer. International Journal of Educational Research, 31, 487-498.

Kelly, R. (1996). Language counselling for learner autonomy: The skilled helper in self-access language learning. In R. Pemberton, E. S. L. Li, W. W. F. Or \& H. D. Pierson (Eds.), Taking control: Autonomy in language learning (pp. 93113). Hong Kong: Hong Kong University Press.

Kohonen, V. (2000a). Experiential learning in foreign language education. London: Longman.

Kohonen, V. (2000b). Exploring the educational possibilities of the "dossier": Some suggestions for developing the pedagogic function of the European language portfolio. In D. Nunan (Ed.), Collaborative language learning and teaching (pp.14-39). Cambridge: Cambridge University Press.

Kohonen, V. (2001). Developing the European language portfolio as a pedagogical instrument for advancing student autonomy. In L. Karlsson, F. Kjisik, \& J. Nordlund (Eds.), All together now (pp. 20-44). Paper from the Nordic conference on autonomous language learning. Helsinki: University of Helsinki Language Centre.

Kumaravadivelu, B. (2003). Beyond methods: Macro strategies for language teaching. New Haven: Yale University Press.

Lai, J. (2001). Toward an analytic approach to assessing learner autonomy. AILA Review, 15, 34-44.

Lamb, T., \& Reinders, H. (2008). Learner and teacher autonomy: Concepts, realities, and responses. Amsterdam: John Benjamins Publishing Company.

Lap, T. (2005). Stimulating learner autonomy in English language education: A curriculum innovation study in a Vietnamese context. Unpublished $\mathrm{PhD}$ dissertation.

Lee, W. (1996). The role of materials in the development of autonomous learning. In R. Pemberton, E. S. L. Li, W. W. F. Or \& H. D. Pierson (Eds.), Taking 
control: Autonomy in language learning (pp. 265-280). Hong Kong: Hong Kong University Press.

Levinson, M. (Ed.). (1999). The demands of liberal education. Oxford: Oxford University Press.

Little, D. (1991). Learner autonomy: Definitions, issues and problems (Vol. 1). Dublin: Authentik.

Little, D. (1995). Learning as dialogue: The dependence of learner autonomy on teacher autonomy. System, 23(2), 175-181.

Little, D. (1999). Learner autonomy is more than a Western cultural construct. In S. Cotterall \& D. Crabbe (Eds.), Learner autonomy in language learning: Defining the field and effecting change (pp. 11-18). Frankfurt am Main: Peter Lang.

Little, D. (2000). Learner autonomy and human interdependence: Some theoretical and practical consequences of a social-interactive view of cognition, learning and language. In B. Sinclair, I. McGrath \& T. Lamb (Eds.), Learner autonomy, teacher autonomy: Future directions (pp. 15-23). Essex: Pearson Education Limited.

Little, D. (2003). Tandem language learning and learner autonomy. In L. Tim \& W. Lesley (Eds.), Autonomous language learning in tandem (pp. 37-44). Sheffield, UK: Academy Electronic Publications Limited.

Little, D. (2007). Language learner autonomy: Some fundamental considerations revisited. Innovation in language learning and teaching, 1(1), 14-29.

Littlejohn, A. (1997). Self-access work and curriculum ideologies. In P. Benson \& P. Voller (Eds.), Autonomy and independence in language learning (pp. 181191). New York: Longman.

Littlemore, J. (2001). Learner autonomy, self-instruction and new technologies in language learning: Current theory and practice in higher education in Europe. In A. Chambers \& G. Davies (Eds.), ICT and language learning: A European perspective (pp. 39-52). Lisse, Netherlands: Swets \& Zeitlinger Publishers.

Littlewood, W. (1996a). "Autonomy": An anatomy and a framework. System, 24(4), 427-435.

Littlewood, W. (1996b). Autonomy in communication and learning in the Asian context. Paper presented at AUTONOMY 2000: The Development of Learning Independence in Language Learning, Bangkok. 
Littlewood, W. (1999). Defining and developing autonomy in East Asian contexts. Applied Linguistics, 20(1), 71-94.

Littlewood, W. (2002). Cooperative and collaborative learning tasks as pathways towards autonomous interdependence. In P. Benson \& S. Toogood (Eds.), Challenges to research and practice (Vol. 7, pp. 29-40). Dublin: Authentik.

Macaro, E., Graham, S., \& Vandeplank, R. (2007). A review of listening strategies: Focus on sources of knowledge and success. In A. D. Cohen \& E. Macaro (Eds.), Language learner strategies (pp. 165-185). Oxford: Oxford University Press.

Mackey, A., \& Gass, S. M. (2005). Second language research: Methodology and design. Mahwah, N.J.: Lawrence Erlbaum.

MacLeod, W. B., Butler, D. L., \& Syer, K. D. (1996). Assessing metacognitive change. Vancouver: Psychology and Special Education, Faculty of Education, University of British Columbia, Vancouver, Canada.

Marshall, J. (1996). The autonomous chooser and 'reforms' in education, Studies in Philosophy and Education, 15, pp. 89-96.

McGarry, D. (1995). The role of authentic texts (Vol. 4). Dublin: Authentik.

McGrath, I. (2000). Teacher autonomy. In B. Sinclair, I. McGrath \& T. Lamb (Eds.), Learner autonomy, teacher autonomy: Future directions (pp. 100-110). London: Longman.

Miller, L., \& Ng, R. (1996). Autonomy in the classroom: Peer assessment. In R. Pemberton, E. S.L.Li, W. W. F. Or \& H. D. Pierson (Eds.), Taking control: Autonomy in language learning (pp. 133-146). Hong Kong: Hong Kong University Press.

Milton, J. (1997). Providing computerized self-access opportunities for the development of writing skills. In P. Benson \& P. Voller (Eds.), Autonomy and independence in language learning (pp. 237-248). New York: Longman.

Mizuki, P. (2003). Metacognitive strategies, reflection, and autonomy in the classroom. In A. Barfield \& M. Nix (Eds.), Autonomy you ask! (pp. 143-156). Tokyo: Learner Development Special Interest Group of the Japan Association for Language Teaching.

Morgan, J. (1996). A defence of autonomy as an educational ideal. Journal of Philosophy of Education, 30(2), 239-252. 
Mynard, J. (2006). Measuring learner autonomy: Can it be done? IndependenceNewsletter of the IATEFL Learner Autonomy Special Interest Group, 37, 3-6.

Nachi, H. E. (2003). Self-assessment and learner strategy training in a coordinated program: Using students and teacher feedback to inform curriculum design. In A. Barfield (Ed.), Autonomy you ask! (pp. 157-174). Tokyo: Learner Development Special Interest Group of the Japan Association for Language Teaching.

Naiman, N., Frohlich, M., Stern, H. H., \& Todesco, A. (1978). The good language learner. Toronto, Ontario: Institute for Studies in Education.

Nakatani, Y. (2005). The effects of awareness-raising training on oral communication strategy use. Modern Language Journal, 89(1), 76-91.

Natri, T. (2007). Active learnership in continuous self- and peer-evaluation. In A. Barfield \& S. H. Brown (Eds.), Reconstructing autonomy in language education: Inquiry and innovation (pp. 108-120). New York: Palgrave Macmillan.

Nguyen, T. C. L. (2008). Learner autonomy and EFL proficiency: A Vietnamese perspective. Asian Journal of English Language Teaching, 18, 67-87.

Nicoll, H. (2007). Seeking autonomy in a lecture course. In A. Barfield \& S. H. Brown (Eds.), Reconstructing learner autonomy in language education: Inquiry and innovation (pp. 120-130). New York: Palgrave Macmillan.

Nix, M. (2003). Writing autonomy; or 'It's the content, stupid!' In A. Barfield \& M. Nix (Eds.), Autonomy you ask! (pp. 197-212). Tokyo: Learner Development Special Interest Group of the Japan Association for Language Teaching.

Nix, M. (2007). Telling tales of transformation. In A. Barfield \& S. H. Brown (Eds.), Reconstructing learner autonomy in language education: Inquiry and innovation (pp. 156-164). New York: Palgrave Macmillan.

Norman, R. (1994). 'I did it my way': Some thoughts on autonomy. Journal of Philosophy of Education, 28(1), 25-34.

Nunan, D. (1996). Toward autonomous learning: Some theoretical, empirical and practical issues. In R. Pemberton, E. S. L .Li, W. W. F. Or \& H. D. Pierson (Eds.), Taking control: Autonomy in language learning (pp. 13-26). Hong Kong: Hong Kong University Press.

Nunes, A. (2004). Portfolios in the EFL classroom: Disclosing and informed practice. ELT Journal, 58(4), 327-335. 
O'Malley, J. M., \& Chamot, A. U. (1990). Learning strategies in second language acquisition. Cambridge: Cambridge University Press.

O'Malley, J. M., \& Pierce, L. V. (1996). Authentic assessment for English language learner: Practical approaches for teachers. Reading, MA: Addison-Wesley Publishing Company.

Ojima, M. (2006). Concept mapping as pre-task planning: A case study of three Japanese writers. System, 34(4), 556-585.

Olssen, M. (2005). Foucault, educational research and the issue of autonomy. Educational Philosophy and Theory, 37(3), 365-387.

Oshima, A., \& Hogue, A. (1999). Writing academic English. White Plains, N.Y.: Longman.

Oxford, R. L. (1990). Language learning strategies: What every teacher should know. New York: Newbury House.

Oxford, R. L. (2003). Toward a more systematic model of L2 learner autonomy. In D. Palfreyman \& R. C. Smith (Eds.), Learner autonomy across cultures: Language education perspectives (pp. 75-91). New York: Palgrave Macmillan.

Pearson, N. (2004). The idiosyncrasies of out-of-class language learning: A study of mainland Chinese students studying English at tertiary level in New Zealand. Paper presented at the Independent Learning Conference in Melbourne, Australia.

Pemberton, R., Toogood, S., Ho, S., \& Lam, J. (2001). Approaches to advising for self-directed learning. AILA Review, 15, 16-25.

Pennycook, A. (1997). Cultural alternatives and autonomy. In P. Benson \& P. Voller (Eds.), Autonomy and independence in language learning (pp. 35-53). New York: Longman.

Pickard, N. (1995). Out-of class language learning strategies: Three case studies. Language Learning Journal, 12, 35-37.

Pickard, N. (1996). Out-of-class language learning strategies. ELT Journal, 50, 150159.

Pintrich, P. R. (1999). The role of motivation in promoting and sustaining selfregulated learning. International Journal of Educational Research, 31, 459470.

Rao, Z. (2005). Developing learner autonomy through portfolios. Teachers' Edition, 19, 20-24. 
Rao, Z. (2007). Training in brainstorming and developing writing skills. ELT Journal, 61(2), 100-106.

Reich, R. (Ed.). (2002). Bridging liberalism and multiculturalism in American education. Chicago: Chicago University Press.

Riley, P. (1988). The ethnography of autonomy. In A. Brooks \& P. Grundy (Eds.), Individualization and autonomy in language learning (pp.12-34). Basingstoke: Modern English Publications in association with the British Councils.

Riley, P. (1997). The guru and the conjurer: Aspects of counselling for self-access. In B. Phil \& P. Voller (Eds.), Autonomy and independence in language learning (pp. 114-131). New York: Longman.

Riley, P. (1999). On the social construction of "The Learner". In S. Cotterall \& D. Crabbe (Eds.), Learner autonomy in language learning: Defining the field and effecting change (pp. 29-39). Frankfurt am Main: Peter Lang.

Rogers, C. R. (Ed.). (1983). Freedom to learn for the 80's. Columbus: Charles E. Merrill Publishing Company.

Rubin, J. (1975). What the good language learner can teach us. TESOL Quarterly, 9(1), 41-51.

Rubin, J. (1987). Learner strategies: Theoretical assumptions, research history, and typology. In A. L. Wenden \& J. Rubin (Eds.), Learner strategies in language learning (pp. 15-30). Englewood Cliffs, N.J.: Prentice-Hall.

Rubin, J. (1997). Developing monitoring and evaluating. Paper presented at the AAAL Conference, March 11.

Rubin, J. (2003). Diary writing as a process: Simple, useful, powerful. Guidelines, 25(3), 10-14.

Rubin, J., Chamot, A. U., Harris, V., \& Anderson, N. J. (2007). Intervening in the use of strategies. In A. D. Cohen \& E. Macaro (Eds.), Language learner strategy: Thirty years of research and practice (pp. 141-160). Oxford: Oxford University Press.

Rubin, J., \& McCoy, P. (2008). Tasks and good language learners. In C. Griffiths (Ed.), Lessons from good language learners (pp. 294-305). Cambridge: Cambridge University Press.

Rubin, J., \& Thompson, I. (1994). How to be a more successful language learner: Toward learner autonomy. Boston: Heinle and Heinle Publishers. 
Santrock, J. W. (2004). Educational psychology (2nd ed.). Boston: McGraw-Hill.

Scharle, A., \& Szabo, A. (2000). Learner autonomy: A guide to developing learner responsibility. Cambridge: Cambridge University Press.

Schmenk, B. (2005). Globalizing learner autonomy. TESOL Quarterly, 39(1), 107118.

Schunk, D. H., \& Zimmerman, B. J. (1998). Self-regulated learning: From teaching to self-reflective practice. New York: Guilford Press.

Sert, N. (2006). EFL student teachers' learning autonomy. The Asian EFL Journal Quarterly, 8(2), 180-201.

Shao, H., \& Wu, Z. (2007). Nurturing language learner autonomy through caring pedagogic practice. In A. Barfield \& S. H. Brown (Eds.), Reconstructing autonomy in language education: Inquiry and innovation (pp. 95-108). New York: Palgrave Macmillan.

Sheerin, S. (1997). An exploration of the relationship between self-access and independent learning. In P. Benson \& P. Voller (Eds.), Autonomy and independence in language learning (pp. 54-65). New York: Longman.

Shimo, E. (2003). Learners' perceptions of portfolio assessment and autonomous learning. In A. Barfield \& M. Nix (Eds.), Autonomy you ask! (pp. 175-188). Tokyo: The Learner Development Special Interest Group of the Japan Association for Language Teaching.

Sinclair, B. (1996). Materials design for the promotion of learner autonomy: How explicit is 'explicit'? In R. Pemberton, E. S. L. Li, W. W. F. Or \& H. D. Pierson (Eds.), Taking control: Autonomy in language learning (pp. 149-165). Hong Kong: Hong Kong University Press.

Sinclair, B. (1999). Wrestling with a jelly: The evaluation of learner autonomy. In B. J. Morrison (Ed.), Experiments: Evaluation in self-access language learning (pp. 95-109). Hong Kong: Hong Kong Association for Self-Access Learning and Development.

Sinclair, B. (2000). Learner autonomy: The next phase. In B. Sinclair, I. McGrath \& T. Lamb (Eds.), Learner autonomy, teacher autonomy: Future directions (pp. 4-14). Essex: Pearson Education Limited.

Slimani, A. (1992). Evaluation of classroom interaction. In J. Anderson \& A. Beretta (Eds.), Evaluating second language acquisition. Cambridge: Cambridge University Press. 
Smith, R. C. (2001). Group work for autonomy in Asia: Insights from teacherresearch. AILA Review, 15, 70-81.

Smith, R. C. (2003). Pedagogy for autonomy as (becoming-) appropriate methodology. In D. Palfreyman \& R. C. Smith (Eds.), Learner autonomy across cultures: Language education perspectives (pp. 129-146). New York: Palgrave Macmillan.

Stephenson, J., \& Kohyama, M. (2003). Turning freshmen into autonomy through student-directed language learning projects. In A. Barfield \& M. Nix (Eds.), Autonomy you ask! (pp. 101-112). Tokyo: Learner Development Special Interest Group of the Japan Association for Language Teaching.

Stern, H. H. (1983). Fundamental concepts of language teaching. Oxford: Oxford University Press.

Stone, C. M. (1990). Autonomy, emotions and desires: Some problems concerning R.F. Dearden's account of autonomy. Journal of Philosophy of Education, 24(2), 271-283.

Sturtridge, G. (1997). Teaching and language learning in self-access centres: Changing roles? In P. Benson \& P. Voller (Eds.), Autonomy and independence in language learning (pp. 66-78). New York: Longman.

Tagaki, A. (2003). Learner autonomy and motivation in a cooperative learning class. In A. Barfield \& M. Nix (Eds.), Autonomy you ask! (pp. 129-142). Tokyo: Learner Development Special Interest Group of the Japan Association for Language Teaching.

Telfer, E. (1975). Autonomy as an educational ideal II. In S. C. Brown (Ed.), Philosophers discuss education (pp. 19-35). London: Macmillan Press.

Thavenius, C. (1999). Teacher autonomy for learner autonomy. In S. Cotterall \& D. Crabbe (Eds.), Learner autonomy in language learning: Defining the field and effecting change (pp. 159-163). Frankfurt am Main: Peter Lang.

Thompson, I., \& Rubin, J. (1996). Can strategy instruction improve listening comprehension? Foreign Language Annals, 29(3), 331-342.

Thomson, C. K. (1996). Self-assessment in self-directed learning: Issues of learner diversity. In R. Pemberton, E. S. L. Li, W. W. F. Or \& H. D. Pierson (Eds.), Taking control: Autonomy in language learning (pp. 77-92). Hong Kong: Hong Kong University Press. 
Tort-Moloney, D. (1997). Teacher autonomy: A Vygotskian theoretical framework (Reports-General No. 0332-3889).

Underhill, A. (1989). Process in humanistic education. ELT Journal, 43(4), 250-260.

Ushioda, E. (Ed.). (1996). The role of motivation (Vol. 5). Dublin: Authentik.

Vickers, C. H., \& Ene, E. (2006). Grammatical accuracy and learner autonomy in advanced writing. ELT Journal, 60(2), 109-116.

Vieira, F. (1999). Pedagogy for autonomy: Teacher development and pedagogical experimentation: An in-service teacher training project. In S. Cotterall \& D. Crabbe (Eds.), Learner autonomy in language learning: Defining the field and effecting change (pp. 149-158). Frankfurt am Main: Peter Lang.

Voller, P., Martyn, E., \& Pickard, V. (1999). One-to-one counselling for autonomous learning in a self-access centre: Final report on an action learning project. In S. Cotterall \& D. Crabbe (Eds.), Learner autonomy in language learning: Defining the field and effecting change (pp. 111-126). Frankfurt am Main: Peter Lang.

Vygotsky, L. S. (1978). Mind in society: The development of higher psychological processes. Cambridge: Harvard University Press.

Weaver, S. J., \& Cohen, A. D. (1997). Strategy-based instruction: A teacher-training manual. Hong Kong: Centre for Advanced Research on Language Acquisition.

Wenden, A. L. (1987). Conceptual background and utility. In A. L. Wenden \& J. Rubin (Eds.), Learner strategies in language learning (pp. 3-13). Englewood Cliffs, N.J.: Prentice-Hall.

Wenden, A. (1991a). Learner strategies for learner autonomy: Planning and implementing learner training for language learners. Englewood Cliffs, N.J: Prentice-Hall.

Wenden, A. L. (1991b). Metacognitive strategies in L2 writing. In J. E. Alatis (Ed.), Georgetown University Round Table on Languages and Linguistics (pp. 302322). Washington, DC: Georgetown University Press.

Wenden, A. L. (1998). Metacognitive knowledge and language learning. Applied Linguistics, 19(4), 515-537.

Wenden, A. L. (1999). An introduction to metacognitive knowledge and beliefs in language learning: Beyond the basics. System, 27(4), 435-441. 
Wenden, A. L. (2001). Metacognitive knowledge in SLA: The neglected variable. In M. P. Breen (Ed.), Learner contributions to language learning: New directions in research (pp. 44-64). Harlow: Longman.

Wenden, A. L. (2002). Learner development in language learning. Applied Linguistics, 23(1), 32-55.

Wenger, E., McDermott, R., \& Snyder, W. M. (2002). Cultivating communities of practice: a guide to managing knowledge. Boston: Harvard Business School Press.

White, C. (1995). Autonomy and strategy use in distance foreign language learning: Research findings. System, 23(2), 207-221.

Winch, C. (2002). Strong autonomy and education. Educational Theories, 52(1), $27-$ 41.

Winnie, H. P., \& Perry, E. N. (2000). Measuring self-regulated learning. In M. Boekaerts, P. R. Pintrich \& M. Zeidner (Eds.), Handbook of self-regulation (pp. 532-566). San Diego: Academic Press.

Woolfolk, A. (2004). Educational psychology (9th ed.). Boston: Pearson A and B.

Yang, N.-D. (1998). Exploring a new role for teachers: Promoting learner autonomy. System, 26(1), 127-135.

Yap, S. S. L. (1998). Out-of-class use of English by secondary school students in a Hong Kong Anglo-Chinese school. MA dissertation. University of Hong Kong. Zhu, W. (2001). Performing argumentative writing in English: Difficulties, processes, and strategies. TESL Canada Journal, 19(1), 34-50.

Zimmerman, B. J. (1998). Developing self-fulfilling cycles of academic regulation: An analysis of exemplary instructional models. In D. H. Schunk \& B. J. Zimmerman (Eds.), Self-regulated learning: From teaching to self-reflective practice (pp. 1-19). New York: Guilford Press.

Zimmerman, B. J. (2000). Attainment of self-regulation: A social cognitive perspective. In M. Boekaerts, P. R. Pintrich \& M. Zeidner (Eds.), Handbook of self-regulation (pp. 13-39). San Diego, C.A.: Academic Press.

Zimmerman, B. J. (2002). Becoming a self-regulated learner: An overview. Theory into Practice, 41(2), 64-71. 


\section{APPENDICES}

All appendices are enclosed in a CD. 